\title{
Intra-tumoural blood vessels and hypoxia: targets for treatment and imaging to improve anti-cancer therapies : pre-clinical investigations
}

Citation for published version (APA):

Landuyt, W. (2002). Intra-tumoural blood vessels and hypoxia: targets for treatment and imaging to improve anti-cancer therapies : pre-clinical investigations. [Doctoral Thesis, Maastricht University]. Universiteit Maastricht. https://doi.org/10.26481/dis.20021219wl

Document status and date:

Published: 01/01/2002

DOI:

10.26481/dis.20021219wl

Document Version:

Publisher's PDF, also known as Version of record

Please check the document version of this publication:

- A submitted manuscript is the version of the article upon submission and before peer-review. There can be important differences between the submitted version and the official published version of record.

People interested in the research are advised to contact the author for the final version of the publication, or visit the DOI to the publisher's website.

- The final author version and the galley proof are versions of the publication after peer review.

- The final published version features the final layout of the paper including the volume, issue and page numbers.

Link to publication

\footnotetext{
General rights rights.

- You may freely distribute the URL identifying the publication in the public portal. please follow below link for the End User Agreement:

www.umlib.nl/taverne-license

Take down policy

If you believe that this document breaches copyright please contact us at:

repository@maastrichtuniversity.nl

providing details and we will investigate your claim.
}

Copyright and moral rights for the publications made accessible in the public portal are retained by the authors and/or other copyright owners and it is a condition of accessing publications that users recognise and abide by the legal requirements associated with these

- Users may download and print one copy of any publication from the public portal for the purpose of private study or research.

- You may not further distribute the material or use it for any profit-making activity or commercial gain

If the publication is distributed under the terms of Article 25fa of the Dutch Copyright Act, indicated by the "Taverne" license above, 
INTRA-TUMOURAL BLOOD VESSELS AND HYPOXIA: TARGETS FOR TREATMENT AND IMAGING TO IMPROVE ANTI-CANCER THERAPIES PRE-CLINICAL INVESTIGATIONS 
Druk : Acco

ISBN 90-9016436-7

D/2002/WILLY LANDUYT, uitgever 


\section{INTRA-TUMOURAL BLOOD VESSELS AND HYPOXIA: TARGETS FOR TREATMENT AND IMAGING TO IMPROVE ANTI-CANCER THERAPIES PRE-CLINICAL INVESTIGATIONS}

\section{Proefschrift}

ter verkrijging van de graad van doctor aan de Universiteit Maastricht, op gezag van de Rector Magnificus, Prof. Dr. A. C. Nieuwenhuijzen Kruseman, volgens het besluit van het College van Decanen, in het openbaar te verdedigen op donderdag 19 december 2002 om 12.00 uur precies

door 


\section{Promotor}

Prof. dr. P. Lambin

\section{Co-promotor}

Prof. dr. A. van Oosterom (K.U.Leuven)

\section{Beoordelingscommissie}

Prof. dr. F. Ramaekers (Voorzitter)

Prof. dr. J. van Engelshoven

Prof. dr. V. Grégoire (U.C.Louvain)

Prof. dr. A. van der Kogel (K.U.Nijmegen)

Prof. dr. J. Wagstaff 
Streef naar het nieuwe,

behoud het goeie

(R. de Leeuw, DLS) 
The animal-based research was done in agreement with the Ethical Committee for Animal Care and Use of the KULeuven and national guidelines (Belgium).

The investigations have been carried out at the KULeuven, Laboratories of Exp. Radiobiology/LEO, Exp. Bacteriology and Radiology-Exp. MR unit; they were supported by grants from the 'Fonds voor Wetenschappelijk Onderzoek-Vlaanderen'. 'FWO-V Krediet aan Navorsers', 'KULeuven Onderzoeksfonds'. 'Vlaamse Kankerliga'. en 'Verkennende Internationale Samenwerking'. The company OXiGENE (Sweden) partly supported the combretastatin A-4 phosphate-related experiments. 


\section{Contents}

\section{CHAPTER I:}

General introduction and research outline

I.1. Selective tumour targeting and imaging: background 12

I.1.1. General remarks 12

$\begin{array}{ll}\text { I.1.2. Tumour vascular status } & 16\end{array}$

1.1.2.a. general

I.I.2.b. inhibition of angiogenesis 19

I.1.2.c. vascular targeting $\quad 21$

I.1.3. Tumour oxygenation status 29

I.1.3.a. general

1.1.3.b. impact on treatment efficacy

I.I.3.c. relation with tumour expansion

I.I.3.d. measuring hypoxia $\quad 32$

I.1.3.d.1. invasive hypoxia measurement $\quad 33$

I.1.3.d.2. non-invasive hypoxia measurements $\quad 36$

I.1.3.e. hypoxia-related treatment 38

I.1.4. Background-based conclusion 43

I.1.5. References 45

I.2. Outline of the principal investigations

\section{CHAPTER II:}

Intra-tumoural blood vessel-related treatments:

relation with tumour size

II.1. Effect of TNP-470 (AGM-1470) on the growth of rat rhabdomyosarcoma tumours with different sizes

II.2. Vascular targeting of solid tumours: a major 'inverse' volume-response relationship with combretastatin A-4 phosphate in rat rhabdomyosarcomas

\section{CHAPTER III:}

Combretastatin A-4 phosphate combined with other anti-cancer agents

III.1. In vivo anti-tumour effect of vascular targeting combined with either ionizing radiation or anti-angiogenesis treatment 
III.2. Combining combretastatin A-4 phosphate with anaerobe

Bacteria-based transfer of therapeutic proteins

III.2.A. Evaluation and improvement of a bacterial vector transfer system with an in vivo rat tumour model

III.2.B. Specific targeting of cytosine deaminase to solid tumours by engineered Clostridium acetobutylicum

\section{CHAPTER IV:}

Non-invasive evaluation of hypoxia modulation: endogenous contrast-based magnetic resonance imaging (MRI)

IV.1. In vivo animal functional MRI: improved image quality with a body-adapted mould

IV, 2 . BOLD contrast functional magnetic resonance imaging of whole tumour during air or carbogen breathing: initial experience in rat rhatodomyosarvoma using eche ptanar imaging at 1.5 Tesla

\section{CMAPTR V:}

Sanamary and gencral discussion

\section{CHAPTER V:}

Samearattime, Curriculuan Vitae ea lijst van publicaties (ranaf 1998) 
Explanation for abbreviations and symbols (if used more than once)

\begin{tabular}{|c|c|c|c|}
\hline ARCON & $\begin{array}{l}\text { accelerated radiotherapy } \\
\text { with carbogen breathing and } \\
\text { nicotinamide }\end{array}$ & AUC & area-under-the-curve \\
\hline BOLD & blood oxygen level dependent & CBM & clostridial basal medium \\
\hline CDase & cytosine deaminase & cDNA & complementary DNA \\
\hline cfu & colony forming units & $\mathrm{CO}_{2}$ & carbon dioxide \\
\hline combreAp & combretastatin A-4 phosphate & CT & computed tomography \\
\hline DMXAA & $\begin{array}{l}\text { 5,6-dimethylxanthenone } \\
\text { 4-acetic acid }\end{array}$ & EORTC & $\begin{array}{l}\text { European Organization for } \\
\text { Rescarch and Treatment of Cancer }\end{array}$ \\
\hline ESTRO & $\begin{array}{l}\text { European Society for Therapeutic } \\
\text { Radiology and Oncology }\end{array}$ & EPI & echoplanar imaging \\
\hline EPO & erythropoictin & FAA & favone acetic acid \\
\hline 5-FC & 5-fluorocytosine & FDG PET & 1"F-2-fluoro-2-deoxyglucose PET \\
\hline FGF & fibroblast growth factor & FMISO & ${ }^{18} \mathrm{~F}$-fluoromisonidazole \\
\hline (f)MRI & $\begin{array}{l}\text { (functional) magnetic resonance } \\
\text { imaging }\end{array}$ & 5-FU & 5-fluorouracil \\
\hline GE & gradient echo & GRE & gradient recalled echo \\
\hline Gy & Gray $(=100 c G y)$ & IFP & interstitial fluid pressure \\
\hline i.p. & intraperitoneal & i.v. & intravenous \\
\hline MAP & multi-angle projection & MR & magnetic resonance \\
\hline MTD & maximum tolerable dose & NITP & $\begin{array}{l}\text { 7-4'-2-nitroimidazole- } \\
\text { butyl-therophyline }\end{array}$ \\
\hline NOS & nitric oxide synthase & OD & optical density \\
\hline PBS & phosphate-buffered saline & PDT & photodynamic therapy \\
\hline PET & positron emission tomography & $\mathrm{pO}_{2}$ & partial oxygen pressure $\left(\mathrm{mmH}_{\mathrm{g}}\right)$ \\
\hline p-value & probability level & $\mathrm{RCM}$ & reinforced clostridial medium \\
\hline s.c. & subcutaneous & SEM & standard error of the mean \\
\hline SNR & signal-to-noise ratio & SIC & signal intensity changes \\
\hline SPM & statistical parametric map & T1...T4 & tumour stage \\
\hline $\mathbf{T}_{1}$ & longitudinal relaxation time & $\mathrm{T}_{2}^{*}$ & $\begin{array}{l}\text { transverse relaxation time } \\
\text { including susceptibility-related } \\
\text { effects }\end{array}$ \\
\hline tle & thin layer chromatography & TNF- $\alpha$ & tumour necrosis factor alfa \\
\hline UV & ultraviolet & & \\
\hline
\end{tabular}





\section{Chapter I}

General Introduction 


\section{I.1. Selective tumour targeting and imaging: background}

\section{I.1.1. General}

The development of cancers involves a complex growth cascade of various cell types, both genetically and phenotypically. The expansion of clonal cell populations that are characterized by a proliferation and survival difference over normal cells defines the evolution of cancer in the body. The change of normal cells into malignant ones is due to the accumulation of several genetic changes that influence cell cycle control; oncogenes such as cyclin D1, tumour suppressor genes such as the retinoblastoma gene, and/or inactivation of p53 gene and DNA repair (e.g. $[1,2]$ and reviews $[3,4]$ ). A catalogue of specific chromosome aberrations to correlate with some particular tumour types is presently becoming available.

Because of the acquired genetic instability, tumours may become both genetically and phenotypically more heterogeneous during evolution (see e.g. [5]). A considerable variety in cellular architecture is by definition related to intra-tumoural functional differences (such as degree of hypoxia, acidity). This heterogeneity changes continuously in area and time during phases of tumour growth (e.g. [6]). It could for example translate into cell populations with different metastatic capacity and resistance to treatment.

On the other hand, in the absence of angiogenesis, most tumours would not grow beyond $1-2 \mathrm{~mm}^{3}[7,8]$. Induction of angiogenesis is mediated by changes in the balance of positive and negative regulatory molecules released by tumour cells and also host cells (e.g. [9]). The initial events are local degradation of the basement membrane and endothelial cell invasion of the surrounding stroma in the direction of the angiogenic signalling. This migration step is followed by endothelial cell proliferation, and subsequently a three-dimensional organization to form vascular tubes. The quality and functionality of these newly formed tumoural vessels is different from the normal tissue vessels. This includes differences in cellular composition, growth regulation and permeability, but also geometrical distribution as the most obvious characteristics [10-12]. To quote the author of a review: “... malignant tumours induce a veritable Medusa's head of vessels supplying the growing core of malignant cells". 
For many tumours a mixture of viable cells is present close to these irregular vascular structures, with necrotic cells beyond an adequate oxygen gradient from the blood vessels, and cells in sub-optimal condition in-between. As such the vascular system dictates the distribution of viable dividing cells, potentially viable cells, and dying necrotic cells (see Figure 1.1).

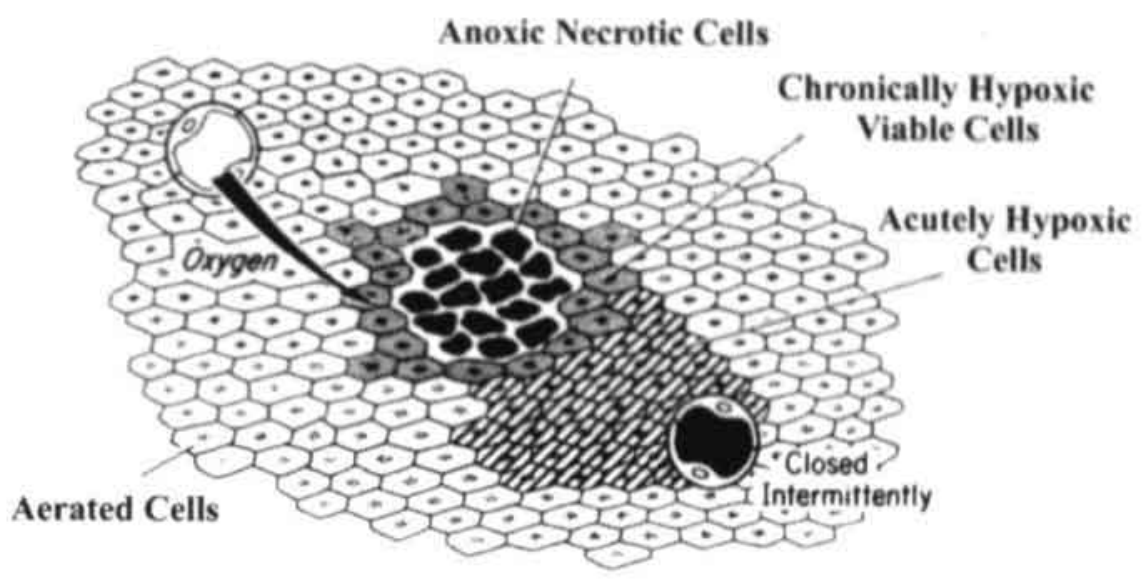

Figure 1.1: Cartoon indicating the stringent relationship between the presence as well as the functional quality of blood vessels and the oxygenation status of tumour cells, with related development of hypoxia, anoxia and cell death (redrawn from Vaupel et al).

Solid tumours thus reveal chronic hypoxic areas that are heterogeneously distributed within well-perfused areas, and which can reside even within a distance of about 120 $\mu \mathrm{m}$ from a vessel with sufficient blood flow. Of at least equal importance is, due to temporally closing and opening of blood vessels, the presence of cells that are thus acutely hypoxic, eventually up to several hours.

The strategy of the presently available 'conventional' cancer therapies (with the exception of surgery), such as radio- and chemotherapy, is related in a major way to the increased proliferation rate of the malignant cells as compared with their normal counterpart. These treatment modalities, although effective for a broad range of tumours, have however been shown not to be cancer cell selective. Regarding radiotherapy, it is the locally surrounding normal tissue structures that limits the total dose to the tumour. With chemotherapy the drug dose limitation is dictated by the rapidly dividing stem cells of the gastrointestinal epithelium and bone marrow, or by 
organ-specific toxicity related to drug accumulation and metabolism (e.g. liver toxicity with 5-fluorouracyl anti-cancer treatment).

Of equal importance is the increased expression of multi-drug resistance genes, that is metabolic adaptation to inactivate drugs (e.g. review [13]). Recent insights into tumour biology reveal an increasingly complex picture of cell and molecular processes that interplay with their micro-environment. Various strategies are under investigation to exploit the differences between the malignant and the normal cells at the molecular level (such as p53 status, tumor suppressor genes, signal transduction pathways) as well as differences in the tissue physiology (e.g. oxygenation status). Furthermore, the possibility to use these differential characteristics may show certain advantages for treatment $[14,15])$.

These intermingling yet complex characteristics of tumour growth, parallel vascular expansion and measurements of hypoxia are related to the present thesis and are explained in detail in the next sections. A concise outline of the investigations is given just after the references to this introduction (on pages 55-57). 
The improvement of methods and technologies in laboratory and clinical cancer practice has allowed researchers to again tackle observations that were made and questions that were posed in the first half of the $20^{\text {th }}$ century and to assess in depth several anti-cancer treatment modalities based selectively on tumour microenvironment characteristics.

\section{To recount in brief, some major questions relate to}

(1) the pathway of blood vessel recruitment and expansion that allows further tumour growth,

(2) the distinct differences in structural morphology and functionality of tumour vessels as compared with normal tissue blood vessels.

(3) the relationship between the aberrant intra-tumoural vessels and the heterogeneous condition of tumour oxygenation and cellular metabolism.

(4) hypoxia as a potential target for adjuvant therapy in individualized anti-cancer strategies,

(5) the appreciation of these tumour micro-environmental pathways using molecular immunohistochemistry and the introduction of non-invasive imaging techniques. 


\section{I.1.2. Tumour vascular status}

\section{I.1.2.a. General}

The development of blood vessels from an existing vascular network, defined as angiogenesis, plays an important role in embryonic life and physiological repair processes. Angiogenesis is also a major part in the development of various diseases such as diabetic retinopathy, but more so during growth of neoplastic tissue. Otherwise, in fully developed normal tissues and organs, vascular expansion is unnecessary and therefore endothelial cells divide rarely [16]. The biology of angiogenesis still remains incompletely understood. A variety of methods have contributed to our current understanding of angiogenesis and allowed the identification of several factors that control its regulation (reviewed by [17-19]). Among the vascular mediators are the well known polypeptides acidic and basic fibroblast growth factor, the family of vascular endothelial growth factors, angiostatin and endostatin, as well as angiogenic cytokines. Expression of some of these angiogenic growth factors is mediated by the transcription factor hypoxia inducible factor 1, a heterodimer in which the alpha subunit is unstable in the presence of oxygen [20]. The release of diffusible angiogenic factors, i.e. the switch to an angiogenic phenotype [9, 21-23], stimulates endothelial migration and proliferation with the subsequent growth of capillary tubes in vivo. Vascular maturation, namely the recruitment of pericytes or smooth muscle cells, is the final process in the blood vessel development, yet to a major extent absent in malignancies. Again, this final vessel remodelling that should result in a mature and functionally stable capillary, has become an area of additional research [24].

To acquire the trigger for the angiogenic process, oncogenes and tumour-suppressor genes in conjunction with the development of hypoxia play an important role next to cell-cell and cell-matrix interactions, involving members of the integrin family as for example $\alpha_{4} \beta_{3}$ (e.g. [25-27]). Finally also macrophages, recruited through the tumour cells' production of chemotactic factors, seem involved with the initial part of the angiogenic process.

This formation of new blood vessels seems, together with branching, crucial for the growth and persistence of primary solid tumours and for the initiation and survival of their eventual metastasis at distant sites [28, 29]. Support for this important 
observation has been offered in the seventies/eighties by various research teams using different in vivo tumour models and techniques, such as with tumours implanted on the chorioallantoic membrane of the chicken egg, in the rabbit eye (cornea or anterior chamber) or in transgenic mice (subcutaneous, or orthotopic for example in the pancreatic islets). Also in human tumours, both (a) the pre-vascular phase that defines poor or no angiogenic activity with inherent very slow or no tumour growth and (b) the neo-vascularization phase during which rapid tumour growth and increased probability of metastasis are evident, has been documented, for example with in situ carcinoma of the cervix [30] or with cutaneous melanoma [31].

The fact that the vascular network of tumours is known to differ from that in normal tissues (see for instance the elegant work of Konerding et al. [11] and references therein, and [32]) highlights the potential therapeutic benefit that should be obtainable from such an anti-cancer treatment approach. Tumour blood vessels are more tortuous, show arterio-venous anastomoses and blunt ends; tumours have vascular plexuses with vessels having 'capillary wall' structure with however a wide diameter and large inter-capillary distances (Figure 1.2, illustrating some of these features in for example a colon carcinoma).

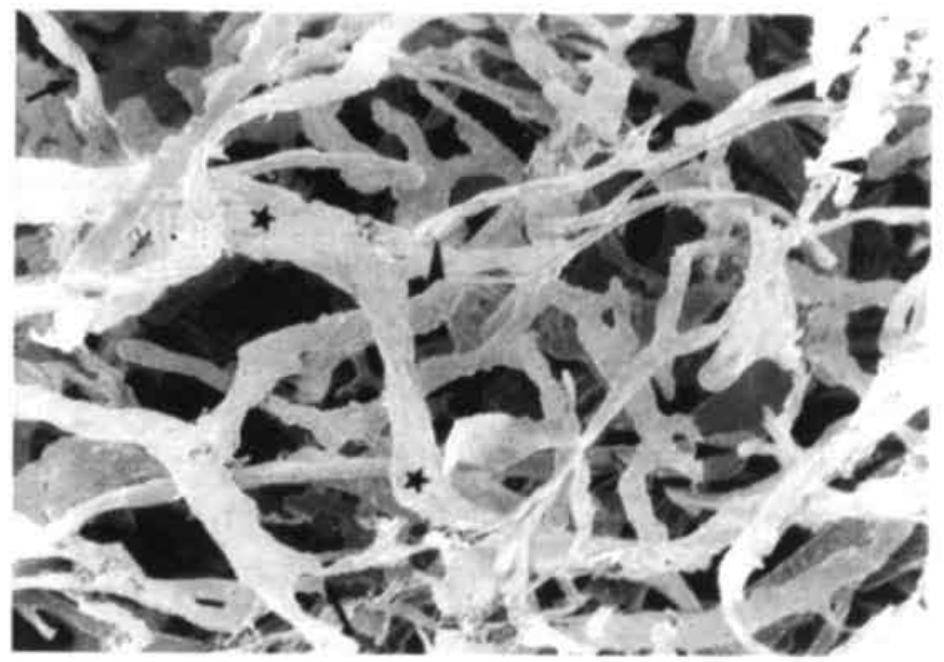

Figure I.2: Scanning electron microscopy of a corrosion cast of the vascular structure of a colon carcinoma: arrow-heads indicate blunt ends; the variability in diameter is marked by stars and arrows (reproduced from [11]; with permission, Springer, Berlin).

Growing capillaries are furthermore characterized by fragmented basement membranes and therefore they are leaky $[33,34]$. Additionally, the assessment of 
endothelial cell proliferation in various experimental and human tumours demonstrated a large difference in proliferation as compared with endothelium in adult normal tissue vessels $[16,35,36]$. The potential doubling time is less than a week for tumour blood vessels, but months or even years for normal tissue vessel expansion; Denekamp and Hobson $[16,37]$ showed a huge increase in labelling index of endothelial cells in tumour vessels.

Conceptually, the blood vessel-based approaches should be applicable to numerous, if not all, types of solid tumours because they rely on vascular expansion for continuous growth. Yet, it should be kept in mind that there is not a 'tumour-type-specific' structural vascular system, either in the morphological and functional aspect (discussed by e.g. [11]). Neither is there a standard endothelial labelling index, not within a single type of tumour, nor within tumours of different histology; and neither does a correlation exist between the proliferation index of the capillary endothelium and the growth rate of the tumours [35].
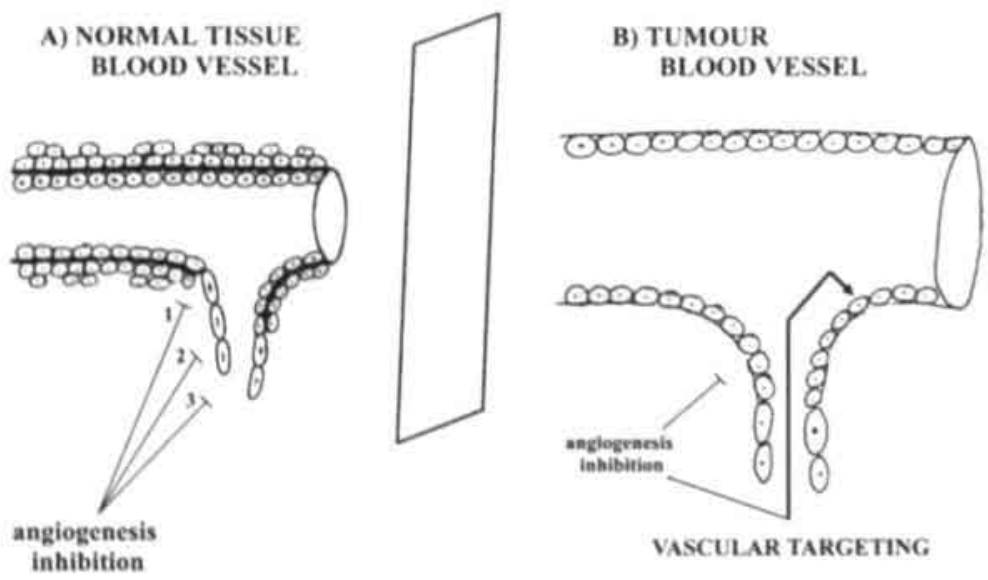

Figure 1.3: This cartoon (partly based on [38]) illustrates the broader hypothetical vascularity-directed strategy in anti-cancer treatment. Left part: inhibition of angiogenesis at the level of (1) extracellular matrix digestion, (2) endothelial cell migration and proliferation, and (3) capillary tube formation. Right part: direct endothelial cell damage in established tumour vasculature.

The impact and the conditions of the angiogenesis process during solid tumour growth have given rise to a major interest in these tumour vessels to serve as a direct target. This idea has been elaborated by the respective pioneers to propose antiangiogenesis [29] and vascular targeting [37], as illustrated in Figure 1.3. An arrest 
of vessel growth or a deliberate and permanent occlusion of existing tumour vessels, respectively, will induce tumour growth arrest and an avalanche of tumour cell death.

\section{I.1.2.b. Anti-angiogenesis modalities}

The rapid intra-tumoural endothelial proliferation however, that has never been identified in any unstimulated mature normal vessel, has obviously triggered various anti-angiogenic strategies (reviewed by $[18,39,40]$ ).

Some of the more promising agents for clinical testing are :

a) naturally occurring inhibitors of angiogenesis, e.g. thrombospondin, endostatin, angiostatin, bactericidal/permeabilityincreasing protein;

b) neutralizing angiogenic peptides, or those binding their receptors, e.g. antibodies to fibroblast growth factor (FGF) or vascular endothelial growth factor (VEGF), suramin;

c) agents that interfere with the extracellular matrix, e.g. matrix metalloprotease inhibitors;

d) anti-adhesion molecules, e.g, anti-integrin $\alpha_{4} \beta_{3}$;

or cytokines, e.g. interleukin 12, tumor necrosis factor alpha $(\mathrm{TNF} \alpha)$ :

e) specific inhibitors of endothelial cell proliferation and migration, e.g. the fumagillin analogue TNP-470, thalidomide.

Various natural inhibitors, such as the multimodular protein thrombospondin-1, were shown to turn off the angiogenic activity when over-expressed and to reduce tumour growth (e.g. [41]). The administration of the more potent endogenous vessel growth inhibitors angiostatin and endostatin not only suppressed the growth of the primary tumours but also their metastases, as shown with xenografted human tumours in mice [42-44]. Other compounds with angiogenesis inhibitory characteristics (interfering at different levels of blood vessel formation) have been synthesized during the last decade. For example, SU5416, selectively binding tyrosine kinase receptors (blocks

the phosphorylation of Flk-1 induced by VEGF) was shown to specifically inhibit sprouting through endothelial cell apoptosis and to influence growth of various 
tumour types (e.g. [45, 46]). The use of anti-VEGF antibodies (Avastin) or inhibitors of FGF-2 expression and activity has been demonstrated to substantially impair angiogenesis and reduce the tumour growth rate $[47,48]$. Saturation of the integrin $\alpha_{v} \beta_{3}$-receptor with the use of the monoclonal antibody (Vitaxin) inhibits angiogenesis by inducing endothelial cell apoptosis [49]. Novel inhibitors, displaying a simultaneous interference with several steps of the blood vessel formation (such as the recently developed peptide Anginex), or endogenous proteins with strong antiangiogenic activity at dose levels without the occurrence of systemic toxicity, are currently under investigation $[50,51]$.

The well-known TNP-470 (AGM1470), a synthetic derivative of fumagillin, strongly interferes with endothelial cell growth and inhibits vessel expansion. This occurs seemingly through the inactivation of type 2 methionine aminopeptidase activity [52, 53], and inhibition of cyclin-dependent kinases [54]. Others demonstrated the cytostatic activity of TNP-470 to be related with a specific late $\mathrm{G}_{1}$ cell cycle arrest $[55,56]$. In vitro data showed inhibition of both proliferation and migration of endothelial cells; and in vivo activity was appreciated as significant growth delay in several tumour types [57-60]. Importantly, not only did TNP-470 inhibit growth of the primary tumour but also to some extent metastasis development [61, 62].

To resume, based on these in vivo studies it became obvious (i) that angiogenesis inhibitors can be very active as a selective anti-tumour agent, (ii) that their use eventually may result in sustained tumour growth inhibition (characterized by a balance between proliferation and apoptosis of tumour cells), if a continuous drug presence can be obtained, (iii) that anti-angiogenic compounds seemingly do not induce drug resistance, as registered during repeated treatment [63-65].

Accepting that continuous tumour growth inherently requires additional blood vessel formation, it is of interest to evaluate the efficacy of an angiogenesis inhibitor at various defined tumour sizes. This aspect has been assessed in the present thesis research.

Based on the fact that a relatively high rate of endothelial cell division exists in the tumour and that several chemotherapeutics act on cycling cells only (interference with DNA replication), it may be appropriate to consider an anti-angiogenic action of such drugs. Effects on tumour blood flow have been described by Murray and 
colleagues, when melphalan was used in the treatment of a mouse sarcoma [66]. An anti-angiogenic effect was observed during the treatment of mouse Lewis lung carcinoma or L1210 leukemia with cyclophosphamide, applied as a repeat-dosing schedule without interruption; an efficacy that was further improved through the combination with TNP-470 [67]. Similarly, Klement and colleagues demonstrated the capacity of 'metronomic' drug dosing with xenografted human neuroblastoma and low-dose vinblastine [68].

The pre-clinical studies indicated that most of these anti-angiogenic compounds are active at doses not associated with treatment-limiting side-effects in the healthy tissues, as is most often the case with classical chemotherapeutic drugs. This fact, together with the selectivity towards tumour endothelium has emerged into their testing in phase I-II clinical studies (see review [69]). The variable success that has been obtained so far is likely related to the much broader variation, and sometimes a low level, of the angiogenesis status in human tumours as compared with the rodent tumours [70]. Also the large variability of the process (both molecular and morphological) within tumours of the same type, and the fact that in phase-I-II large tumours inherently are evaluated, may add to the lack of overall benefits from antiangiogenic treatments. However, their main clinical future, certainly as a single agent, will probably not lie in massive tumour cell kill and regression, but rather in preventing expansion of small-sized tumours and eventually inhibiting the metastasis formation. Combination treatments involving angiogenesis inhibitors and for example radiotherapy or vascular targeting agents should be at the forefront. To some extent, this aspect is part of the present thesis research.

\section{I.1.2.c. Vascular targeting modalities}

In contrast with the anti-angiogenesis strategies that aim to arrest new vessel growth, the vascular targeting concept in its 'pure definition' consists attacking the existing intra-tumoural neovasculature. Given the existence of an aberrant and immature vascular system in tumours, it is obvious to introduce strategies that take advantage of these aberrations (some examples are lined-up in Table L.a) . 
Table I. a

\section{Vascular targeting :}

e.g. - compounds such as tubulin interfering agents (combretastatin A-4, ZD6126, ...)

- hyperthermia

- photodynamic therapy

\section{Encapsulated drug delivery :}

e.g. - cytotoxic drug-containing (Stealth ${ }^{\mathrm{TM}}$ ) liposomes

\section{Receptor-based gene therapy :}

e.g. - $\alpha_{3} \beta_{3}$ integrin

- Flk-1

The aberrant morphology, and likely also the altered functionality of the tumour vessels, render them more susceptible to the vascular targeting agents. The endothelial cells are directly accessible to the circulating vascular targeting agents. Since several thousands of tumour cells rely on a single capillary for their oxygen and nutrient supply, even a limited damage and reduction of the vascular structures will result in an avalanche of tumour cell death.

From the late seventies onwards, the at-that-time-period novel anti-cancer therapy, hyperthermia that aims to deliver localized heat, was shown to affect tumours by damaging differentially newly formed vessels as opposed to normal vessels [71]. This tumour vessel damage may be appreciated by endothelial cell lethality, increased vascular permeability and reduced blood flow. Although a therapeutic window could be set forward, at least for some tumour locations, the broad use of hyperthermia was and still is hampered in clinical practice by the lack of methods to administer and monitor deep heat without critical normal tissue damage.

In parallel with hyperthermia, the activation of a systemically administered nontoxic compound by visible light to release cell-killing activated oxygen species, termed photodynamic therapy (PDT), was investigated for its anti-tumour activity. Similar to hyperthermia, endothelial cell damage (separate from direct tumour cell kill) with subsequent vessel permeability changes as well as blood flow alterations, 
were documented in various tumour models (see e.g. [72, 73]). Various cellular targets for photodynamic activity have been described, with disruption of mitochondrial integrity as the most important one [74]. In the broad context of tumour vascular targeting, it is of interest to mention the impact of nitric oxide inhibition in the PDT-induced vessel damage and subsequent anti-tumour efficacy [75]. Until now, the use of PDT remains restricted to the external treatment of superficial tumours or as an intra-operative therapy of tumour remnants after tumour resection (e.g. [75]). Pre-clinical research in PDT is ongoing to broaden the therapeutic potential based on an improved differential efficacy towards the tumour versus the normal tissues at risk, with the use of more selective and potent photosensitizers [76, 77].

More recently, "chemotherapy" has been discussed as being active against tumours by affecting the intra-tumoural vasculature to some extent. More evidence of a combined direct but also indirect (vascular damage-mediated) tumour cell kill from the use of cytotoxic drugs was presented by the Auckland-New Zealand research team [78]. They documented the vessel damaging capacity of vinblastine and colchicine in a mouse colon adenocarcinoma, by describing the rapidly induced extensive haemorrhagic necrosis that is the consequence of acute blood vessel collapse. Reductions in blood flow of rodent tumours from the administration of vinca alkaloids and flavone acetic acid (FAA) have been confirmed in parallel studies $(e, g,[79,80])$. Regarding colchicine, already as early as the thirties, vessel-mediated anti-tumour activities were strongly suggested (not really 'proven') in various rodent tumour models (nicely reviewed by Ludford [81]). These clear-cut experiments demonstrated a highly similar vascular damage-mediated anti-tumour activity to the one observed in more recent experiments with FAA and TNF- $\alpha$ [82]. Specifically, the publication of the latter group, that involved a rodent subcutaneous colon adenocarcinoma and the intramuscular EMT-6/Ak mammary carcinoma, did add conclusive information about the involvement of reduced blood flow and vessel perfusion, respectively 15 minutes or 3 hours after a single FAA injection [83]. Seemingly, activity may be dependent on tumour type (tumour site?) in that study, because the poorly vascularized EMT-6/Ak spheroids implanted in the peritoneal space were in that study shown to be much less responsive.

Notwithstanding the various promising in vivo rodent tumour investigations, these compounds were not at all equally successful in clinical trials $[84,85]$, and 
analogues with an improved therapeutic ratio were searched for (e.g. [85]). Regarding FAA for example, a structural analogue 5,6-dimethylxanthenone 4-acetic acid (DMXAA) has been synthesized, with increased anti-tumour activity in rodent tumour models [86, 87]. The activity of the acetic acid compounds seems, apart from involved immunomodulation, mediated mainly by TNF- $\alpha[82,88]$. With the use of DMXAA (as opposed to FAA), TNF $\alpha$ seems however differentially expressed in favour of tumour tissues as compared with normal tissues $[88,89]$. Separate from any possible pharmacokinetic explanation, activity was shown for most if not all experimental tumours at drug dosages that were very near the maximum tolerable dose (MTD) for the tumour-host systems under investigation. Regarding the taxoids, research has demonstrated inhibition of endothelial cell motility during tumourinduced angiogenesis through microtubule stabilization and induction of apoptosis, which was observed independent from cytotoxic tumour cell activity. (e.g. [90]). However, apart from the potent anti-cancer properties, these drugs also exhibit treatment-limiting side effects. Novel, second-generation compounds are being developed (e.g. [91]).

Separate, but within the same time-frame as the DMXAA studies, tubulinbinding compounds of the combretastatin family, isolated from the Combretum caffrum tree [92], have been introduced and tested for activity [93-95]. Combretastatin is a compound with two phenyl rings linked by a two-carbon bridge. The cis-form of combretastatin A-4 (see Figure I.4) was found most potent in vitro and was synthesized for further pre-clinical research, after being phosphated to enable better water solubility and improved in vivo administration. Anti-mitotic activity was found with various tumour cell lines, such as P388 leukemia, colon and lung cancer $[94,95]$. 


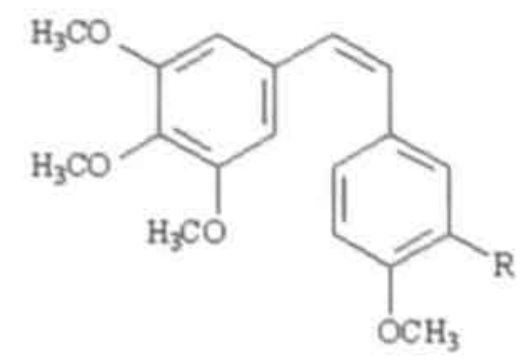

Combretastatin A-4 when $\mathrm{R}=\mathrm{OH}$

Combretastatin A-4 phesphate when $\mathrm{R}=\mathrm{OPO} \mathrm{N}_{3}$

Figure 1.4: compound structure.

The combretastatin A-4 shows a structural similarity to colchicines [94, 96], but possesses a higher affinity for the binding site on tubulin and causes a catastrophic microtubule disruption [92]. Colchicine affects proliferating endothelial cells in growing capillaries and shuts down the blood flow in experimental tumours, but only at systemic toxic doses. Several in vitro studies showing different characteristics of combretastatin A-4 phosphate (combreAp) are published. Damaging effects from combreAp are seen only in proliferating endothelial cells and not in the quiescent population [97]; condensation of tubulin and rounding-up of the endothelial cells are documented [98]. Another important morphological change induced by the drug includes reorganization of the actin skeleton and the formation of actin stress fibres [99].

The in vivo plasma half-life of combreAp is of the order of 4-9 minutes; but the dephosphorylated active combretastatin A-4 shows two plasma half-lives, with an initial one of about 15 minutes and a terminal one of 1-2 hours up to 9.4 hours [100]. A single intraperitoneal (i.p.) injected combreAp dose of $1 / 10^{\text {th }}$ to $1 / 4^{\text {th }}$ of the MTD (being about $1.000 \mathrm{mg} / \mathrm{kg}$ in mice) resulted in an early and major blood vessel damage in small mouse tumours, reflected by decreased blood flow and perfusion as well as haemorrhagic necrosis typical for a vascular mode of action of the drug (e.g. [97, 101. 102]). The blood flow rate of a subcutaneous (s.c.) transplanted P22 carcinosarcoma rat tumour was reduced to a nearly undetectable level in less than 6 hours following 
the injection of $30 \mathrm{mg} / \mathrm{kg}$ combreAp i.p. [103]. With a window chamber study using the rat P22 tumour model, vascular shutdown and reduced red blood cell velocity were observed even as rapid as 10-20 minutes after the combreAp injection $[97,98]$. Much less and only very transient blood flow reductions were seen in normal tissues and organs of rats [103]. The mean oxygen partial pressure was largely reduced throughout the tumour, as measured in $\mathrm{C} 3 \mathrm{H}$ mammary carcinoma of mice following the drug administration [101].

Some potential mechanisms to explain the acute tumour blood flow and oxygenation reduction have recently been put forward. Indirect and direct evidence for the nitric oxide synthase (NOS) pathway to be involved in the combreAp anti-tumour activity has been deduced from increased efficacy of the drug when NOS inhibition is introduced $[104,105]$. The very rapid (10-20 minutes) changes in the proliferating endothelial cells' area and form [98] add strength to the acute increase in vascular resistance and blood flow decrease. The increase in vessel wall permeability may further add, through increased interstitial pressure, to the changes of these functional vascular parameters. From 30 minutes post-treatment, an increased number of nonfunctioning blood vessels was recorded following the combination with a NOS inhibitor as compared with combreAp alone, an effect which seemed additive only; the combreAp on its own induced a severe reduction over vehicle or NOS inhibitor. Such a result involving the NO pathway correlates with the observation of stronger anti-tumour activity from PDT (also vascular targeting, cfr supra) when NOS is inhibited [106].

Separate from the pre-clinical research involving locally growing solid tumour models, a few rodent tumour studies also demonstrated a strong anti-metastatic action from combreAp. Using a Lewis lung carcinoma model; very few lung metastases were seen after a fractionated drug injection as compared with untreated mice [107]. Grosios and colleagues observed combreAp-induced necrosis in metastatic deposits of an orthotopically growing human colon tumour in mice [108].

Not only with syngeneic rodent tumours, but also with xenograft models were such strong anti-vascular effects measured after combreAp treatments. This has for example been illustrated in a non-Hodgkin lymphoma xenografted to severe combined immune-defecient (SCID) mice [109]. Both single and fractionated combreAp injections (always to the same total drug dose) resulted in substantial growth delay as well as increased survival time. Yet, the total combreAp dose used in 
this tumour model was the MTD, making a straight comparison with other rodent studies difficult.

Several other novel compounds with tubulin-interfering activity have been entered into pre-clinical research. A combreAp derivative, the serine prodrug AC-7700 (cleaved by aminopeptidase to the active form) has been shown in vivo to exert very significant activity against several rodent tumours as well as a human colon adenocarcinoma [110, 111]. Similar to the combreAp mechanism of anti-tumoural action, a reduction of endothelial cell proliferation and blood flow with subsequent hemorrhagic necrosis were demonstrated selectively in tumour tissue. The more recent developments are towards e.g. the oral administration of vascular targeting compounds (for example BTO-956), displaying potentially stronger anti-tumour activity as combreAp and obviously without the induction of systemic toxicity [112].

Since the vascular targeting compounds have been shown to tackle by definition the developed vessel structures in the tumour and to induce vessel shutdown with subsequent tumour cell kill through starvation (see cartoon Figure I.5), it is of great interest to investigate their activity in large sized tumours. All published data concern small tumours (most often less than $0.5 \mathrm{~cm}^{3}$ ). Larger tumours however inherently have more established immature vasculature than small ones, and the antitumour efficacy of the drugs could be stronger. As these compounds are aimed at killing indirectly the hypoxic tumour cells (resistant to classical therapy), a broadening of the therapeutic benefit may be expected. This evaluation is a major theme of the present thesis research. 


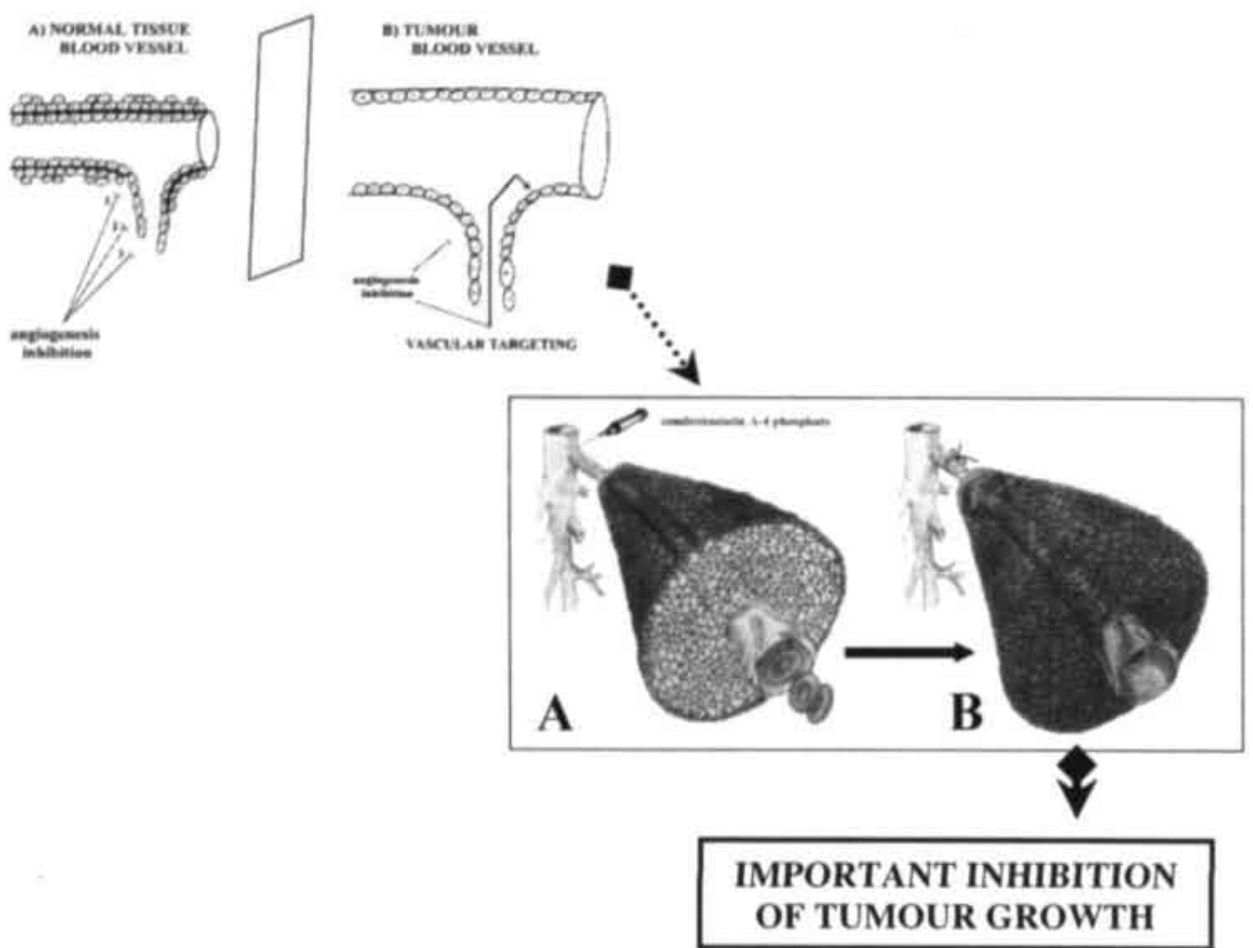

Figure I.5: This threefold-cartoon relates the underlying mechanism of the combreAp to our hypothesis: larger tumours contain more established (post-angiogenic, ill-formed) blood vessels, thus offering more targets for the activity of the combreAp and thus a stronger anti-tumour effect.

All of the in vivo pre-clinical combreAp studies, as well as with other vascular targeting agents (such as DMXAA and AC-7700) thus clearly demonstrate massive necrosis, yet leaving a small but viable rim of tumour cells at the periphery. From this peripheral tissue, the tumour continued growth if left untreated. Therefore it is obviously necessary to combine the vascular targeting treatment with a conventional cancer therapy in an optimal time-sequence.

Various combination treatment approaches have been and still are being tested with several rodent tumour models, aiming to broaden the therapeutic window. The combination of vascular targeting with ionising radiations, with several types of chemotherapeutic drugs, and with hyperthermia, were shown in those studies to increase anti-tumour efficacy of vascular targeting to different extents. Indeed, a larger reduction in clonogenic KHT sarcoma tumor cell survival has been published by $\mathrm{Li}$ and colleagues, when combre Ap was combined with a single dose irradiation 
[113-115]. A similar improved anti-tumour result has been obtained when DMXAA was combined with irradiation [116]. Importantly, although until now only evaluated using the acute irradiation response in rodent skin (desquamation incidence) as the endpoint, one report indicates the absence of enhanced epidermal irradiation reaction when combreAp was added shortly after the single dose irradiation [115]. Other studies involving a rat glioma model or mouse mammary carcinoma, combined the combreAp administration with hyperthermia and indicated an enhancement of the heat-induced damage in the combination experiments $[117,118]$. Combining 5fluorouracyl (5-FU) or cis-platinum injections with the combreAp treatment resulted in a significantly larger growth delay as compared with either agent alone [119, 120]. The potential of an increased anti-tumoural effect from the combination of combreAp with irradiation or anti-angiogenesis is part of the present thesis research.

\section{I.1.3. Tumour oxygenation status}

\section{I.1.3.a. General}

Molecular oxygen is an essential requirement for the oxidative phosphorylation that provides the cellular energy in the form of adenosine triphosphate in tissues. To make this provision possible in normal tissues, the macroand microvascular branching is in perfect balance thus assuring the necessary supply of oxygen.

Solid tumours outgrow their blood supply, consequently the vasculature is unable to meet the demands, and inherently hypoxic and anoxic areas develop.

The emergence of a hypoxia status in solid tumours is majorly the result of (1) the reduced oxygen-binding capacity of hemoglobin, (2) an aberrant oxygen consumption gradient, (3) an oxygen diffusion limitation (chronic), resulting from the increasing distance between blood flow and tumour cells (likely related to some extent to the interstitial fluid pressure increases), (4) intermittent perfusion-limiting vessel lumen changes, defined as acute hypoxia and (5) a sluggish blood flow as the result of poorly organized vasculature. The morphological, structural and functional deficiencies of the intratumoural microcirculation thus provide an aberrant micro-environmental condition regarding cellular responses and treatment efficacy (Figure I.6). 

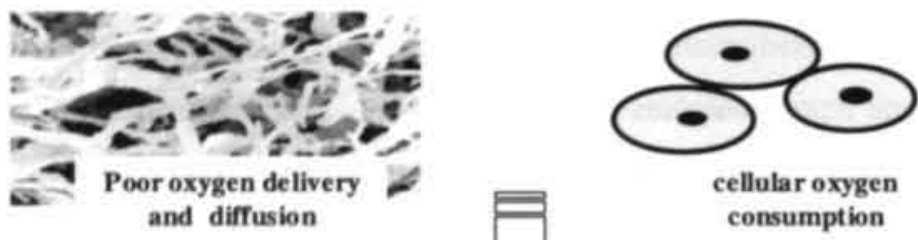

REDUCED

INTRA-TUMOURAL
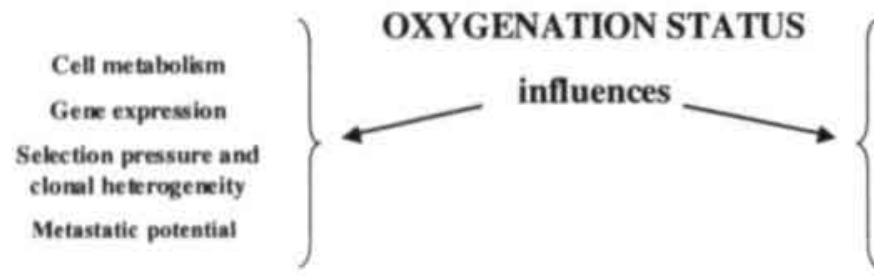

Response to major treatment strategies

Design and efficacy of novel hypoxiadirected therapies

Figure 1.6: Overview of major parameters that may be influenced by reduced oxygenation status (based on Figure 8 in [121]).

\section{I.1.3.b. Impact on treatment efficacy}

In the last 10-15 years, a remarkable progress has been made in the understanding of intrinsic cellular properties that determine radio- and chemoresistance. Some of these have been set forward as major characteristics: such as inherent radiation sensitivity [122, 123], multidrug resistance [124] and gene amplification [125]. Realizing their importance, researchers have in parallel focussed on the biochemical and physiological heterogeneity within tumours. These are aspects that not only highlight the differential condition between tumour and normal tissues, but moreover critically define the cells' reaction to treatment. Some of these microenvironmental conditions are the oxygenation status (see infra for further description in relation to treatment and imaging), the extracellular $\mathrm{pH}$ and glucose metabolism.

Tumour hypoxia and anoxia play a significant role in determining the curability of most cancers for all treatment options available in overall-oncology clinics at the present time. 
Regarding the hypoxia-related radiation-resistance aspect, Gray and colleagues demonstrated already in 1953 the important role of tissue oxygen concentrations prior to and during the irradiation [126]. Lower $\mathrm{pO}_{2}$ values relate to a reduced relative radiation-sensitivity, and thus inherently to a lesser cell kill. Hypoxic cells are 2-3 times more resistant to ionising radiation than their well-oxygenated counterpart [127]. The absence of oxygen allows for instance a more adequate repair of the free radicals in critical molecular cell structures such as DNA, which results in a higher incidence of cell survival. During the last 15 years, sufficient data have been accumulated to underline the importance of the tumour oxygenation status. Tumour oxygenation status has been shown to be an independent prognostic factor for radiotherapy outcome (local control and disease-free survival) of for example advanced cervix cancer [128-130] or head and neck cancer [131, 132]. Stadler and colleagues introduced the description of 'hypoxic sub-volume' in their head and neck squamous cell carcinoma study, a parameter they consider of great radiobiological value and which takes into account the total number of hypoxic cells [132]. Yet, compared with the available data describing e.g. median $\mathrm{pO}_{2}$, the hypoxic subvolume factor merely confirms the known correlation with treatment outcome and disease progression. Furthermore, the combination of hypoxic status and hemoglobin concentration showed a positive relation with treatment outcome for cancer of the uterine cervix [133].

But hypoxia is also influencing the response of tumours to chemotherapy; since most chemo-drugs target dividing cells, their activity is much reduced and even absent because cells do poorly or not proliferate in a continuous hypoxic environment [134]. Moreover, drug delivery into hypoxic areas is hindered by the inherent (causal relationship) ill-formed and non-functional intra-tumoural vascularity. Obviously, the efficiency of radio- and chemotherapy is also influenced by several other biological factors: such as the distribution of cells within their cell cycle, the mitotic activity and the $\mathrm{pH}$ value (all parameters with potential impact prior during treatment).

The existence of a straight relationship between the severity of hypoxia and the reduced success of surgical treatment has been demonstrated with for example advanced cervical cancer [135]. 


\section{I.1.3.c. Relation with tumour expansion}

Furthermore, evidence has been gathered on the contribution of hypoxia to malignant progression, e.g. by influencing signal transduction pathways and the regulation of various genes such as hypoxic inducible factor (HIF) $-1 \alpha$, erythropoietin (EPO) and p53 (e.g. review [136]). Graeber et al indicated that the hypoxic condition does provide a selective pressure in tumours for the development of apoptosisdeficient more malignant variants [137]. Various proto-oncogenes have been shown to be up-regulated by hypoxia [138]. Increased invasiveness and metastatic potential, to a major extent a result of loss in apoptotic ability and the switch to a pro-angiogenic phenotype, are being documented both in pre-clinical tumour models as well as with patient studies [139-142].

\section{I.1.3.d. Measuring hypoxia}

The presence of tissue-areas with a low oxygen status is, though not unique (as for example with the ischemic heart), a major characteristic property of solid mammalian malignancies beyond an early phase of their growth (e.g. [143, 144]).

The premise that hypoxia influences to a large extent the outcome of many cancer treatment modalities introduced the necessity to measure these hypoxic cell populations with retained viability. One of the initial approaches involved the use of radiosensitizer adducts such as misonidazole to mark the hypoxic cells (reviewed e.g. by Chapman [145]). These results, and those obtained with other methodologies such as oxygen electrode techniques, showed both in experimental and in human tumours that tissue oxygenation is quite heterogeneous within the tumour volume. Areas with high $\mathrm{pO}_{2}$, comparable with normal tissue, as well as areas with severe hypoxia can be found; the latter being the result of an imbalance between the supply and the consumption of oxygen. The fraction of $\mathrm{pO}_{2}$ values $<5 \mathrm{~mm} \mathrm{Hg}$ measured in metastatic lesions is higher as compared with the hypoxic status of the related primary lesion (e.g. illustrated by Vaupel et al. [146]).

The fact whether the degree of hypoxia rises with increasing tumour size is to some extent still a matter of dispute, at least for some types of malignancies. For example, in breast cancer, no such relationship was found by Vaupel et al. in their small-scaled patient study [143]. Yet, this 'controversial aspect' could result from inter-tumour 
variability (not the same tumours being followed-up during growth) or from insufficient representative intra-tumoural oxygen tension measurements for the tumours at various phases of growth. It has been pointed out by Fyles and colleagues that at least 5 micro-electrode tracks and a sufficient number of measurements per track may be necessary to minimize the variation within tumours compared with the heterogeneity between different tumours [130]. The data of Vaupel et al. [143], as well as those from Nordsmark and Overgaard [147], contrast the more extensive breast cancer patient investigation of Runkel et al. [148] which shows a clear-cut association between tumour size (stage T1-T2 versus T3-T4) and oxygen partial pressure: larger tumours present with an increased hypoxia level. The presence of an association between the hypoxic condition and the size of the tumour has also been pointed at by Zhao and colleagues using the rat Dunning prostate R3327-HI adenacarcinoma; their data showed higher $\mathrm{pO}_{2}$ values in small tumours as opposed to large ones [149]. One important consideration: tumour size has definitively been shown to be highly significantly related to disease-free survival (e.g. [130, 150-152]). All these investigations highlight the necessity to incorporate tumour volume in the analysis of therapy results, and point to the potential impact of the inherent differences in hypoxic fraction on treatment choice and outcome.

It thus is very important to develop reliable methods for measuring the oxygen level in tumours. Entire meetings have been dedicated to discussions on the methodologies to measure hypoxia and the relation of such measurements with the efficacy of various therapies (e.g. [153, 154]). Well-defined and established assays will provide patient prognosis and identification of patients whose tumours would be most likely to respond positively to treatment strategies targeted at hypoxic cells. These hypoxia measurements are routinely divided into invasive and non-invasive approaches.

\section{I.1.3.d.I. Invasive hypoxia measurements}

One of the first clinical applicable attempts to measure tumour oxygenation status in situ used polarographic oxygen electrodes (Eppendorf, Hamburg, Germany). optimised to reduce measurement bias from tissue oxygen consumption at the probe tip [155]. The evaluation of the apparatus, its validation in patients and the reproducibility have initially been reported by Kallinowski and colleagues [156]. Since more than a decade, this methodology, be it invasive and necessitating optimal calibration and multiple intra-tumoural positioning, has proven relatively successful 
for estimating the oxygenation status in several tumour types and tumour locations in humans. More importantly, these electrode-based oxygenation measurements to some extent allowed the prognosis of tumour treatment responsiveness, both in terms of loco-regional tumour control as overall patient survival.

Recently a newly invented fibre-optic monitor "OxyLite" (Oxford company, Oxford, United Kingdom) has been introduced in pre-clinical in vivo research. Light pulses carried by an optical fibre induce fluorescent pulses of a luminophor incorporated into a silicone rubber polymer at the probe tip. The lifetime of the fluorescent pulse is inversely proportional to the oxygen tension at the tip. A continuous read-out of $\mathrm{pO}_{2}$ can thus be obtained. Without doubt, at least two important advantages over the Eppendorf micro-electrode system have been defined. The luminescence-based probes do not consume oxygen, allowing real-time evaluation of $\mathrm{pO}_{2}$ changes at the same inta-tumoural position, and they provide accurate oxygenation values well below a $\mathrm{pO}_{2}$ of $5 \mathrm{~mm} \mathrm{Hg}$ (true radiobiologic hypoxia). This instrument therefore carries a larger clinical potential. Correlation with other hypoxia measurements, for example with pimonidazole hypoxic cell labelling and with Eppendorf electrode measurements have been made in syngeneic rodent and xenografted human tumours (e.g. [157, 158]). Bearing in mind that the two micro-probe devices can not be considered exclusive on their own, results show that the fibre-optic instrument allows regions with $\mathrm{pO}_{2}$ values less than $5 \mathrm{~mm} \mathrm{Hg}$ to be more accurately defined.

Other methodologies to estimate the hypoxic condition in tumours are the biopsy-based immuno-histochemistry staining using bioreductive probes with their respective antibodies, such as pimonidazole, 7-4'-2-nitroimidazole-1-butyltherophyline (NITP) and fluorinated etanidazole [159-161]. These 2-nitroimidazoles are metabolised as one-electron reduction by intracellular nitroreductases; subsequently the nitro-radical is further reduced in oxygen-depleted environment and identification of hypoxic cells through the bound metabolites can proceed with the appropriate antibody. Various pre-clinical and clinical data-sets and peer-reviewed publications support presently the utility of these staining procedures.

Further refinement to stain the biopsies and surgical resection materials, frozen or paraffinized, is ongoing. A recent retrospective cancer patient study combined vesselendothelial cell staining with a diffusion limited fraction (DLF) measurement (translating chronic hypoxia at a fixed distance of $120 \mu \mathrm{m}$ ) to estimate treatment 
outcome, thus aiming to avoid the necessity to inject a bioreductive stain [162]. The DLF measurements seemed to correlate to some extent with the pimonidazole stained areas in relation to the blood vessels, but the methodology needs further elaboration. Begg and colleagues demonstrated with an in vivo rodent tumour the potential to use deoxyuridine labelling as a marker of perfusion-limited acute hypoxia [163]. Triple staining for hypoxia simultaneously with vessel quantity and functionality has been under investigation in pre-clinical laboratory research using xenotransplanted human tumours [164]. These data also indicated chronic hypoxia through NITP staining at increasing distance from blood vessels (stained with 9F1), with not all vessels being perfused (Hoechst dye uptake). The use of intrinsic markers, such as the hypoxia inducible factors (HIF- $1 \alpha$ and $2 \alpha$ ), or the glucose transporters (Glut-1 and Glut-3) and carbonic anhydrase IX (CA-IX) both under transcriptional control of hypoxia, is also under investigation both pre-clinical as with patient studies involving for example head and neck squamous cell carcinoma and cervical carcinoma (e.g. [165-167]). These results show potential for their application as 'surrogate' markers of hypoxia. specifically because a significant correlation seems for example present between the mean vessel density plus the amount of necrosis and the CA-IX expression (perinecrotic staining). The fact however that overlap between the different staining procedures (including pimonidazole) is not always seen, partly related to e.g. differentiation between acute versus chronic hypoxia, highlights the need to continue comparative investigation using various tumour types and sites of growth. All these studies, for which the techniques appear feasible on their own, definitely point at the broad intra- and inter-tumoural heterogeneity of perfusion and diffusion in relation with oxygenation status, which seems independent of tumour type, size or location.

Such a heterogenous situation (as for example reflected in the $\mathrm{pO}_{2}$ measurements) necessitates a correct characterisation of the descriptive parameters, biological and statistical, as clearly discussed by Thews and Vaupel [168], and the application of complementary methodologies. Of equal importance is to perform repeated measurements, at best of the 'undisturbed' whole tumour rather than only very small parts. The literature offers discussion on how many biopsies or microelectrode tracks are necessary to allow a representative evaluation of hypoxia for each individual tumour. Regarding biopsies, at least 3-4 would be needed, whereas 5 tracks 
would be a necessary number to minimize the influence of variation within tumours compared with heterogeneity between different tumours (e.g. [130, 169]). These factors, specifically in view of repetition during treatment, together with the fact that deep-seated tumours or those near critical structures cannot be assessed, introduce the strong need of non-invasive methodologies.

\section{I.1.3.d.2. Non-invasive hypoxia measurements}

Several possibilities involving imaging techniques have been introduced and tested for estimating parameters of the tumour micro-environment in a non-invasive way, specifically related with positron emission tomography (PET) and single-photon emission computed tomography (SPECT), computed tomography (CT) and magnetic resonance imaging (MRI).

For example, ${ }^{18} \mathrm{~F}$-fluoromisonidazole (FMISO) and more recently ${ }^{18} \mathrm{~F}$ fluoroerythro-nitroimidazole (FETNIM) and ${ }^{18}$ F-labeled nitroimidazol-acetamide derivative (EF3) or ${ }^{18} \mathrm{~F}$-2-fluoro-2-deoxyglucose (FDG) PET are becoming established clinical imaging techniques to measure respectively tumour hypoxia and glucose metabolism (e.g. [170-173]). These techniques, based on capturing annihilation photons from positron-emitting tracers, thus provide information on the metabolic activity and functional capacity of tumours as a whole as well as regions of interest, with additionally the possibility to quantify changes in time. FDG PET measurements of the glucose metabolism, translated as standard uptake value, demonstrated the differential between tumour and normal tissues and indicated the prognostic value of this approach (e.g. [174]).

The use of FMISO and ${ }^{123} \mathrm{I}$-iodoazomycinarabinoside (IAZA) enable an indirect (tracer uptake inversely proportional to intracellular oxygen concentration) estimate of tumour oxygenation (e.g. [175-177]). Among these tracers, FMISO has been most extensively studied. The method allows to image approximately the whole tumour and at the same time to estimate the heterogeneity within the individual tumour, as indicated in a study concerning various types of malignancies [176]. Despite these encouraging results, sub-optimal imaging properties have limited the routine use of FMISO in clinical practice. Research is ongoing to further evaluate and validate the existing azomycin-nucleoside markers, to test novel hypoxic cell-specific chelates, and to define the optimal timing of image-acquisition of maximal hypoxia signalling (see e.g. $[170,178])$. 
Using contrast-based CT, the oxygenation condition of tumours can be appreciated indirectly through the measurement of perfusion. This quantitative approach has been demonstrated elegantly by Hermans and colleagues in head and neck squamous cell carcinoma; a positive correlation between perfusion rate and local control after radiotherapy was found [179].

Tumour oxygenation measurements, on the other hand, have also been performed by using fluorine ${ }^{19} \mathrm{~F}$ magnetic resonance imaging (MRI) spectroscopy; they allowed the evaluation of dynamic changes from baseline oxygenation status when applying different hyperoxic gasses (e.g. [149, 180, 181]). Other MRI spectroscopy methods involve phosphorus ${ }^{31} \mathrm{P}$ and proton ${ }^{1} \mathrm{H}$ (see e.g. review [182]) which measure tumour parameters that relate to oxygenation, such as $\mathrm{pH}$, lactate or high energy phosphates (ATP), with some results found to correlate relatively with Eppendorf electrode and fraction of radiobiological hypoxia evaluations in the same tumour model [183, 184]. The classical MRI provides the detection and delineation of tumours in the body [185]. The method is based on differences in signal intensity between tumours and normal tissues related to the water content. Spatial information is obtained by changes in magnetic field gradients at specific times during and after radiofrequency pulses. MRI enables the use of each point (voxel) in each individual tumour as its own control, thus providing a longitudinal statistically powerful test of the effects from treatments. Contrast enhancement techniques have been entered to image the tumour physiology and micro-environment, such as blood flow and hypoxia, more efficiently. For example, evaluation of the rate of uptake of gadolinium-diethylenetriaminepentaacetic acid (Gd-DTPA) is extensively used to estimate tumour perfusion [186]. In a proof-of-principle evaluation involving locally advanced uterine cervix carcinoma, the use of dynamic contrast enhanced MRI has been indicated to correlate relatively well with the Eppendorf electrode measurements [187].

Blood oxygen level dependent (BOLD) functional MRI is, compared to dynamic MRI methods, an interesting non-invasive approach because no exogenous contrast agent is necessary. The BOLD effect uses hemoglobulin as intrinsic contrast agent: oxyhemoglobin has no magnetic properties, while deoxyhemoglobin is paramagnetic. So, deoxyhemoglobin causes magnetic susceptibility effects that lower $\mathrm{T}_{2}{ }^{*}$-weighted image intensity; improving blood oxygenation therefore results in $\mathrm{T}_{2}{ }^{*}$-weighted image intensity increases. It has been extensively applied for the non-invasive monitoring of cerebral activity upon exercise or external stimuli (e.g. [188-190]). 
Changes in the ratio oxy- to deoxyhemoglobin are translated into signal intensity changes, and indicate changes in blood and tissue oxygenation.

Evidence that BOLD contrast in tumours is sensitive to changes in oxygen saturation of blood caused by oxygenation treatment was demonstrated first by Karczmar and colleagues with a rat mammary adenocarcinoma [191]. During inhalation of $100 \%$ oxygen or carbogen, large and reproducible changes in $\mathrm{T}_{2}{ }^{*}$-weighted images occurred. The likely explanation of these changes was that increased oxygen delivery decreases blood deoxyhemoglobin, resulting in an increase in signal intensity on $\mathrm{T}_{2}{ }^{*}$. weighted images. Increases in blood flow, oxyhemoglobin saturation and tissue $\mathrm{pO}_{2}$ are expected to be greatest in tumour regions where oxygen delivery was previously inadequate to satisfy demand. The $\mathrm{T}_{2}{ }^{*}$ changes during hyperoxic breathing were small in surrounding muscle, providing support for the fact that oxygen-enriched gas is not expected to significantly increase the oxy- to deoxyhemoglobin ratio in normal tissues. Through literature screening it is evident that these signal intensity changes, from the application of a hyperoxic gas, differ among tumour types (e.g. [182, 192, 193]). This observation was not only true for pre-clinical tumour evaluation, but in a similar way when tumours in patients were evaluated with the MRI [194, 195]. The methodologies altogether indicate potential predictive power in cancer therapy; they allow us to estimate the level of hypoxia and its change during and after a specific single or combined therapy (e.g. [194]).

The introduction of functional MRI in tumour imaging, using gradient echo sequences, thus offered a major benefit; yet, due to the pulse sequence design, only one slice through the tumour is measured.

The final part of the present thesis research is aimed to test the feasibility of applying gradient echo functional MRI with an echoplanar imaging (EPI) sequence to evaluate the oxygenation condition of the tumours in total using multiple slices.

\section{I.1.3.e. Hypoxia-related treatment}

The hypoxic condition can be exploited or, on the other hand, can be reduced to advance additional anti-cancer treatments. Various options (see Table I. b) can be offered to use the presence of hypoxia and anoxia for the benefit of cancer treatment and improved outcome. 


\section{Table I. b}

\section{Hypoxia-selective 'bioreductive' drugs :}

e.g. - nitroimidazoles, such as misonidazole and nimorazole

- tirapazamine

- $\mathbf{A Q 4 N}$

\section{Hypoxia-based gene delivery :}

e.g. - transfection of tumour cells with the HRE-CDase gene

\section{Hypoxia/anoxia/necrosis-based therapeutic protein transfer :}

e.g. - anaerobe bacteria, such as non-pathogenic Clostridium, with incorporated CDase or TNF $\alpha$

\section{Reduction of hypoxia:}

\section{e.g. - erythropoietin}

- hyperoxic gasses, such as hyperbaric oxygen and carbogen

The principle of using radiosentizing agents, such as misonidazole and etanidazole, is that they mimic the effects of oxygen at the time of irradiation thereby enlarging the DNA damage. Although proven efficient as sensitizers in laboratory tumour models, their clinical application showed a very limited benefit because of unacceptable sideeffects. Nimorazole, a drug of the same family, but showing little systemic toxicity, has been used more successfully in a randomised phase-III study [196].

Extensively investigated in pre-clinical settings, are the class of hypoxia-activated (bioreductive) prodrugs (see review [197, 198]). Such compounds require a metabolic reduction (optimal at low oxygen levels in the tumour) to produce the cytotoxic agents. Two novel compounds, tirapazamine (SR4233) [199], which currently is evaluated in clinical trials (e.g. $[200,201])$ and alkylaminoanthraquinone $\mathrm{N}$-oxide (AQ4N) [202] show great potential to increase cancer treatment efficacy. With tirapazamine for example, the combination with either fractionated irradiation, or with cisplatin, or the 'triplet'-combination resulted in an increased growth delay [203-205]. 
With $\mathrm{AQ} 4 \mathrm{~N}$, reduced to $\mathrm{AQ}_{4}$ that intercalates within DNA, an important enhancement of chemo- and radiation-induced cell kill has been shown with rodent tumours [206].

Recently, experiments have demonstrated several possibilities to use the hypoxic environment for the transfer of therapeutic proteins selectively to the tumour. One of these strategies involved the combination of a "hypoxia responsive element (HRE)' with the suicide gene cytosine deaminase (CDase), to transfect tumour cells for a strictly on-site therapeutic activity [207]. Intra-tumoural cytotoxicity, through the conversion of the systemically delivered prodrug 5-fluorocytosine (5-FC) to the chemotherapeutic 5-fluorouracil (5-FU) by the CDase, only occurred with cells in the hypoxic condition. These data provided a first proof-of-principle of the possibility to control the regulation of prodrug activation in a hypoxia-selective way. On the basis of vascular endothelial growth factor (VEGF) expression under hypoxia, Shibata and colleagues developed a cytomegalovirus-driven hypoxia-responsive vector which may allow for improved tumour-selective therapeutic gene expression [208].

In parallel, a bacteria-based methodology to transfer therapeutic proteins has been investigated [209-211]. This idea has found its roots in the pioneering work of at least two research teams in the fifties-sixties, using non-engineered apathogenic Clostridium species [212, 213] and later research using combinations with chemotherapy [214]. The use of anaerobic clostridia is based on the presence of areas in tumours that lack oxygen, thus allowing the proliferation of these bacteria exclusively intra-tumoural. This was not only shown for Clostridium butyricum [215] and Clostridium saccharoperbutylacetonicum [210] and very recently for Clostridium novyi-NT [216], but is also well documented for Bifidobacterium longum [217].

The data from our research group (Experimental Radiobiology and Bacteriology, K.U.Leuven) indicated absence of a major immune response as well as absence of any toxicity. Although spores (metabolically inactive) were detected in normal organs of tumour-bearing rats, no germination occurred and the spores disappeared from all organs within a few weeks. Using the $C$. novyi-NT strain, devoid of toxin genes, Dang and colleagues still recorded mortality in their mouse experiments, which they assume to be related to the tumour lysis syndrome [216]. The application of an appropriate antibiotic eradicates all bacteria from the rat body (part of this thesis).

Non-pathogenic recombinant clostridia may thus be used as highly tumourselective factories to locally produce an anti-tumoural component. There is no need 
for insertion of the gene coding for the therapeutic protein into the tumour cell genome, and therefore problems involving genomic instability and insufficient transduction efficiency are avoided. This has been demonstrated for Clostridium acetobutylicum DSM792 recombinant for either the cytokine tumor necrosis factor alpha gene (TNF $\alpha$ ) [218]or the suicide CDase gene (part of this thesis: [219]). With both TNF $\alpha$ and 5-FU, severe normal tissue toxicity is present when given systemically at doses that cause tumour cell death. The bacterial transfer system circumvents this problem, and, together with the pleiotropic anti-tumour effect of TNF $\alpha$ (against tumour cells and vasculature) and the bystander effect of 5-FU [220], thus offers great potential in anti-cancer treatment combinations. Very recently, another group presented an in vivo investigation on the use of Clostridium sporogenes recombinant for CDase in combination with the prodrug 5-FC [221]. These data illustrated the sufficient production of 5-FU through the bacteria-based enzymeprodrug system to induce a significant growth delay. The levels that have been obtained with this system thus should be sufficient to obtain improvement of irradiation treatments. The potential to find increased radiation efficacy from the 5-FU presence has been indicated through a theoretical modelling of necessary 5-FU concentrations [222]. The deduction and calculation, based on 5-FU literature data, indicates radio-sensitization factors between 1.1-1.2 when bacteria-CDase-based conversion efficiency is as low as $1-3 \%$. The combination with radiotherapy could improve anti-cancer results, next to the temporal control of therapeutic protein expression through radiation-inducible promoters, as elaborated by Nuyts and colleagues at our research units $[223,224]$.

The combination of the anaerobe bacteria-based therapeutic gene transfer with vascular targeting, based on the hypothesis to provide an intra-tumoural environment that increases the proliferation of the recombinant bacteria, has been evaluated by us using combreAp (this thesis research). Dang and colleagues more recently combined the non-recombinant Clostridium novyi-NT with mitomycin $\mathrm{C}$ and dolastatin, and showed a stronger 'bacterial' activity against two different tumour types as compared with either agent alone [216].

More bacterial species are presently being evaluated for the use as selective anticancer probes, either as such or as recombinant for a specific therapeutic protein (see brief review [225]). Also stronger promoters such as the glutamine-synthetase gene 
from $C$. beijerinckii could advance the expression and secretion of the inserted therapeutic proteins [226].

Finally, agents that reduce the hypoxic status have been considered to improve the tumour responses to radiotherapy. The alteration of oxygen delivery to the tumour tissue has been assessed already in the eighties, including methods such as blood transfusion or perfluorochemicals administration (e.g. [227, 228]). Using the perfluorocarbon Fluosol-DA, the oxygen-carying capacity of the blood could be increased several fold. Radiosensitization with the administration of perfluorochemicals has been documented (see e.g. review [229]).

Hemoglobin concentration is well known as a prognostic factor for local control in e.g. radiotherapy of uterine cervix cancer $[230,231]$ as well as head and neck carcinoma patients $[232,233]$; low levels $(<12-13 \mathrm{~g} / \mathrm{dl})$ are positively correlated with poor local control and overall survival in these and other tumour types. Erythropoietin (EPO) is up-regulated in response to hypoxia, and stimulates red blood cell production in the bone marrow, with consequently an improved oxygenation. This has led to the introduction of recombinant EPO administrations to anaemic cancer patients, data showing some beneficial effects (e.g. [234, 235]).

Another equally important strategy to improve tumour tissue oxygenation is the application of hyperoxic gasses (see also section I.1.3.d.2. on non-invasive imaging). The use of hyperbaric oxygen breathing has initially shown some benefit in experimental rodent tumours and patients with head and neck cancer [236, 237]; yet, no confirmation followed [238]. Hyperbaric oxygen was abandoned because of severe side-effects that occured in some clinical trials (e.g. [239]) and it was timeconsuming, and also because apparently more appropriate hypoxic cell sensitizers were being introduced.

A more recently tested approach combines the breathing of a mixture of oxygen and carbon dioxide (classical carbogen $\left.=95 \% \mathrm{O}_{2}+5 \% \mathrm{CO}_{2}\right)$ in combination with the administration of nicotinamide [240]. Its introduction along with radiotherapy was specifically based on the hypothesis that carbogen and nicotinamide would target the chronic and the acute hypoxia respectively to increase tumour cell radiosensitivity (e.g. [241, 242]). The use of these agents simultaneously has subsequently been shown to increase the radiation damaging effect in a variety of rodent tumour models $[154,243-246]$. 
Based on that demonstrated pre-clinical therapeutic advantage, the concept was thereafter introduced in the clinic (e.g. [247-250]). An increased oxygenation of tumours from the use of carbogen breathing with nicotinamide has been demonstrated in patients. The strategy of this "Accelerated Radiotherapy with CarbOgen breathing and Nicotinamide" (ARCON) is logical and thoroughly described [154]: briefly, introducing a shorter overall radiation treatment time counteracts the rapid proliferation of the tumour cells, whilst the carbogen-nicotinamide application sensitises the hypoxic tumour cells. Very promising results have been obtained in several, however, non-randomized clinical studies using this combination in conjunction with accelerated irradiation: treatment of stage $T_{3}-T_{4}$ squamous cell carcinoma (SCC) tumours of the larynx $[248,251]$, and patients presenting with large bulky tumours of the hypopharynx and oropharynx [251] as well as bladder carcinoma [250]. These positive findings however were not confirmed by a phase I/II study of the EORTC that involved head and neck SCC tumours of various localizations and late stages [252]. Neither did the EORTC study involving non small cell lung cancer [253], nor the EORTC trial with glioblastoma multiforme patients [254], indicate a benefit from the use of ARCON. The selection of tumour type, but certainly also the localization, has to be rigid to allow further clinical improvements (cfr. supra; and [251]). Pre-treatment measurements of the tumour oxygenation status and response to modulators, specifically in a non-invasive manner, may further help to sort the 'ideal' patients for ARCON-based treatment (cfr. supra: part 1.1.3.d.2.) as well as for other hypoxia-related combination therapies.

\section{I.1.4. Background-based conclusion}

The studies reviewed in the present introductory notes do provide important information about the intra-tumoural angiogenesis, established tumour vascularity, and related treatment options (anti-angiogenesis and vascular targeting). They invite us to broaden research and application in pre-clinical laboratory models to further advance novel anti-cancer strategies.

Hypoxia-selective cancer therapy has been, based on molecular knowledge and tools, broadened from the use of specific cytotoxins to the application of gene 
therapy and related methods. The best ways to continue the search for improvement appear to include agents that increase hypoxia or combinations with irradiation and anti-angiogenesis.

Generalizations about intra-tumoural oxygenation based on tumour size, tumour stage, or any other stratification, are not possible. Therefore the need to encompass the whole tumour volume when investigating the hypoxic status of an individual tumour, rather than a few biopsies or a single slice, is a stringent necessity. Nevertheless, complementary evaluations of hypoxia remain a priority as well in laboratory animal as clinical cancer research to define the most optimal therapy for eliminating tumours. 


\section{I.1.5. References}

1. Graeber TG, Osmanian C. Jacks T, Housman DE, Koch CJ, Lowe SW, and Giaceia AJ (1996) Hypoxia-mediated selection of cells with diminished apoptotic potential in solid tumours. 379, 88-91

2. Royds JA, Dower SK. Qwarnstrom EE, and Lewis CE (1998) Response of tumour cells to hypoxia: role of p53 and NFkB. Mol Pathol 51, 55-61

3. Strasser A, Harris AW, Huang DC, Krammer PH, and Cory S (1995) Bcl-2 and Fas/APO-1 regulate distinct pathways to lymphocyte apoptosis. EMBO J 14, 6136 6147

4. Chinnaiyan AM, ORourke K. Tewari M, and Dixit VM (1995) FADD, a novel death domain-containing protein, interacts with the death domain of Fas and initiates apoptosis. 81, 505-512

5. Pathak S (1990) Cytogenetic abnormalities in cancer: with special emphasis on tumor heterogeneity. Cancer Metastasis Rev 8, 299-318

6. Rew DA (1998) The importance of heterogeneity in tumor pathology. Adv Anat Pathol 5, 156-163

7. Goldman E (1907) The growth of malignant disease in man and the lower animals with special reference to the vascular system. 2, 1236-1240

8. Folkman J (1992) The role of angiogenesis in tumor growth. Semin Cancer Biol 3. $65-71$

9. Hanahan D and Folkman J (1996) Patterns and emerging mechanisms of the angiogenic switch during tumorigenesis. 86, 353-364

10. Malkusch W, Konerding MA, Klapthor B, and Bruch J (1995) A simple and accurate method for 3-D measurements in microcorrosion casts illustrated with tumour vascularization. Anal Cell Pathol 9, 69-81

11. Konerding MA, Miodonski AJ, and Lametschwandtner A (1995) Microvascular corrosion casting in the study of tumor vascularity: a review. Scanning Microsc 9. 1233-1243

12. Shah-Yukich AA and Nelson AC (1988) Characterization of solid tumor microvasculature: a three-dimensional analysis using the polymer casting technique. Lab Invest 58, 236-244

13. Gottesman MM and Pastan 1 (1993) Biochemistry of multidrug resistance mediated by the multidrug transporter. Annu Rev Biochem 62, 385-427

14. Croce CM (2001) How can we prevent cancer? Proc Natl Acad Sci U S A 98, 1098610988

15. van Oosterom AT, Judson I, Verweij J, Stroobants S, Donato dP. Dimitrijevic S, Martens M, Webb A, Sciot R, Van Glabbeke M, Silberman S, and Nielsen OS (2001) Safety and efficacy of imatinib (STI571) in metastatic gastrointestinal stromal tumours: a phase I study. 358, 1421-1423

16. Hobson B and Denekamp J (1984) Endothelial proliferation in tumours and normal tissues: continuous labelling studies. Br J Cancer 49, 405-413

17. Bicknell R and Harris AL (1991) Novel growth regulatory factors and tumour angiogenesis. Eur J Cancer 27, 781-785

18. Liekens S, De Clercq E, and Neyts J (2001) Angiogenesis: regulators and clinical applications. Biochem Pharmacol 61, 253-270

19. Auerbach R, Auerbach W, and Polakowski I (1991) Assays for angiogenesis: a review. Pharmacol Ther 51, 1-11

20. Iyer NV, Kotch LE, Agani F, Leung SW, Laughner E, Wenger RH, Gassmann M, Gearhart JD, Lawler AM, Yu AY, and Semenza GL (1998) Cellular and 
developmental control of $\mathrm{O} 2$ homeostasis by hypoxia- inducible factor 1 alpha. Genes Dev 12, 149-162

21. Klagsbrun M, Knighton D, and Folkman J (1976) Tumor angiogenesis activity in cells grown in tissue culture. Cancer Res 36, 110-114

22. Polverini PJ (1995) The pathophysiology of angiogenesis. Crit Rev Oral Biol Med 6, 230-247

23. Miller JW, Adamis AP, Shima DT, D'Amore PA, Moulton RS, OReilly MS, Folkman J, Dvorak HF, Brown LF, Berse B, Yeo TK, and Yeo KT (1994) Vascular endothelial growth factor/vascular permeability factor is temporally and spatially correlated with ocular angiogenesis in a primate model. Am J Pathol 145, 574-584

24. Darland DC and D'Amore PA (1999) Blood vessel maturation: vascular development comes of age. J Clin Invest 103, 157-158

25. Bischoff J (1997) Cell adhesion and angiogenesis. J Clin Invest 100, S37-S39

26. Eliceiri BP and Cheresh DA (1999) The role of alphav integrins during angiogenesis: insights into potential mechanisms of action and clinical development. J Clin Invest $103,1227-1230$

27. Dejana E (1996) Endothelial adherens junctions: implications in the control of vascular permeability and angiogenesis. J Clin Invest 98, 1949-1953

28. Folkman J (1995) Angiogenesis in cancer, vascular, theumatoid and other disease. Nat Med 1, 27-31

29. Folkman J and Cotran R (1976) Relation of vascular proliferation to tumor growth. Int Rev Exp Pathol 16, 207-248

30. Sillman F, Boyce J, and Fruchter R (1981) The significance of atypical vessels and neovascularization in cervical neoplasia. Am J Obstet Gynecol 139, 154-159

31. Folkman J (1987) What is the role of angiogenesis in metastasis from cutaneous melanoma? Eur J Cancer Clin Oncol 23, 361-363

32. Denekamp J and Hill S (1991) Angiogenic attack as a therapeutic strategy for cancer. Radiother Oncol 20 Suppl 1, 103-112

33. Nagy JA, Brown LF, Senger DR, Lanir N, Van de WL, Dvorak AM, and Dvorak HF (1989) Pathogenesis of tumor stroma generation: a critical role for leaky blood vessels and fibrin deposition. Biochim Biophys Acta 948, 305-326

34. Dvorak HF, Nagy JA, Dvorak JT, and Dvorak AM (1988) Identification and characterization of the blood vessels of solid tumors that are leaky to circulating macromolecules. Am J Pathol 133, 95-109

35. Denekamp J and Hobson B (1982) Endothelial-cell proliferation in experimental tumours. Br J Cancer 46, 711-720

36. Tannock IF and Hayashi S (1972) The proliferation of capillary endothelial cells. Cancer Res 32, 77-82

37. Denekamp J (1984) Vascular endothelium as the vulnerable element in tumours. Acta Radiol Oncol 23, 217-225

38. Hanahan D (1998) A flanking attack on cancer. Nat Med 4, 13-14

39. Fox SB, Gasparini G, and Harris AL (2001) Angiogenesis: pathological, prognostic, and growth-factor pathways and their link to trial design and anticancer drugs. Lancet Oncol 2, 278-289

40. OReilly MS (1997) The preclinical evaluation of angiogenesis inhibitors. Invest New Drugs 15, 5-13

41. Streit M, Velasco P. Brown LF, Skobe M, Richard L, Riccardi L, Lawler J, and Detmar M (1999) Overexpression of thrombospondin-1 decreases angiogenesis and inhibits the growth of human cutaneous squamous cell carcinomas. Am J Pathol 155. $441-452$

42. Wu Z, OReilly MS, Folkman J, and Shing Y (1997) Suppression of tumor growth with recombinant murine angiostatin. Biochem Biophys Res Commun 236, 651-654

43. OReilly MS, Holmgren L, Chen C. and Folkman J (1996) Angiostatin induces and sustains dormancy of human primary tumors in mice. Nat Med 2, 689-692 
44. OReilly MS (1997) Angiostatin: an endogenous inhibitor of angiogenesis and of tumor growth. 79, 273-294

45. Haspel HC, Scicli GM, McMahon G, and Scicli AG (2002) Inhibition of Vascular Endothelial Growth Factor-Associated Tyrosine Kinase Activity with SU5416 Blocks Sprouting in the Microvascular Endothelial Cell Spheroid Model of Angiogenesis. Microvasc Res 63, 304-315

46. Fong TA, Shawver L.K. Sun L, Tang C, App H, Powell TJ, Kim YH, Schreck R, Wang X, Risau W, Ullich A. Hirth KP, and McMahon G (1999) SU5416 is a potent and selective inhibitor of the vascular endothelial growth factor receptor (Flk-1/KDR) that inhibits tyrosine kinase catalysis, tumor vascularization, and growth of multiple tumor types. Cancer Res 59, 99-106

47. Dinney CP, Bielenberg DR, Perrotte P. Reich R. Eve BY, Bucana CD, and Fidler IJ (1998) Inhibition of basic fibroblast growth factor expression, angiogenesis, and growth of human bladder carcinoma in mice by systemic interferon-alpha administration. Cancer Res 58, 808-814

48. Prewetl M, Huber J, Li Y, Santiago A, OConnor W, King K, Overholser J. Hooper A. Pytowski B, Witte L. Bohlen P, and Hicklin DJ (1999) Antivascular endothelial growth factor receptor (fetal liver kinase 1) monoclonal antibody inhibits tumor angiogenesis and growth of several mouse and human tumors. Cancer Res 59, 5209. 5218

49. Gutheil JC, Campbell TN, Pierce PR, Watkins JD. Huse WD, Bodkin DJ, and Cheresh DA (2000) Targeted antiangiogenic therapy for cancer using Vitaxin: a humanized monoclonal antibody to the integrin alphavbeta3. Clin Cancer Res 6 , 3056-3061

50. Griffioen AW, van der Schaft DW, Barendsz-Janson AF, Cox A, Struijker Boudier $\mathrm{HA}$, Hillen HF, and Mayo KH (2001) Anginex, a designed peptide that inhibits angiogenesis. Biochem J 354, 233-242

51. van der Schaft DW, Toebes EA. Haseman JR, Mayo KH, and Griffioen AW (2000) Bactericidal/permeability-increasing protein (BPI) inhibits angiogenesis via induction of apoptosis in vascular endothelial cells. $96,176-181$

52. Ingber D, Fujita T, Kishimoto S, Sudo K, Kanamaru T, Brem H, and Folkman J (1990) Synthetic analogues of fumagillin that inhibit angiogenesis and suppress tumour growth. 348, 555-557

53. Griffith EC, Su Z, Turk BE, Chen S, Chang YH, Wu Z, Biemann K, and Liu JO (1997) Methionine aminopeptidase (type 2) is the common target for angiogenesis inhibitors AGM-1470 and ovalicin. Chem Biol 4, 461-471

54. Abe J, Zhou W, Takuwa N, Taguchi J, Kurokawa K, Kumada M, and Takuwa Y (1994) A fumagillin derivative angiogenesis inhibitor, AGM-1470, inhibits activation of cyclin-dependent kinases and phosphorylation of retinoblastoma gene product but not protein tyrosyl phosphorylation or protooncogene expression in vascular endothelial cells. Cancer Res 54, 3407-3412

55. Kusaka M, Sudo K. Matsutani E, Kozai Y, Marui S, Fujita T, Ingber D, and Folkman $\mathrm{J}$ (1994) Cytostatic inhibition of endothelial cell growth by the angiogenesis inhibitor TNP-470 (AGM-1470). Br J Cancer 69, 212-216

56. Zhang Y. Griffith EC, Sage J, Jacks T, and Liu JO (2000) Cell cycle inhibition by the anti-angiogenic agent TNP-470 is mediated by p53 and p21WAF1/CIP1. Proc Natl Acad Sci U S A 97, 6427-6432

57. Yanase T, Tamura M, Fujita K, Kodama S, and Tanaka K (1993) Inhibitory effect of angiogenesis inhibitor TNP-470 on tumor growth and metastasis of human cell lines in vitro and in vivo. Cancer Res 53, 2566-2570

58. Farinelle S, Malonne H. Chaboteaux C, Decaestecker C. Dedecker R, Gras T, Darro F. Fontaine J, Atassi G, and Kiss R (2000) Characterization of TNP-470-induced modifications to cell functions in HUVEC and cancer cells. J Pharmacol Toxicol Methods $43,15-24$ 
59. Antoine N, Greimers R, De Roanne C, Kusaka M, Heinen E, Simar L, and Castronovo V (1994) AGM-1470, a potent angiogenesis inhibitor, prevents the entry of normal but not transformed endothelial cells into the GI phase of the cell cycle. Cancer Res 54, 2073-2076

60. Liekens S, Verbeken E, Vandeputte M, De Clercq E, and Neyts J (1999) A novel animal model for hemangiomas: inhibition of hemangioma development by the angiogenesis inhibitor TNP-470. Cancer Res 59, 2376-2383

61. Bernsen HJ, Rijken PF, Peters H, Bakker H, and van der Kogel AJ (1998) The effect of the anti-angiogenic agent TNP-470 on tumor growth and vascularity in low passaged xenografts of human gliomas in nude mice. J Neurooncol 38, 51-57

62. Sasaki A, Alcalde RE, Nishiyama A, Lim DD, Mese H, Akedo H, and Matsumura T (1998) Angiogenesis inhibitor TNP-470 inhibits human breast cancer osteolytic bone metastasis in nude mice through the reduction of bone resorption. Cancer Res 58 . $462-467$

63. Boehm T, Folkman J, Browder T, and OReilly MS (1997) Antiangiogenic therapy of experimental cancer does not induce acquired drug resistance. 390, 404-407

64. Holmgren L, OReilly MS, and Folkman J (1995) Dormancy of micrometastases: balanced proliferation and apoptosis in the presence of angiogenesis suppression. Nat Med 1, 149-153

65. Voest EE, Kenyon BM, OReilly MS, Truitt G, D'Amato RJ, and Folkman J (1995) Inhibition of angiogenesis in vivo by interleukin 12. J Natl Cancer Inst 87, 581-586

66. Murray JC, Randhawa V, and Denekamp J (1987) The effects of melphalan and misonidazole on the vasculature of a murine sarcoma. Br J Cancer 55, 233-238

67. Browder T, Butterfield CE, Kraling BM, Shi B, Marshall B, OReilly MS, and Folkman J (2000) Antiangiogenic scheduling of chemotherapy improves efficacy against experimental drug-resistant cancer. Cancer Res 60, 1878-1886

68. Klement G, Baruchel S, Rak J, Man S, Clark K, Hicklin DJ, Bohlen P, and Kerbel RS (2000) Continuous low-dose therapy with vinblastine and VEGF receptor-2 antibody induces sustained tumor regression without overt toxicity. J Clin Invest 105, R15-R24

69. Cristofanilli M. Charnsangavej C, and Hortobagyi GN (2002) Angiogenesis modulation in cancer research: novel clinical approaches. 1, 415-426

70. Eberhard A, Kahlert S, Goede V, Hemmerlein B, Plate KH, and Augustin HG (2000) Heterogeneity of angiogenesis and blood vessel maturation in human tumors: implications for antiangiogenic tumor therapies. Cancer Res 60, 1388-1393

71. Reinhold HS, Zurcher C, and van den Berg-Blok AE (1990) Differential heat sensitivity of tumour microvasculature. Eur J Cancer 26, 541-543

72. Fingar VH (1996) Vascular effects of photodynamic therapy. J Clin Laser Med Surg 14, 323-328

73. Moore JV, West CM, and Whitehurst C (1997) The biology of photodynamic therapy. Phys Med Biol 42, 913-935

74. Oleinick NL and Evans HH (1998) The photobiology of photodynamic therapy: cellular targets and mechanisms. Radiat Res 150, S146-S156

75. Dougherty TJ, Gomer CJ. Henderson BW, Jori G, Kessel D, Korbelik M, Moan J. and Peng Q (1998) Photodynamic therapy. J Natl Cancer Inst 90, 889-905

76. Dolmans DE, Kadambi A, Hill JS, Waters CA, Robinson BC, Walker JP, Fukumura D, and Jain RK (2002) Vascular accumulation of a novel photosensitizer, MV6401, causes selective thrombosis in tumor vessels after photodynamic therapy. Cancer Res $62,2151-2156$

77. Kamuhabwa AA, Cosserat-Gerardin I. Didelon J, Notter D, Guillemin F, Roskams T, DHallewin MA, Baert L, and De Witte PA (2002) Biodistribution of hypericin in orthotopic transitional cell carcinoma bladder tumors: implication for whole bladder wall photodynamic therapy. Int J Cancer 97, 253-260

78. Baguley BC, Holdaway KM, Thomsen LL, Zhuang L, and Zwi LJ (1991) Inhibition of growth of colon 38 adenocarcinoma by vinblastine and colchicine: evidence for a vascular mechanism. Eur J Cancer 27, 482-487 
79. Bibby MC, Double JA, Loadman PM, and Duke CV (1989) Reduction of tumor blood flow by flavone acetic acid: a possible component of therapy. I Natl Cancer Inst $81,216-220$

80. Hill SA, Lonergan SJ, Denekamp J, and Chaplin DJ (1993) Vinca alkaloids: antivascular effects in a murine tumour. Eur J Cancer 29A, 1320-1324

81. Ludford RJ (1945) Colchine in the experimental chemotherapy of cancer. J Natl Cancer Inst 6, 89-101

82. Baguley BC, Calveley SB, Crowe KK, Fray LM, ORourke SA, and Smith GP (1989) Comparison of the effects of flavone acetic acid, fostriecin. homoharringtonine and tumour necrosis factor alpha on colon 38 tumours in mice. Eur J Cancer Clin Oncol 25, 263-269

83. Zwi LJ, Baguley BC, Gavin JB, and Wilson WR (1989) Blood flow failure as a major determinant in the antitumor action of flavone acetic acid. J Natl Cancer Inst 81 . 1005-1013

84. Kaye SB, Clavel M, Dodion P, Monfardini S, ten Bokkel-Huinink W, Wagener DT, Gundersen S. Stoter G. Smith J. Renard J. Van Glabbeke M, and Cavalli F (1990) Phase II trials with flavone acetic acid (NCS. 347512, LM975) in patients with advanced carcinoma of the breast, colon, head and neck and melanoma. Invest New Drugs 8 Suppl 1, S95-S99

85. Kerr DJ and Kaye SB (1989) Flavone acetic acid--preclinical and clinical activity. Eur J Cancer Clin Oncol 25, 1271-1272

86. Rewcastle GW, Atwell GJ, Baguley BC, Calveley SB, and Denny WA (1989) Potential antitumor agents. 58. Synthesis and structure-activity relationships of substituted xanthenone-4-acetic acids active against the colon 38 tumor in vivo. J Med Chem 32, 793-799

87. Ching LM, Joseph WR, and Baguley BC (1992) Antitumour responses to flavone-8acetic acid and 5,6- dimethylxanthenone-4-acetic acid in immune deficient mice. $\mathrm{Br}$ J Cancer 66, 128-130

88. Joseph WR, Cao Z, Mountjoy KG, Marshall ES, Baguley BC, and Ching LM (1999) Stimulation of tumors to synthesize tumor necrosis factor-alpha in situ using 5,6dimethylxanthenone-4-acetic acid: a novel approach to cancer therapy. Cancer Res 59, 633-638

89. Ching LM, Joseph WR, Crosier KE, and Baguley BC (1994) Induction of tumor necrosis factor-alpha messenger RNA in human and murine cells by the flavone acetic acid analogue 5,6-dimethylxanthenone- 4-acetic acid (NSC 640488). Cancer Res 54, 870-872

90. Belotti D. Vergani V. Drudis T, Borsotti P, Pitelli MR, Viale G. Giavazzi R, and Taraboletti G (1996) The microtubule-affecting drug paclitaxel has antiangiogenic activity. Clin Cancer Res 2, 1843-1849

91. Miller ML and Ojima 1 (2001) Chemistry and chemical biology of taxane anticancer agents. Chem Rec 1, 195-211

92. Pettit GR, Singh SB, Hamel E, Lin CM. Alberts DS, and Garcia-Kendall D (1989) Isolation and structure of the strong cell growth and tubulin inhibitor combretastatin A-4, 45, 209-211

93. Hamel $\mathrm{E}$ and Lin CM (1983) Interactions of combretastatin, a new plant-derived antimitotic agent, with tubulin. Biochem Pharmacol 32, 3864-3867

94. McGown AT and Fox BW (1989) Structural and biochemical comparison of the antimitotic agents colchicine, combretastatin A4 and amphethinile. Anticancer Drug Des 3. 249-254

95. el Zayat AA, Degen D. Drabek S, Clark GM , Pettit GR, and Von Hoff DD (1993) In vitro evaluation of the antineoplastic activity of combretastatin A- 4, a natural product from Combretum caffrum (arid shrub). Anticancer Drugs 4, 19-25

96. Lin CM. Ho HH, Pettit GR, and Hamel E (1989) Antimitotic natural products combretastatin A-4 and combretastatin A-2: studies on the mechanism of their inhibition of the binding of colchicine to tubulin. Biochemistry (Mosc) 28, 6984-6991 
97. Dark GG, Hill SA, Prise VE, Tozer GM, Pettit GR, and Chaplin DJ (1997) Combretastatin $\mathrm{A}-4$, an agent that displays potent and selective toxicity toward tumor vasculature. Cancer Res 57, 1829-1834

98. Galbraith SM, Chaplin DJ, Lee F, Stratford MR, Locke RJ, Vojnovic B, and Tozer GM (2001) Effects of combretastatin A4 phosphate on endothelial cell morphology in vitro and relationship to tumour vascular targeting activity in vivo. Anticancer Res $21,93-102$

99. Kanthou $\mathrm{C}$ and Tozer GM (2002) The tumor vascular targeting agent combretastatin A-4-phosphate induces reorganization of the actin cytoskeleton and early membrane blebbing in human endothelial cells. 99, 2060-2069

100. Dowlati A, Robertson K, Cooney M, Petros WP, Stratford M, Jesberger J, Rafie N, Overmoyer B, Makkar V, Stambler B, Taylor A, Waas J, Lewin JS, McCrae KR, and Remick SC (2002) A phase I pharmacokinetic and translational study of the novel vascular targeting agent combretastatin a -4 phosphate on a single-dose intravenous schedule in patients with advanced cancer. Cancer Res 62, 3408-3416

101. Horsman MR, Ehrnrooth E, Ladekarl M, and Overgaard J (1998) The effect of combretastatin A-4 disodium phosphate in a $\mathrm{C} 3 \mathrm{H}$ mouse mammary carcinoma and a variety of murine spontaneous tumors. Int J Radiat Oncol Biol Phys 42, 895-898

102. Chaplin DJ. Pettit GR. Parkins CS, and Hill SA (1996) Antivascular approaches to solid tumour therapy: evaluation of tubulin binding agents. Br J Cancer Suppl 27. S86-S88

103. Tozer GM, Prise VE, Wilson J, Locke RJ, Vojnovic B, Stratford MR. Dennis MF. and Chaplin DJ (1999) Combretastatin A-4 phosphate as a tumor vascular-targeting agent: early effects in tumors and normal tissues. Cancer Res 59, 1626-1634

104. Parkins CS, Holder AL, Hill SA, Chaplin DJ, and Tozer GM (2000) Determinants of anti-vascular action by combretastatin A-4 phosphate: role of nitric oxide. $\mathrm{Br} \mathrm{J}$ Cancer 83, $811-816$

105. Tozer GM, Prise VE, Wilson J, Cemazar M, Shan S, Dewhirst MW, Barber PR, Vojnovic B, and Chaplin DJ (2001) Mechanisms associated with tumor vascular shut-down induced by combretastatin A-4 phosphate: intravital microscopy and measurement of vascular permeability. Cancer Res 61, 6413-6422

106. Korbelik M. Parkins CS, Shibuya H. Cecic I, Stratford MR, and Chaplin DJ (2000) Nitric oxide production by tumour tissue: impact on the response to photodynamic therapy. Br J Cancer 82, 1835-1843

107. Griggs J, Brindle KM, Metcalfe JC, Hill SA, Smith GA, Beauregard DA, and Hesketh R (2001) Potent anti-metastatic activity of combretastatin-A4. Int J Oncol 19. $821-825$

108. Grosios K. Holwell SE, McGown AT, Pettit GR, and Bibby MC (1999) In vivo and in vitro evaluation of combretastatin $\mathrm{A}-4$ and its sodium phosphate prodrug. $\mathrm{Br} \mathrm{J}$ Cancer 81, 1318-1327

109. Nabha SM, Mohammad RM, Wall NR. Dutcher JA, Salkini BM, Pettit GR, and Al Katib AM (2001) Evaluation of combretastatin A-4 prodrug in a non-Hodgkin's lymphoma xenograft model: preclinical efficacy. Anticancer Drugs 12, 57-63

110. Hori K. Saito S, Nihei Y, Suzuki M, and Sato Y (1999) Antitumor effects due to irreversible stoppage of tumor tissue blood flow: evaluation of a novel combretastatin A-4 derivative. AC7700. Jpn J Cancer Res 90, 1026-1038

111. Nihei Y, Suga Y, Morinaga Y, Ohishi K, Okano A, Ohsumi K, Hatanaka T, Nakagawa R. Tsuji T, Akiyama Y, Saito S, Hori K. Sato Y, and Tsuruo T (1999) A novel combretastatin A-4 derivative, AC-7700, shows marked antitumor activity against advanced solid tumors and orthotopically transplanted tumors. Jpn J Cancer Res $90,1016-1025$

112. Shan S, Lockhart AC, Saito WY, Knapp AM, Laderoute KR. and Dewhirst MW (2001) The novel tubulin-binding drug BTO-956 inhibits R3230AC mammary carcinoma growth and angiogenesis in Fischer 344 rats. Clin Cancer Res 7, 25902596 
113. Li L. Rojiani A, and Siemann DW (1998) Targeting the tumor vasculature with combretastatin A-4 disodium phosphate: effects on radiation therapy. Int J Radiat Oncol Biol Phys 42, 899-903

114. Horsman MR, Murata R, and Overgaard J (2001) Improving local tumor control by combining vascular targeting drugs, mild hyperthermia and radiation. Acta Oncol 40. 497-503

115. Murata R, Siemann DW. Overgaard J, and Horsman MR (2001) Interaction between combretastatin $\mathrm{A}-4$ disodium phosphate and radiation in murine tumors. Radiother Oncol 60, 155-161

116. Wilson WR, Li AE, Cowan DS, and Siim BG (1998) Enhancement of tumor radiation response by the antivascular agent 5,6-dimethylxanthenone-4-acetic acid. Int J Radiat Oncol Biol Phys 42, 905-908

117. Eikesdal HP, Schem BC, Mella O, and Dahl O (2000) The new tubulin-inhibitor combretastatin A-4 enhances thermal damage in the BT4An rat glioma. Int J Radiat Oncol Biol Phys 46, 645-652

118. Murata R, Overgaard J, and Horsman MR (2001) Combretastatin A-4 disodium phosphate: a vascular targeting agent that improves that improves the anti-tumor effects of hyperthermia, radiation, and mild thermoradiotherapy. Int J Radiat Oncol Biol Phys 51, 1018-1024

119. Grosios K. Loadman PM, Swaine DJ, Pettit GR, and Bibby MC (2000) Combination chemotherapy with combretastatin A-4 phosphate and 5. fluorouracil in an experimental murine colon adenocarcinoma. Anticancer Res 20, 229-233

120. Chaplin DJ. Pettit GR, and Hill SA (1999) Anti-vascular approaches to solid tumour therapy: evaluation of combretastatin A4 phosphate. Anticancer Res 19, 189-195

121. Vaupel P. Thews O, Kelleher DK, and Hoeckel M (1998) Current status of knowledge and critical issues in tumor oxygenation. Results from 25 years research in tumor pathophysiology. Adv Exp Med Biol 454, 591-602

122. Fertil B and Malaise EP (1985) Intrinsic radiosensitivity of human cell lines is correlated with radioresponsiveness of human tumors: analysis of 101 published survival curves. Int J Radiat Oncol Biol Phys 11, 1699-1707

123. Weichselbaum RR, Dahlberg W, and Little JB (1985) Inherently radioresistant cells exist in some human tumors. Proc Natl Acad Sci U S A 82, 4732-4735

124. Pastan I and Gottesman M (1987) Multiple-drug resistance in human cancer. N Engl J Med 316, 1388-1393

125. Schimke RT (1984) Gene amplification, drug resistance, and cancer. Cancer Res 44 , 1735-1742

126. Gray LH. Conger AD, Ebert M. Hornsey S, and Scott OCA (1953) The concentration of oxygen dissolved in tissues at the time of irradiation as a factor in radiotherapy. $\mathrm{Br}$ J Radiol 26, 638-648

127. Wright EA and Howard-Flanders P (1957) The influence of oxygen on the radiosensitivity of mammalian tissues. Acta Radiol 48, 26-32

128. Hockel M, Knoop C, Schlenger K, Vorndran B, Baussmann E, Mitze M, Knapstein PG, and Vaupel P (1993) Intratumoral pO2 predicts survival in advanced cancer of the uterine cervix. Radiother Oncol 26, 45-50

129. Okunieff P, de Bie J. Dunphy EP, Terris DJ, and Hockel M (1996) Oxygen distributions partly explain the radiation response of human squamous cell carcinomas. Br J Cancer Suppl 27, S185-S190

130. Fyles AW, Milosevic M. Wong R, Kavanagh MC, Pintilie M, Sun A. Chapman W, Levin W, Manchul L. Keane TJ, and Hill RP (1998) Oxygenation predicts radiation response and survival in patients with cervix cancer. Radiother Oncol 48. 149-156

131. Brizel DM, Sibley GS, Prosnitz LR, Scher RL, and Dewhirst MW (1997) Tumor hypoxia adversely affects the prognosis of carcinoma of the head and neck. Int J Radiat Oncol Biol Phys 38. 285-289 
132. Stadler P, Becker A, Feldmann HJ, Hansgen G, Dunst J, Wurschmidt F, and Molls M (1999) Influence of the hypoxic subvolume on the survival of patients with head and neck cancer. Int J Radiat Oncol Biol Phys 44, 749-754

133. Knocke TH, Weitmann HD, Feldmann HJ, Selzer E, and Potter R (1999) Intratumoral pO2-measurements as predictive assay in the treatment of carcinoma of the uterine cervix. Radiother Oncol 53, 99-104

134. Tannock IF and Kopelyan I (1986) Influence of glucose concentration on growth and formation of necrosis in spheroids derived from a human bladder cancer cell line. Cancer Res 46, 3105-3110

135. Hockel M, Schlenger K, Aral B, Mitze M, Schaffer U, and Vaupel P (1996) Association between tumor hypoxia and malignant progression in advanced cancer of the uterine cervix. Cancer Res 56, 4509-4515

136. Wouters BG. Weppler SA, Koritzinsky M, Landuyt W, Nuyts S. Theys J, Chiu RK. and Lambin P (2002) Hypoxia as a target for combined modality treatments. Eur J Cancer 38, 240-257

137. Graeber TG, Peterson JF, Tsai M. Monica K, Fornace AJ, Jr., and Giaccia AJ (1994) Hypoxia induces accumulation of $\mathrm{p} 53$ protein, but activation of a G1- phase checkpoint by low-oxygen conditions is independent of p53 status. Mol Cell Biol 14, 6264-6277

138. Ausserer WA, Bourrat-Floeck B, Green CJ, Laderoute KR, and Sutherland RM (1994) Regulation of c-jun expression during hypoxic and low-glucose stress. Mol Cell Biol 14, 5032-5042

139. Young SD, Marshall RS, and Hill RP (1988) Hypoxia induces DNA overreplication and enhances metastatic potential of murine tumor cells. Proc Natl Acad Sci U S A 85, 9533-9537

140. Mazure NM, Chen EY, Yeh P. Laderoute KR , and Giaccia AJ (1996) Oncogenic transformation and hypoxia synergistically act to modulate vascular endothelial growth factor expression. Cancer Res 56, 3436-3440

141. Hockel M, Schlenger K, Mitze M, Schaffer U, and Vaupel P (1996) Hypoxia and Radiation Response in Human Tumors. Semin Radiat Oncol 6, 3-9

142. Giaccia AJ (1996) Hypoxic Stress Proteins: Survival of the Fittest. Semin Radiat Oncol 6, 46-58

143. Vaupel P. Schlenger K, Knoop C, and Hockel M (1991) Oxygenation of human tumors: evaluation of tissue oxygen distribution in breast cancers by computerized $\mathrm{O} 2$ tension measurements. Cancer Res 51, 3316-3322

144. Moulder JE and Rockwell S (1984) Hypoxic fractions of solid tumors: experimental techniques, methods of analysis, and a survey of existing data . Int J Radiat Oncol Biol Phys 10, 695-712

145. Chapman JD (1984) The detection and measurement of hypoxic cells in solid tumors. $54,2441-2449$

146. Vaupel P. Thews O. Kelleher DK, and Hoeckel M (1998) Oxygenation of human tumors: the Mainz experience, Strahlenther Onkol 174 Suppl 4, 6-12

147. Nordsmark M and Overgaard J (2000) A confirmatory prognostic study on oxygenation status and loco-regional control in advanced head and neck squamous cell carcinoma treated by radiation therapy. Radiother Oncol 57, 39-43

148. Runkel S, Wischnik A, Teubner J, Kaven E, Gaa J, and Melchert F (1994) Oxygenation of mammary tumors as evaluated by ultrasound-guided computerizedpO2-histography. Adv Exp Med Biol 345, 451-458

149. Zhao D, Constantinescu A, Hahn EW, and Mason RP (2001) Tumor oxygen dynamics with respect to growth and respiratory challenge: investigation of the Dunning prostate R3327-HI tumor. Radiat Res 156, 510-520

150. Lambin P. Kramar A, Haie-Meder C. Castaigne D, Scalliet P. Bouzy J. Malaise EP. and Gerbaulet A (1998) Tumour size in cancer of the cervix. Acta Oncol 37. 729-734

151. Dubben HH. Thames HD, and Beck-Bornholdt HP (1998) Tumor volume: a basic and specific response predictor in radiotherapy. Radiother Oncol 47, 167-174 
152. Rudat V, Dietz A, Schramm O, Conradt C, Maier H, Fentje M, and Wannenmacher M (1999) Prognostic impact of total tumor volume and hemoglobin concentration on the outcome of patients with advanced head and neck cancer after concomitant boost radiochemotherapy. Radiother Oncol 53, 119-125

153. Stone HB, Brown JM, Phillips TL, and Sutherland RM (1993) Oxygen in human tumors: correlations between methods of measurement and response to therapy.

Summary of a workshop held November 19-20, 1992, at the National Cancer Institute, Bethesda, Maryland. Radiat Res 136, 422-434

154. Denekamp J and Fowler JF (1997) ARCON--current status: summary of a workshop on preclinical and clinical studies. Acta Oncol 36, 517-525

155. Whalen WJ, Riley J, and Nair P (1967) A microelectrode for measuring intracellular PO2. J Appl Physiol 23, 798-801

156. Kallinowski F, Zander R, Hoeckel M. and Vaupel P (1990) Tumor tissuc oxygenation as evaluated by computerized-pO2-histography. Int J Radiat Oncol Biol Phys 19. 953-961

157. Collingridge DR, Young WK, Vojnovic B, Wardman P, Lynch EM, Hill SA, and Chaplin DJ (1997) Measurement of tumor oxygenation: a comparison between polarographic needle electrodes and a time-resolved luminescence-based optical sensor. Radiat Res 147. 329-334

158. Braun RD, Lanzen JL, Snyder SA, and Dewhirst MW (2001) Comparison of tumor and normal tissue oxygen tension measurements using OxyLite or microelectrodes in rodents. Am J Physiol Heart Cire Physiol 280, H2533-H2544

159. Raleigh JA, Chou SC. Arteel GE, and Horsman MR (1999) Comparisons among pimonidazole binding, oxygen electrode measurements, and radiation response in C3H mouse tumors, Radiat Res 151, 580-589

160. Hodgkiss RJ (1998) Use of 2-nitroimidazoles as bioreductive markers for tumour hypoxia. Anticancer Drug Des 13, 687-702

161. Koch CJ, Evans SM, and Lord EM (1995) Oxygen dependence of cellular uptake of EF5 [2-(2-nitro-1H-imidazol-1- yl)-N-(2,2,3,3,3-pentafluoropropyl)a cet amide] : analysis of drug adducts by fluorescent antibodies vs bound radioactivity. $\mathrm{Br} \mathrm{J}$ Cancer 72, 869-874

162. Haustermans K, Hofland I, Van de PL, Geboes K, Varia M, Raleigh J, and Begg AC (2000) Diffusion limited hypoxia estimated by vascular image analysis: comparison with pimonidazole staining in human tumors. Radiother Oncol 55, 325-333

163. Begg AC, Hofland I, Van DP, I, Van Der SB, and Haustermans K (2000) Use of thymidine analogues to indicate vascular perfusion in tumours. $\mathrm{Br} \mathrm{J}$ Cancer 83,899 . 905

164. Bussink J, Kaanders JH, Rijken PF, Martindale CA, and van der Kogel AJ (1998) Multiparameter analysis of vasculature, perfusion and proliferation in human tumour xenografts. Br J Cancer 77, 57-64

165. Olive PL, Aquino-Parsons C, MacPhail SH, Liao SY, Raleigh JA, Lerman MI , and Stanbridge EJ (2001) Carbonic anhydrase 9 as an endogenous marker for hypoxic cells in cervical cancer. Cancer Res 61, 8924-8929

166. Beasley NJ, Wykoff CC, Watson PH, Leek R, Turley H. Gatter K. Pastorek J, Cox GJ. Ratcliffe P. and Harris AL (2001) Carbonic anhydrase IX, an endogenous hypoxia marker, expression in head and neck squamous cell carcinoma and its relationship to hypoxia, necrosis, and microvessel density. Cancer Res 61, 5262-5267

167. Talks KL. Turley H, Gatter KC, Maxwell PH. Pugh CW. Ratcliffe PJ, and Harris AL (2000) The expression and distribution of the hypoxia-inducible factors HIF- Ialpha and HIF-2alpha in normal human tissues, cancers, and tumor- associated macrophages. Am J Pathol 157, 411-421

168. Thews $O$ and Vaupel $P$ (1996) Relevant parameters for describing the oxygenation status of solid tumors. Strahlenther Onkol 172, 239-243 
169. Cline JM, Rosner GL, Raleigh JA, and Thrall DE (1997) Quantification of CCI-103F labeling heterogeneity in canine solid tumors. Int J Radiat Oncol Biol Phys 37, 655 662

170. Josse O, Labar D, Georges B, Gregoire V , and Marchand-Brynaert J (2001) Synthesis of [18F]-labeled EF3 [2-(2-nitroimidazol-1-yl)-N-(3,3,3-trifluoropropyl)acetamide], a marker for PET detection of hypoxia. Bioorg Med Chem 9, 665-675

171. Lehtio K, Oikonen V, Gronroos T, Eskola O, Kalliokoski K, Bergman J, Solin O, Grenman R, Nuutila P, and Minn H (2001) Imaging of blood flow and hypoxia in head and neck cancer: initial evaluation with $[(15) \mathrm{O}] \mathrm{H}(2) \mathrm{O}$ and [(18)F]fluoroerythronitroimidazole PET. J Nucl Med 42, 1643-1652

172. Lewis JS and Welch MJ (2001) PET imaging of hypoxia. Q J Nucl Med 45, 183-188

173. Mankoff DA and Bellon JR (2001) Positron-emission tomographic imaging of cancer: glucose metabolism and beyond. Semin Radiat Oncol 11, 16-27

174. Rigo P, Paulus P, Kaschten BJ, Hustinx R, Bury T, Jerusalem G, Benoit T, and Foidart-Willems J (1996) Oncological applications of positron emission tomography with fluorine- 18 fluorodeoxyglucose. Eur J Nucl Med 23. 1641-1674

175. Groshar D. McEwan AJ, Parliament MB, Urtasun RC, Golberg LE, Hoskinson M, Mercer JR, Mannan RH. Wiebe LI, and Chapman JD (1993) Imaging tumor hypoxia and tumor perfusion. J Nucl Med 34, 885-888

176. Rasey JS, Koh WJ, Evans ML, Peterson LM, Lewellen TK, Graham MM, and Krohn KA (1996) Quantifying regional hypoxia in human tumors with positron emission tomography of [18F]fluoromisonidazole: a pretherapy study of 37 patients. Int J Radiat Oncol Biol Phys 36, 417-428

177. Koh WJ, Rasey JS, Evans ML, Grierson JR, Lewellen TK, Graham MM, Krohn KA, and Griffin TW (1992) Imaging of hypoxia in human tumors with [F-

18]fluoromisonidazole. Int J Radiat Oncol Biol Phys 22, 199-212

178. Chapman JD, Zanzonico P, and Ling CC (2001) On measuring hypoxia in individual tumors with radiolabeled agents. J Nucl Med 42, 1653-1655

179. Hermans R, Lambin P, Van der GA, Van Den BW, Verbist B, Weltens C, and Delaere PR (1999) Tumoural perfusion as measured by dynamic computed tomography in head and neck carcinoma. Radiother Oncol 53, 105-111

180. van der Sanden BP. Heerschap A, Simonetti AW, Rijken PF, Peters HP, Stuben G, and van der Kogel AJ (1999) Characterization and validation of noninvasive oxygen tension measurements in human glioma xenografts by $19 \mathrm{~F}-\mathrm{MR}$ relaxometry. Int J Radiat Oncol Biol Phys 44, 649-658

181. Mason RP. Hunjan S, Le D, Constantinescu A, Barker BR. Wong PS. Peschke P. Hahn EW, and Antich PP (1998) Regional tumor oxygen tension: fluorine echo planar imaging of hexafluorobenzene reveals heterogeneity of dynamics. Int J Radiat Oncol Biol Phys 42, 747-750

182. McCoy CL, McIntyre DJ, Robinson SP, Aboagye EO, and Griffiths JR (1996) Magnetic resonance spectroscopy and imaging methods for measuring tumour and tissue oxygenation. Br J Cancer Suppl 27, S226-S231

183. Vaupel P. Schaefer C, and Okunieff P (1994) Intracellular acidosis in murine fibrosarcomas coincides with ATP depletion, hypoxia, and high levels of lactate and total Pi. NMR Biomed 7, 128-136

184. Sostman HD, Rockwell S, Sylvia AL, Madwed D, Cofer G, Charles HC, Negro-Vilar R, and Moore D (1991) Evaluation of BA1112 rhabdomyosarcoma oxygenation with microelectrodes, optical spectrophotometry, radiosensitivity, and magnetic resonance spectroscopy. Magn Reson Med 20, 253-267

185. Koutcher JA. Goldsmith M, and Damadian R (1978) NMR in cancer. X. A malignancy index to discriminate normal and cancerous tissue. 41, 174-182

186. Bock JC, Henrikson O, Gotze AH. Wlodarczyk W, Sander B, and Felix R (1995) Magnetic resonance perfusion imaging with gadolinium-DTPA. A quantitative approach for the kinetic analysis of first-pass residue curves. Invest Radiol 30, 693699 
187. Cooper RA, Carrington BM, Loncaster JA, Todd SM, Davidson SE, Logue JP. Luthra AD, Jones AP, Stratford I, Hunter RD, and West CM (2000) Tumour oxygenation levels correlate with dynamic contrast-enhanced magnetic resonance imaging parameters in carcinoma of the cervix. Radiother Oncol 57, 53-59

188. Ogawa S, Lee TM, Kay AR, and Tank DW (1990) Brain magnetic resonance imaging with contrast dependent on blood oxygenation. Proc Natl Acad Sci U S A 87, 9868 9872

189. Kwong KK, Belliveau JW, Chesler DA, Goldberg IE, Weisskoff RM, Poncelet BP, Kennedy DN, Hoppel BE, Cohen MS. Turner R. Cheng HM. Brady TJ, and Rosen BR (1992) Dynamic magnetic resonance imaging of human brain activity during primary sensory stimulation. Proc Natl Acad Sci U S A 89, 5675-5679

190. Sunaert S, Dymarkowski S, Van Oostende S, Van Hecke P. Wilms G, and Marchal G (1998) Functional magnetic resonance imaging ( $\mathrm{MRI}$ ) visualises the brain at work. Acta Neurol Belg 98, 8-16

191. Karczmar GS, River JN, Li J, Vijayakumar S, Goldman Z and Lewis MZ (1994) Effects of hyperoxia on $\mathrm{T}_{2}^{*}$ and resonance frequency weighted magnetic resonance images of rodent tumours. NMR Biomed 7, 3-11

192. Robinson SP, Rodrigues LM, Ojugo AS, MeShechy PM, Howe FA, and Griffiths JR (1997) The response to carbogen breathing in experimental tumour models monitored by gradient-recalled echo magnetic resonance imaging. $\mathrm{Br}$ J Cancer 75, 1000-1006

193. Robinson SP. Howe FA, Rodrigues LM. Stubbs M, and Griffiths JR (1998) Magnetic resonance imaging techniques for monitoring changes in tumor oxygenation and blood flow. Semin Radiat Oncol 8, 197-207

194. Griffiths JR, Taylor NJ, Howe FA, Saunders MI, Robinson SP, Hoskin PJ, Powell ME, Thoumine M, Caine LA. and Baddeley H (1997) The response of human tumors to carbogen breathing, monitored by Gradient-Recalled Echo Magnetic Resonance Imaging. Int J Radiat Oncol Biol Phys 39, 697-701

195. Taylor NJ, Baddeley H, Goodchild KA, Powell ME. Thoumine M, Culver LA. Stirling JJ, Saunders MI, Hoskin PJ, Phillips H, Padhani AR, and Griffiths JR (2001) BOLD MRI of human tumor oxygenation during carbogen breathing. J Magn Reson Imaging 14, 156-163

196. Overgaard J, Hansen HS, Overgaard M, Bastholt L, Berthelsen A, Specht L, Lindelov B, and Jorgensen K (1998) A randomized double-blind phase III study of nimorazole as a hypoxic radiosensitizer of primary radiotherapy in supraglottic larynx and pharynx carcinoma. Results of the Danish Head and Neck Cancer Study (DAHANCA) Protocol 5-85. Radiother Oncol 46, 135-146

197. Workman P and Stratford IJ (1993) The experimental development of bioreductive drugs and their role in cancer therapy. Cancer Metastasis Rev 12, 73-82

198. Denny WA (2000) The role of hypoxia-activated prodrugs in cancer therapy. Lancet Oncol 1, 25-29

199. Brown JM (1993) SR 4233 (tirapazamine): a new anticancer drug exploiting hypoxia in solid tumours. Br J Cancer 67, 1163-1170

200. Treat J, Johnson E. Langer C, Belani C, Haynes B, Greenberg R, Rodriquez R, Drobins P. Miller W, Jr., Meehan L, McKeon A, Devin J, von Roemeling R, and Viallet J (1998) Tirapazamine with cisplatin in patients with advanced non-small-cell lung cancer: a phase II study. J Clin Oncol 16, 3524-3527

201. Rischin D. Peters L, Hicks R, Hughes P, Fisher R, Hart R, Sexton M, DCosta I, and von Roemeling R (2001) Phase I trial of concurrent tirapazamine, cisplatin, and radiotherapy in patients with advanced head and neck cancer. J Clin Oncol 19, 535542

202. Patterson LH and McKeown SR (2000) AQ4N: a new approach to hypoxia-activated cancer chemotherapy. Br J Cancer 83, 1589-1593

203. Dorie MJ and Brown JM (1993) Tumor-specific, schedule-dependent interaction between tirapazamine (SR 4233) and cisplatin. Cancer Res 53, 4633-4636 
204. Wouters BG, Wang LH, and Brown JM (1999) Tirapazamine: a new drug producing tumor specific enhancement of platinum-based chemotherapy in non-small-cell lung cancer. Ann Oncol 10 Suppl 5, S29-S33

205. Craighead PS, Pearcey R, and Stuart G (2000) A phase I/II evaluation of tirapazamine administered intravenously concurrent with cisplatin and radiotherapy in women with locally advanced cervical cancer. Int J Radiat Oncol Biol Phys 48, 791-795

206. Patterson LH, McKeown SR, Ruparelia K, Double JA, Bibby MC, Cole S, and Stratford IJ (2000) Enhancement of chemotherapy and radiotherapy of murine tumours by $\mathrm{AQ} 4 \mathrm{~N}$, a bioreductively activated anti-tumour agent. $\mathrm{Br} \mathrm{J}$ Cancer 82 , 1984-1990

207. Dachs GU, Patterson AV, Firth JD, Ratcliffe PJ, Townsend KM, Stratford IJ, and Harris AL (1997) Targeting gene expression to hypoxic tumor cells. Nat Med 3, 515 520

208. Shibata T, Giaccia AJ, and Brown JM (2000) Development of a hypoxia-responsive vector for tumor-specific gene therapy. Gene Ther 7, 493-498

209. Fox ME, Lemmon MJ, Mauchline ML, Davis TO, Giaccia AJ, Minton NP, and Brown JM (1996) Anaerobic bacteria as a delivery system for cancer gene therapy: in vitro activation of 5-fluorocytosine by genetically engineered clostridia. Gene Ther 3 . 173-178

210. Lambin P, Theys J, Landuyt W, Rijken P, van der Kogel A, van der Schueren E, Hodgkiss R, Fowler J, Nuyts S, de Bruijn E, Van Mellaert L, and Anne J (1998) Colonisation of Clostridium in the body is restricted to hypoxic and necrotic areas of tumours. 4, 183-188

211. Lemmon MJ, van Zijl P, Fox ME, Mauchline ML, Giaccia AJ, Minton NP, and Brown JM (1997) Anaerobic bacteria as a gene delivery system that is controlled by the tumor microenvironment. Gene Ther 4, 791-796

212. Malmgren RA and Flanigan CC (1955) Localization of the vegetative form of Clostridium tetani in mouse tumors following intravenous spore administration. Cancer Res 15, 473-478

213. Mose JR and Mose G (1964) Oncolysis by Clostridia. I. Activity of Clostridium butyricum (M-55) and other nonpathogenic Clostridia against the Ehrlich carcinoma. Cancer Res 24, 212-216

214. Schlechte H, Schwabe K, Mehnert WH, Schulze B, and Brauniger H (1982) Chemotherapy for tumours using clostridial oncolysis, antibiotics and cyclophosphamide: model trial on the UVT 15264 tumour. Arch Geschwulstforsch $52,41-48$

215. Carey RW. Holland JF. Whang HY, Neter E, and Bryant B (1967) Clostridial oncolysis in man. Eur J Cancer 3, 37-46

216. Dang LH, Bettegowda C. Huso DL, Kinzler KW, and Vogelstein B (2001) Combination bacteriolytic therapy for the treatment of experimental tumors. Proc Natl Acad Sci U S A 98, 15155-15160

217. Yazawa K, Fujimori M, Amano J, Kano Y, and Taniguchi S (2000) Bifidobacterium longum as a delivery system for cancer gene therapy: selective localization and growth in hypoxic tumors. Cancer Gene Ther 7, 269-274

218. Theys J. Nuyts S, Landuyt W, Van Mellaert L. Dillen C. Bohringer M, Durre P. Lambin P, and Anne J (1999) Stable Escherichia coli-Clostridium acetobutylicum shuttle vector for secretion of murine tumor necrosis factor alpha. Appl Environ Microbiol 65, 4295-4300

219. Theys J, Landuyt W. Nuyts S, Van Mellaert L, van Oosterom A. Lambin P. and Anne J (2001) Specific targeting of cytosine deaminase to solid tumors by engineered Clostridium acetobutylicum. Cancer Gene Ther 8, 294-297

220. Huber BE, Austin EA. Richards CA. Davis ST, and Good SS (1994) Metabolism of 5-fluorocytosine to 5-fluorouracil in human colorectal tumor cells transduced with the cytosine deaminase gene: significant antitumor effects when only a small percentage of tumor cells express cytosine deaminase. Proc Natl Acad Sci U S A 91. 8302-8306 
221. Liu SC, Minton NP, Giaccia AJ, and Brown JM (2002) Anticancer efficacy of systemically delivered anaerobic bacteria as gene therapy vectors targeting tumor hypoxia/necrosis. Gene Ther 9, 291-296

222. Lambin P. Nuyts S, Landuyt W. Theys J, de Bruijn E. Anne J. Van Mellaert L and Fowler J (2000) The potential therapeutic gain of radiation-associated gene therapy with the suicide gene cytosine deaminase. Int J Radiat Biol 76, 285-293

223. Nuyts S, Van Mellaert L, Theys J, Landuyt W, Lambin P, and Anne J (2002) Clostridium spores for tumor-specific drug delivery. Anticancer Drugs 13.115-125

224. Nuyts S, Van Mellaert L, Theys J, Landuy W, Bosmans E, Anne J, and Lambin P (2001) Radio-responsive recA promoter significantly increases TNFalpha production in recombinant clostridia after $2 \mathrm{~Gy}$ irradiation. Gene Ther 8, 1197-1201

225. Jain RK and Forbes NS (2001) Can engineered bacteria help control cancer? Proc Natl Acad Sci U S A 98, 14748-14750

226. Quixley KW and Reid SJ (2000) Construction of a reporter gene vector for Clostridium beijerinckii using a Clostridium endoglucanase gene. J Mol Microbiol Biotechnol 2, 53-57

227. Hirst DG (1986) Anemia: a problem or an opportunity in radiotherapy? Int J Radiat Oncol Biol Phys 12, 2009-2017

228. Goodman RL, Moore RE, Davis ME, Stokes D, and Yuhas JM (1984)

Perfluorocarbon emulsions in cancer therapy: preliminary observations on presently available formulations. Int J Radiat Oncol Biol Phys 10, 1421-1424

229. Teicher BA (1992) Use of perfluorochemical emulsions in cancer therapy. Biomater Artif Cells Immobilization Biotechnol 20, 875-882

230. Girinski T, Pejovic-Lenfant MH, Bourhis J, Campana F, Cosset JM, Petit C, Malaise EP. Haie C, Gerbaulet A, and Chassagne D (1989) Prognostic value of hemoglobin concentrations and blood transfusions in advanced carcinoma of the cervix treated by radiation therapy: results of a retrospective study of 386 patients. Int J Radiat Oncol Biol Phys 16, 37-42

231. Pedersen D, Sogaard H, Overgaard J, and Bentzen SM (1995) Prognostic value of pretreatment factors in patients with locally advanced carcinoma of the uterine cervix treated by radiotherapy alone. Acta Oncol 34, 787-795

232. van Acht MJ, Hermans J, Boks DE, and Leer JW (1992) The prognostic value of hemoglobin and a decrease in hemoglobin during radiotherapy in laryngeal carcinoma. Radiother Oncol 23, 229-235

233. Lee WR, Berkey B, Marcial V, Fu KK, Cooper JS, Vikram B, Coia LR, Rotman M, and Ortiz H (1998) Anemia is associated with decreased survival and increased locoregional failure in patients with locally advanced head and neck carcinoma: a secondary analysis of RTOG 85-27. Int J Radiat Oncol Biol Phys 42, 1069-1075

234. Lavey RS (1998) Clinical trial experience using erythropoietin during radiation therapy . Strahlenther Onkol 174 Suppl 4, 24-30

235. Glaser CM, Millesi W, Kornek GV, Lang S, Schull B, Watzinger F, Selzer E, and Lavey RS (2001) Impact of hemoglobin level and use of recombinant erythropoietin on efficacy of preoperative chemoradiation therapy for squamous cell carcinoma of the oral cavity and oropharynx. Int J Radiat Oncol Biol Phys 50, 705-715

236. Henk JM (1986) Late results of a trial of hyperbaric oxygen and radiotherapy in head and neck cancer: a rationale for hypoxic cell sensitizers? Int J Radiat Oncol Biol Phys 12, 1339-1341

237. Brizel DM. Hage WD. Dodge RK. Munley MT. Piantadosi CA, and Dewhirst MW (1997) Hyperbaric oxygen improves tumor radiation response significantly more than carbogen/nicotinamide. Radiat Res $147,715-720$

238. Dische S (1991) What have we learnt from hyperbaric oxygen? Radiother Oncol 20 Suppl 1, 71-74

239. Dische S, Saunders MI, Sealy R, Werner ID, Verma N, Foy C, and Bentzen SM (1999) Carcinoma of the cervix and the use of hyperbaric oxygen with radiotherapy: a report of a randomised controlled trial. Radiother Oncol 53, 93-98 
240. Rojas A, Joiner MC, and Denekamp J (1992) Extrapolations from laboratory and preclinical studies for the use of carbogen and nicotinamide in radiotherapy. Radiother Oncol 24, 123-124

241. Chaplin DJ, Horsman MR, and Trotter MJ (1990) Effect of nicotinamide on the microregional heterogeneity of oxygen delivery within a murine tumor. J Natl Cancer Inst 82, 672-676

242. Kjellen E, Joiner MC, Collier JM, Johns H, and Rojas A (1991) A therapeutic benefit from combining normobaric carbogen or oxygen with nicotinamide in fractionated $\mathrm{X}$. ray treatments. Radiother Oncol 22, 81-91

243. Siemann DW, Horsman MR, and Chaplin DJ (1994) The radiation response of KHT sarcomas following nicotinamide treatment and carbogen breathing. Radiother Oncol 31. 117-122

244. Horsman MR, Siemann DW, Nordsmark M, Khalil AA, Overgaard J, and Chaplin DJ (1994) The combination of nicotinamide and carbogen breathing to improve tumour oxygenation prior to radiation treatment. Adv Exp Med Biol 361, 635-642

245. Rojas A, Hirst VK, Calvert AS, and Johns H (1996) Carbogen and nicotinamide as radiosensitizers in a murine mammary carcinoma using conventional and accelerated radiotherapy. Int J Radiat Oncol Biol Phys 34, 357-365

246. Fenton BM, Lord EM, and Paoni SF (2000) Enhancement of tumor perfusion and oxygenation by carbogen and nicotinamide during single- and multifraction irradiation. Radiat Res $153,75-83$

247. Laurence VM, Ward R, Dennis IF, and Bleehen NM (1995) Carbogen breathing with nicotinamide improves the oxygen status of tumours in patients. Br J Cancer 72, 198 205

248. Kaanders JH, Pop LA, Marres HA, Liefers J, van den Hoogen FJ, van Daal WA, and van der Kogel AJ (1998) Accelerated radiotherapy with carbogen and nicotinamide (ARCON) for laryngeal cancer. Radiother Oncol 48, 115-122

249. Saunders MI. Hoskin PJ, Pigott K. Powell ME, Goodchild K, Dische S, Denekamp J. Stratford MR, Dennis MF, and Rojas AM (1997) Accelerated radiotherapy, carbogen and nicotinamide (ARCON) in locally advanced head and neck cancer: a feasibility study. Radiother Oncol 45, 159-166

250. Hoskin PJ, Saunders MI, and Dische S (1999) Hypoxic radiosensitizers in radical radiotherapy for patients with bladder carcinoma: hyperbaric oxygen, misonidazole, and accelerated radiotherapy, carbogen, and nicotinamide. 86, 1322-1328

251. Bussink J, Kaanders JH, and van der Kogel AJ (1999) Clinical outcome and tumour microenvironmental effects of accelerated radiotherapy with carbogen and nicotinamide. Acta Oncol 38, 875-882

252. Bernier J. Denekamp J, Rojas A, Minatel E, Horiot J, Hamers H, Antognoni P, Dahl O, Richaud P, Van Glabbeke M, and Pi inverted question mM (2000) ARCON: accelerated radiotherapy with carbogen and nicotinamide in head and neck squamous cell carcinomas. The experience of the Co-operative group of radiotherapy of the european organization for research and treatment of cancer (EORTC). Radiother Oncol 55, 111-119

253. Bernier J. Denekamp J, Rojas A, Trovo M , Horiot JC. Hamers H. Antognoni P. Dahl O, Richaud P, Kaanders J, Van Glabbeke M, and Pierart M (1999) ARCON: accelerated radiotherapy with carbogen and nicotinamide in non small cell lung cancer: a phase I/II study by the EORTC. Radiother Oncol 52, 149-156

254. Miralbell R, Mornex F, Greiner R, Bolla M. Storme G, Hulshof M, Bernier J. Denekamp J, Rojas AM, Pierart M, Van Glabbeke M, and Mirimanoff RO (1999) Accelerated radiotherapy, carbogen, and nicotinamide in glioblastoma multiforme: report of European Organization for Research and Treatment of Cancer trial 22933. J Clin Oncol 17, 3143-3149 


\section{I.2. Outline of the principal investigations}

As may be obvious from the foregoing introductory notes, information on the tumour micro-environment, and its changes during tumour growth, has accumulated during the last 10-15 years.

Separate from the established anti-cancer treatments that directly target the tumour cells, therapy has been broadened to additional strategies related to aspects of the tumour micro-environment. Among the latter are those that utilize compounds that interfere with the angiogenesis process and those that are selectively directed at the hypoxic tumour cells. Novel therapies have been elaborated during the last decade. Among these are the 'clinical potential' vascular targeting drugs (such as flavonoid derivatives and tubulin-binders), either as a single agent, or more promisingly, as an adjuvant to other treatments.

Also virus- and liposome-based gene therapy, targeting either tumour-specific antigens (e.g. EGFr or c-kitr) or micro-environmental conditions (e.g. glucose deprivation), has become a promising anti-cancer development. Alternatively. engineered non-pathogenic bacteria are being investigated as a delivery system for therapeutic proteins, such as the cytokine TNF $\alpha$ and the suicide protein CDase, to the solid tumour. Among these bacteria are non-pathogenic obligatory anaerobic clostridia, shown to selectively localize and proliferate in severely hypoxic and necrotic tumour areas.

In parallel, the need for a non-invasive visualisation of the metabolic and proliferative quality of the tumour micro-environment, including deep-seated and critically positioned malignancies, has evolved in the exploration of various imaging techniques (such as CT, PET, MRI). Using these scanners to evaluate, not only the morphology, but more importantly the functional quality of tumours before, during and after treatment, may allow the selection and guidance of an optimised therapy.

The objectives of the present pre-clinical in vivo investigations involved the use of tumour vascularity and hypoxic/anoxic status for the benefit of selective therapy and for non-invasive diagnosis. The basis for the various hypotheses and related questions is presented in a diagram (Figure 1.7) 


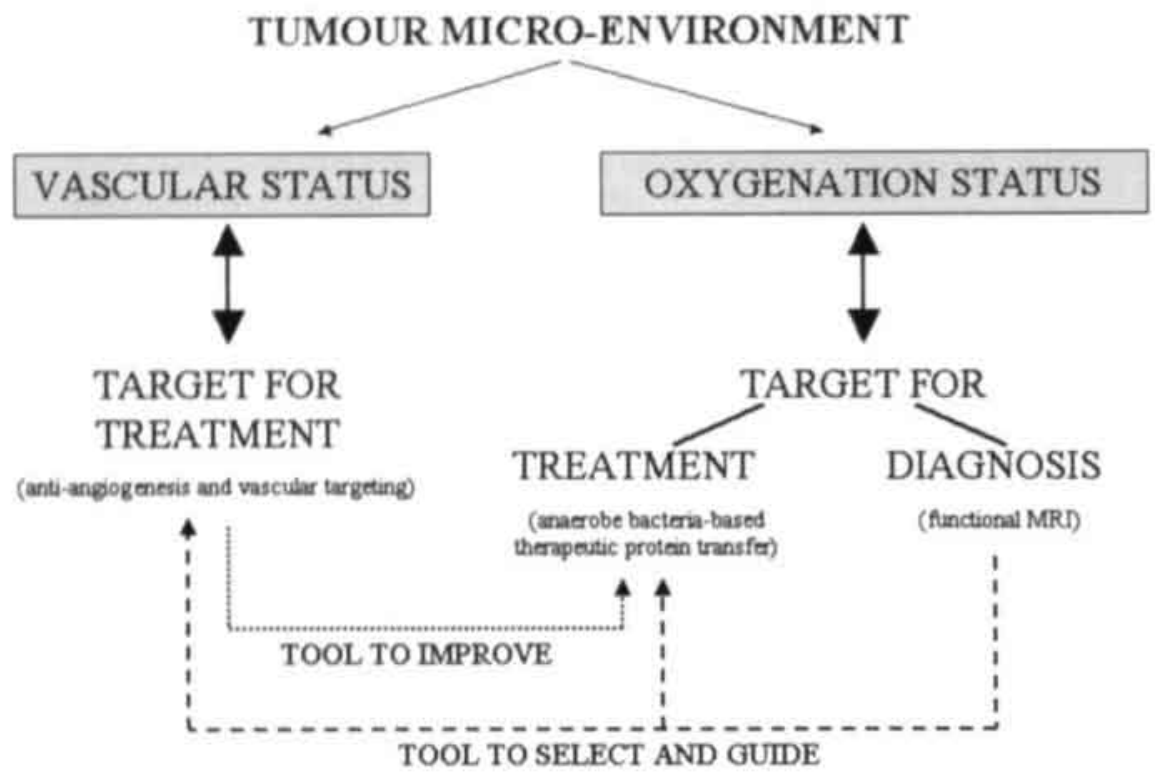

Figure 1.7 : Relationship between two most important tumour micro-environmental conditions regarding the studies of the present thesis research.

Hypothesis and questions that have been addressed specifically:

- It is hypothesized that the efficacy of blood vessel-related treatments may depend on the tumour volume at the time of application.

We therefore studied

a) the effect of anti-angiogenesis using TNP-470 in rhabdomyosarcoma tumours of different sizes;

b) the potential of vascular targeting using combretastatin A-4 phosphate (combreAp) to exert activity in tumours of different sizes; with two related questions: (i) is it possible to evaluate the acute vessel damage in a clinical applicable setting (radiological angiography)?; and (ii) what would be the outcome of combreAp repeat-treatment in relation to tumour size?

- Based on the hypothesis that the tumour rim (not affected by combreAp treatment because of the presence of peripheral mature host vasculature) consists of well-oxygenated tumour cells, can a benefit be obtained from combining combreAp vascular targeting with ionising radiation? 
- Based on the hypothesis that tumours, regrowing after the initial combreAp treatment, will be characterized by blood vessel expansion, we added the anti-angiogenesis TNP- 470 treatment at a pre-selected timing to evaluate the potential benefit?

- With the knowledge that combreAp induces a major proportion of necrosis, irrespective of the tumour volume at treatment, would its combination with an anaerobe bacteria-based transfer of a therapeutic gene selectively improve the tumour colonisation and the expression of these proteins?

- Considering the potential of magnetic resonance imaging in cancer screening, we aimed to evaluate a non-invasive fast functional MRmethodology (with an echo planar imaging sequence) for the assessment of tumour oxygenation. This should enable tumours to be selected which might be preferentially responsive to the above mentioned treatment options. 



\section{Chapter II}

\section{II.1. Effect of TNP-470 (AGM-1470) on the growth of rat rhabdomyosarcoma tumours with different sizes}

Published in : Cancer Invest. 19: 35-40, 2001

Willy Landuyt, Jan Theys, Sandra Nuyts, Maria Drijkoningen, Jack Fowler, Alex Reijnders, Sandra Liekens, Johan Neyts, Ernst de Bruijn, Jozef Anné and Philippe Lambin 


\section{Summary}

Potential anti-cancer therapy with the fumagillin analog TNP-470 was investigated in the present project using subcutaneously growing rhabdomyosarcomas in rats. Specifically, influences of different tumor sizes at the start of treatment as well as dose/schedules were evaluated. The results show a significant $(p \leq 0.01)$ reduction of the growth rate, even for relatively large-sized $\left(>7 \mathrm{~cm}^{3}\right)$ tumors, when $50 \mathrm{mg} / \mathrm{kg}$ TNP-470 was used every other day for up to 3 or 5 injections. With $30 \mathrm{mg} / \mathrm{kg}$ TNP-470 injections, effects were seen only with tumors measuring less than $7 \mathrm{~cm}^{3}$. The histologic examinations demonstrate an increase in necrosis, both in the centre and in the peripheral part of TNP-470-treated tumors.

Overall, both tumor volume and drug dose determine treatment outcome with the rat rhabdomyosarcoma. The results suggest that angiogenesis inhibitors could represent a valid component in the treatment of progressive tumor growth. 


\section{II.1.1. Introduction}

To support cell survival and growth, a tumor relies on neovascularization and thus on endothelial cell proliferation [1]. The consequent effect of angiogenesis on tumor growth and the establishment of metastases is well documented. During the last two decades much attention has focused on the development of anti-angiogenic compounds. One such inhibitor of angiogenesis is the fumagillin analog TNP-470 (AGM-1470). The compound has shown in vivo anti-angiogenic effect in various tumor models (e.g. [2-5]) and is currently in phase VII clinical trials for the treatment of a variety of solid tumors. Although the full mechanism of the anti-angiogenic activity has not yet been clarified, important inhibition of proliferation and migration of endothelial cells and of capillary tube formation has been observed $(e, g .[6,7])$.

The present report describes the anti-tumor effect of TNP-470 on the syngeneic thabdomyosarcoma in rats. This poorly differentiated tumor has been induced following irradiation [8]. Our study specifically focuses on the relation between dosing/scheduling of TNP-470 and the size of the tumor at the start of the treatments. Tumor growth delay and histological appearance as well as the profile of the major side effects was assessed.

\section{II.1.2. Materials and methods}

Male WAG/Rij rats, aged $12-14$ weeks and weighing about $280 \mathrm{~g}$ were bred in our conventional animal housing facility. The rats had free access to water and food during the total experimental period. The syngeneic rat rhabdomyosarcoma was implanted subcutaneously (s.c.) in the lower flank of anaesthetised animals using tumor pieces of about $1 \mathrm{~mm}^{3}$. This experimental tumor model has been firmly established in radiobiology research and described thoroughly in a vast number of publications (e.g. [8-11]). Briefly, the rhabdomyosarcoma originated in the jaw musculature of inbred $\mathrm{WAG} / \mathrm{Rij}$ rats that received total body irradiations. From this irradiation-induced tumor, a cell line was established using the classical procedures, giving reproducibly growing tumors in WAG/Rij rats.

The TNP-470 was received from Takeda Chemical Industries (Japan). For each experiment, the TNP-470 solution was freshly prepared in $10 \%$ ethanol and $5 \%$ arabic gum in saline. Control rats were treated with the vehicle only. Volumes for 
injection varied between 1 and $1.5 \mathrm{ml}$ (depending on the drug concentration and animal weight). Animals were injected s.c. in the neck region distant from the tumor. Several TNP-470 administration schedules and dosages were evaluated. Either 30 $\mathrm{mg} / \mathrm{kg}$ or $50 \mathrm{mg} / \mathrm{kg}$ were given 3 or 5 times, with 2 day intervals between the successive injections. In the case of the $30 \mathrm{mg} / \mathrm{kg}$ dose, the effect of a single TNP-470 treatment was also evaluated.

Treatments started when tumors reached the predetermined volume, which were either $<3 \mathrm{~cm}^{3}, 3-7 \mathrm{~cm}^{3}$ and $>7 \mathrm{~cm}^{3}$ and referred to as small, medium or large, respectively. Measurements of the tumor volumes were regularly performed with a calliper. The volume (V) was calculated according to the standard procedure for ellipsoid growth : $\mathrm{V}=(\mathrm{a} \times \mathrm{b} \times \mathrm{c}) \times \pi / 6$ ( $\mathrm{a}=$ length $; \mathrm{b}=$ width $; \mathrm{c}=$ thickness) expressed in $\mathrm{cm}^{3}$.

To enable an easy display of the anti-tumor effect, the curves representing the measurements of TNP-470 treated tumors were normalised with respect to the control (vehicle only treatment) tumors. Starting volumes of the various TNP-470 groups thus superimpose the control growth curve at the equivalent volume. This is indicated in all graphs by an arrow. Student's t-test was used for comparison of the tumor growth curves.

The histological characteristics of TNP-470 treated rhabdomyosarcomas were examined and compared with tumor sections of vehicle only treated rats. The pieces were selected from both the center and the periphery of the tumor separately. They were fixed in Bouin followed by a $10 \%$ formalin solution and processed using the routine histologic techniques. Hematoxylin-eosin and periodic acid stained sections were evaluated by light microscopy.

The experimental procedures were approved by the "University of Leuven (KUL) Animal Care and Use Committee" in compliance with European Guidelines.

\section{II.1.3. Results}

The effect of TNP-470 on the growth of the s.c. transplanted rhabdomyosarcoma was evaluated at different tumor starting sizes and drug doses. The small $\left(<3 \mathrm{~cm}^{3}\right)$, medium $\left(3-7 \mathrm{~cm}^{3}\right)$ and large $\left(>7 \mathrm{~cm}^{3}\right)$ sized tumors showed different responses, with TNP-470 either slowing or even inhibiting tumor progression. 
With small tumors the effect of the $5 \times 50 \mathrm{mg} / \mathrm{kg}$ TNP-470 treatments was significantly more prominent than for the $5 \times 30 \mathrm{mg} / \mathrm{kg}$ dosing (Figure II.1.1A). However, the growth delay was similar for both treatments with the medium sized tumors (Figure II.1.1B). The growth inhibitory effect of the $5 \times 50 \mathrm{mg} / \mathrm{kg}$ treatment was also demonstrated with rats bearing tumors larger than $7 \mathrm{~cm}^{3}$ (Figure II.1.2A).
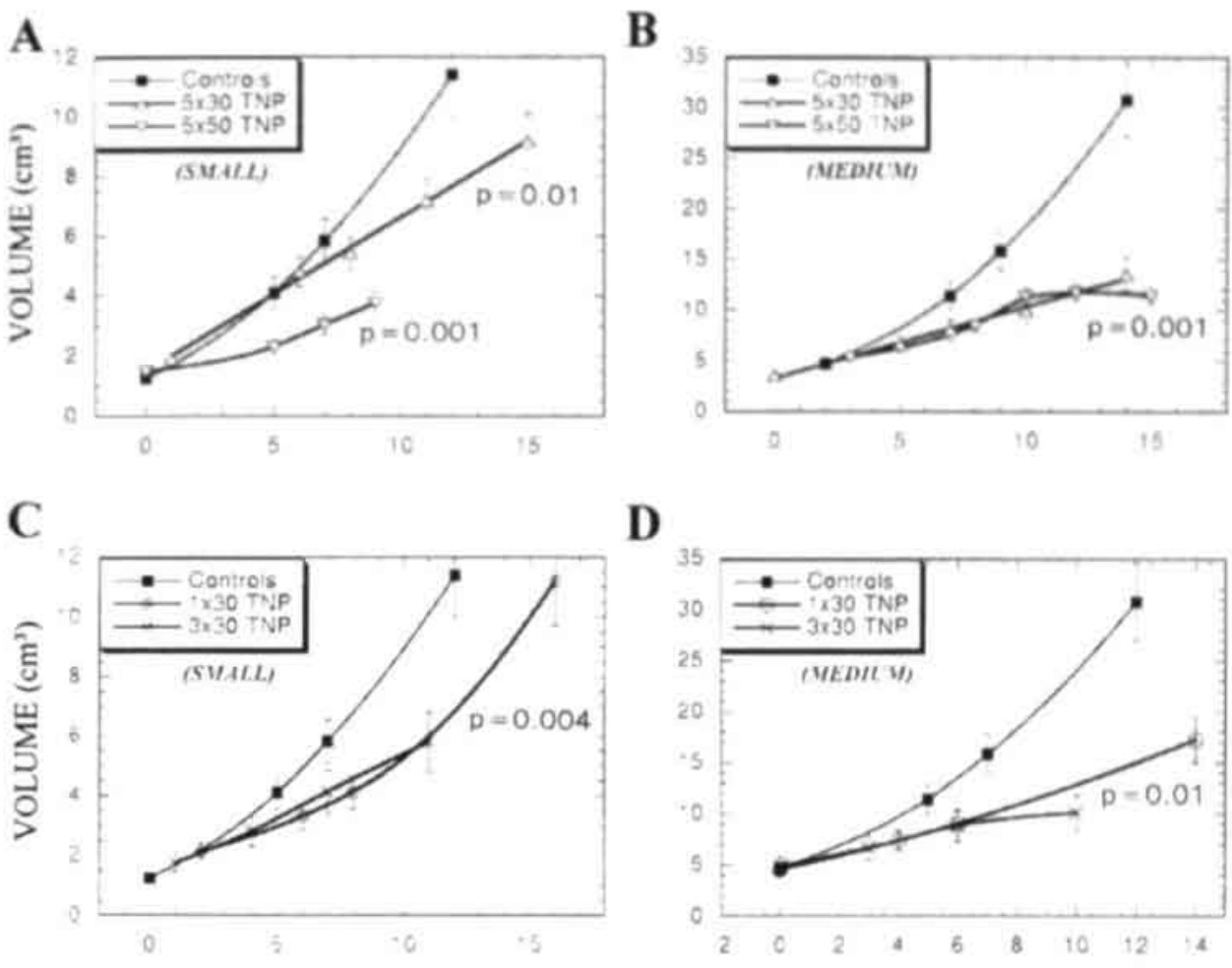

DAYS

D

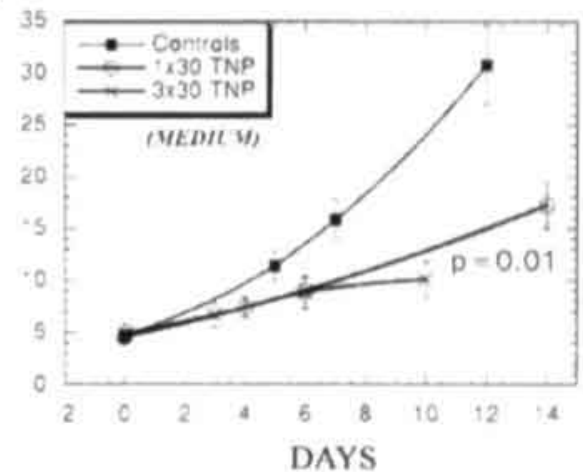

Figure II.1.1. Growth of vehicle (controls) and of TNP-470 treated tumors. Drug injections were every other day. Normalisation of the starting volumes of the latter with respect to control growth curve is done, as explained in Materials and Methods. Panels $A$ and $C$ represent the results for small $\left(<3 \mathrm{~cm}^{3}\right)$ tumors. Panels $B$ and $D$ represent the results for medium $\left(3.7 \mathrm{~cm}^{3}\right)$ tumors. Vertical bars represent standard errors and the p-values are calculated using the Student's t test.

The effect on tumor growth from $3 \times 30 \mathrm{mg} / \mathrm{kg}$ was comparable to the delay measured with the $5 \times 30 \mathrm{mg} / \mathrm{kg}$ TNP-470 administrations (see above). These results for both small and medium sized tumors are displayed in Figures II.1.IC and ID and are to be compared with the data in Figures II.1.1A and IB. The growth inhibitory effect of $3 \times 30 \mathrm{mg} / \mathrm{kg}$ drug was not significant when tumors larger than $7 \mathrm{~cm}^{3}$ were treated (Figure II. 1.2B). 

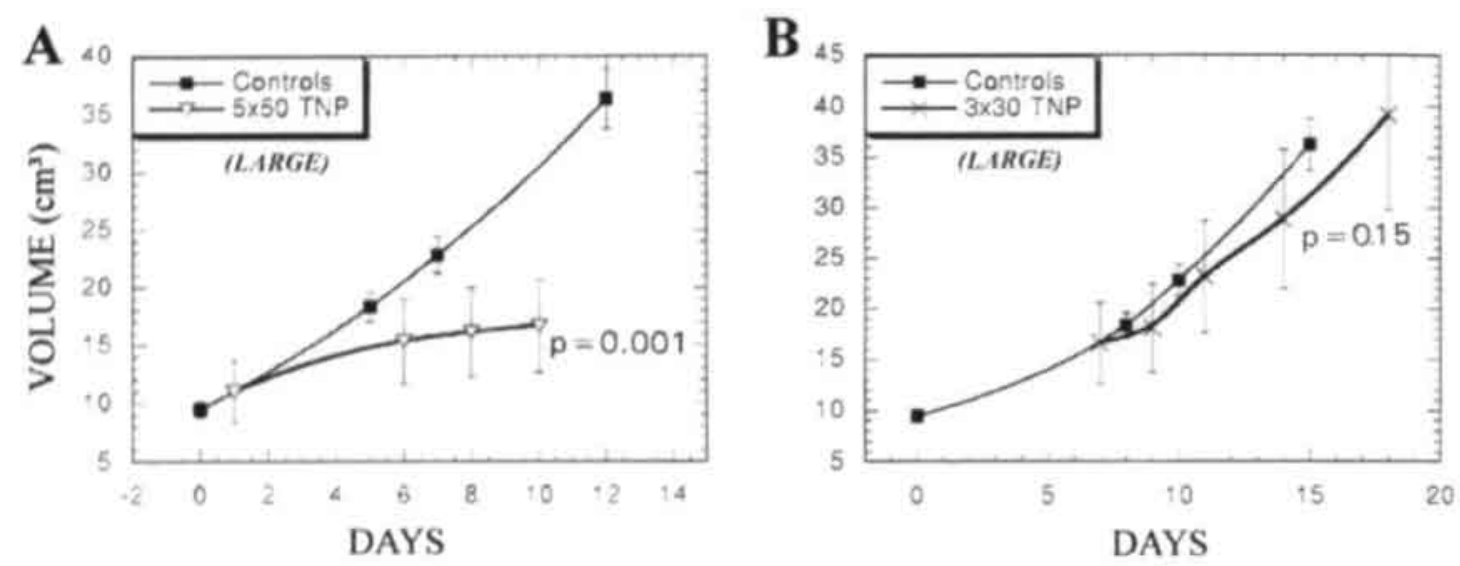

Figure II.1.2. Growth of vehicle (controls) and of TNP-470 treated tumors larger than 7 $\mathrm{cm}^{3}$. Drug injections were every other day. Normalisation of the starting volumes as explained in 'Materials and methods'; Vertical bars represent standard errors and the pvalues are calculated using the Student's t test.

On histologic examination, the non-treated rhabdomyosarcomas are very cellular. They consist of spindle cells, surrounding somewhat dilated vascular spaces. The cells show obvious atypia ; mitoses are numerous. Necrosis is sparsely present in the periphery of the tumors, but is more pronounced in the centre. With increase in tumor volume, necrotic areas become relatively larger, especially in the central part of very large tumors. After treatment with the repeated doses of TNP-470, necrosis is much more prominent in the medium and large tumors in the central as well as in the peripheral areas. This is illustrated in Figure II.1.3 for a TNP-470 treatment of $3 \times 30 \mathrm{mg} / \mathrm{kg}$ only, and is representative for the other schedules. In the small tumors, this effect is also present, but less pronounced. In some of the very large tumors (about $15 \mathrm{~cm}^{3}$ ) little or no effect of TNP-470 treatment on the extension of necrosis is seen. The diameter of the blood vessels is not altered by the TNP- 470 administration. 


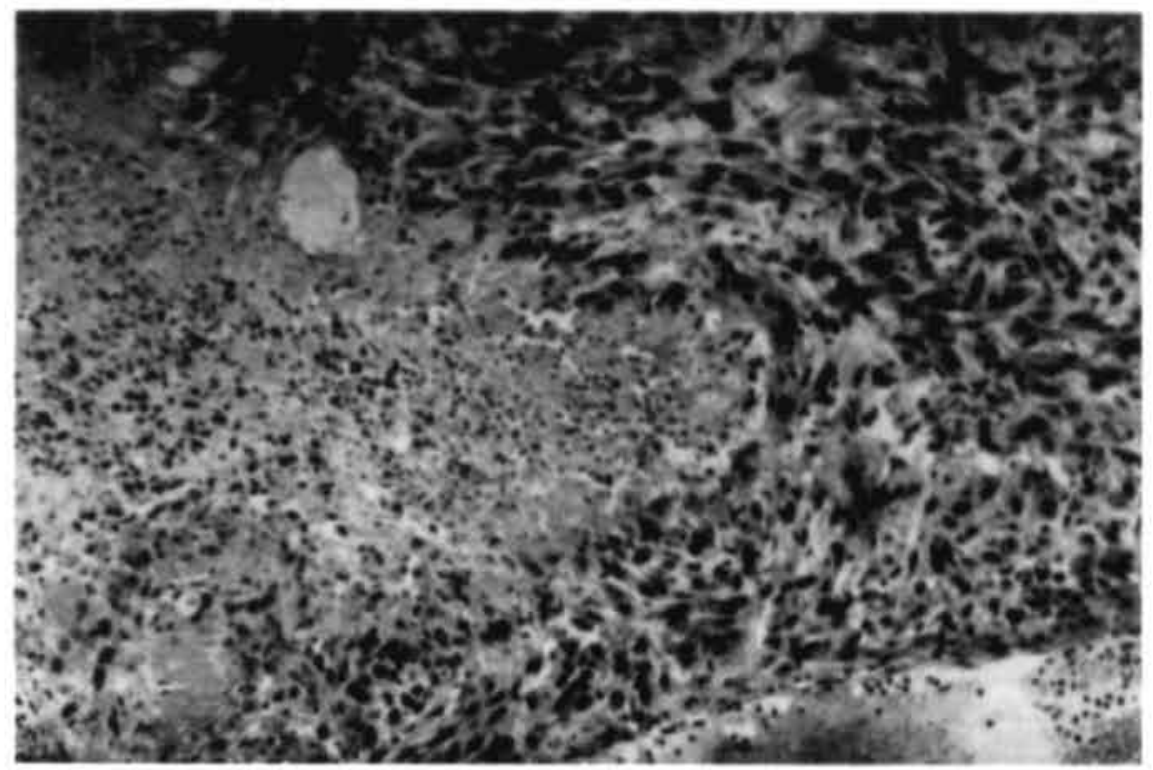

Figure II.1.3. Representative light microscopy image of rhabdomyosarcoma treated with TNP.470 (3x30mg/kg i.p. injections). Large necrotic areas are intermingled with remaining areas of viable tumor cells. Magnification $x 360$.

In a final set of experiments we studied the use of a single TNP-470 treatment of $30 \mathrm{mg} / \mathrm{kg}$. As can be deduced from Figure II.1.1C and ID, a clear-cut reduction of tumor growth was already obtained with this single TNP-470 treatment for rat rhabdomyosarcomas with volumes smaller than $7 \mathrm{~cm}^{3}$.

However, with most of these TNP-470 treatments also toxicities were observed. Overall, these were more severe with the $5 \times 50 \mathrm{mg} / \mathrm{kg}$ than with the $5 \times 30$ $\mathrm{mg} / \mathrm{kg}$ dosage and consisted of severe local skin damage at the site of the s.c. injection and of body weight loss. The loss in body weight occurred from 2 days after the first injection, and was between 10 and $30 \%$ for both dosages, being progressive throughout the observation period. Lowering the total TNP-470 doses to $3 \times 30 \mathrm{mg} / \mathrm{kg}$ did not fully resolve the problem of both skin and body weight effects. However, most of the animals started to recover their loss in body weight before the end of the follow-up period. The vehicle-treated tumor-bearing rats always showed an increase in body weight of $4-7 \%$ for the same time period as the TNP- -470 series. The skin 
damage was a local ulceration present during the series of s.c. injections in all drug expriments, with healing thereafter.

\section{II.1.4. Discussion}

Inhibition of tumor angiogenesis has been recognized as a potential adjuvant in the anticancer treatment arsenal. The fumagillin analog TNP-470 (AGM-1470) has retained special attention because of its strong inhibition of proliferation and migration of endothelial cells in tumor systems. This endotheliostatic effect was reflected in various laboratory in vivo biological models by a reduced growth rate of the primary tumor or a decreased formation of metastasis (e.g. $[2-4,6,7,12])$.

So far, however, data on the effect of TNP-470 are only available for very small primary tumors (less than $1 \mathrm{~cm}^{3}$ ). The present report deals with several series of experiments on the s.c. rat rhabdomyosarcoma with volumes between 1 and $10 \mathrm{~cm}^{3}$ at the start of the TNP-470 treatments.

Our results demonstrate that TNP-470 is also an active modulator of rhabdomyosarcoma growth, even for relatively large-sized tumors. Indeed, with all the drug-fractionation schedules tested, a substantial reduction or inhibition of growth was seen. The overall examination of the stained tumor slices revealed the major enlargement (factor $4-5$ at least) of necrotic areas in TNP-470 as compared with vehicle-treated medium and large sized tumors. There is ample literature information on the effect of TNP-470 on the endothelium and the inhibition of angiogenesis (e.g. $[6,7])$. These observations might explain the presence of a decreased growth rate and enlarged necrosis seen in the present rhabdomyosarcomas treated with TNP-470. Interestingly, even a single TNP-470 dose of $30 \mathrm{mg} / \mathrm{kg}$ slowed the tumor growth. The latter effect is important to quote, as it is measured in rats with a firmly developed tumor load.

The reductions in growth capacity that were observed in the rat thabdomyosarcoma following TNP-470 treatments seem consistent with the hypothesis that rapidly proliferating tumors are more angiogenesis-dependent [13]. Cell kinetic measurements with the rhabdomyosarcoma indeed showed a short cell cycle time of about 20 hours [9]. Also, from our tumor growth curve for rats injected with the vehicle only, a volume doubling time of 4-6 days can be deduced. These 
rapid tumor growth characteristics could partly explain the TNP-470 effect on the evolution of s.c. implanted tumors whatever the size at the start of treatment.

A recently published clinical phase I study also cited the effectiveness of TNP470 with relatively large tumors as demonstrated in our study. Repeated TNP-470 administration affected in some patients the pulmonary cervix carcinoma metastases with a volume of about $14 \mathrm{~cm}^{3}[14]$. It is likely that such a promising therapeutic approach will encourage the discovery of more potent and/or less toxic tumor vasculature targeted compounds.

\section{II.1.5. References}

1. Folkman J. Tumor angiogenesis : therapeutic implications. New Engl J Med 285: 1182 . 1185 (1971).

2. Yamaoka M, Yamamoto T, Msakai T, Ikeyama S, Sudo K. Fujita T. Inhibition of tumor growth and metastasis of rodent tumors by the angiogenesis inhibitor $\mathrm{O}$ (chloroacetyl-carbamoyl) fumagillol (TNP-470 ; AGM-1470). Cancer Res 53; 4262 4267 (1993).

3. Konno H, Tanaka T, Matsuda I, Kanai T, Maruo Y, Nishino N, Nakamura S, Baba S. Comparison of the inhibitory effect of the angiogenesis inhibitor, TNP-470, and mitomycin $\mathrm{C}$ on the growth and liver metastasis of human colon cancer. In. J Cancer 61: 268-271 (1995).

4. Tanaka T, Konno H, Matsuda I, Nakamura S, Baba S. Prevention of hepatic metastasis of human colon cancer by angiogenesis inhibitor TNP-470. Cancer Res 55: 836-839 (1995).

5. Kalebic T, Tsokos M, Helman LJ. Suppression of rhabdomyosarcoma growth by fumagillin analog TNP-470. Int J Cancer 68: 596-599 (1996).

6. Ingber D, Fujita T, Kishimoto S, Sudo K, Kanamaru T, Brem H, Folkman J. Synthetic analogues of fumagillin that inhibit angiogenesis and suppress tumor growth. Nature 348: 555-557 (1990),

7. Kusaka M, Sudo K. Matsutani E. Kozai Y, Marui S, Fujita T, Ingber D. Folkman J. Cytostatic inhibition of endothelial cell growth by the angiogenesis inhibitor TNP-470 (AGM-1470), Br J Cancer 69: 212-216 (1994).

8. Hermens AF. Barendsen GW. Cellular proliferation patterns in an experimental rhabdomyosarcoma in the rat. Eur J Cancer 3: 361-369 (1967). 
9. Curtis SB, Barendsen GW, Hermens AF. Cell kinetic model of tumor growth and regression for a rhabdomyosarcoma in the rat: undisturbed growth and radiation response to large single doses. Eur J Cancer 9: 81-87 (1973).

10. Schiffner G, Zywietz F, Lierse W. Histologische und morphometrische Untersuchungen am Rhabdomyosarkom der Ratte nach Bestrahlung und MikrowellenHyperthermie. Strahlenther Onkol 164: 94-104 (1998).

11. Barendsen GW, Broerse JJ. Experimental radiotherapy of a rat rhabdomyosarcoma with $15 \mathrm{MeV}$ neutrons and $300 \mathrm{kV}$ X-rays. I. Effects of single exposures. Eur J Cancer 5: 373-391 (1969).

12. Castronovo V, Belotti D. TNP-470 (AGM-1470) : Mechanism of action and early clinical development. Eur J Cancer 32A: 2520-2527 (1996).

13. Kim KJ, Li B, Winer J, Armanini M, Gillett N. Phillips HS, Ferrara N. Inhibition of vascular endothelial growth-factor-induced angiogenesis-suppressed tumour growth in vivo. Nature (Lond.) 362: 841-844 (1993).

14. Kudelka AP, Verschraegen CF, Loyer E. Complete remission of metastatic cervical cancer with the angiogenesis inhibitor TNP-470. New Engl J Med 338: 991-992 (1998). 


\section{Chapter II}

II.2. Vascular targeting of solid tumours: a major 'inverse' volume-response relationship with combretastatin A-4 phosphate in rat rhabdomyosarcomas

Published in : Eur. J. Cancer 36: 1833-1843, 2000

Willy Landuyt, Odette Verdoes, Daniel O. Darius, Maria Drijkoningen, Sandra Nuyts, Jan Theys, Luc Stockx, Wim Wynendaele, John F. Fowler, Geert Maleux, Walter Van den Bogaert, Jozef Anné, Allan van Oosterom and Philippe Lambin 


\section{Summary}

Tumour-specific vascularisation may be therapeutically approached in two different ways: by anti-angiogenic treatments specifically directed to dividing and migrating endothelial cells, or by agents that target principally the inadequate and ill-structured tumour vasculature. Combretastatin A-4 phosphate (combreAp), a recently synthesized prodrug (OXiGENE, Lund, Sweden), is a vascular targeting agent of the latter kind.

We evaluated the effect of a single intraperitoneal combreAp injection on the growth of rhabdomyosarcomas syngeneic in WAG/Rij rats. Different tumour volume groups, ranging between 0.1 and $27 \mathrm{~cm}^{3}$, were selected to assess the relationship between the size at treatment time and the response to combreAp. A double combreAp treatment ( $2 \times 25 \mathrm{mg} / \mathrm{kg}$ ) was investigated within the same overall aim: relation between growth delay and tumour size.

Our results show that the systemic administration of combreAp induces a clear-cut differential growth delay in the solid rat rhabdomyosarcomas: with large tumours $\left(\geq 7 \mathrm{~cm}^{3}\right)$, an 18-fold stronger effect was measured than with smaller tumours $\left(<3 \mathrm{~cm}^{3}\right)$. This is the inverse of the volume-response seen with the conventional therapeutic approaches (radiotherapy, chemotherapy or surgery). These combreAp anti-tumour responses were observed without treatment limiting systemic toxicity in the rats. With clinical digital subtraction angiography, using microsurgical cannulation of a major tumour draining vessel, and with histopathology, we demonstrate that growth delay is related to an early (within 3-6 hours) and extensive break-down of tumour blood vessels. The experiments involving a second injection also indicate a volume dependent effectivity of combreAp in reducing the regrowth rate of small or large thabdomyosarcomas.

This significant differential volume-response obtained with 'selective' vascular targeting, stronger in larger tumours than smaller ones, suggests the potential of broadening the therapeutic window. 


\section{II.2.1. Introduction}

Maintenance and improvement of vasculature is critical for the continued growth of solid tumours. These blood vessels represent therefore a target for potential new anti-cancer therapies [for reviews, see e.g. 1-6]. Definitive damage will lead to an avalanche of ischaemic tumour cell death and necrosis. As a consequence, inhibition of angiogenesis and more recently specific vascular targeting are being extensively investigated [7-10].

Angiogenesis inhibition in solid tumours is defined as the prevention of new

blood vessel formation from the existing vascular bed $[1,7,8,11]$. The actions of these drugs thus primarily consist of inhibiting growth and migration of the endothelial cell. Subsequent to such anti-angiogenic treatment, tumour growth that is critically dependent on angiogenesis will be prevented.

Vascular targeting treatments, on the contrary, are based on the fact that predominantly the already acquired tumour vasculature is selectively attacked $[1,12$, 13]. This type of therapy takes advantage of the weaknesses of established tumour endothelial cells and their supporting structures and induces collapse, thrombosis and/or hemorrhage. Obviously, depending on the agent and the dose intensity selected for this treatment, the proliferating endothelial cells of newly growing blood vessels might serve as an additional target.

Selectively targeting the acquired tumour blood vessels may constitute a potential tool, complementing traditional anticancer therapy that is majorly directed against the malignant cells themselves. Occlusion or collapse of the tumour vessels inherently leads to ischaemic or hemorrhagic necrosis. The acute reduction of tumour vasculature will initiate an immense loss of tumour cells because of nutrient deprivation, and might thus result in stabilization or reduction of growth. This has been demonstrated with hyperthermic treatment [14, 15], with flavone acetic acid injections [13, 16], with tumour necrosis factor- $\alpha[13,17]$ and with an anti-tumour endothelial cell immunotoxin [18, 19]. Another vascular targeting approach, involving tubulin-binding agents, recently gained increasing attention. As such, colchicine, vinblastine and dolostatin have been tested for their effect on tumour growth through anti-vascular activity $[12,20,21]$. Of particular interest is the novel compound combretastatin A-4, derived from the South African tree Combretum caffrum $[22,23]$. The more soluble phosphated prodrug showed the potential to induce a similar extent 
of vascular shutdown and necrosis, but without the severe side-effects of the parent compound [24-26]. These studies, as well as all other vascular targeting investigations have, however, been restricted to only small-sized mouse tumours. They therefore lack potentially useful information on the relation between tumour size and the effectiveness of a selective vascular targeting compound.

The present study assessed the in vivo anti-tumour effect by vascular targeting with combretastatin A-4 phosphate prodrug (combreAp) in a broad range of tumour volumes, using the syngeneic WAG/Rij rat rhabdomyosarcoma model. This tumour grows subcutaneously (s.c.) in the flank region to much larger sizes than have been described in the literature for mouse models. Such a growth capacity up to several tens of $\mathrm{cm}^{3}$ favours clinical relevance, as many cancer patients present with already large tumour masses. In addition, we have tested a clinical imaging technique consisting of digital subtraction angiography for its applicability to evaluate the antivasculature and anti-tumour effects of combreAp in our rat tumour model.

The overall goal of our research was to determine the relation between tumour volume and the vascular/anti-tumour effect of combreAp. Our investigations covered (i) the extent of the anti-tumour activity in terms of growth delay. (ii) histopathological examinations, and (iii) the visualisation of the effect of combreAp on tumour vasculature with digital subtraction angiography. Using the latter two methods, we also focussed on the time-relation between the combreAp injection and the sequence of the major events involved in the development of tumour damage and eventual regrowth. Finally, a double combreAp treatment was evaluated for its additional tumour growth delay and the presence of a related size dependent phenomenon.

\section{II.2.2. Materials and methods}

\section{Tumour model}

The in vivo tumour system used in the present project is a highly-reproducible experimental syngeneic rhabdomyosarcoma in WAG/Rij rats [27]. Briefly, the tumour cell line has been derived from a radiation-induced tumour in the jaw musculature of inbred WAG-Rij rats. Alternate subcutaneous (s.c.) tumour cell inoculation and tumour piece transplantation are routinely used in our laboratory to maintain qualitatively the characteristics of the rhabdomyosarcoma. The tumour shows a 
regular growth pattern without the development of metastases, and has the property of subcutaneous growth up to $40-50 \mathrm{~cm}^{3}$ in the flank region of rats without causing any obvious disturbance of the animals' health. Indeed, no anaemia, weight loss or change in physical behaviour was recorded during the time of this growth. This allowed us to investigate the effectiveness of combreAp in a large range of tumour sizes. It was, however, decided to sacrifice rats bearing tumours larger than $40 \mathrm{~cm}^{3}$ (or less if adequate information is obtained earlier during growth) at any time during the followup period. For the present experiments we transplanted tumour pieces of about $1 \mathrm{~mm}^{3}$ s.c. into the lower flank of adult rats ( 260 to $300 \mathrm{~g}$ ). This technique avoids spread of growth along the injection track, which often occurred after s.c. inoculation of 1-3 X $10^{6}$ tumour cells, and allows adequate and reproducible tumour volume measurements.

\section{Preparation of the vascular targeting compound solution}

The combretastatin A-4 prodrug (OXiGENE Inc., Lund, Sweden) was dissolved in $0.9 \%$ saline immediately before use. The solution was injected intraperitoneally (i.p.) in a volume of $0.5 \mathrm{ml}$. The control rats received an i.p. injection of $0.5 \mathrm{ml} 0.9 \%$ saline only.

\section{Growth delay measurements}

Three orthogonal diameters were measured with a caliper and used to calculate the volume of the tumour with the formula : $\mathrm{a} \times \mathrm{b} \times \mathrm{c} \times \pi / 6=$ volume, expressed in our study as $\mathrm{cm}^{3}$. Correction for skin thickness of $1 \mathrm{~mm}$ was applied at all the measured diameters. To evaluate the relationship between tumour size and the combreAp administration, 5 different tumour volume ranges were selected prior to any treatment. These ranges were $<1 \mathrm{~cm}^{3}, 1-3 \mathrm{~cm}^{3}, 3-7 \mathrm{~cm}^{3}, 7-14 \mathrm{~cm}^{3}$ and $>14 \mathrm{~cm}^{3}$, referred to in our study as "very small", "small", "medium", "large" and "very large". respectively.

\section{Histopathology examination.}

After removal of the tumour from the animals, at selected time-intervals after the combreAp injection, transsections were made of pre-determined tumour size ranges. Either the whole segment (for small tumours) or half of the segment (medium 
to very large tumours) was fixed in $10 \%$ formaldehyde solution. Care was taken to enable the evaluation of both the central and peripheral tumour area in the same slice. Following paraffin embedding, $10 \mu \mathrm{m}$ sections were stained with the haematoxylineosin combination. All sections were screened independently, generally using a X100 and a X400 magnification, by the principal investigator and the histopathologist. The latter was blinded to the treatment protocol.

\section{Microsurgical cannulation of the tumours for digital subtraction angiography}

Spontaneously breathing anaesthetised rats (Fentanyl - Dehydroperidole mixture $0.4 \mathrm{ml} / 100 \mathrm{~g}$, i.p.) were placed in dorsal decubitus and pinned to a cork operation table. Through transcutaneal and transsuperficial fascia midline incision, the encapsulated tumour was exposed. The wound was retracted, and the tumour vascular pedicle was dissected under microsurgical viewing. The major feeding artery and vein were followed by proceeding proximally up to the confluence site with the iliac artery and iliac vein, respectively. Because the pedicle of the exposed tumour often appeared kinked and occasionally compressed by vascular sheet bands, the sheet and the adventitia of the vein were trimmed. Following the cannulation, a flush with $0,2 \mathrm{cc}$ pure heparin was made and the syringe with contrast medium was attached to allow injection during imaging. An occlusive microvascular clamp was applied proximally to prevent possible backflow of contrast medium into the blood circulation. At the end of the angiographic recording, the cannula was withdrawn and the operation wound was closed with $4 / 0$ Prolene running suture. Only the large and very large tumours were investigated in this way since the smaller ones had a narrow vascular pedicle that made cannulation impossible. 


\section{Digital subtraction angiography technique}

Following micro-dissection and cannulation of the major tumour draining blood vessel, angiography of the tumour was initiated. For this purpose, $1 \mathrm{ml}$ of ioxaglate meglumine/ioxaglate sodium (Hexabrix) $200 \mathrm{mg} \mathrm{V} / \mathrm{ml}$, a water soluble low osmolar ionic contrast agent, was injected. The animals remained anaesthetised to obtain recordings without movement artifacts. Pulse mode X-ray image acquisition was done at a fixed voltage of $70 \mathrm{kV}$ with a Siemens Polytron apparatus, using a constant image intensifier field. Scanning of the tumour vascularity was performed at 3 frames per second during the injection. The images were stored and digital subtraction of the body-background was performed to improve the analytical quality. Selected images were printed on Agfa films. The tumour vasculature images were offered for interpretation to two independent radiologists blinded to the study plan. Number and size (numerical grading), location (peripheral; central) and gross morphology (regular or irregular) of the blood vessels were the parameters used to evaluate the anti-vasculature effects of combreAp.

\section{Statistics}

The results presented in the growth delay graphs are means with standard error of the mean. Differences between groups were evaluated with Multiple Regression Analysis.

\section{General aspects}

The overall number of tumours used to assess growth delays, tissue changes and vascularity amounts to a total of about 320 , including repeat experiments. The research protocol was in accordance with the Ethical Committee for Animal Care and Use of the University of Leuven (K.U.L.) and national guidelines.

\section{II.2.3. Results}

Systemic toxicity evaluations of a single i.p. combreAp injection clearly indicated that doses above $50 \mathrm{mg} / \mathrm{kg}$ (MTD) resulted in severe weight loss. A combreAp dose of $100 \mathrm{mg} / \mathrm{kg}$ resulted in $25 \%$ mortality in the rats. It was therefore decided to use combreAp injections of $25 \mathrm{mg} / \mathrm{kg}$ or less in all experiments, as no 
significant signs of general toxicity were observed in both tumour-free and tumourbearing rats.

The subcutaneous (s.c.) growth of control tumours, evaluated between $0.1 \mathrm{~cm}^{3}$ and more than $40 \mathrm{~cm}^{3}$, consistently occurred at a volume doubling rate of $2.5-3.5$ days. The effect of combreAp on the growth rate of rhabdomyosarcomas was evaluated with 5 pre-selected tumour volume ranges. Each point of all the growth curves represents the mean volume $\left(\mathrm{cm}^{3}\right)$ of at least 20 tumours. Using a single i.p. injection of $25 \mathrm{mg} / \mathrm{kg}$ a distinct volume-dependent anti-tumour effect was seen (Figure II.2.1). With tumours referred to as very small to medium $\left(<7 \mathrm{~cm}^{3}\right)$, growth delays of at most 5 days were seen (Figure II.2.1.A, B and C). Tumours with a volume at injection larger than $7 \mathrm{~cm}^{3}$ responded well to the treatment, with growth delays between 9 and 18 days (Figure II.2.1.D and E). The slowing of tumour growth was already measurable at 2 days after treatment. For the very large tumours, not only a stabilisation in size but even a regression of tumour volume was detected (Figure II.2.1.E). Palpation of the control and treated tumours revealed, for all the changes in volume, a consistently firm tumour mass that was later confirmed at transsection. To enable a precise quantification of the growth delay relative to the treatment starting volume, it was decided to interpolate the measured growth delay at 1.5 times the increase in size. The results of these calculations are summarised in Table II.2.1. The two extremes in the present study, i.e. no growth delay for very small tumours versus a mean of 17.6 days delay with the very large tumours, clearly demonstrate the sizedependency of the combreAp effectiveness with this rhabdomyosarcoma tumour model. 
Table II.2.1. Rat rhabdomyosarcoma and combretastatin A-4 phosphate (25 mg/kg i.p.)

\begin{tabular}{|c|c|c|c|c|}
\hline \multirow[t]{2}{*}{$\begin{array}{l}\text { Pre-determined } \\
\text { volume groups }\left(\mathrm{cm}^{3}\right)\end{array}$} & \multicolumn{2}{|c|}{$\begin{array}{l}\text { Time lapse for volume } \\
\text { change (days) }\end{array}$} & \multirow[t]{2}{*}{$\begin{array}{l}\text { Relative growth } \\
\text { delay (days) }\end{array}$} & \multirow{2}{*}{$\begin{array}{c}\text { Statistical } \\
\text { significance for } \\
\text { growth changes }^{(6)}\end{array}$} \\
\hline & control & CombreAp & & \\
\hline Very large $(>14)$ & 3.4 & 21.0 & 17.6 & $p<0.0001$ \\
\hline Large $(7-14)$ & 2.6 & 12.1 & 9.5 & $p<0.0001$ \\
\hline Medium (3-7) & 2.5 & 7.0 & 4.5 & $p<0.002$ \\
\hline Small (1-3) & 2.4 & 4.8 & 2.4 & $p=0.0044$ \\
\hline Very small $(<1)$ & 2.9 & 2.9 & 0 & . \\
\hline
\end{tabular}

(a) Time (days) necessary for tumours to increase $1.5 \mathrm{x}$ in volume;

(b) Time difference (days) between combre Ap-treated and control tumours to increase I.5 $\mathrm{x}$ in size:

(c) Significance level of the change in tumour growth between combreAp-treated and control tumours estimated from the full growth curves (see Figures I and 2) using Multiple Regression Analysis.

When the single i.p. dose of combreAp was reduced to $10 \mathrm{mg} / \mathrm{kg}$, a smaller reduction in the growth rate was observed, still with a more marked effect at the larger tumour volumes (data not shown). With large-sized rhabdomyosarcomas, 5 days delay in growth was measured, as compared with 9.5 days when $25 \mathrm{mg} / \mathrm{kg}$ was used with this tumour size. With medium sized tumours $\left(3-7 \mathrm{~cm}^{3}\right), 1.5$ days growth delay was obtained after injection of $10 \mathrm{mg} / \mathrm{kg}$ combreAp instead of 4.5 days as observed with $25 \mathrm{mg} / \mathrm{kg}$ drug. 
A
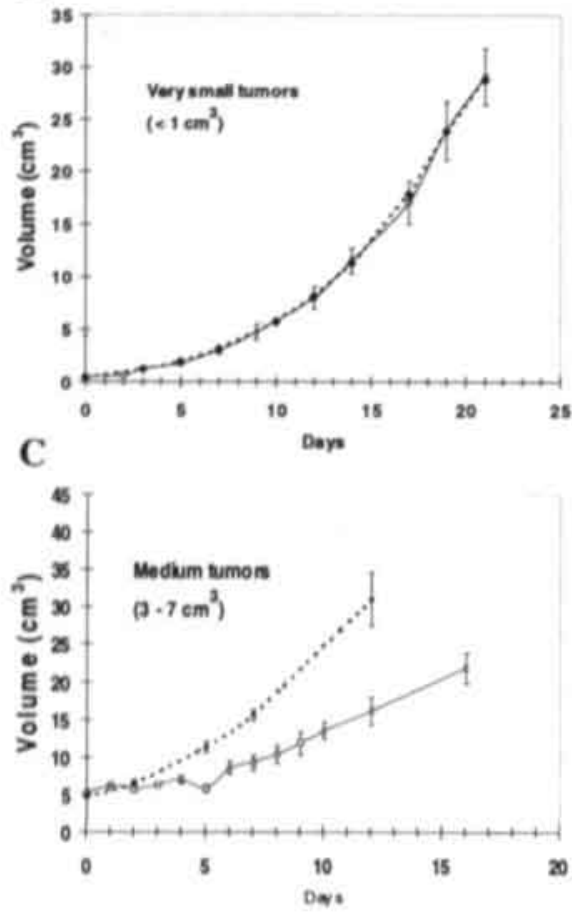

B

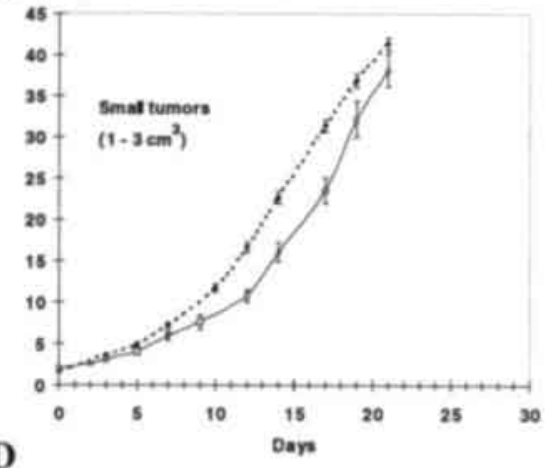

D

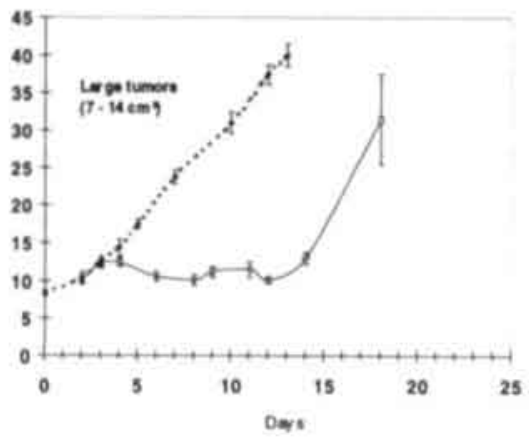

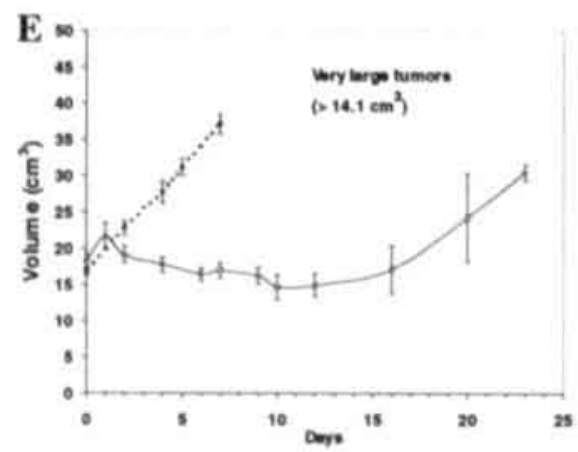

Figure II.2.1. Growth of rhabdomyosarcomas implanted s.c. in the flank of WAG/Rij rats : control tumours (closed symbol, broken line) and combreAp-treated tumours (open symbol, full line). The different panels display the results with the very small tumours (1.A), small (I.B), medium (I.C). large (I.D) and very large (I.E) tumours. The combreAp dosage was 25 $\mathrm{mg} / \mathrm{kg}$ given as a single i.p. injection. Vertical bars represent the standard error of the mean (S.E.M.).

The digital subtraction angiographic images of control tumour-bearing rats showed the relatively rich vascularity of the large sized rhabdomyosarcomas (Figure II. 2.2.A). Vascularisation was always more intense in the periphery than in the centre of the tumour, the latter being partially necrotic (see histopathological screening). The majority of the blood vessels in these control tumours were large and showed a 
regular morphology. A striking effect of the treatment with $25 \mathrm{mg} / \mathrm{kg}$ combre Ap on the tumour vascularity was imaged.
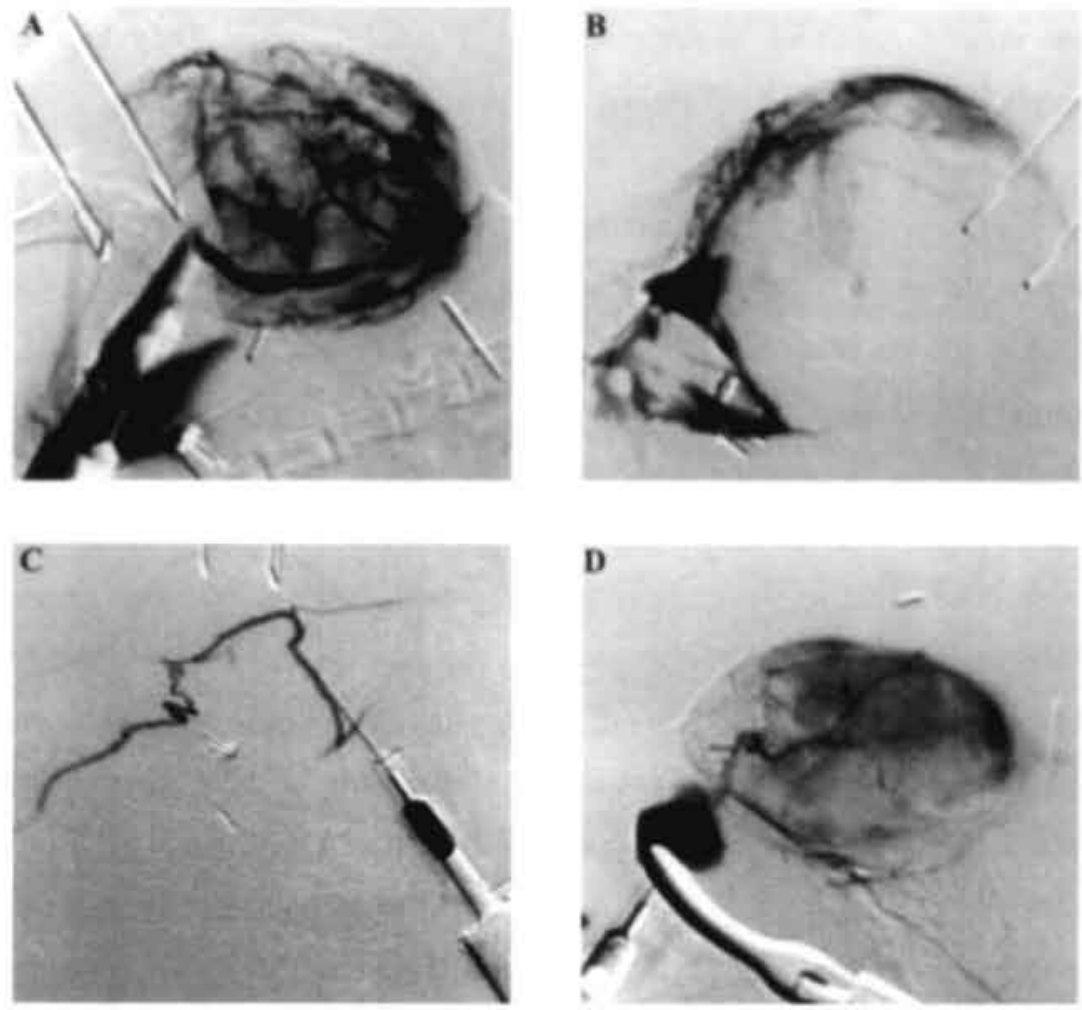

Figure II.2.2. Angiographic images (with digital subtraction of the body-background) of large sized rhabdomyosarcomas growing s.c. in the flank of WAG/Rij rats. They were randomly selected and representative for the imaging of tumour vascularity in control and combreAp treatment condition. A, Control, non-treated, tumour showing the wealth of 'abnormal' blood vessels. B, Image obtained at 6 hours after the combreAp treatment (25 $\mathrm{mg} / \mathrm{kg}$ ). A decrease in size and in number of the blood vessels was observed. C, Angiographic screening of tumours at 3 days after the combreAp injection revealed very poor vascularity, present only in the peripheral area. The remaining vessels had a reduced diameter and showed an irregular morphology. D, At 10 days after combreAp treatment, characteristic features of newly-formed vessel-morphology were seen. Compared with the images obtained at the 3 days time-interval, an increase in number of blood vessels was present.

At 3 hours after drug administration, a slightly reduced number of vessels was seen in the periphery and towards the center. These blood vessels showed an irregular shape as well as a reduction in diameter. At 6 hours a clear decrease in number and size of blood vessels was observed and they were found to be irregular (Figure II.2.2.B). At both time-intervals, a back-pressure was present during the injection of the contrast medium. Screening the rhabdomyosarcomas at 1 day after the combreAp 
treatment revealed similar pictures as those at 6 hours. Blood vessels were, however, now present only in the peripheral area. The images obtained at 3 days after drug injection showed that vascularity was absent in the major part of the tumour and that few vessels remained at the periphery (Figure II.2.2.C). They had an irregular morphology and reduced diameter.

The histopathological examination of control rhabdomyosarcomas showed for all sizes a majorly cellular tumour with numerous actively dividing cells (Figure II.2.3.A and B). Blood vessels were rather abundant and randomly located, showing a normal morphology. Sections of medium to very large control tumours $\left(>3 \mathrm{~cm}^{3}\right)$ revealed areas of necrosis dispersed in the centre as well as in the periphery. The blood vessels adjacent to these necrotic tumour parts were dilated. After injection of a single dose of $25 \mathrm{mg} / \mathrm{kg}$ combreAp, the picture promptly changed. Apart from the blood vessels present in the periphery of the tumour, dilatation and congestion were observable at $3 \mathrm{~h}$ post-injection of combreAp. Moreover, several small foci of fresh necrosis were present in the potentially viable parts of the tumours. After $6 \mathrm{~h}$, the necrotic foci were larger and started to merge. After 1 day, the whole tumour showed extensive necrosis, except for a very narrow rim of potentially viable tumour cells. The blood vessels that were present in the peripheral rim showed no abnormalities. Just beneath this rim, small hemorrhagic zones were seen. Vessel wall interruption and endothelial cell damage were present in the necrotic area. At 2 and 3 days after combreAp injection, the rim of potentially viable tumour was even thinner and the hemorrhagic/necrotic area practically occupied the whole tumour volume (Figure II.2.3.C and D): at this time interval, no bleeding was present when the tumours were transsected. Analysis of the rhabdomyosarcoma tumours with volumes less than $3 \mathrm{~cm}^{3}$ indicated that the combreAp-induced effects were quantitatively less than those described for the larger tumours: the ratio of induced necrosis to the viable looking areas was less than with the larger rhabdomyosarcomas. The time-scale for presenting any vascular damage with subsequent necrosis was however again the same as described in detail above. 

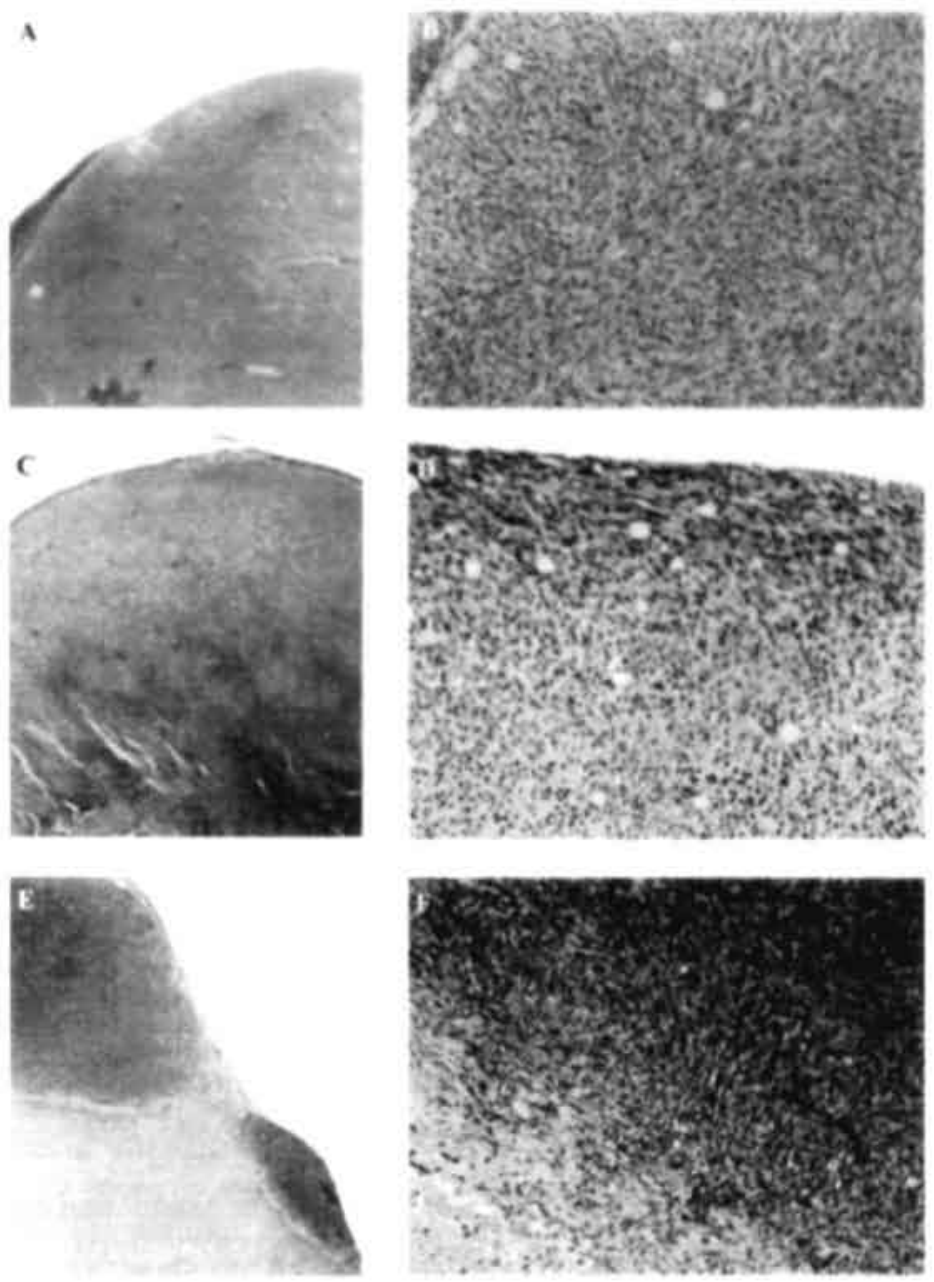

Figure II.2.3. Vascular targeting effect with combreAp in rat rhabdomyosarcomas. Photographs are representative of the tissue changes in large tumours, as observed at day 2.3 (panels $\boldsymbol{C}$ and $\boldsymbol{D}$ ) and at day 10-1/ (panels $\boldsymbol{E}$ and $\boldsymbol{F}$ ) following a single i.p. injection of 25 $m g / k g$ combreAp. The pannels $\boldsymbol{A}$ and $\boldsymbol{B}$ are microscopic images of control ( no combreAp ) tumours. The paraffin embedded tumour tissue slices are stained with hematoxilin/eosin. Magnifications are $x 10$ (panels A, C and E) or $x 100$ (panels B, D and F).

The strong anti-tumour effects observed in the large and very large tumours, after the single combreAp injections and with three different techniques, were however not permanent. Subsequent to the period of reduced growth rate, a renewed increase in size was measured in these tumours, at a rate similar to the tumour growth observed in the control groups (Figure II.2.1.A and B). This regrowth is also clearly 
blood vessels and their endothelial cells, with more specifically the inhibition of tubulin polymerisation. Apoptotic death has been demonstrated in vitro with normal human umbilical vein endothelium [29]. More details about the action mechanisms of combreAp specifically in tumour blood vessels remain to be unravelled, and further discussion of this aspect is beyond the scope of the present paper.

Recently, using transplanted tumours in mice, several laboratories have shown that a single administration of combreAp induced a vascular shutdown as soon as 6 to $12 \mathrm{~h}$ after injection, with subsequently the formation of hemorrhagic necrosis [24-26, 30]. To our knowledge, all of these reported in vivo data involve the treatment of very small rodent tumour models. It is obviously important to screen, when possible, the activity of such a compound in larger tumours of any type. In radio- and chemotherapy it is firmly documented that a differential anti-tumour effectivity exists, and this for different reasons, with respect to tumour size at treatment time.

Our investigations, using the established rat rhabdomyosarcoma cancer model, are intriguing in that they illustrate the dramatic change in growth pattern from combreAp relative to the tumour volume at the time of treatment. With the very small and small rhabdomyosarcomas, respectively no or a borderline significant growth delay was measured. This result is similar to the published very small mouse tumour data, wherewith also no growth delay was seen at a systemically non-toxic combreAp dose $[25,26,30]$. However, as the rhabdomyosarcoma tumour volume at the time of the combreAp injection was larger ( $\gg 3 \mathrm{~cm}^{3}$ ), the growth delay became more important. For instance, the difference in delay with the rhabdomyosarcoma between the small $\left(1-3 \mathrm{~cm}^{3}\right)$ to very small $\left(<1 \mathrm{~cm}^{3}\right)$ and the very large $\left(>14 \mathrm{~cm}^{3}\right)$ tumours is respectively 8 - and 17 -fold. With the latter tumour size, even a significant shrinkage was measured rapidly after the combreAp injection (see Figure II.2.2.B). This 'inverse' volume-response relation (compared with e.g. radio- or chemotherapy) could be expected, if one accepts that the corollary presence of newly acquired blood vessels increases with the size of the tumour. This implies at first glance that larger tumours may have proportionately more ill-formed and eventually combreAp sensitive vasculature than small tumours, that initially have their nutrient supply through the peripheral and the co-opted host vasculature [6, 31]. A further and strong impairment of the already inadequate blood supply due to combreAp activity will 
consequently stop tumour growth and may lead to tumour growth retardation, as is clearly demonstrated in the present study specifically with the tumours larger than 7 $\mathrm{cm}^{3}$.

Digital subtraction angiography was performed with an iodinated contrastmedium and with image analysis, available as a standard in neuroradiology and interventional radiology, to evaluate the overall blood vessel changes. The applied intra-operative technique avoids the dilution of the contrast medium in the total body circulation, which occurred when we used injections in the tail vein. The angiographic images obtained at $3 \mathrm{~h}$ after the combreAp injections already showed effects on the tumour vascularity. At later time-intervals (up to 3 days) reduction in vessel diameter, changes in morphology and extensive loss of blood vessels within the tumour were obvious. The histopathologic microscopy observations of tumour slices were in agreement with these findings, with the first signs of vascular damage (dilation and congestion) being clearly detectable at $3 \mathrm{~h}$ post-injection. At $6 \mathrm{~h}$ after the combreAp treatment, evidence of damage of blood vessels and endothelium was detectable with the microscopic analysis. An obvious deduction from the combination of the two clinico-analytical approaches is the relation between the 'disappearance' of blood vessels and the increase in necrosis, both phenomena clearly present 1 day after the combreAp treatment. The early presence of tissue changes was histopathologically also observed in the smaller rhabdomyosarcomas, similar to the reports on small mouse tumour models which documented acute vascularity changes and blood flow reductions $[12,24,26]$. Such an acute manifestation of necrosis has separately been reported with experiments involving mouse tumours treated with flavone acetic acid (FAA) [20]. A strong reduction in tumour blood flow, indicative for vessel damage, was measured within 4-6 hours after the FAA administration [16, 21, 33]. The overall pattern of the combreAp-induced necrosis, being preceded by vascular defects, also resembles the anti-tumour effects observed with tumour necrosis factor- $\alpha$. Both Baguley and colleagues [20] and Mahadevany et al. [33] discussed the tumour necrosis factor- $\alpha$ involvement when analysing the anti-tumour effects of FAA as measured in their biological systems. Anyhow, the straightforward relation between the severity of vascular shutdown and the anti-tumour effect seems obvious. Indeed, a significant growth delay was only obtained following a temporary clamping of tumour blood supply for 12-14 hours, whereas 1-2 hours occlusion induced little tumour 
blood vessels and their endothelial cells, with more specifically the inhibition of tubulin polymerisation. Apoptotic death has been demonstrated in vitro with normal human umbilical vein endothelium [29]. More details about the action mechanisms of combreAp specifically in tumour blood vessels remain to be unravelled, and further discussion of this aspect is beyond the scope of the present paper.

Recently, using transplanted tumours in mice, several laboratories have shown that a single administration of combreAp induced a vascular shutdown as soon as 6 to $12 \mathrm{~h}$ after injection, with subsequently the formation of hemorrhagic necrosis [24-26, 30]. To our knowledge, all of these reported in vivo data involve the treatment of very small rodent tumour models. It is obviously important to screen, when possible, the activity of such a compound in larger tumours of any type. In radio- and chemotherapy it is firmly documented that a differential anti-tumour effectivity exists, and this for different reasons, with respect to tumour size at treatment time.

Our investigations, using the established rat rhabdomyosarcoma cancer model, are intriguing in that they illustrate the dramatic change in growth pattern from combreAp relative to the tumour volume at the time of treatment. With the very small and small thabdomyosarcomas, respectively no or a borderline significant growth delay was measured. This result is similar to the published very small mouse tumour data, wherewith also no growth delay was seen at a systemically non-toxic combreAp dose $[25,26,30]$. However, as the rhabdomyosarcoma tumour volume at the time of the combreAp injection was larger $\left(\gg 3 \mathrm{~cm}^{3}\right)$, the growth delay became more important. For instance, the difference in delay with the rhabdomyosarcoma between the small $\left(1-3 \mathrm{~cm}^{3}\right)$ to very small $\left(<1 \mathrm{~cm}^{3}\right)$ and the very large $\left(>14 \mathrm{~cm}^{3}\right)$ tumours is respectively 8 - and 17 -fold. With the latter tumour size, even a significant shrinkage was measured rapidly after the combreAp injection (see Figure II.2.2.B). This 'inverse' volume-response relation (compared with e.g. radio- or chemotherapy) could be expected, if one accepts that the corollary presence of newly acquired blood vessels increases with the size of the tumour. This implies at first glance that larger tumours may have proportionately more ill-formed and eventually combreAp sensitive vasculature than small tumours, that initially have their nutrient supply through the peripheral and the co-opted host vasculature $[6,31]$. A further and strong impairment of the already inadequate blood supply due to combreAp activity will 
consequently stop tumour growth and may lead to tumour growth retardation, as is clearly demonstrated in the present study specifically with the tumours larger than 7 $\mathrm{cm}^{3}$.

Digital subtraction angiography was performed with an iodinated contrastmedium and with image analysis, available as a standard in neuroradiology and interventional radiology, to evaluate the overall blood vessel changes. The applied intra-operative technique avoids the dilution of the contrast medium in the total body circulation, which occurred when we used injections in the tail vein. The angiographic images obtained at $3 \mathrm{~h}$ after the combreAp injections already showed effects on the tumour vascularity. At later time-intervals (up to 3 days) reduction in vessel diameter. changes in morphology and extensive loss of blood vessels within the tumour were obvious. The histopathologic microscopy observations of tumour slices were in agreement with these findings, with the first signs of vascular damage (dilation and congestion) being clearly detectable at $3 \mathrm{~h}$ post-injection. At $6 \mathrm{~h}$ after the combreAp treatment, evidence of damage of blood vessels and endothelium was detectable with the microscopic analysis. An obvious deduction from the combination of the two clinico-analytical approaches is the relation between the 'disappearance' of blood vessels and the increase in necrosis, both phenomena clearly present 1 day after the combreAp treatment. The early presence of tissue changes was histopathologically also observed in the smaller rhabdomyosarcomas, similar to the reports on small mouse tumour models which documented acute vascularity changes and blood flow reductions $[12,24,26]$. Such an acute manifestation of necrosis has separately been reported with experiments involving mouse tumours treated with flavone acetic acid (FAA) [20]. A strong reduction in tumour blood flow, indicative for vessel damage, was measured within 4-6 hours after the FAA administration [16, 21, 33]. The overall pattern of the combreAp-induced necrosis, being preceded by vascular defects, also resembles the anti-tumour effects observed with tumour necrosis factor- $\alpha$. Both Baguley and colleagues [20] and Mahadevany et al. [33] discussed the tumour necrosis factor- $\alpha$ involvement when analysing the anti-tumour effects of FAA as measured in their biological systems. Anyhow, the straightforward relation between the severity of vascular shutdown and the anti-tumour effect seems obvious. Indeed, a significant growth delay was only obtained following a temporary clamping of tumour blood supply for 12-14 hours, whereas 1-2 hours occlusion induced little tumour 
growth changes [34]. It seems clear that the suppression of rhabdomyosarcoma tumour growth by combreAp is majorly the result of a selective targeting of the acquired tumour neo-vasculature. This is consistent with the fact that the absolute tumour volume, and inherently the absolute number of tumour cells depending on these established ill-formed blood vessels for their survival, seems to be an important parameter determining the growth delay after treatment. Also, larger tumours inherently may have more newly formed blood vessels which can be abberant in structure and functionality and thus more vulnerable for such agents. A correlation between small and large rhabdomyosarcomas and their vasculature may be indirectly deducible from the comparison of our results obtained with anti-angiogenesis treatment in the same tumour model [36] and the present combreAp data. With the use of TNP-470, a fumagillin analogue and specific angiogenesis inhibitor, growth delays were more pronounced in tumours smaller than $7 \mathrm{~cm}^{3}$. This opposes, with regard to tumour volume, to the effect seen with the combreAp administration. Both these observations taken together may demonstrate the differential aspect of tumour sizerelated vascular quality ( and quantity).

It could also be hypothesized that the combreAp finds activation through hypoxia, present to a much greater extent in large tumours as compared with those smaller than $3 \mathrm{~cm}^{3}$. It may be worthy to think about this possibility, since we earlier showed with the same tumour model that only tumours larger than $4-5 \mathrm{~cm}^{3}$, having a sufficient amount of severe hypoxia / necrosis, could be colonised with anaerobic bacteria [32]. The possibility for such an inter-related activation will be investigated.

Finally, some direct cytotoxic effect of combreAp towards the tumour cell population, as indicated in the recent literature for some tumour cell types $[25,30$, 35], may have to be taken into account in our in vivo rhabdomyosarcoma studies.

The present data describing the influence of tumour size on the outcome of vascular targeting treatment, may be compared with only a few other studies. Indications for a similar size-response relationship have to our knowledge only been suggested for hyperthermia and for FAA treatments [15, 16]. In some of these experiments, the effect of treatment was also less with very small tumours as compared with relatively larger ones. However, the use of these agents at their respective anti-cancer effectivity was hampered by severe side-effects. The absence of obvious systemic toxicity related to the combreAp dosage and injection site, used in our investigations, are therefore an additional advantage. The rats maintained normal 
activity. with no evidence of bleeding, diarrhea, or skin lesions at the tumour transplantation or injection site. The absence of normal tissue injury in parallel with strong tumour cell kill has been quoted by other research groups using various mouse tumour models [24-26, 30].

In view of the absence of systemic side-effects, the overall research with combreAp encourages the use of such tumour vessel targeting drugs as a novel cancer treatment modality, specifically for large tumours. With the present rhadomyosarcoma tumour model, a clear-cut measurable 'inverse' tumour volume versus response relation with combreAp injection is demonstrated. Also the double combreAp treatment indicates this positive volume-dependent growth delay effect. The data furthermore demonstrate that even tumours smaller than $3 \mathrm{~cm}^{3}$ can be significantly inhibited in growth with an appropriately scheduled repeat injection of combreAp. This is at first surprising as well as promising since traditional anti-cancer therapies, such as radiotherapy and chemotherapy, are less effective on large solid tumours than on small ones [37, 38].

It is obvious that, since a single combreAp treatment is not curative on its own, a combined strategy with e.g. radiotherapy and/or chemotherapeutic drugs will be necessary to improve tumour control. Pilot experiments involving the mouse CaNT tumour model, with either irradiation or with cis-Platinum in combination with combreAp, provide a positive indication [30].

Corroborating the results described herein with the rhabdomyosarcoma tumour model, it is conceivable that patients who present with large inoperable solid tumours or who relapse after other treatments, may benefit from a vasculature targeting treatment. At present phase I trials with combreAp treatments are ongoing in Europe and the USA, of which the results are eagerly awaited.

\section{II.2.5. References}

1. Denekamp J. Review article: Angiogenesis, neovascular proliferation and vascular pathophysiology as targets for cancer therapy. Br J Radiol 66: 181-196 (1993).

2. Denekamp J. Vascular endothelium as the vulnerable element in tumours. Acta Radiol Oncol 23: 217-225 (1984).

3. Folkman J. The role of angiogenesis in tumor growth. Semin Cancer Biol 3: 65-71 (1992). 
4. Folkman J. What is the evidence that tumors are angiogenesis dependent? J Natl Cancer Inst 82: 4-6 (1990).

5. Folkman J. Tumor angiogenesis: therapeutic implications. New Engl J Med 285: 1182 1186 (1971).

6. Hanahan D. A flanking attack on cancer. Nature Medicine 4: I3-14 (1998).

7. Sipos EP, Tamargo RJ, Weingart JD, Brem H. Inhibition of tumor angiogenesis. Ann NY Acad Sci 732: 263-272 (1994).

8. Auerbach W, Auerbach R. Angiogenesis inhibition: a review. Pharmacol Ther 63: 265311 (1994).

9. Molema G, Griffioen AW. Rocking the foundations of solid tumor growth by attacking the tumor's blood supply. Trends Immunol Today 19; 392-394 (1998).

10. Barinaga M. Designing therapies that target tumor blood vessels. Science 275 : $482-484$ (1997).

11. O'Reilly MS, Holmgren L, Chen C, Folkman J. Angiostatin induces and sustains dơmancy of human primary tumors in micê. Natufể Med 2: 689-692 (1996).

12. Chaplin DJ, Pettit GR, Parkins CS, Hill, S.A. Antivascular approaches to solid tumours therapy: evaluation of tubulin binding agents. Br J Cancer 74: S86-S88 (1996).

13. Baguley BC, Calveley SB, Crowe KK, Fray LM, O'Rourke SA, Smith, GP. Comparison of the effects of flavone acetic acid, fostriecin and homoharringtonine and tumour necrosis factor- $\alpha$ on colon 38 tumours in mice. Eur J Cancer Clin Oncol 25: 263-269 (1989).

14. Song CW. Effect of local hyperthermia on blood flow and microenvironment: a review. Cancer Res 44: 4721s-4730s (1984).

15. Reinhold HS, Zurcher C, Van den Berg-Blok AE. Differential heat sensitivity of tumour microvasculature. Eur J Cancer 26: $541-543$ (1990).

16. Hill S, Williams KB, Denekamp J. Vascular collapse after flavone acetic acid: a possible mechanism of its anti-tumour action. Int J Cancer Clin Oncol 25: 1419-1424 (1989).

17. Watanabe N. Niitsu Y, Umeno H. Kuriyama H, Neda H, Yamanchi N, Maeda M, Urushizaki I. Toxic effect of tumour necrosis factor on tumour vasculature in mice. Cancer Res 48: 2179-2183 (1988).

18. Burrows FJ. Thorpe PE. Eradication of large solid tumors in mice with an immunotoxin directed against tumor vasculature. Proc Natl Acad Sci USA 90: 8996-9000 (1993).

19. Seon BK, Matsuno F, Haruta Y, Kondo M, Barcos M. Long-lasting complete inhibition of human solid tumors in SCID mice by targeting endothelial cells of tumor vasculature with antihuman endoglin immunotoxin. Clin Cancer Res: 1031-1044 (1997). 
20. Baguley BC, Holdaway KM. Thomsen L. Zhuang L Zwi LJ. Inhibition of growth of colon 38 adenocarcinoma by vinblastine and colchicine: evidence for a vascular mechanism. Eur J Cancer 27: 482-487 (1991).

21. Hill SA, Sampson LE, Chaplin DJ. Anti-vascular approaches to solid tumor therapy: evaluation of vinblastine and flavone acetic acid. Int J Cancer 63: 119-123 (1995).

22. Pettit GR, Singh SB, Boyd MR, Hamel E, Pettit RK, Schmidt JM, Hogan F. Antineoplastic agents 291. Isolation and synthesis of combretastatins A-4, A-5 and A-6. J Med Chem 291: 1666-1672 (1995).

23. Lin CM, Singh SB, Chu PS, Dempcy RO, Schmidt JM, Pettit GR, Hamel E, Interactions of tubulin with potent natural and synthetic analogs of the antimitotic agent combretastatin: a structure-activity study. Mol Pharmacol 34: 200-208 (1988).

24. Dark GG. Hill SA, Prise VE, Tozer GM. Pettit GR, Chaplin, DJ. Combretastatin A-4, an agent that displays potent and selective toxicity toward tumor vasculature. Cancer Res 57: $1829-1834$ (1997).

25. Lingyun L, Rojiani A, Siemann DW. Targeting the tumor vasculature with combretastatin A-4 disodium phosphate: effects on radiation therapy. Int J Radiat Oncol Biol Phys 42: 899-903 (1998).

26. Horsman MR, Ehrnrooth E, Ladekarl M, Overgaard J. The effect of combretastatin A-4 disodium phosphate in a $\mathrm{C}_{3} \mathrm{H}$ mouse mammary carcinoma and a variety of murine spontaneous tumors. Int J Radiat Oncol Biol Phys 42: 895-898 (1998).

27. Hermens AF, Barendsen GW. Cellular proliferation patterns in an experimental rhabdomyosarcoma in the rat. Eur J Cancer 3: $361-369$ (1967).

28. Dorr RT, Dvorakova K, Snead K, Alberts DS, Salmon SE, Pettit GR. Antitumor activity of combretastatin A-4 phosphate, a natural product tubulin inhibitor. Invest New Drugs 14: 131-137 (1996).

29. Iyer S, Chaplin DJ, Rosenthal DS, Boulares AH, Li LY, Smulson ME. Induction of apoptosis in proliferating human endothelial cells by the tumor-specific antiangiogenesis agent combretastatin A-4. Cancer Res 58: $4510-4514$ (1998).

30. Chaplin DJ. Pettit GR, Hill SA. Anti-vascular approaches to solid tumour therapy: evaluation of combretastatin A-4 phosphate. Anticancer Res 19: 189-196 (1999).

31. Denekamp J. Dasu A. Waites A. Vasculature and microenvironmental gradients: the missing links in novel approaches to cancer therapy? Advan Enzyme Regul 38: 281-299 (1998).

32. Lambin P, Theys J, Landuyt W, Rijken P, Van der Kogel A, van der Schueren E, Hodgkins R. Fowler J, Nuyts S, de Bruijn E, Van Mellaert L, Anné J. Colinisation of Clostridium in the body is restricted to hypoxic and nectrotic areas of tumours. Anaerobe 4: $183-188$ (1998). 
33. Mahadevany MS, Meager A, Fiers W, Lewis GP, Hart IR. Role of tumor necrosis factor in flavone acetic acid induced vascular shutdown. Cancer Res 50: 5537-5542 (1990).

34. Denekamp J, Hill SA, Hobson B. Vascular occlusion and tumour cell death. Eur J Cancer Clin Oncol 19: 271-275 (1983).

35. El-Zayat AAE, Degen D, Drabek S, Clark GM, Pettit GR, Von Hoff DD. In vitro evaluation of the antineoplastic activity of combretastatin A-4, a natural product from Combretum caffrum (arid shrub). Anti-Cancer Drugs 4: 19-25 (1993).

36. Landuyt W, Theys J, Nuyts S, Drijkoningen M, Fowler J, Reijnders A, Liekens S, Neyts J, de Bruijn E, Anné J, Lambin Ph. Effect of TNP-470 (AGM-1470) on the growth of rat rhabdomyosarcoma tumors with different sizes. Cancer Invest accepted (1999).

37. Lambin Ph, Kramar A, Haie-Meder C, Castaigne D, Scalliet P, Bouzy J, Malaise E-P, Gerbaulet A. Tumour size in cancer of the cervix. Acta Oncol 37: 729-734 (1998).

38. Dubben H-H, Thames HD, Beck-Bomholdt H-P. Tumor volume: a basic and specific response predictor in radiotherapy. Radiother Oncol 47: 167-174 (1998). 


\section{Chapter III}

III.1. In vivo anti-tumour effect of vascular targeting combined with either ionizing radiation or anti-angiogenesis treatment

Published in : Int. J. Radiat. Oncol. Biol. Phys. 49: 443-450, 2001

Willy Landuyt, Bisan Ahmed, Sandra Nuyts, Jan Theys, Michel Op de Beeck, Alex Reijnders, Jozef Anné, Allan van Oosterom, Walter Van den Bogaert and Philippe Lambin 


\section{Summary}

Interference with the tumor blood vessels through anti-angiogenesis or vascular targeting can suppress tumor growth. Vascular targeting of solid tumors, using tubulin compromizing agents, seems a promising and selective novel treatment. We aimed to evaluate the potential (hypothesis-based) benefit from combinations of vascular targeting with combretastatin A-4 phosphate (combreAp) and either ionizing radiation or anti-angiogenesis.

Rhabdomyosarcoma tumor pieces were inplanted subcutaneously (s.c.) in the flank region of syngeneic adult WAG/Rij rats. Tumors were grown until different sizes, between small $\left(<3 \mathrm{~cm}^{3}\right)$ and large $\left(7-14 \mathrm{~cm}^{3}\right)$, and stratified for the different treatment groups. CombreAp was injected intraperitoneally: injections of TNP-470 were s.c. in the neck area. Localized single dose ( $8 \mathrm{~Gy}$ ) irradiations of tumors were done under Nembutal anesthesia, always 1 day prior a single combreAp $(25 \mathrm{mg} / \mathrm{kg}$ ) injection. The TNP-470 treatment ( 3 times $30 \mathrm{mg} / \mathrm{kg}$ in I week) started I day after a double ( 8 days interval between both) combreAp administration. Tumor responses were evaluated by the growth delay assay and statistical significancy of tumor growth changes was computed.

Large tumors responded better to combreAp treatment than did the smaller ones. Combining irradiation with combreAp resulted in a tumor size-dependent growth delay. With small and medium tumor volumes, a similar response was measured after the combination treatment when compared with irradiation only. Large tumors however showed a strong (at least additive) increase of the growth delay with the combined therapy. The difference in tumor growth between the two treatment groups was very significant $(p<0.0001)$.

When TNP-470 was combined with combreAp, no significant lengthening of the growth delay was present, irrespective of the tumor size.

The current data show a significant advantage from the combination of combreAp with irradiation in rhabdomyosarcomas having a large size $\left(7-14 \mathrm{~cm}^{3}\right)$ at treatment. Such a benefit in tumor response was not observed with the smaller tumors, seemingly because irradiation as such was very effective. No significant gain in growth delay was observed when TNP-470 was added to the combreAp treatment. This presumebly reflex only little angiogenesis during the first week of rhabdomyosarcoma regrowth after the combreAp treatment. 


\section{III.1.1. Introduction}

Tumors require blood vessels for nutrient and oxygen supply to maintain their viability. In the first time-stage of growth, this demand is anticipated by the cooptation of host vasculature. To continue tumoral expansion, the formation of additional blood supply is a prerequisite $[1,2]$. The presence of these morphologically and functionally abnormal blood vessels makes vascular targeting an attractive approach in anti-cancer treatment [reviewed by e.g. 3, 4]. Tubulin binding agents were identified to exert anti-vascular activity in solid tumors, though not without some morbidity $[5,6]$. Recent experiments involving the combretastatin A-4 family, compounds that interfere with the tubulin polymerisation, provided evidence for in vivo anti-tumor effectivity at systemically non-toxic doses [e.g. 7, 8]. It is at this point relevant to state that the magnitude of effectiveness of the combretastatin A-4 phosphate (combreAp) can be related to the tumor size. Tumor size has been discussed to be an important determinant in the tumor response to a specific treatment [e.g. 9, 10]. Using specifically combreAp, an 'inverse' volume-response relation (with respect to radio- or chemotherapy) has been demonstrated with a single injection, at least in the rat rhabdomyosarcoma tumor model [11]. Longer growth delays were measured with large tumors $\left(>7 \mathrm{~cm}^{3}\right)$ as compared with those that measured less than $3 \mathrm{~cm}^{3}$ at the start of the treatment. Notwithstanding a major necrosis induction, this vascular targeting treatment did not result in a complete tumor response [e.g. 7, 11]. To find an improvement of the anti-tumor response, we now examined the effect from combinations of combreAp with two basically and mechanistically different treatment modalities.

The first series of experiments combined combreAp vascular targeting with ionizing radiation for treatment of rat rhabdomyosarcomas. We hypothesized to obtain a (supra-)additive anti-tumor response with the combined direct (irradiation) and indirect (combreAp) cytotoxic effect. It was assumed that the proliferating tumor cells, predominantly present in the peripheral host vessel-irrigated region of the tumor, should be most vulnerable for ionizing radiation. The combreAp on the other hand should induce, as the result of collapse of the post-angiogenesis intra-tumoral vascularity, a cascade of indirect tumor cell death including the killing of hypoxic, radioresistant cells. Based on this hypothesis, we further assumed to obtain an 
important advantage with tumors having large sizes and inherently more hypoxic areas at the start of the combination treatment.

In the second part of the investigations we assumed that the tumor regrowth following the combreAp treatment would be parallelled by a renewed angiogenesis. Blocking the latter process would than result in a further arrest of tumor growth. Indeed the more established anti-angiogenesis compounds, including the synthetic fumagillin analogue TNP-470, were demonstrated to interfere to a variable degree with tumor growth [reviewed by e.g. 12, 13]. TNP-470 was therefore in the present study given in conjunction with the combreAp treatment. Again we incorporated the question of tumor size-dependent effectiveness of this combination strategy. The selection of TNP-470 was related to our previous experience with this compound in the rat rhabdomyosarcoma tumor model [14].

In general, the data presented thus aimed to demonstrate an improvement of the combreAp vascular targeting treatment from the combination with either ionizing radiation or TNP-470 anti-angiogenesis and to eventually relate the results with the tumor volume.

\section{III.1.2. Materials and methods}

\section{In vivo tumor model}

Male adult WAG/Rij rats, weighing at least $270 \mathrm{~g}$, were used for all the present experiments. The animals were housed 4 per cage and had food and water ad libitum. The syngeneic rhabdomyosarcoma, at its origin an X-ray induced jaw muscle tumor [15], was implanted subcutaneously (s.c.) in the lower flank of lightly ether anesthetized animals. Pieces of about $1 \mathrm{~mm}^{3}$ were used in the sequential series for at most 10-12 passages, whereafter transplantation was restarted from the frozen cellstocks.

Treatment was initiated when tumours reached the predetermined size: either $1-3 \mathrm{~cm}^{3}, 3-7 \mathrm{~cm}^{3}$ or $7-14 \mathrm{~cm}^{3}$; these sizes are referred to respectively as small, medium and large.

After the start of any treatment, rats were weighed regularly and the mean body weights were compared with those for the appropriate single agent controls including a batch of untreated tumor-bearing rats. 
All experimental conditions have been approved by the ethical committee of the University of Leuven, in compliance with the national guidelines on animal research.

\section{Drug treatment}

The vascular targeting compound combretastatin A-4 phosphate (combreAp) was obtained from OXiGENE, Lund, Sweden, and stored at $4{ }^{\circ} \mathrm{C}$. Immediately prior intraperitoneal (i.p.) injection, it was dissolved in $0.9 \%$ saline. A dose of $25 \mathrm{mg} / \mathrm{kg}$ was used, a selection based on our previous toxicity evaluation [11].

The angiogenesis inhibitor TNP-470, synthesized by Takeda Chemical Industries, Japan, was kept at $-20^{\circ} \mathrm{C}$, and solutions were freshly prepared before use in $10 \%$ ethanol $/ 5 \%$ arabic gum in saline. Injections of $30 \mathrm{mg} / \mathrm{kg}$ each were s.c. in the neck area of the rats; the dosage was based on previous TNP-470 experience in WAG/Rij rats [14].

\section{Radiation treatment}

Local tumor irradiation, with the remainder of the body adequately shielded, was done with a linear accelerator (Saturne 42, General Electrics) using a 18 megavolt beam and a dose-rate of $3 \mathrm{~Gy} / \mathrm{min}$. Dosimetry was performed in treatment condition. A perspex tissue-equivalent plate of $2.5 \mathrm{~cm}$ thickness was placed above the tumors. To allow a correct positioning of the tumor, rats were anesthetized with sodium pentobarbital (Nembutal. $0.1 \mathrm{ml} / 100 \mathrm{~g}$ body weight).

\section{Treatment protocols and response evaluation}

\section{(1) CombreAp plus ionizing radiation:}

CombreAp was given as a single i.p. injection $(25 \mathrm{mg} / \mathrm{kg})$ and combined with a single radiation dose of $8 \mathrm{~Gy}$, given 1 day prior the combreAp.

(2) CombreAp plus TNP-470:

For the different pre-selected tumor sizes, combreAp was injected i.p. (25 $\mathrm{mg} / \mathrm{kg}) 2$ times (days 0 and 8 ). The TNP-470 (30 mg/kg) was given s.c. 3 times during 7 days, starting one day after the second combreAp injection (days 9, 12 and 15).

The response of rat rhabdomyosarcoma to the various treatments was evaluated by the classical tumor growth assay. Using calipers, tumors were measured 2-3 times per 
week, and volumes were calculated as $[(\mathrm{a} \times \mathrm{b} \times \mathrm{c}) \times \pi / 6]$ where $\mathrm{a}, \mathrm{b}$ and $\mathrm{c}$ are orthogonal dimensions. Tumor growth delay time was derived from the mean growth curves.

Computed analysis to differentiate between the treatment groups was performed using 'Generalized Linear Models'based on the asymptotic chi-squared distribution of the likelihood ratio statistics. Values of $\mathrm{p}<0.05$ were considered as significant difference.

\section{III.1.3.Results}

Most of the combination experiments indicated the absence of a body weight reduction when compared with the use of either agent alone. Only in the series combining the double combreAp ( $2 \times 25 \mathrm{mg} / \mathrm{kg}$ i.p.) and the triple TNP-470 ( $3 \times 30$ $\mathrm{mg} / \mathrm{kg} \mathrm{s.c.)} \mathrm{at} \mathrm{most} \mathrm{a} \mathrm{body} \mathrm{weight} \mathrm{loss} \mathrm{of} 10-15 \%$ was recorded. This reduction lasted for about 2-3 weeks in some animals, before recovery in body weight was measured.

\section{(1) CombreAp plus ionizing radiation effect:}

Figure III.1.1 (A, B and C) illustrates the growth pattern of rat rhabdomyosarcoma treated with combreAp alone $(25 \mathrm{mg} / \mathrm{kg}$ ), single dose irradiation ( $8 \mathrm{~Gy}$ ) alone and combreAp combined with irradiation, including the growth in untreated condition. The treatments were evaluated in tumors with the various pre-selected volumes ranging between 1 and $14 \mathrm{~cm}^{3}$, and these experiments were carried out two times independently.

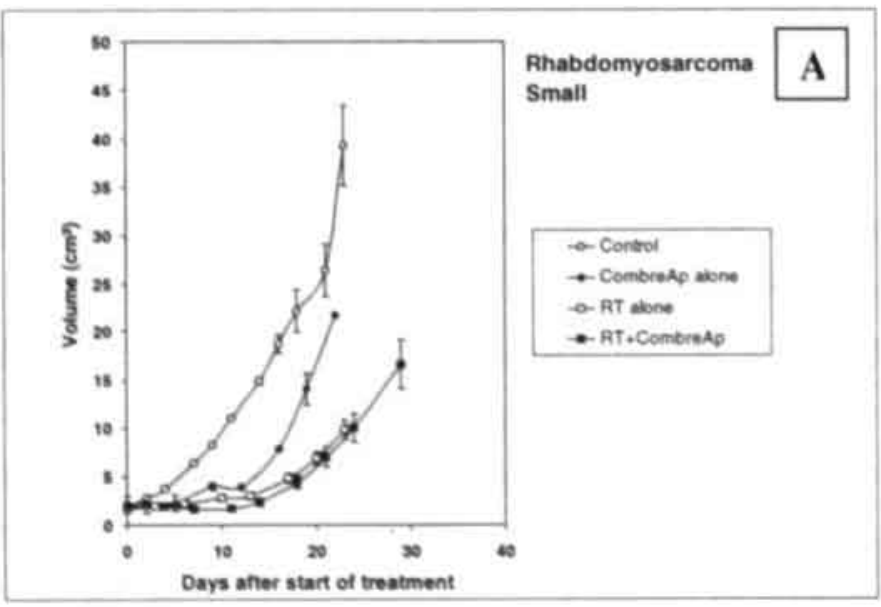



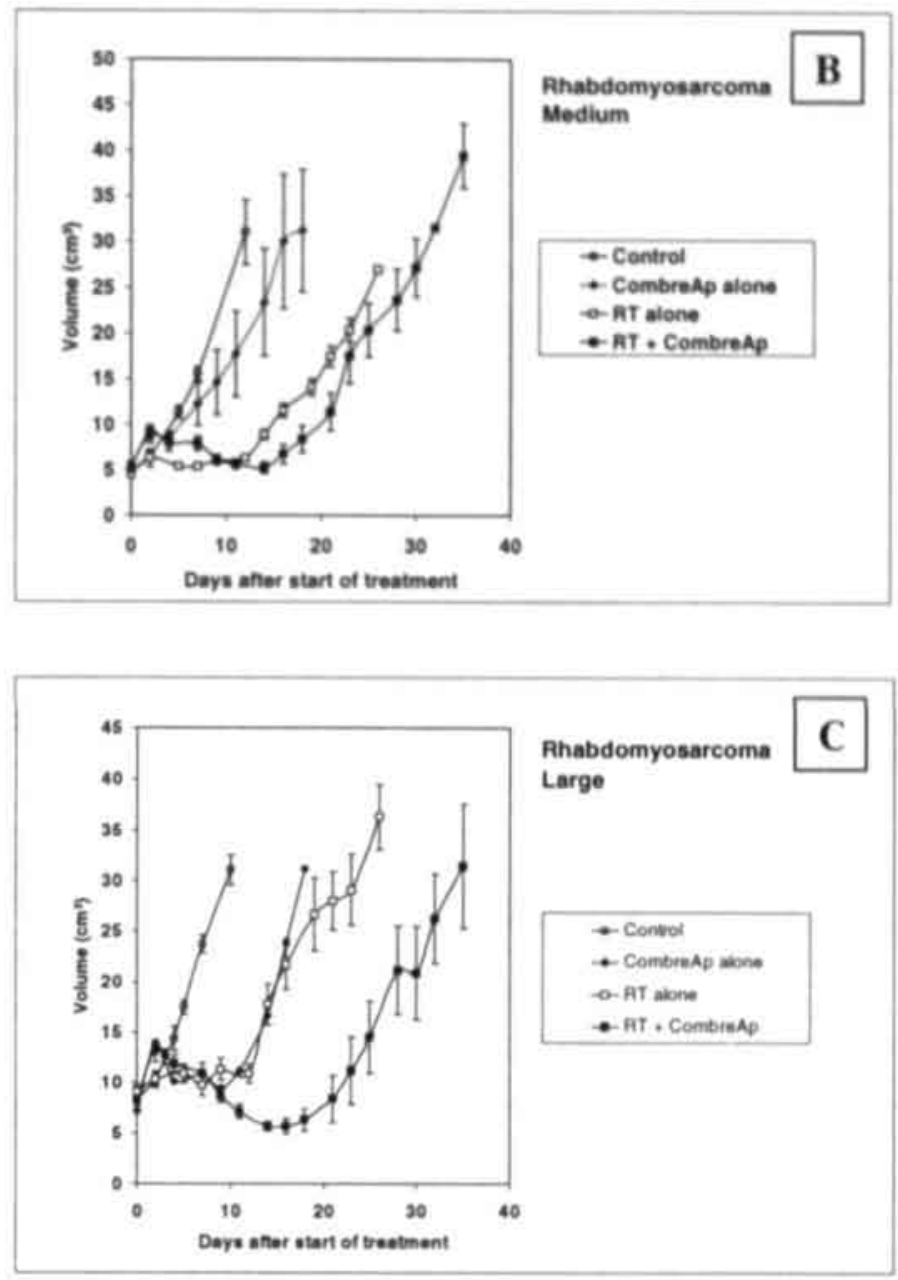

Figure III.1.1. CombreAp plus ionizing radiation; Growth curves for rat rhabdomyosarcoma in the three different treatment series: $(\boldsymbol{A})$ small, $(\boldsymbol{B})$ medium, or $(\boldsymbol{C})$ large tumors at the start of treatments. CombreAp $=1 \times 25 \mathrm{mg} / \mathrm{kg}$, given i.p.; $R T=8 \mathrm{~Gy}$ single dose. Combination: Irradiation at I day prior combreAp. All values represent the mean \pm S.E.M.

These data demonstrate a clear-cut size-dependent strenghtening of the growth delay as compared with radiotherapy alone. With small tumors $\left(1-3 \mathrm{~cm}^{3}\right)$ at the start of the treatment, no increase in growth delay was seen with this combination (Figure III.1.1.A). The medium and the large tumors on the contrary showed respectively a weak ( 3 days) or strong (10 days) enlargement of the growth delay (Figure III.1.1.B 
and 1.C respectively). The resulting growth delays and related significancy levels are summarized in Table III.1.1.A for each tumor size and treatment.

Table III.1.1. Growth delays with rat rhabdomyosarcomas for the various pre-selected tumor volumes and the different treatments

Singe dose irradiation ( $8 \mathrm{~Gy})$ and combre Ap. $(1 \times 25 \mathrm{mg} / \mathrm{kg})$

\begin{tabular}{lccc} 
Volume $\left(\mathrm{cm}^{3}\right)$ & SD irrad + combreAp & SD irrad. alone & combreAp alone \\
\hline small $(1-3)$ & 13.5 days $(\mathrm{N} . \mathrm{S} .)^{*}$ & 13 days & 5 days \\
medium $(3-7)$ & 18 days $(\mathrm{N} . \mathrm{S})^{*}$ & 15 days & 6 days \\
large $(7-14)$ & 22 days $(<0.0001)^{*}$ & 12 days & 8 days \\
\hline
\end{tabular}

B) combreAp $(2 \times 25 \mathrm{mg} / \mathrm{kg})$ and TNP-470 anti-angiogenesis $(3 \times 30 \mathrm{mg} / \mathrm{kg})$

\begin{tabular}{lccc} 
Volume $\left(\mathrm{cm}^{3}\right)$ & combreAp + TNP.470 & combreAp alone & TNP -470 al \\
\hline small $(1-3)$ & 8 days $(\text { N.S. })^{* *}$ & 5 days & 6 days \\
medium (3-7) & 9 days $(0.047)^{* *}$ & 7 days & 6 days \\
large $(7-14)$ & 15 days $($ N.S.) & 13 days & 8 days \\
\hline
\end{tabular}

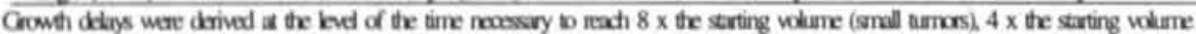

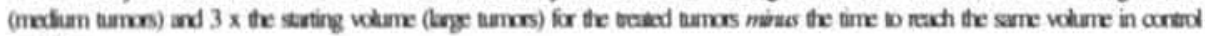
condition

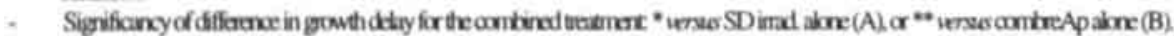
NS. : nce siprificant

\section{(2) CombreAp plus TNP-470 effect:}

Rats bearing s.c. rhabdomyosarcoma tumors were treated twice with a combreAp dose of $25 \mathrm{mg} / \mathrm{kg}$. The time interval between the two injections was 8 days, a selection based on our previous studies with rat rhabdomyosarcoma. The TNP-470 was injected s.c. three times in 7 days, with the first injection of $30 \mathrm{mg} / \mathrm{kg}$ at I day after the second combreAp administration. Experiments were carried out in duplicate. The results of these tumor size-related experiments are displayed in Figure III.1.2 (A: small, B: medium and C: large tumors).

The application of the TNP-470 after the combreAp introduced only a minor, nonsignificantly, additional growth delay of 2 days, compared with that seen for combreAp alone. This additional growth delay was independent of the tumor size at the start of the treatment (see Table III.1.1.B for details). 

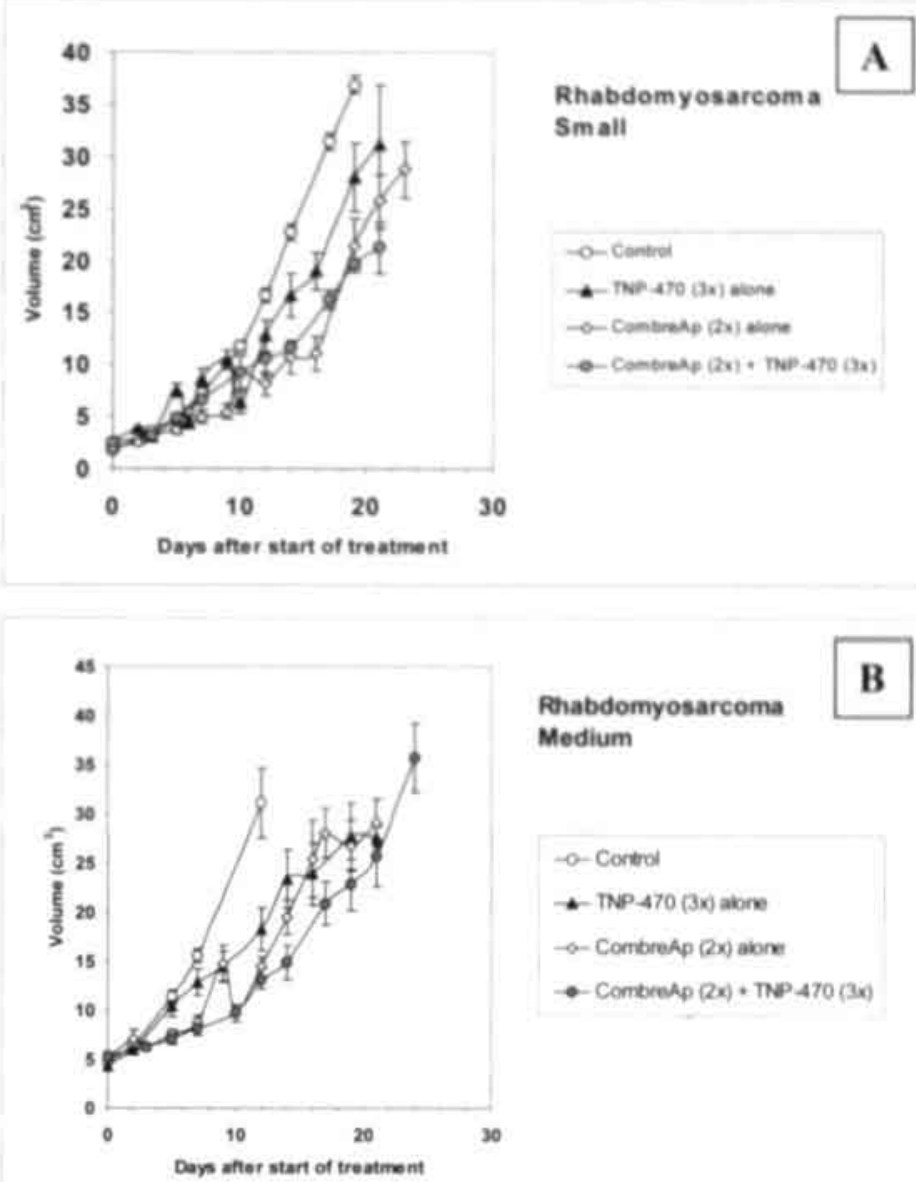

B Medium
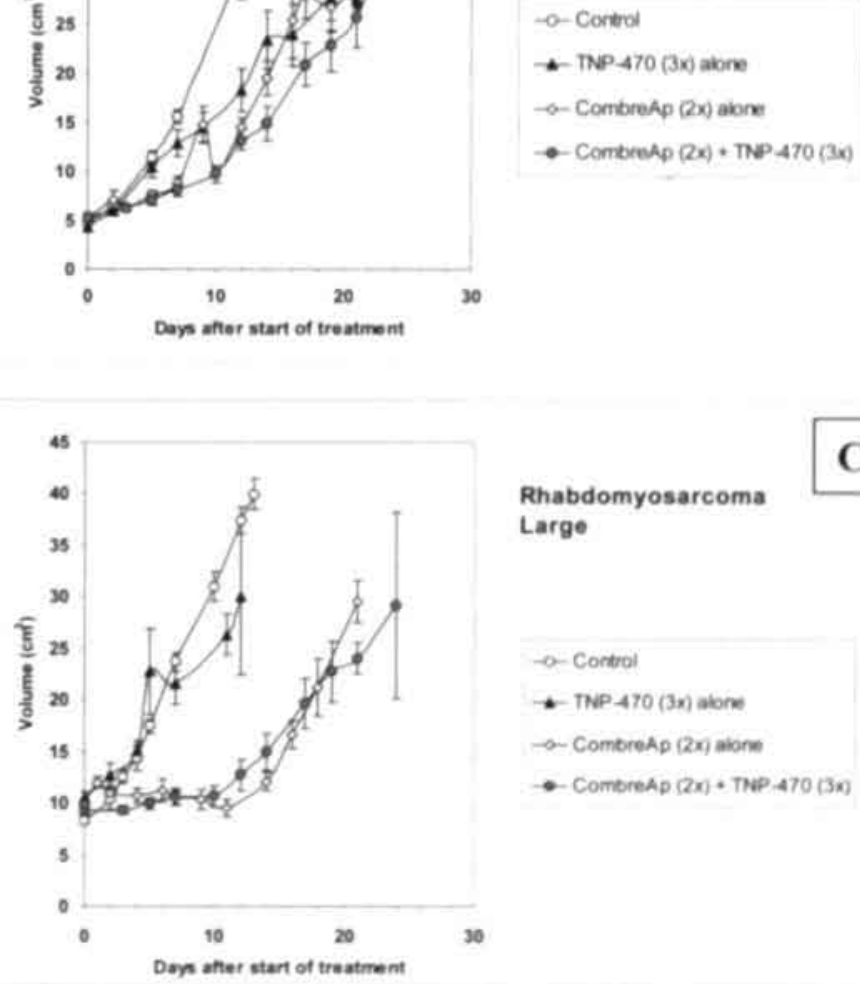

Rhabdomyosarcoma Large

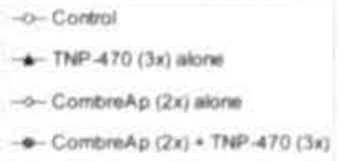

Figure III.1.2. CombreAp plus TNP-470; Growth pattern of rat rhabdomyosarcoma for either control condition and for the various treatment series. Results are presented for $(\boldsymbol{A})$ small, $(\boldsymbol{B})$ medium, and $(\boldsymbol{C})$ large tumors at the start of treatments. TNP-470 $=3 \times 30 \mathrm{mg} / \mathrm{kg}$ in I week, given s.c.; CombreAp $=2 \times 25 \mathrm{mg} / \mathrm{kg}$ in 8 days, given i.p.Combination: TNP.470 treatment started I day after the second combreAp injection. All values represent the mean \pm S.E.M. 


\section{III.1.4 Discussion}

The introduction of anti-angiogenesis in the eighties, and more recently of vascular targeting, provided new ways to attack solid tumor growth and its spread in the body. Their mode of action involves a selective interference with blood vessel constituents, and subsequently a cascade of tumor cell death.

In the perspectives of vascular targeting, modalities such as targeting tissue factors, blocking antibodies to angiogenic factors or endothelium-related gene therapy are being tested [16-18]. Separately, the use of vascular targeting with tubulin compromising compounds carries a substantial promise $[19,20]$. Specifically with combreAp, a single injection of a non-toxic dose resulted in an extremely rapid and extensive collapse of tumor vasculature. This effect and the resulting indirect antitumor response have been demonstrated with several rodent tumor models $[7,8]$. Whereas these detailed studies involved only small tumors $\left(\ll<3 \mathrm{~cm}^{3}\right)$, we demonstrated at least with a rat rhabdomyosarcoma tumor model that the extent of growth delay depended on the size of the tumor at the time of combreAp injections: i.e. the larger the tumor $\left(\gg 3 \mathrm{~cm}^{3}\right)$, the firmer the response [11]. In comparison with the standard radio- or chemotherapy, this clearly is a reverse size-dependent responsiveness. It is therefore in our opinion important to introduce when possible the volume-response relation into studies; moreover so since patients often present with tumors much bigger than $2-3 \mathrm{~cm}^{3}$.

On the other hand, and for two decades already, anti-angiogenesis has also been the topic of extensive anti-cancer research. The effectivity within the wide range of angiogenesis inhibitors under investigation may be categorized between 'some growth retardation' and tumor 'dormancy'. Also with TNP-470, a fumagillin analog that inhibits proliferation and migration of endothelial cells and consequently unables new vessel formation, in vivo activity has been demonstrated with a battery of tumor models. Our earlier investigations in rat rhabdomyosarcoma with TNP-470 also showed tumor growth retardation, with the effectivity depending on the schedule/dosing used as well as the tumor volume at the start of the treatment [14].

Both these two different modes of vasculature-directed treatments, since not curative on their own, have been combined in a few studies with tumor cell cytotoxic 
agents, e.g. cis-Platinum, Cyclophosphamide, Taxol or ionizing radiation, and this with variable success $[8,21-23]$.

The present in vivo investigations, using a rat thabdomyosarcoma tumor model, examined the effect from combining combreAp either with ionizing radiation or with TNP-470 anti-angiogenic treatment.

\section{(1) Ionizing radiation plus combreAp:}

The idea to apply irradiation before the combreAp treatment was to avoid a reduced radiation damage due to radioresistence from an enlarged hypoxic tumor cell population. CombreAp indeed introduces necrosis, a process that is preceeded as well as parallelled by hypoxia, as evidenced in rat rhabdomyosarcoma and other tumor models $[24,25]$. The selection of $8 \mathrm{~Gy}$ was based on the clinical use of such a fraction size, as demonstrated for the relief of pain from skeletal metastases [e.g. 26, 27]. Our results with combreAp ( $25 \mathrm{mg} / \mathrm{kg}$ ) given 1 day after the single irradiation demonstrate a tumor size-dependent additional growth delay when compared with radiotherapy given alone. The effectivity of the combined treatment was much more beneficial, at least additive, in tumors larger than $7 \mathrm{~cm}^{3}$ versus those that were smaller at treatment time, thus confirming our hypothesis. This differential overall response seen between large and small tumors seems related to the stronger impact of the combreAp treatment, and conversely, related to a lesser radiation effect because of the presence of many more hypoxic cells in large tumors. The existence of severe hypoxia in large tumors has been indicated previously in the rat rhabdomyosarcoma in a direct way using the hypoxic marker NITP and indirectly with the degree of anaerobic bacterial colonization with apathogenic Clostridium [28]. On the other hand, the lack of a positive change in growth delay in small tumors may be explained as the result of the very efficient tumor cell killing from the irradiation as such. The induction of combreAp related vessel damage would thus not substantially add (measurable in a growth delay assay) to the tumor cell killing from irradiation. Our data differ from the results obtained with the mouse adenocarcinoma CaNT tumor model by Chaplin et al, demonstrating a clear-cut gain in growth delay from combining irradiation with combreAp [8]. In contrast however with our study, a fractionated irradiation schedule was used in combination with a double combreAp injection. This difference may. besides the fact that also carbogen breathing was concomittantly applied, offer some explanation for the discrepancy. In addition, and of at least equal importance, the 
overall response to such a combined treatment will be related to the different characteristics of each type of tumor cell: this means the sensitivity to irradiation with at the same time the possibility of radiation-damaged cells to tolerate a prolonged hypoxia condition as likely introduced by the combreAp treatment. The differential effectivity will obviously also depend on the amount and the inherent quality of the acquired tumor vessels in the various in vivo models. The in vivo/in vitro mouse KHT sarcoma experiments from $\mathrm{Li}$ et al [29] also show evidence of enhanced tumor cell kill when combreAp is combined with single dose irradiation, but the results are not translated into growth delays and therefore unable a direct comparison with our data.

Whether this tumor-type independent improved response incorporates a broadening of the therapeutic window remains a question. Based on the available information in the literature about the combreAp activity and selectivity, combined treatment limiting normal tissue reactions are not to be expected; the clinically oriented question however deserves an answer with appropriate normal tissue in vivo models.

\section{(2) CombreAp plus TNP-470:}

We aimed to identify in rat rhabdomyosarcoma the possiblility of an improved response from combining combreAp with TNP-470, based on their distinctively different vessel-related action mechanisms. We hypothesized that the use of TNP-470 after the combreAp injections, specifically during the time of tumor regrowth, may result in increased tumor cell kill through the inhibition of the renewal of vascularity. Proof of principle of anti-angiogenic activity being the major mechanism of TNP-470 anti-tumor activity has been discussed by several research groups [e.g, 30]. Underlying our reasoning is the fact that rat rhabdomyosarcoma regrowth was clearly parallelled by angiogenesis, as evidenced with digital subtraction angiography [11].

The present experiment results obtained with the combreAp plus TNP-470 combination show no statistically significant strengthening of the growth delay in rat rhabdomyosarcoma as compared with the effect from combreAp alone. Independent of tumor size, about 2 days of absolute extra growth delay was measured (see Table 1B). The easy explanation for the very small effect from the TNP-470 may be found in the possibility that not many new blood vessels were being formed at the time of the TNP-470 application. This would obviously result in less vascular related anti-tumor effects. Should we on the other hand think of a reduced accessibility of the TNP-470 
which was injected after the combreAp? Possibly, but we hypothesized that majorly the acquired intra-tumor vasculature will be severely damaged by combreAp, leaving host vessels at the periphery of the tumor intact. This has been indicated in the rat rhabdomyosarcoma using digital subtraction angiography and standard histopathology techniques [11]. Since vessel sprouting only can occur from these intact vessels in the tumor periphery. TNP-470 should not find any obstruction to reach its target and should thus do the job.

In conclusion, the present data and those from other groups [8, 29] demonstrate a potential benefit from combining ionizing radiation with combreAp treatments, but at the same time illustrate a tumor size and -type dependent effectivity. Our results also indicate no significant improvement from the use of a TNP-470 treatment given after the combreAp injection.

The fact that the mechanisms of combreAp activity are not yet fully understood, necessitates more experiment data involving different sequences, treatment duration/fractionation/dosing as well as immunohistochemical measurements related to endothelial cell growth factors and hypoxia.

\section{III.1.5. References}

1. Folkman J. The role of angiogenesis in tumor growth. Semin Cancer Biol 3: 65-71 (1992).

2. Folkman J. What is the evidence that tumors are angiogenesis dependent? J Natl Cancer Inst 82: 4-6 (1990).

3. Denekamp J. Review article: Angiogenesis, neovascular proliferation and vascular pathophysiology as targets for cancer therapy. Br J Radiol 66: 181-196 (1993).

4. Barinaga M. Designing therapies that target tumor blood vessels. Science 275 : 482-484 (1997).

5. Hill SA, Sampson LE, Chaplin DJ. Antivascular approaches to solid tumor therapy: evaluation of vinblastine and flavone acetic acid. Int J Cancer 63: 119-123 (1995).

6. Hill SA, Lonergan SJ, Denekamp J, et al. Vinca alkaloids: anti-vascular effects in a murine tumour. Eur J Cancer 29: 1320-1324 (1993).

7. Dark GG. Hill SA. Prise VE et al. Combretastatin A4. An agent that displays potent and selective toxicity towards tumour vasculature. Cancer Res 57: 1829-1834 (1997).

8. Chaplin D, Pettit GR, Hill SA. Anti-vascular approaches to solid tumor therapy: evaluation of combretastatin A-4 phosphates. Anticancer Res 19: 189-196 (1999). 
9. Dubben H-H, Thames HD, Beck-Bornholdt H-P. Tumor volume: a basic and specific response predictor in radiotherapy. Radiother Oncol 47: 16-174 (1998).

10. Lambin Ph, Kramar A, Haie-Meder C, et al. Tumour size in cancer of the cervix. Acta Oncol 37: 729-734 (1998).

11. Landuyt W, Verdoes O. Darius DO, et al. Vascular targeting of solid tumours: a major "inverse" volume-response relationship with combretastatin A-4 phosphate in rat rhabdomyosarcoma. Eur J Cancer: accepted (2000).

12. Sipos EP. Tamargo RJ, Weingart JD, et al. Inhibition of tumor angiogenesis. Ann NY Acad Sci 732: 263-272 (1994).

13. Auerbach W, Auerbach B. Angiogenesis inhibition: a review. Pharmacol Ther $63: 265-$ 311 (1994).

14. Landuyt W. Theys J, Nuyts S, et al. Effect of TNP-470 (AGM-1470) on the growth of rat rhabdomyosarcoma tumors with different sizes. Cancer Invest: in press (2000).

15. Hermens A, Barendsen G. Cellular proliferation patterns in an experimental rhabdomyosarcoma in the rat. Eur J Cancer 3: 361-369 (1967).

16. Brown JM, Giaccia AJ. The unique physiology of solid tumors: opportunities (and problems) for cancer therapy. Cancer Res 58: 1408-1416 (1998).

17. Harris AL. Antiangiogenesis for cancer therapy. Lancet 349:1 3-15 (1997).

18. Bicknell R. Vascular targeting and the inhibition of angiogenesis. Ann of Oncol 5: S45S50 (1994).

19. Pettit GR, Singh SB, Hamel E. et al. Isolation and structure of the strong cell growth and tubulin inhibitor combretastatin A-4. Experientia 45: 209-211 (1989).

20. Giannakakou P. Sackett D. Fojo T. Tubulin/microtubules: still a promising target for new chemotherapeutic agents. J Natl Cancer Inst 92: 182-183 (2000).

21. Mauceri HJ, Hanna NN, Beckett MA, et al. Combined effects of angiostatin and ionizing radiation in antitumour therapy. Nature 394: 287-291 (1998).

22. Satoh H. Ishikawa M. Fujimoto M. et al. Combined effects of TNP-470 and Taxol in human non-small cell lung cancer cell lines. Anticancer Res 18: 1027-1030 (1998).

23. Teicher BA, Holden SA. Ara G, et al. Potentiation of cytotoxic cancer therapies by TNP470 alone and with other anti-angiogenic agents. Int J Cancer 57: 920-925 (1994).

24. Landuyt W. Theys J. Nuyts S, et al. Tumor colonisation with anaerobic bacteria following vascular targeting treatment: improvement for anaerobic vector gene therapy developments. Tumor Targeting: in press (2000).

25. Horsman MR. Ehrnrooth E, et al. The effect of combretastatin A-4 disodium phosphate in a $\mathrm{C}_{3} \mathrm{H}$ mouse mammary carcinoma and a variety of murine spontaneous tumors. Int $\mathrm{J}$ Radiat Oncol Biol Phys 42: 895-898 (1998). 
26. Steenland E, Leer J, van Houwelingen $\mathrm{H}$, et al. The effect of a single fraction compared to multiple fractions on painful bone metastases: a global analysis of the Dutch Bone Metastases Study. Radiother Oncol 52:101-109 (1999).

27. Yarnold JR. (on behalf of the Bone Pain Trial Working Party). 8 Gy single fraction radiotherapy for the treatment of metastatic skeletal pain: randomized comparison with a multifraction schedule over 12 months of patient follow-up. Radiother Oncol 52: 111-121 (1999).

28. Lambin P. Theys J, Landuyt W, et al. Colonisation of Clostridium in the body is restricted to hypoxic and necrotic areas of tumours. Anaerobe 4: 183-188 (1998).

29. Li L, Rojiani A, Siemann DW. Targeting the tumor vasculature with combretastatin A-4 disodium phosphate: effects on radiation therapy. Int J Radiat Oncol Biol Phys 42: 899. 903 (1998).

30. Brem H. Folkman J. Analysis of experimental antiangiogenic therapy. J Pediatr Surg 28: $445-451$ (1993). 



\section{Chapter III}

III.2. Combining combretastatin A-4 phosphate with anaerobe bacteria-based transfer of therapeutic proteins 



\section{III.2.A. Evaluation and improvement of a bacterial vector}

gene transfer system with an in vivo rat tumour model

Published in : FEMS Immunol. Med. Microbiol. 30: 37-41, 2001

Jan Theys*, Willy Landuyt*, Sandra Nuyts, Lieve Van Mellaert, Alex Rijnders,

Walter Van Den Bogaert, Allan van Oosterom, Jozef Anné and Philippe Lambin 


\section{Summary}

Previous studies have demonstrated the feasibility of using apathogenic clostridia as a promising strategy for hypoxia-specific tumour targeting. The present study shows that the use of the vascular targeting compound combretastatin A-4 phosphate could significantly $(p<0.001)$ increase the number of Clostridium vegetative cells in rat rhabdomyosarcomas with sizes between $0.2 \mathrm{~cm}^{3}$ and $3 \mathrm{~cm}^{3}$. Furthermore, this study showed that administration of metronidazole for a 9-day period was sufficient to eliminate systemically administered Clostridium from the tumour. Moreover, previous Clostridium spore administration did not effect tumour colonisation, regardless of the immune response status of the host. 


\section{III.2.A.1. Introduction}

The potential use of gene therapy as an oncologic treatment modality has been extensively addressed. Most viral and non-viral transfer systems developed so far are however hampered in their use due to the lack of tumour specificity and low transduction efficiencies [1]. An innovative approach for tumour specific delivery of therapeutic proteins is to use bacterial vector systems [2, 3, 4]. Infections with anaerobic bacteria can spontaneously occur in rodent as well as in human tumours [5. 6]. Tumours can also be infected by systemic injections of spores of anaerobic bacteria, as shown both in rodent tumours [7] and in cancer patients in clinical trials [8]. This is explained by the fact that rodent [e.g. 9] and most human [e.g. 10] solid tumours have size-related hypoxic/necrotic regions. Hypoxic conditions are normally absent in healthy tissues and necrosis is never detected [10].

Recombinant DNA techniques and specific transformation protocols are available to engineer Clostridium to express and secrete proteins that have a potential antitumoral effect $[11,12]$. Administration of such recombinant Clostridium to a tumour-bearing organism may thus likely result in a tumour-specific effect.

Using the rhabdomyosarcoma rat tumour model we have previously quantified the specific colonisation of tumours with volumes larger than $3 \mathrm{~cm}^{3}$ following systemic administration of clostridial spores. Tumours with smaller size were inefficiently colonised. Spores did not germinate in normal tissues [2].

Experiments were now set up in order to improve the colonisation capacity of this bacterial-based vector system in much smaller tumours $\left(<3 \mathrm{~cm}^{3}\right)$. Such tumours inherently have less hypoxia and little or no necrosis. It was previously shown in several rodent tumour models that combretastatin A-4 phosphate (combreAp), injected at systemically non-toxic doses, induced a severe vascular shutdown within 3-6 hours resultting in the development of extensive necrosis at 1-3 days [e.g. 13, 14]. Based on this knowledge, administration of Clostridium spores was combined with combreAp administration and the effect on increase in bacterial colonisation was analysed.

We further investigated the efficiency by which Clostridium could be removed from a tumour-bearing organism following antibiotic treatment. This safety aspect is of much importance in case adverse effects should occur. Finally, the extent of the 
host immune response and the possible hindrance on colonisation capacity of the tumour with Clostridium after a first application was evaluated.

\section{III.2.A.2. Materials and methods}

\section{Bacterial strain, tumour model and colonisation experiments}

Clostridium sporogenes used in this study was isolated in our laboratory and identified following $16 \mathrm{~S}$ rRNA sequence determination. This strain was cultivated in an anaerobic incubator (Forma Scientific, model 1024) with palladium as a catalyst on trypticase-soy-agar medium (BioMérieux) enriched with 5\% defribinated horse blood for 10 days at $37^{\circ} \mathrm{C}$. Spores were collected from the agar plates as described [2].

Male WAG/Rij rats with subcutaneously (s.c.) transplanted syngeneic rhabdomyosarcomas were used as in vivo model [2]. The test tumours were divided into groups of predetermined volume: $<1 \mathrm{~cm}^{3}, 1-3 \mathrm{~cm}^{3}$ and $>3 \mathrm{~cm}^{3}$, depending on the type of experiments. Before and during the follow-up period, the rats were given food and water ad libitum in a conventional housing facility. When tumours reached the predetermined volume, $10^{8}$ spores were systemically administered to the rats and colonisation was analysed as described [2].

\section{Vascular targeting compound}

Freshly prepared solutions of combretastatin A-4 phosphate (CombreAp; OXiGENE, Lund, Sweden) were given i.p. as a $0.5 \mathrm{ml}$ saline solution in a concentration of $25 \mathrm{mgkg}^{-1}, 4 \mathrm{~h}$ after Clostridium administration. This allowed the distribution of the bacteria throughout the vascular network and, specifically, in the tumours, prior to any possible tumour blood vessel damage. A number of tumourbearing rats received a sham-injection of saline only.

\section{Metronidazole treatment and subsequent tumour colonisation}

To test the effect of antibiotic therapy, metronidazole (Flagyl ${ }^{8}$ ) dissolved in saline was injected intraperitoneally (i.p.) at $200 \mathrm{mgkg}^{-1}$ twice a day for up to 9 days, starting at day 5 following spore administration. Control animals received the same 
volume of saline. Six hours after the last injection, bacterial colonisation was determined [2]. Each experiment was repeated three times, each time with a minimum of 3 to 5 animals per point.

The possibility of Clostridium to colonise tumours in animals that had been treated with metronidazole to eradicate previously administered clostridia was investigated. Non-tumour bearing rats were therefore injected systemically with $10^{8}$ spores. To control the distribution of bacteria in the body, liver and spleen were removed from randomly selected rats at day 5 following injection and analysed for the presence of Clostridium spores (ref. 2 for technique). All other animals were after spore injection treated with metronidazole according to the optimal schedule and time (see 'Results'). Five weeks after the antibiotic treatment, tumours were implanted s.c. in the flank of the treated animals. When the tumours reached a volume of at least 4 $\mathrm{cm}^{3}$, clostridial spores were systemically injected and five days later, colonisation was evaluated. A control group of tumour-bearing WAG/Rij rats, which did not receive pretreatment with clostridial spores and metronidazole, were injected only once with a suspension of $10^{8}$ spores. Tumour specimen were microscopically inspected at the time of removal. Quantification of Clostridium-specific antibodies was assessed using an ELISA-assay (Eurogenetics, Tessenderlo, Belgium). WAG/Rij rats with and without tumour, not previously injected with Clostridium were used as a negative control. During the course of the experiments body temperature and weight was followed.

\section{ELISA assay}

Blood samples were taken from each rat and the amount of Clostridiumspecific antibodies in serum was estimated using an enzyme immunoassay. Therefore, clostridial cell lysates were generated by sonication, and $150 \mu 1$ of 100 -fold dilutions of the protein extracts were used to coat the solid phase in a 96-well microtitre plate. Following overnight incubation at $4^{\circ} \mathrm{C}$, plates were washed three times with phosphate-buffered saline (PBS). For signal detection, $125 \mu \mathrm{l}$ of the isolated rat antisera used as primary antibodies were diluted 1/2000 in PBS containing 7.5\% BSA, incubated for $45 \mathrm{~min}$. at $37^{\circ} \mathrm{C}$. $125 \mu \mathrm{l}$ of horse radish peroxidase conjugated rabbit anti-rat immunoglobulins (1/1000) was taken as secondary antibodies (Dakopatts). It was subsequently added to the appropriate wells and incubated for $45 \mathrm{~min}$. at $37^{\circ} \mathrm{C}$. 
After each antibody incubation step, blots were washed five times with PBS $+0.1 \%$ Tween-80. For detection, $100 \mu \mathrm{l}$ substrate was added to each well. The reaction was stopped after $20 \mathrm{~min}$. by adding $50 \mu \mathrm{l}$ of $2 \mathrm{~N} \mathrm{H}_{2} \mathrm{SO}_{4}$ and the colour change in the plates was read at $450 \mathrm{~nm}$. A standard curve was prepared by serially diluting a pool of maximal responders in PBS containing $7.5 \%$ bovine serum albumin, and ranged from 1 to 1000 arbitrary units $/ \mathrm{ml}$. Samples and controls were added in duplicate to the appropriate wells.

\section{III.2.A.3. Results}

\section{(1) Improvement of clostridial tumour colonisation}

In a first series of experiments, rats bearing tumours with volumes larger than $3 \mathrm{~cm}^{3}$ were injected systemically with $10^{8}$ Clostridium spores. The tumours were resected 4-5 days after the injection and dilutions of the tumour homogenates were prepared in saline. The analysis of bacterial growth in these larger tumours revealed the presence of at least $10^{7}$ colony forming units (cfu) per g of tumour tissue (Figure 1, left panels). 


\section{Sham-treated tumours}
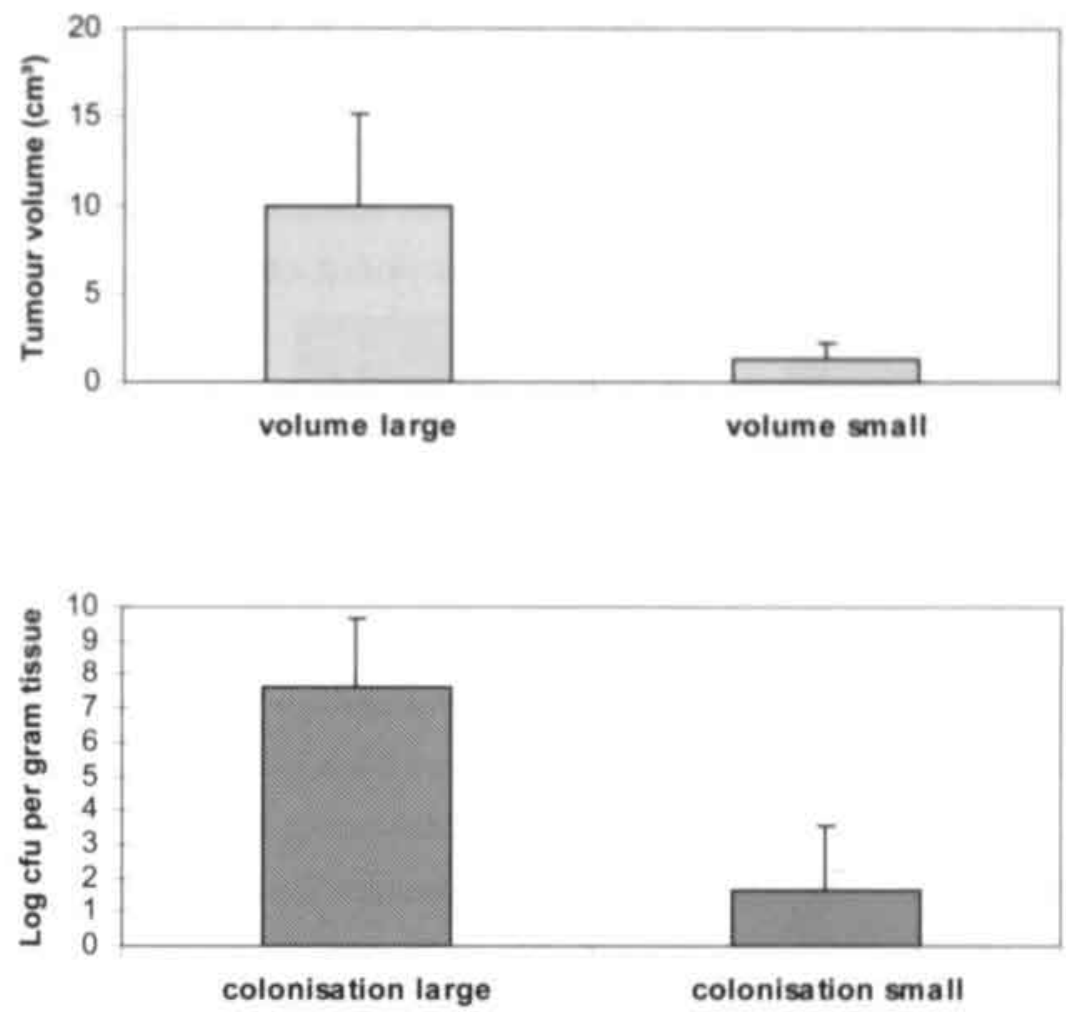

Figure 1. The number of colony forming units (cfu) measured in large $\left(>3 \mathrm{~cm}^{3}\right)$ (left panels) and small $\left(0.2-3 \mathrm{~cm}^{3}\right)$ tumours (right panels). Bars represent mean $\pm S E$. The difference between colonisation "large" and colonisation "small" is very significant $(p<0.0001)$.

In a second series, $10^{8}$ Clostridium spores were injected in rats bearing tumours measuring between 0.2 and $3 \mathrm{~cm}^{3}$. In contrast to the larger tumours, the number of vegetative cells in these tumours was significantly lower $(\mathrm{p}<0.0001)$ (Figure 1, right panels) and varied between $0 \mathrm{cfu}$ and $10^{3} \mathrm{cfu}$ per $\mathrm{g}$ tissue, with exceptionally a tumour containing $10^{6} \mathrm{cfu}$ per $\mathrm{g}$ tissue. When these small tumours were classified in volumes between 1 and $3 \mathrm{~cm}^{3}$ and volumes less than $1 \mathrm{~cm}^{3}$, the differences in colonisation were even more striking (Figure 2, left panels). In the very small tumours $\left(<1 \mathrm{~cm}^{3}\right)$, on average about $10^{0.5} \mathrm{cfu}$ of Clostridium per $\mathrm{g}$ tissue were detected. 
In parallel with these investigations, rats bearing rhabdomyosarcomas of closely matched sizes were treated with a single i.p. injection of combreAp at $4 \mathrm{~h}$ after administration of the Clostridium spores. This resulted in a strongly improved colonisation (Figure 2, right panels). Particularly, tumours smaller than $1 \mathrm{~cm}^{3}$ contained in most instances $10^{6}-10^{7}$ cfu per $\mathrm{g}$ tissue. The bacterial colonisation of combreAp-treated tumours of $1-3 \mathrm{~cm}^{3}$ or $<1 \mathrm{~cm}^{3}$ was significantly higher than the colonisation of sham-treated tumours of a similar size (with $p<0.001$ and $p<0.0001$ respectively).

Gross examination of excised sham-treated small tumours always revealed a firm, viable and well-vascularised tissue at transsection. Histopathological examination demonstrated few, scattered foci of necrosis only in some tumours of 1-3 $\mathrm{cm}^{3}$, whereas this was not observed in tumours $<1 \mathrm{~cm}^{3}$. In tumours treated with combreAp alone, a large core of necrosis with a rim of viable tumour tissue was observed at 4-5 days post-injection (the standard time-interval for colonisation measurements). When Clostridium spores were injected $4 \mathrm{~h}$ prior to the combreAp treatment, most of the tumours became soft on palpation during the follow-up period. When transsected for the colonisation study, these tumours showed some degree of liquid necrosis. Also in these tumours, viable tissue was a rim surrounding the necrotic centre. 


\section{A}

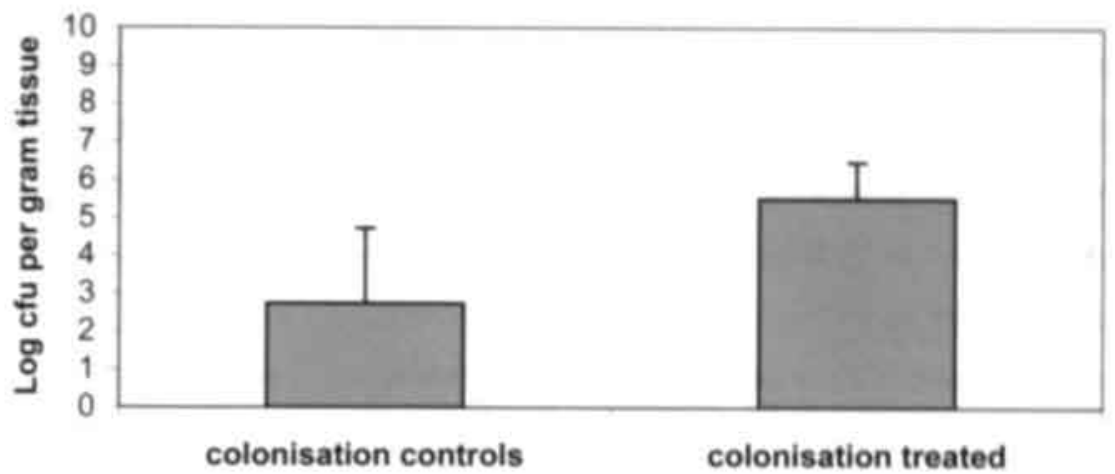

\section{B}

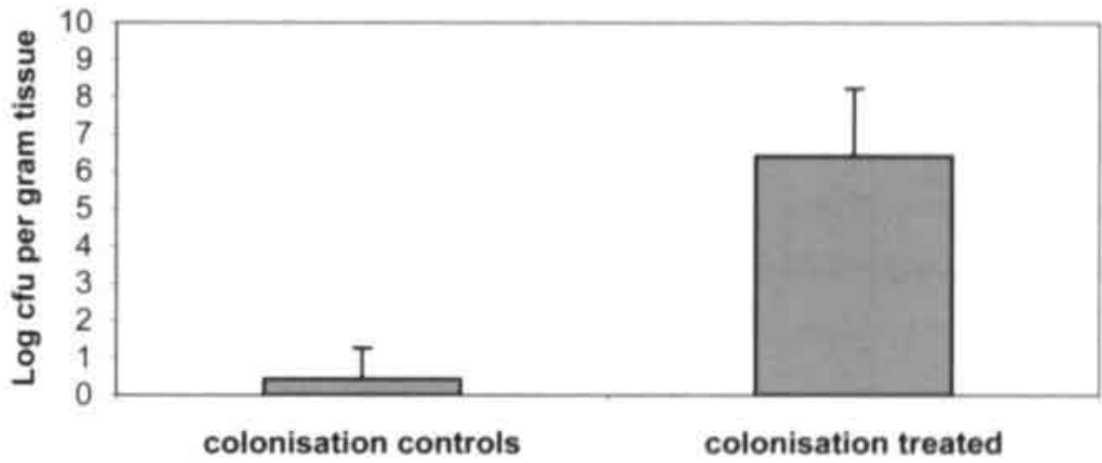

Figure 2. The number of cfu measured in rhabdomyosarcomas with volumes between $I$ and $3 \mathrm{~cm}^{3}(A)$ and with volumes less than $I \mathrm{~cm}^{3}(B)$ for sham-treated (left panels) and combreAp-treated (right panels) rats. Colonisation is significantly higher in the combreAp-treated tumours ( $p<0.001$ and $p<0.0001$, respectively). Bars represent mean $\pm S E$.

\section{(2) Removal of Clostridium from the tumour by antibiotic treatment}

Experiments were designed to determine the effectiveness of an antibiotic treatment specific for anaerobes in order to stop tumour colonisation, if desired. After treatment with metronidazole, a decreasing number of cfu was measured in the tumour as a function of treatment duration. In these treated animals, the number of 
cells before and after heating was not significantly different (data not shown), which means that all the vegetative cells were killed. After 9 days no bacterial growth nor presence of spores was detected in the tumours of metronidazole treated animals (Figure 3). During this period, colonisation in tumours of animals that were not treated with antibiotics remained high. These results clearly indicate that metronidazole eradicates Clostridium.

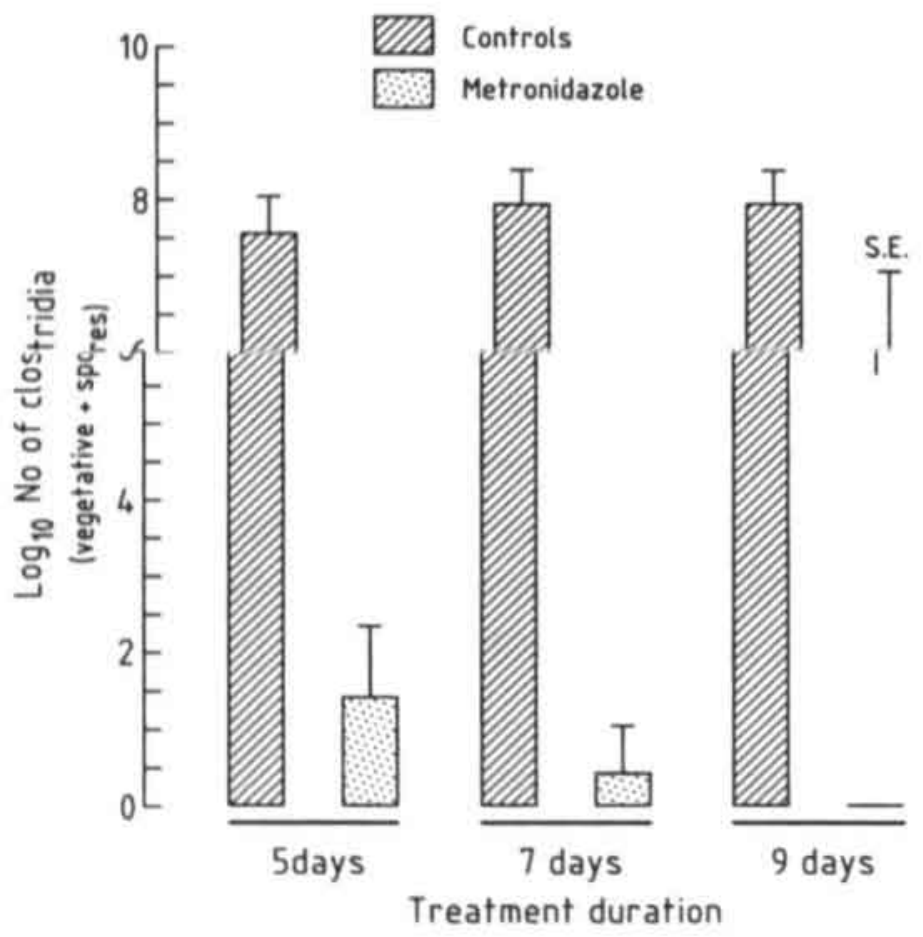

Figure 3. Effect on the number of colony forming units (cfu) in tumours after 5,7 or 9 days of treatment with metronidazole. The number of bacteria with and without metronidazole treatment are indicated. After treatment with metronidazole, a decreasing number of cfu was measured in the tumour.

(3) Analysis of the occurrence of Clostridium-specific antibodies and effect on tumour colonisation

An ELISA assay was developed to quantify the amount of Clostridiumspecific antibodies in serum of rats that were previously injected with Clostridium 
spores and treated with metronidazole before re-injection. A comparison was made both with animals receiving Clostridium spores only once and with animals that were not treated at all. To obtain a sensitive assay, optimum concentrations of primary serum antibody, HRP labeled second antibody and antigen were determined. A maximum discrimination between the points in the standard curve could thus be obtained. After a single injection of Clostridium spores, an immune response was induced but only a small amount of Clostridium-specific antibodies could be detected ( $<50 \mathrm{AU})$. The majority $(8 / 12)$ of animals that were injected twice with Clostridium spores could be labeled as 'non-responders': the amount of Clostridium-specific antibodies was not different compared to the animals that received only one injection of the spore suspension. In the other animals of this experimental group (4/12), an increase (up to tenfold) of Clostridium-specific antibodies in the serum could be demonstrated. Interestingly, regardless of the immune response status, tumour colonisation did occur to the same extent in animals that were previously injected with a clostridial spore suspension compared to animals that were not treated before. Again, spores as well as vegetative cells were present in the tumour as concluded from the difference in c.f.u. before and after heat treatment and confirmed by microscopical evaluation of the tumour suspensions. During the course of the experiments, no change in body temperatures or body weights could be detected.

\section{III.2.A.4. Discussion}

It is a well established phenomenon that certain species of Clostridium can selectively colonise hypoxic/necrotic regions of solid tumours [2, 3]. It intrinsically means that if a recombinant Clostridium is administered to a tumour-bearing subject for therapeutic purposes, the metabolically active cells that produce the therapeutic proteins will be present only in the solid tumour. In addition to this tumour selectivity, a major advantage of using an anaerobic bacterial vector system is the fact that the therapeutic gene has not to be transduced into the genome of the tumour cell. Eventual problems herewith associated such as a low transduction efficiency or the risk of insertional mutagenesis can be avoided, since the anti-cancer gene will be expressed and secreted from the bacteria.

However, one of the disadvantages of such type of vector system so far was that only larger tumours $\left(>3 \mathrm{~cm}^{3}\right)$ could become colonised with Clostridium. The 
latter finding would hamper the overall advantage of the proposed Clostridium tumour targeting system being of low value when considering both small tumours or tumours not containing severe hypoxic/necrotic regions. The present investigations demonstrated that a significant improvement of tumour colonisation in very small tumours $\left(<3 \mathrm{~cm}^{3}\right)$ could be obtained when the rats were injected with combreAp after the administration of clostridial spores. The results of the histopathological analysis as well as the gross appearance at the transsection of the tumour indicated the strong relationship between the increased presence of Clostridium and the level of necrosis induced by the combreAp.

Important considerations using 'classical' gene therapy vectors should be made regarding the safety issues. The concern that viral vectors could recombine with endogenous viruses remains. If the therapeutic gene would have unexpected major side-effects, the recombinant virus can not be removed from the body and gene expression can not be stopped. Furthermore, viruses are classified as hazardous agents class 2 in the European list of infectious agents. In contrast, the apathogenic bacteria used in our approach are classified as hazardous agents class 1 and sensitive to antibiotics. Moreover, as demonstrated in our studies, complete removal of vegetative Clostridium cells, even from the tumour tissue, could be achieved after 9 days with metronidazole, a standard antibiotic for anaerobic infection,. Metronidazole and other electron-affinity drugs have also been used as hypoxic radiosensitizers in cancer treatment, which suggests that these compounds have the ability to reach the hypoxic, badly perfused tumour areas [15]. This indicates that their anti-bacterial effectivity is not hindered by the absence of an adequate intratumoral vascular network.

Another important factor to be taken into consideration is an eventually induced host immune response after a single or repeated administration of Clostridium and its consequences on tumour colonisation. The results indicated the absence of such an induced immune response in most rats. Moreover, even in those animals that showed a tenfold increase in Clostridium-specific antibodies in the serum following a second bacterial administration, colonisation of tumours was not affected. This is of great importance, since it implies that long-term production of the therapeutic proteins from the engineered Clostridium is possible in tumours.

Taken together, these findings illustrate the advantages of a vascular targeting approach for use in Clostridium-guided tumour targeting systems. Furthermore, this combined anti-cancer approach may also incorporate radiation therapy. Combining 
combreAp with single dose irradiation irradiation seems to result in an increased tumour-cell kill, as indicated by at least three research teams (Li et al. [16], Chaplin et al. [17] and Landuyt et al. [18]) using rodent tumours. These strategies may be exploited to improve both the selectivity to target the solid tumours, and the subsequent production of the therapeutic protein into the extracellular microenvironment of these tumours.

\section{III.2.A.5. References}

1. Gomez-Navarro J, Curiel D T, Douglas JT. Gene therapy for cancer. Eur J Cancer 35: $867-885$ (2000).

2. Lambin P, Theys J. Landuyt W, Rijken P, Van der Kogel A, van der Schueren E, Hodgkiss R, Fowler J, Nuyts S, de Bruijn E, Van Mellaert L. Anné J. Colonisation of Clostridium in the body is restricted to hypoxic and necrotic areas of tumours. Anaerobe 4: 183-188 (1998).

3. Minton NP, Mauchline ML, Lemmon MJ Brehm JK. Fox M, Michael N P, Giaccia A, Brown JM. Chemotherapeutic tumour targeting using clostridial spores. FEMS Microbiol Rev 17: $357-364$ (1995).

4. Brooks Low K, Ittensohn M, Le T, Platt J, Sodi S, Amoss M, Ash O, Carmichae, E, Chakraborty A, Fisher J, Lin SL, Luo X, Miller SI, Zheng LM, King I, Pawelek JM, Bermudes, D. Lipid A mutant Salmonella with suppressed virulence and TNF $\alpha$ induction retain tumor-targeting in vivo. Nature BioTechnol 17: 37-41 (1999).

5. Brook I. Bacteria from solid tumours. J Med Microbiol 32: 207-210 (1990).

6. Kornbluth AA, Danzig JB, Bernstein LH. Clostridium septicum infection and associated malignancy. Medicine 68: 30-37 (1989).

7. Malmgren RA, Flanigan CC. Localization of the vegetative form of Clostridium tetani in mouse tumours following intravenous spore administration. Cancer Res 15: 473-478 (1955).

8. Carey RW. Clostridial oncolysis in man. Eur J Cancer 3: 37-46 (1967).

9. Moulder JE, Rockwell S. Hypoxic fractions of solid tumours: experimental techniques, methods of analysis and a survey of existing data. Int J Radiat Oncol Biol Phys 110: 695-712 (1984),

10. Vaupel P, Kallinowski F, Okuneff P. Blood flow, oxygen and nutrient supply and metabolic microenvironment of human tumours: a review, Cancer Res 49: 6449-6465 (1996). 
11. Theys J, Nuyts S, Landuyt W, Van Mellaen L, Dillen C, Böhringer M, Dürre P, Lambin P. Anné J. Stable Escherichia coli-Clostridium acetobutylicum shuttle vector for secretion of murine tumor necrosis factor alpha. Appl Environ Microbiol 65: 4295-4300 (1999).

12. Lemmon MJ, van Zijl P, Fox ME, Mauchline ML, Giaccia AJ, Minton NP, Brown JM. Anaerobic bacteria as a gene delivery system that is controlled by the tumour microenvironment. Gene Ther 4: 791-796 (1997).

13. Dark GG, Hill SA, Prise VE, Tozer GM, Pettit GR, Chaplin, DJ. Combretastatin A-4, an agent that displays potent and selective toxicity toward tumour vasculature. Cancer Res 57: $1829-1834$ (1997).

14. Landuyt W, Verdoes O, Darius OD, Drijkoningen M, Nuyts S, Theys J, Stockx L, Wynendaele W, Fowler J, Maleux G, Van den Bogaert W, Anné J, van Oosterom A, Lambin P. Vascular targeting of solid tumours: a major inverse volume-response relation with combretastatin A-4 phosphate in rat rhabdomyosarcomas. Eur J Cancer 36: 1844 1852 (2000).

15. Brady LW. Radiation sensitizers: their use in the clinical managemant of cancer, $521 \mathrm{pp}$, Masson Publishing USA, Inc (1980).

16. Li L, Rojiani A, Siemann DW. Targeting the tumour vasculature with combretastatin A4 disodium phosphate : effects on radiation therapy. Int J Radiat Oncol Biol Phys 42: $899-903$ (1998).

17. Chaplin DJ, Pettit GR, Hill SA. Anti-vascular approaches to solid tumor therapy: evalulation of combretastating A-4 phosphate. Anticancer Res 19: 189-196 (1999).

18. Landuyt W, Ahmed B. Nuyts S. Theys J, Op de Beeck M, Tech A. Rijnders A, Anné J, van Oosterom A, Van den Bogaert W, Lambin P. In vivo anti-tumor effect of vascular targeting combined with either ionizing radiation or anti-angiogenesis treatment. Int $J$ Radiat Oncol Biol Phys (In press) (2000). 
III.2.B Specific targeting of cytosine deaminase to solid tumours by engineered Clostridium acetobutylicum

Published in : Cancer Gene Ther. 8: 294-297, 2001

Jan Theys, Willy Landuyt, Sandra Nuyts, Lieve Van Mellaert, Jozef Anné and Philippe Lambin 


\section{Summary}

Anaerobic bacteria selectively proliferate in and colonize the hypoxic/necrotic regions of solid tumors. As a consequence, recombinant apathogenic clostridia can be used as a selective vector system in an enzyme/prodrug approach for the treatment of cancer. To test this hypothesis, the Escherichia coli cytosine deaminase coding sequence was fused in-frame to the clostridial clostripain promoter and signal sequence and cloned in the pKNT19 shuttle plasmid to transform Clostridium acetobutylicum.

Significant levels of functional cytosine deaminase were detected in lysates and supernatants of the recombinant clostridia as measured by thin layer chromatography analysis. More importantly, for the first time the in vivo applicability of recombinant Clostridium as a tumor specific vector for the local secretion of cytosine deaminase in the tumor was demonstrated by the administration of the engineered Clostridium to WAG/Rij rats bearing subcutaneously implanted syngeneic thabdomyosarcomas. Four days after the recombinant bacteria were injected, enzyme activity was detected in the tumors but not in normal tissues.

These results demonstrate the potential use of recombinant $C$. acetobutylicum as a tumor-specific delivery system for the transfer of therapeutic genes to solid tumors. 


\section{III.2.B.1. Introduction}

Despite the improvement of conventional radio- and chemotherapy, lengthy survival rates and prognosis remain poor for many cancer patients. This led to a strong interest in the investigation of anti-cancer protocols based on gene therapy. Herein, the use of suicide genes has been put forward to create artificial differences in sensitivity between normal and malignant cells, with specifically the CDase/5-FC suicide gene/prodrug system being well investigated. The major hurdle, however, remains the tumor-specific transfer of the gene encoding the therapeutic protein.

A fundamental difference between normal and tumor tissue is the presence of extensive hypoxia, responsible for e.g. resistance to radiotherapy and chemotherapy. Hypoxia can however also be appreciated as an opportunity for tumor selective therapy [1]. Apathogenic clostridia have been proven to selectively proliferate in the hypoxic/necrotic regions of solid tumors and the potential use of Clostridium as an anti-tumor agent has been indicated earlier in clinical studies. With the current availability of recombinant DNA technology for clostridia and the possibility to transform Clostridium, the use of these strictly anaerobic bacteria has attracted renewed interest. As such, recombinant apathogenic clostridia may be used as a selective vector system in an enzyme/prodrug approach for the treatment of cancer.

In the present report, we describe the development of recombinant C. acetobutylicum strains secreting high amounts of cytosine deaminase (CDase) in medium. The $E$. coli CDase was therefore placed under transcriptional control of the $C$. histolyticum clostripain promotor, preceded by the clostripain signal sequence, and cloned in a stable E. coli-Clostridium shuttle vector. We also document the expression and secretion of functional enzyme at the tumor site, when recombinant clostridia were administered to rhabdomyosarcoma-bearing WAG/Rij rats. The use of vascular targeting treatment with Combretastatin A-4 phosphate in combination with the suicide gene transfer system enabled a dose intensification of CDase activity.

\section{III.2.B.2. Materials and methods}

\section{Bacterial strains, plasmids, DNA manipulations and transformation procedures}

C. acetobutylicum DSM792 and NI4082 were cultivated in 2xYT medium or

RCM (supplemented with erythromycin when needed) at $37^{\circ} \mathrm{C}$ in an anaerobic 
cabinet. Transformation procedures and DNA manipulations were carried out essentially as described ${ }^{2}$. The $E$. coli/C. acetobutylicum shuttle plasmid pKNT19 was used as a cloning vector. The $E$. coli CDase gene $(\operatorname{codA})$ was present on the pSD112 plasmid, kindly provided by S. Danielsen. The clostripain regulatory sequence was available on Cl60-23, a gift from Weisheimer Malz (Andernach, Germany).

\section{Plasmid construction}

Mutations were carried out using the 'Altered Sites ${ }^{\text {TM }}$ in vitro Mutagenesis kit' (Promega). An EcoRI site (oligonucleotide 5'ATTATCCTTGGATTGAATTCCTGGA-TTTGCATA-3') was introduced four codons upstream of the signal sequence cleavage site of the clostripain regulatory sequence. The resulting $1.04 \mathrm{~kb}$ HindIII/EcoRI fragment was cloned in pBluescript, leading to pBsclosEcoRI. A Scal site was introduced two codons downstream of the GTG initiation codon of the $\operatorname{codA-cDNA}$ with oligo 5 GCGTTATTCGACACAGTACTCCTCCACATGC-3'. pBsclosEcoRI was digested with EcoRI, treated with Klenow polymerase, digested with $\mathrm{BamHI}$ and treated with alkaline phosphatase prior to in-frame fusion with the $1.5 \mathrm{~kb} S c a \mathrm{~L} / \mathrm{Bam} \mathrm{HI}$ fragment containing the codA-cDNA. Finally, the closcodA-fragment was isolated by HindIII/BamHI digestion and inserted into the BamHI/HindIII digested pKNT19 shuttle vector.

\section{Detection and activity measurement of cytosine deaminase in vitro}

Detection of CDase was performed using Western blot analysis with mAb $16 \mathrm{D} 8 \mathrm{~F} 2^{3}$. For quantification of CDase activity, bacteria were sampled at various stages of growth. To $45 \mu \mathrm{l}$ of Tris. $\mathrm{HCl}$ ( $\mathrm{pH} \mathrm{7.5)} \mathrm{buffered} \mathrm{lysates} \mathrm{and} \mathrm{supernatants,} \mathrm{5-}$ FC $(15 \mathrm{mM})$ was added and the solution was incubated for $24 \mathrm{~h}$ at $37{ }^{\circ} \mathrm{C}$. Five $\mu \mathrm{l}$ aliquots of the samples and 5-FC/5-FU controls were then applied to tlc plates (Silica gel $60 \mathrm{~F}_{254}$. Merck) that were developed in $86 \%$ butanol in water. Sections of the plates that contained the 5-FU UV-absorbing spots $(254 \mathrm{~nm})$ were cut out and 5-FU was extracted with methanol. The extract was dried in a vacuum centrifuge (Hetovac) and the residue was resuspended in $50 \mu \mathrm{l}$ of methanol. A $10 \mu \mathrm{l}$ aliquot was then added to $190 \mu \mathrm{HCl} 0.1 \mathrm{M}$ and the concentration of 5-FU was assayed spectrophotometrically at $\mathrm{OD}_{266 \mathrm{~nm}}$. This approach made quantitative monitoring of CDase activity possible without the need of radioactive substrates. Before incubation 
with 5-FC, the $\mathrm{pH}$ of the buffered reaction mixture was controlled and proven to be $\mathrm{pH} 7.2-7.4$, for all samples taken at different stages during growth.

\section{In vivo studies}

WAG/Rij rats with subcutaneously implanted rhabdomyosarcomas of 6 to 20 $\mathrm{cm}^{3}$ were used. Recombinant $C$. acetobutylicum DSM792 and N14082 spores were administered intratumorally. Injection of $C$. acetobutylicum having no or the empty vector, was used as a control. Four to five days following injection, tumors and normal tissues excised and grinded to look microscopically for the presence of Clostridium vegetative cells following Gram-staining. CDase activity in tumors was measured following homogenisation of the tumor $(-350 \mathrm{mg})$ in $450 \mu \mathrm{l}$ of PBS containing $1 \mu \mathrm{gml}^{-1}$ aprotinin, $30 \mu \mathrm{gml}^{-1}$ phenylmethylsulfonyl fluoride and $5 \mathrm{mM}$ EDTA. Following incubation for 24 hours at $37^{\circ} \mathrm{C}$ with $15 \mathrm{mM} \mathrm{5-FC,} 50 \mu \mathrm{l}$ aliquots were taken, quenched in methanol and applied on Silicagel $60 \mathrm{~F}_{244}$ sheets that were developed in $86 \%$ butanol/water. After drying, 5-FU spots were visualized under short-wave UV illumination.

\section{III.2.B.3. Results and discussion}

\section{(1) In vitro analysis of recombinant CDase activity in Clostridium}

The recombinant constructs in $E$. coli were quality-controlled by DNA sequence analysis and Western blotting. pKNT19closcodA was subsequently electroporated into C. acetobutylicum DSM792 and NI4082. After Western blotting of proteins present in supernatants and lysates of early-logarithmic growth phase recombinant Clostridium cultures, mAb $16 \mathrm{D} 8 \mathrm{~F} 2$ strongly reacted with a protein of about $52 \mathrm{kDa}$, which corresponds to $E$. coli CDase. No CDase could be detected in supernatants or lysates of plasmid-free $C$. acetobutylicum cultures, or in cultures carrying the empty pKNT19 plasmid alone. The functionality of the clostripain regulatory sequences preceding the CDase coding sequence was herewith evidenced, not only for its expression but also for the secretion of this large protein by Clostridium. Our results parallel the observation that shuttle vectors based on the replicon of the Bacillus plasmid pIM13 showed structural and segregational stability. We previously demonstrated this with the E. coli-C. acetobutylicum pKNTI9 and 
pIMPI shuttle vectors, developed for the secretion of the anti-tumor and radiosensitizing agent tumor necrosis factor alpha (TNF $\alpha$ ). Significant amounts of biologically active TNF $\alpha$ were measured in both lysates and supernatants of recombinant clostridia [2].

Because of the potential importance of CDase and 5-FC/5-FU conversion in antitumor therapy, we focused on the expression and secretion of CDase by Clostridium at various stages of growth. Maximum enzyme activity in lysates (1084.5 \pm 189.5 pmol 5-FC converted to 5 -FU $\mathrm{min}^{-1} \mathrm{ml}^{-1}$ cell lysate) was obtained as the bacteria reached the stationary growth phase $\left(\mathrm{OD}_{600 \mathrm{~mm}} \sim 1.5\right)$ (Fig. 1A). This activity level was maintained within the follow-up period of 20 hours (data not shown). In supernatants of recombinant $C$. acetobutylicum NI4082, the CDase activity reached a maximum (701.9 $\pm 104.3 \mathrm{pmol} 5$-FC converted into 5-FU $\mathrm{min}^{-1} \mathrm{ml}^{-1}$ supernatants) at the early-logarithmic growth phase at $\mathrm{OD}_{600 \mathrm{~nm}} \sim 1.2$ (Fig. 1B). Subsequently, CDase activity decreased. This might be a consequence of the acidification of the culture medium resulting in denaturation of CDase. Experiments with the recombinant $C$. acetobutylicum DSM792 strain resulted in similar CDase activity patterns in both lysates and supernatants (data not shown). When high levels of active CDase could be delivered at the tumor site, this would result in significant amounts of 5-FU in the tumor, which could lead to tumor control by 5-FU without systemic toxicity. Interestingly, it has been reported that 5-FU at the tumor site does not return rapidly into the systemic circulation, offering the opportunity for the therapeutic agent to exert locally its antineoplastic effects [3]. 

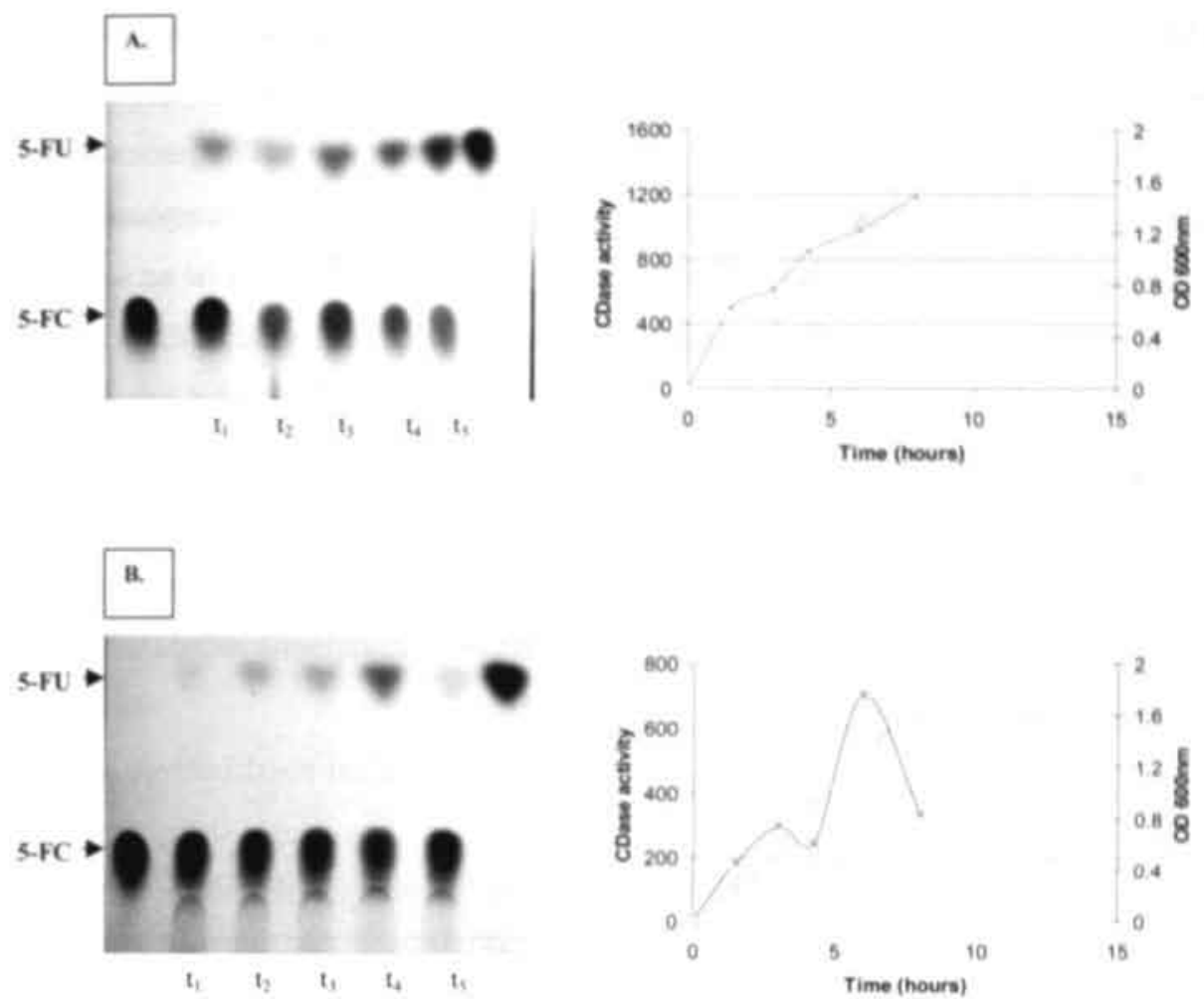

Figure 1. CDase activity in lysates (A) and supernatant (B) of C. acetobutylicum NI4082 transformed with pKNTI9closcodA as a function of growth stage( ). Samples were taken at various time points during growth $\left(t_{1} \rightarrow t_{5}\right)$ and applied to thin layer chromatography plates (left panel). The amount of 5-FU on the corresponding tlc plates was quantified as described in the 'Materials and Methods' section and the CDase activity $(X)$ was calculated as pmol 5 . FU produced $\min ^{-1} m l^{\prime}$ cell culture (right panel).

\section{(2) Detection of functional cytosine deaminase in vivo}

The results of the in vivo observations are summarised in Table 1. Gramstaining revealed the presence of vegetative Clostridium cells in tumor specimen, but not in samples of liver or spleen. CDase activity was present only in tumors injected with recombinant bacteria. As expected, no functional enzyme was present in tumors injected with plasmid-free bacteria, in tumors treated with bacteria carrying the empty plasmid or in the normal tissues (liver, spleen) that were investigated. Animals, concomitantly treated with CombreAp, showed higher incidence of CDase positive tumours (100\% versus 58\%). Moreover, the level of active CDase in these tumor specimens was considerably higher (mean conversion efficiency of 5-FC to 5-FU $-11 \%$ ) as compared to tumours not treated with CombreAp (mean conversion 
efficiency of 5-FC to 5-FU $\sim 3 \%$ ). We already showed that targeting the tumor vasculature in rhabdomyosarcoma bearing WAG/Rij rats using CombreAp resulted in extensive necrosis, observed already at 4 days post-injection [4]. The present results with recombinant clostridia confirmed the hypothesis that combining the administration of clostridia with CombreAp treatment should result in an increased therapeutic dose intensity. This should obviously also be expected in combinations with other strategies that induce tumor necrosis, such as radiotherapy or chemotherapy. The engineered Clostridium strains can thus be considered as in situ 'cell factories', that produce and secrete anti-tumor therapeutics specifically at the tumor site, restricting activity to the tumor being targeted. As a consequence, this strategy holds promise for circumventing the limited therapeutic window of 5-FU treatment.

Table 1. Overview of the in vivo experiments with clostridia recombinant for CDase

\begin{tabular}{|c|c|c|c|c|c|}
\hline Strain & Tissue & CombreAp" & $\begin{array}{l}\text { Presence }^{b} \\
\text { Cdase }\end{array}$ & Incidence (\%) & $\begin{array}{l}\text { CDase } \\
\text { level }^{c}\end{array}$ \\
\hline \multirow[t]{3}{*}{ NI4082/pKNT19closcodA } & tumor & - & yes & $10 / 18(55)$ & + \\
\hline & liver & - & no & $0 / 5(0)$ & $\mathrm{NA}^{\mathrm{d}}$ \\
\hline & spleen & - & no & $0 / 5(0)$ & NA \\
\hline NI4082/pKNT19 & tumor & - & No & $0 / 6(0)$ & NA \\
\hline \multirow[t]{3}{*}{ DSM792/pKNT19closcodA } & tumor & + & yes & $9 / 9(100)$ & +t \\
\hline & liver & + & no & $0 / 5(0)$ & NA \\
\hline & spleen & + & no & $0 / 5(0)$ & NA \\
\hline \multirow[t]{3}{*}{ DSM792/pKNT19closcodA } & tumor & - & yes & $4 / 6(66)$ & + \\
\hline & liver & - & no & $0 / 3(0)$ & NA \\
\hline & spleen & - & no & $0 / 3(0)$ & NA \\
\hline \multirow[t]{2}{*}{ DSM792/pKNTI9 } & tumor & + & no & $0 / 4(0)$ & NA \\
\hline & tumor & - & no & $0 / 6(0)$ & NA \\
\hline
\end{tabular}

\footnotetext{
"single i.p. administration, $25 \mathrm{mg} \mathrm{kg}{ }^{-1}$

"presence of CDase was evaluated using tlc-analysis, measuring conversion of 5-FC to 5-FU

'+, low; ++, moderate-high

${ }^{d} \mathrm{NA}$ : not applicable
} 
To show that the conversion of 5-FC to 5-FU was a consequence of the CDase present in the tumor and was not due to the metabolic activity of the Clostridium during the incubation, metronidazole $\left(50 \mu \mathrm{g} \mathrm{ml}^{-1}\right)$ was added to rhabdomyosarcoma tumor homogenates prior to the incubation to kill all bacteria. No difference in the 5 FC/5-FU conversion pattern was observed whether or not metronidazole was added. Moreover, CDase activity was also detected when only supernatants of tumor homogenates were incubated with 5-FC. Conversion efficiencies of 5-FC to 5-FU after incubation with supernatants were similar as obtained after incubation with the whole tumor homogenates. Taken together, this clearly indicates that the CDase activity, recovered from the intratumoral tissue, originates from active enzyme that is secreted by metabolically active recombinant clostridia during the in vivo colonization of the tumor.

Separated from its anti-neoplastic effects, 5-FU also sensitizes tumor cells to irradiation, and significant improvements in tumor response can therefore be anticipated when the approach described in the present manuscript would be combined with radiotherapy. We recently showed that sufficient 5-FU should be available if the conversion efficiency from $5-\mathrm{FC}$ is $1-3 \%$, enabling sensitization enhancement ratios of 1.1 to 1.2 with daily 2 Gy fractioned radiotherapy [5]. Based on the obtained conversion efficiencies both in vitro and in vivo using the plasmids discussed above, it is reasonable to expect that clinically significant radiosensitizing effects can be achieved using the recombinant clostridia.

Besides its exquisite tumor selectivity, the application of the clostridial delivery vehicle is very safe. It elicits only a minor host immune response and the clostridial cells can be removed from the body at any time by the administration of metronidazole.

Overall, the present in vivo/in vitro investigations provide strong evidence for the potential use of apathogenic clostridia, genetically engineered to express cytosine deaminase in anticancer therapy. 


\section{III.2.B.4. References}

1. Brown JM, Giaccia AJ. The unique physiology of solid tumors: opportunities and problems for cancer therapy. Cancer Res 58: 1408-1416 (1998).

2. Theys J, Nuyts S, Landuyt W, et al. Stable Escherichia coli-Clostridium acetobutylicum shuttle vector for secretion of murine tumor necrosis factor alpha. Appl Environm Microbiol 65: 4295-4300 (1999).

3. Haack K, Moebius U, Knebel Doeberitz MV, et al. Detection of cytosine deaminase in genetically modified tumor cells by specific antibodies. Hum Gene Ther 8: 1395-1401 (1997).

4. Landuyt W, Verdoes O, Darius DO, et al. Vascular targeting of solid tumours: a major 'inverse' volume-response relationship following combretastatin A-4 phosphate treatment of rat rhabdomyosarcomas. Eur J Cancer 36: 1833-1843 (2000).

5. Lambin P, Nuyts S, Landuyt W, et al. The potential therapeutic gain of radiationassociated gene therapy with the suicide gene cytosine deaminase. Int J Radiat Biol 76: 285-293 (2000). 


\section{Chapter IV}

IV.1. In vivo animal functional MRI: improved image quality with a body-adapted mold

Published in : J. Magn. Reson. Imaging (JMRI); in press, 2002

Willy Landuyt, Stefan Sunaert, Davide Farina, Martijn Meijerink, Eric Béatse, Paul Van Hecke, Robert Hermans, Guy Marchal, Philippe Lambin and Hilde Bosmans 


\section{Summary}

Purpose: To reduce functional MRI susceptibility distortion at the air/tissue interphase in animal experiments .

Materials and Methods: We investigated the applicability of a body-adaptable flexible mold consisting of a fast setting alginate. This technique was implemented for subcutaneous growing tumors in rats and for the brains of monkeys.

Results: The $\mathrm{T}_{2}{ }^{*}$-weighted GE-EPI data obtained with body-adapted mold showed a reduction of susceptibility artefacts and improved image quality. With both rat tumor and monkey brain, an optimized match with the anatomical T1 images was possible.

Conclusion: The present mold methodology is a rapid, easy and inexpensive way to reduce magnetic susceptibility during animal GE-EPI. 


\section{IV.1.1. Introduction}

Functional MRI techniques that are based on the paramagnetic properties of oxygen, i.e. the blood oxygen level dependent (BOLD) endogenous contrast, rely on $\mathrm{T}_{2}{ }^{*}$ effects [e.g. 1,2]. Gradient-echo, echo planar imaging (GE-EPI) acquisitions are implemented to achieve high temporal resolution and optimal visualization of the BOLD effect within the whole organ/body.

In our research groups, we have 2 major applications for the BOLD effect: (i) investigations in rats with subcutaneously growing tumors, aiming to non-invasively define the tumors that may respond to hypoxia modulators; and (ii) the study of the brain function, performed in monkeys. These GE-EPI studies highlighted a well known difficulty: signal loss and image distortions due to magnetic field inhomogeneity specifically at the air/tissue interface. Magnetic susceptibility distortion could be reduced after shimming, but the results remained unsatisfactory in the pilot experiments.

The present study reports a practical procedure that involves a body-adapted alginate mold. This mold was tested first in the GE-EPI acquisitions for rat tumors and later on in imaging monkey brains, with the results showing improved image quality.

\section{IV.1.2. Materials and methods}

One set of experiments was performed with male adult WAG/Rij rats, weighting $280-300 \mathrm{~g}$. Rhabdomyosarcoma tumors were implanted subcutaneously at the lower flank region as $1 \mathrm{~mm}^{3}$ pieces and had grown to a size of $3-14 \mathrm{~cm}^{3}$ at the time of the present functional MRI study. To avoid movement, the rats were anesthetized with $0.1 \mathrm{ml} / 100 \mathrm{~g} \mathrm{Nembutal} \circledast$ injected intraperitoneally a few minutes prior the imaging. They were positioned supine within a home made cylindrical resonator coil of $14 \mathrm{~cm}$ diameter.

A separate investigation involved the use of Macaque monkeys. The brains were imaged in awake animals, positioned supine in the magnet. They were specifically trained to behave and feel at ease and thus allowing an adequate imaging. 


\section{Functional MRI}

Imaging was performed using a whole body 1.5 T MR scanner (Magnetom Vision, Siemens; Erlangen, Germany), without and with the body-adapted mold.

The imaging session started with the acquisition of a scout sequence in 3 directions, followed by a multi-angle projection (MAP) shim and the functional MRI acquisition with a series of single shot $\mathrm{T}_{2}{ }^{*}$-weighted GE-EPI images (TE $39 \mathrm{~ms}$ ).

Anatomical images were obtained using $T_{1}$-weighted spin echo measurements.

\section{Susceptibility-reduction procedure}

Rat study

The anaesthetized animals were placed supine in a flexible plastic recipient, to allow a correct mold application and an easy insertion in the cylindrical coil. A mold of about $1.5 \mathrm{~cm}$ thickness was applied securely around the tumors and the major part of the body up to the claviculae. The mold material consisted of a fast setting alginate powder Xantalgin ${ }^{\circ}$ Select (Bayer Dental, Leverkusen, Germany), which after mixing with tepid water became a viscous mass that stiffened gently in less than 2 minutes. The mold remained flexible and did not interfere with the breathing capacity of the animals. The mold could be removed rapidly from the body without any difficulty.

\section{Monkey study}

The initially viscous mold was positioned on the upper part of the head and allowed to stiffen before the insertion of the animal into the magnet.

\section{Data evaluation}

Images of the tumor-bearing rat and of the monkey brain without and with mold, obtained after careful shimming, were printed together with the anatomical images. Quality and global confidence was appreciated on images with the mold not being visible.

\section{IV.1.3. Results}

\section{Rat study}

Images of the rats that were acquired without the use of any covering mold showed major susceptibility artefacts. These problems are demonstrated by 
representative images from sagittal sections of two different rats at the level of the tumor (Fig. 1B and 2A). The folded upper surface and the edgy tumor massa, as well as loss of tumor/body volume, are visible. Without the alginate mold, mapping the GE-EPI data to the $\mathrm{T}_{1}$-weighted anatomical MR images (see for example in Fig. 1B versus $1 \mathrm{~A})$ was very difficult, as was also the identification of the location of the tumor. Classical MAP shimming resulted in a minor amelioration of the image quality.

With the use of the body-adapted mold and after applying MAP shimming, GE-EPI image improvement was obvious: easily appreciated were the flattening of the base of the sagittal image and an increase in the body diameter parallel with the phase encoded dorso-ventral direction (Fig. IC and $2 \mathrm{~B}$ ). The $\mathrm{T}_{2}{ }^{*}$-weighted images of the rats with the mold more closely resembled the whole body volume and to some extent the anatomy obtained with the $\mathrm{T}_{1}$-weighted spin echo scanning (Fig.1D and 2C). It became possible to un-ambigously locate the tumor and to describe the shape of the lesion. 

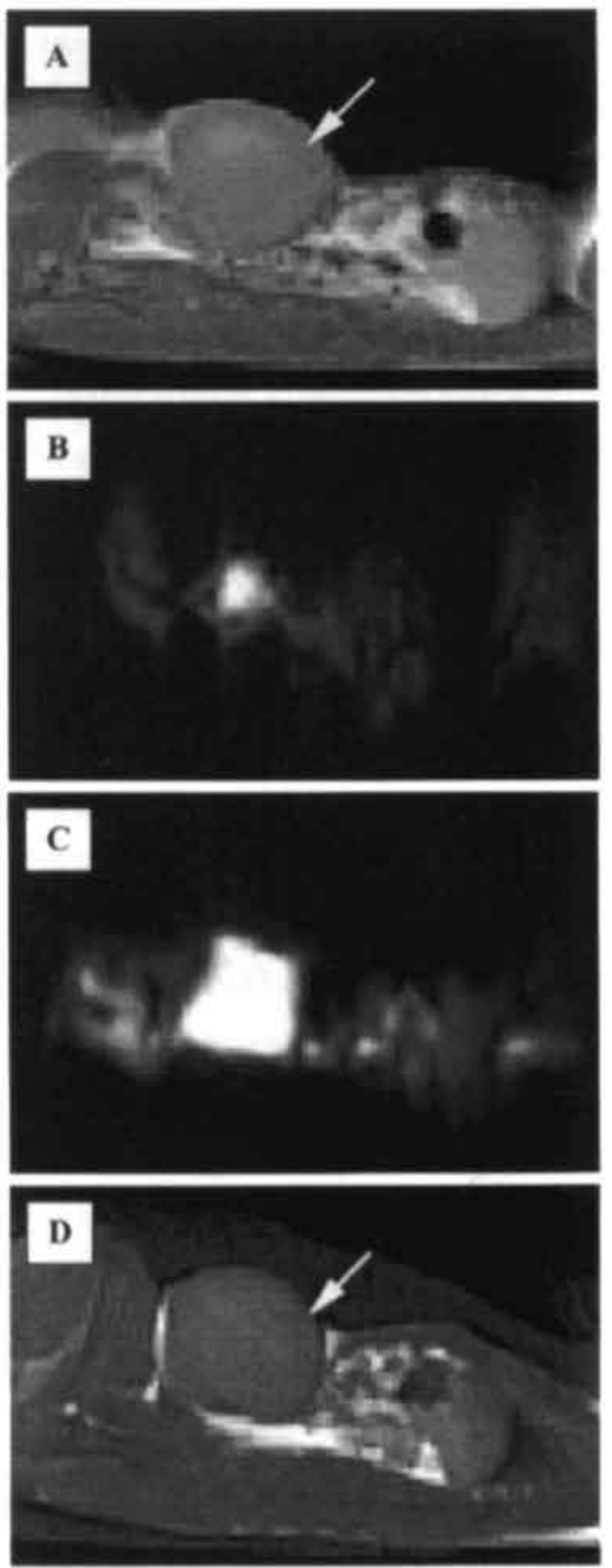

Figure 1: Panel $A$ is the sagittal $T_{1}$ anatomical image of a rat at the level of the tumor (see arrow), without the mold, illustrating the reproducible positioning (comparison with panels $B, C$ and $D$ ) and the much lesser effect of the mold on $T$-weighted imaging ( $A$ versus D). Sagittal GE-EPI $T_{2}^{*}$-weighted images, $(\boldsymbol{B})$ without and $(\boldsymbol{C})$ with the alginate mold; the tumor location and its volume presented in panel $C$ correlate with the anatomical image shown in panel $D$. 

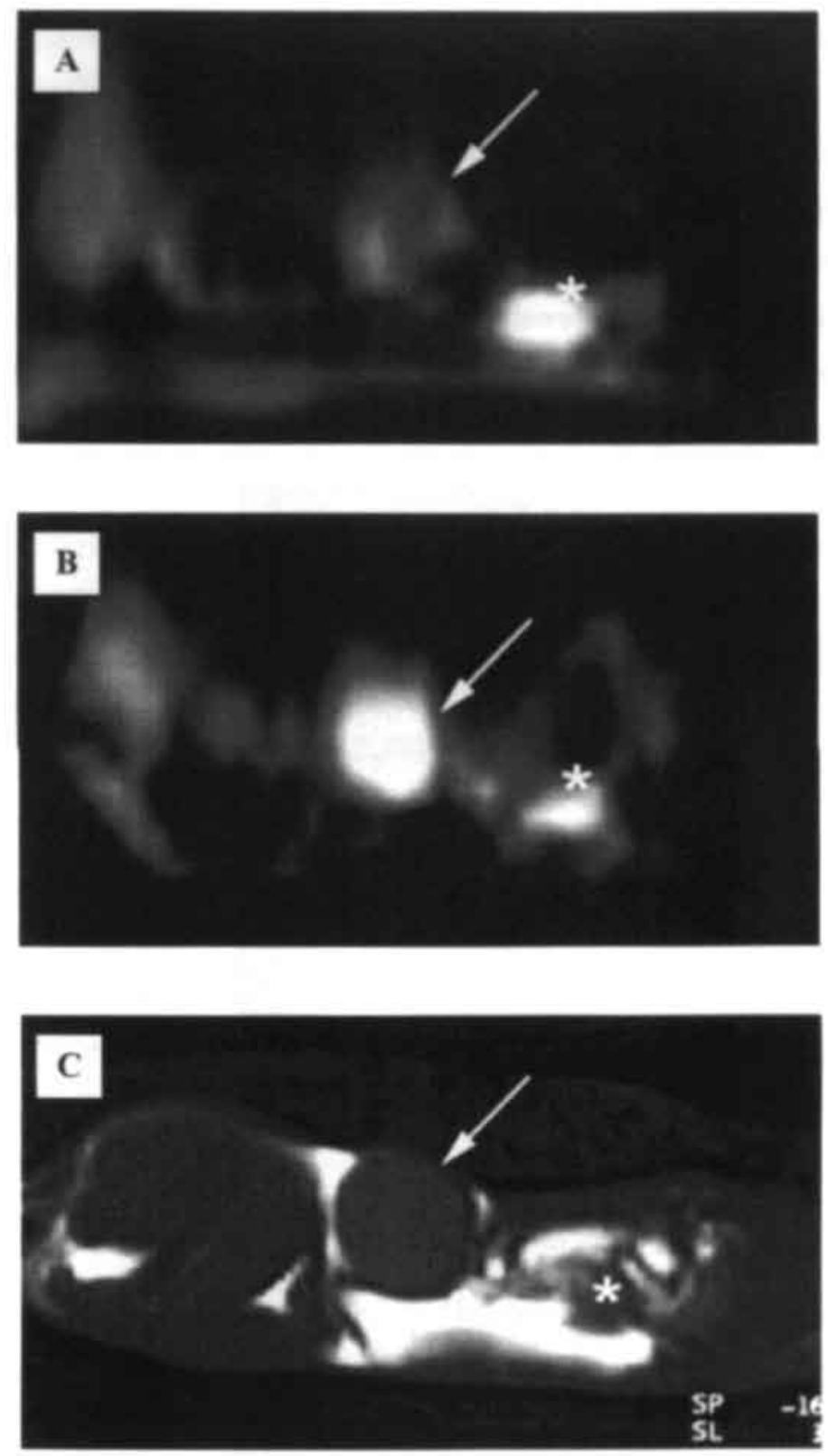

Figure 2: Sagittal GE-EPI $T_{2} *$ images of the rat body at the level of the tumor (see arrow). (A) without and $(\boldsymbol{B})$ with the body-adapted mold (same slice position through tumor). The $T_{1}$. weighted anatomical image is added for comparison $(C)$. In the presence of the mold, the obvious artifacts from susceptibility variations are reduced (panel B) and the image allows analysis of the whole tumor volume. The asterix indicates the stomach for further clarification of the reproducible positioning during imaging without and with the alginate mold. 


\section{Monkey study}

The use of a $2 \mathrm{~cm}$ thick mold always resulted in an improved brain delineation, as can be appreciated from the example in figure 3. A transverse GE-EPI image through the brain of a monkey, prior to the use of the mold, is shown in figure $3 \mathrm{~A}$. From the comparison with the anatomical image taken at the same level of the brain (Fig. 3C), an important deviation along the phase encoded direction is obvious. Following the positioning of the flexible mold material, an almost perfect match of the contour of the brain has been obtained (Fig. 3B).
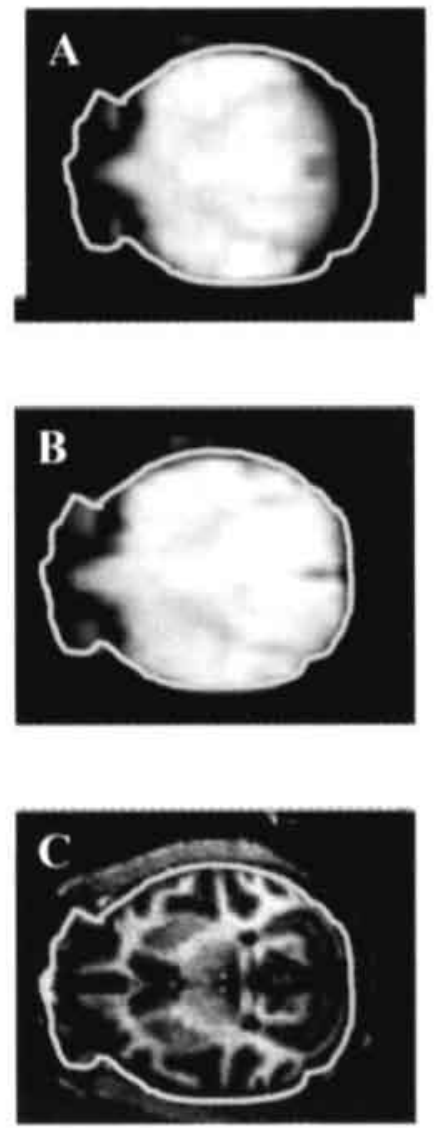

Figure 3: (A) GE-EPI transversal section obtained without and (B) GE-EPI transversal section at the same location as (A), with body-adapted mold applied on the superior part of the monkey cranium. (C) Transversal $T_{1}$-weighed section depicting the anatomy and topology of the monkey brain (same location as A). The brain contour has been delineated with Adobe Photoshop software in panel $C$, and was then pasted onto (A) and (B). It is seen that especially along the phase encoded direction. i.e. from front to back in this animal study. distortions are much reduced. 


\section{IV.1.4. Discussion}

One of the shortcomings with GE sequences for in vivo whole body functional MRI, with BOLD endogenous contrast, is the major geometric distortion and susceptibility artifacts related to the air/tissue interface.

The present data describe a practical and inexpensive method by which this important source of distortion and susceptibility can be reduced. The body-adapted alginate mold increases the accuracy to delineate regions of intensity changes and the quantification of these changes. This technique has been successfully used in a larger series of investigations which evaluated modulation of tumor oxygenation [3]. The application of this type of mold also improves the image quality and the delineation of the anatomical structures to be investigated, such as indicated with the monkey brain. A dedicated BOLD and MION functional MRI study using the mold material, more broadly demonstrates the necessity to obtain high quality images to assess motionrelated brain function in monkeys [4].

In summary, the impact of the susceptibility-reducing mold procedure as seen with the rodent tumor model as well as with the monkey brain analysis is obvious. It is a rapid and easy technique that introduces an objective decrease of magnetic susceptibility, a result that will contribute to the basic research in functional imaging.

\section{IV.1.5. References}

1. Ogawa S, Lee TM, Nayak AS, Glynn P. Oxygenation-sensitive contrast in magnetic resonance image of rodent brain at high magnetic fields. Magn Reson Med 1990; 14: 68-78.

2. Bandettini PA, Wong EC, Jesmanowicz A, Hinks RS, Hyde JS. Spin-echo and gradient-echo EPI of human brain activation using BOLD contrast: a comparative study at 1.5T. NMR Biomed 1994: 7:12-20.

3. W. Landuyt, R. Hermans, H. Bosmans, et al. BOLD contrast fMRI of whole rodent tumour during air or carbogen breathing using echo planar imaging at 1.5 Tesla. Eur Radiol 2001: 11 : 2332-2340.

4. Vanduffel W, Fize D, Mandeville JB, et al. Visual motion processing investigated using contrast-agent enhanced $\mathrm{AMRI}$ in awake behaving monkeys. Neuron 2001; 32 : $465-477$. 



\section{Chapter IV}

IV.2. BOLD contrast functional magnetic resonance imaging of whole tumour during air or carbogen breathing: initial experience in rat rhabdomyocarcoma using echo planar imaging at 1.5 Tesla

Published in : Eur. Radiol. 11: 2332-2340, 2001

Willy Landuyt, Robert Hermans, Hilde Bosmans, Stefan Sunaert, Eric Béatse,

Davide Farina, Martijn Meijerink, Hao Zhang, Walter Van den Bogaert,

Philippe Lambin and Guy Marchal 


\section{Summary}

To evaluate the feasibility of functional magnetic resonance imaging (fMRI) at 1.5 Tesla, exploiting 'blood oxygenation level-dependent' (BOLD) contrast, for detecting changes in whole tumour oxygenation induced by carbogen $\left(5 \% \mathrm{CO}_{2}+95 \% \mathrm{O}_{2}\right)$ inhalation of the host.

Adult WAG/Rij rats with rhabdomyosarcomas growing subcutaneously in the lower flank, were imaged when tumours reached sizes between $1 \mathrm{~cm}^{3}$ and $11 \mathrm{~cm}^{3}(\mathrm{n}=12)$. Air and carbogen were alternatively supplied at $2 \mathrm{l} / \mathrm{min}$ using a snouth mask. Imaging was done on a 1.5 T MR scanner using a $\mathrm{T}_{2} *$ weighted GE-EPI sequence. Analysis of the whole tumour EPI images was based on statistical parametric maps; voxels with and without signal intensity changes (SIC) were recorded. Significance thresholds were set at $\mathrm{p}<0.05$, corrected for multiple comparisons.

In continuous air breathing condition, 3/12 tumours showed significant negative SIC and I tumour had a clearcut positive SIC. The remaining tumours showed very little or no change. When switching to carbogen breathing, the SIC were significantly positive in 10/12 tumours. Negative SIC were present in 4 tumours, of which three were simultaneously characterised by positive SIC. The overall analysis indicated that 6 of the 12 tumours could be considered as strong positive responders to carbogen.

Our research demonstrates the applicability of fMRI GE-EPI at $1.5 \mathrm{~T}$ to study ole tumour oxygenation non-invasively. The observed negative SIC during air condition may reflect the presence of transient hypoxia during these measurements. Selection of tumours on the basis of their individual response to carbogen is possible, indicating a role of such noninvasive measurements for using tailor-made treatments. 


\section{IV.2.1. Introduction}

The inappropriate vascular remodeling and the related hypoxia are critical issues for survival and certainly growth of tumours,as well as for the presence of radio- and chemotherapy resistance; tumours with high oxygenation status on average responded more favourably than those that were poorly oxygenated [e.g. 1-3]. This knowledge has led to the introduction and evaluation of agents that may have the potential to promote the oxygenation status of the tumour. Agents such as carbogen ( 5 $\% \mathrm{CO}_{2}+95 \% \mathrm{O}_{2}$ ) and nicotinamide have been shown to selectively improve tumour oxygenation, both with rodent and human tumours [4-6]. Subsequently, the combination of such agents specifically with radiotherapy demonstrated the potential benefit of positive tumour oxygenation changes [7-10].

Research has in parallel also focussed on the measurement of hypoxia levels in tumours, using a battery of different techniques [11-15]. A drawback is their invasiveness and the absence of whole tumour information. Although improving the understanding of the physiology and biology of different tumour types, such techniques on their own do not meet the requirements to enable f.i. non-invasive repeated oxygenation measurements, before and during treatments, in relatively short time. They neither allow the assessment of anatomically difficult and deep seated tumours. The availability of a non-invasive total body imaging technique could thus positively guide oxygenation modulating treatments that aim to improve tumour control and patient survival.

One potential candidate principle, extensively used in functional MRI to assess brain activity triggered with external stimuli, involves the endogenous blood oxygenation level-dependent (BOLD) contrast [16-18]. The BOLD contrast relates to the endogenous change of paramagnetic deoxyhemogiobine that is translated in variation of MR signals. The method thus likely offers a non-invasive and clinically applicable tool to detect changes in tumour oxygenation from different treatments without the need to inject contrast agents, nor to disturb the tumour microenvironment. Tumour oxygenation data were therefrom collected using fMRI applying a gradient-recalled echo (GRE) technique, specifically in function of responses to various gas breathing [19-22]. Two important limitations remain. The measurements have been performed with single slice techniques and they often involved magnetic field strenghts above $4 \mathrm{~T}$, exept some limited experience with both 
animal and patient pilot studies [23-26]; extrapolation of these results to lower field strength systems is not straightforward.

The major objective of our investigation was to evaluate the application of BOLD contrast fMRI at a clinical whole body $1.5 \mathrm{~T}$ using a fast EPI sequence, as a non-invasive tool to determine changes in tumour oxygenation from carbogen breathing of the host. The relationship between carbogen responses and tumour volume was also adressed. Finally, the question was raised whether the proposed analysis allowed for clearcut selection of carbogen responsive tumours.

\section{IV.2.2. Materials and methods}

\section{In vivo tumour model}

Male adult WAG/Rij rats, with a body weight of about $270 \mathrm{~g}$, were implanted subcutaneously (s.c.) in the lower flank region with a $1 \mathrm{~mm}^{3}$ piece of syngeneic rhabdomyosarcoma ( $\mathrm{R}$ I tumour). At the time of the fMRI study their volume was estimated using a calliper, correcting for the thickness of the skin. The experiments were planned to incorporate various tumour sizes ranging between 0.1 and $14 \mathrm{~cm}^{3}$.

\section{Animal preparation for imaging}

The rats were anaesthetised with $0.1 \mathrm{ml} / 100 \mathrm{~g} \mathrm{Nembutal}{ }^{*}$ (SANOfi, Brussels, Belgium) injected intraperitoneally a few minutes prior to imaging. To reduce susceptibility artefacts, the animals were placed supine in a flexible plastic recipient, and a mould of about $1.5 \mathrm{~cm}$ thickness was applied around the tumours and the major part of the body. This mould consists of the fast setting alginate powder Xantalgin ${ }^{8}$ (Bayer Dental, Leverkusen, Germany), remaining flexible and not interfering with the breathing capacity of the animals; it could be removed rapidly from the body without difficulty [27].

Throughout the measurements, the animals were breathing air or carbogen $\left(95 \% \mathrm{O}_{2}, 5 \% \mathrm{CO}_{2}\right)$ at a flow rate of $2 \mathrm{l} / \mathrm{min}$ through a small snout mask.

These animal-based experiments were in agreement with the Ethical Committee for Animal Care and Use of the K.U.Leuven (Belgium) and the national guidelines. 


\section{Imaging technique}

The fMRI studies were performed on a whole body 1.5 Tesla MR scanner (Magnetom Vision, Siemens, Erlangen, Germany), equipped with a gradient system achieving $25 \mathrm{mT} / \mathrm{m}$ in $300 \mu \mathrm{s}$. A home made cylindrical coil of $14 \mathrm{~cm}$ diameter was used as antenna.

The imaging sessions consisted of the acquisition of scout images, followed by shimming and fMRI acquisitions. For the fMRI acquisitions, series of sagittal $\mathrm{T}_{2}$ * weighted echo planar imaging (EPI) images were acquired through the entire animal. The parameters for the single shot $\mathrm{T}_{2}{ }^{*}$ weighted EPI sequence used were: TE $39 \mathrm{~ms}$, echo spacing $0.8 \mathrm{~ms}$, band width $1950 \mathrm{~Hz}$ /pixel, field of view $288 \times 384 \mathrm{~mm}$, matrix $96 \times 128$, slice thickness $3 \mathrm{~mm}$, interslice gap $1 \mathrm{~mm}$.

Two series, each consisting of 120 measurements of 16 slices and each lasting 8 min, were obtained sequentially. During the first series air was continuously delivered, while during the second series air and carbogen were delivered alternatively (i.e. one min of air / five min of carbogen / two min of air).

\section{Data analysis}

The images were transferred to a work station (Silicon Graphics), corrected for motion and spacially smoothed by convoluting the data using a Gaussian imput function with a full-width at $1 / 2$ maximum. Statistical parametric maps (SPM) were computed using SPM96 $[28,29]$. The evaluation of the $T_{2} *$ images was always done with reference to the mean baseline signal intensity (obtained for air condition during the first min of the imaging) of every individual tumour screening. The different conditions were modeled with a box car function convolved with the hemodynamic response function implemented as a delayed Gaussian function [30] in the context of the general linear model, as employed by SPM96. Global changes were adjusted for by proportional scaling, and low-frequency confounding effects were removed by an appropriate high pass filter. Specific effects were tested by applying appropriate linear contrasts to the parameter estimates for each condition, resulting in a $t$ statistic for each voxel. These statistics constitute an SPM. Significance thresholds were set at p < 0.05 , corrected for multiple comparisons.

Using a mouse-controlled cursor, the borders of the tumours were manually traced on the $T_{2}{ }^{*}$ weighed EPI images by the same experienced radiologist (R.H.). 
The number of voxels within the defined tumour volumes was counted, and a MR determined tumour volume was calculated by multiplying the number of voxels with their dimensions ( $3 \times 3 \times 4 \mathrm{~mm})$; the MR determined tumour volume was compared with the calliper-method using linear regression.

Voxels showing a statistically significant increase or decrease in signal intensity during air breathing were counted. The relative degree of signal intensity changes (SIC) during air condition, compared to the baseline signal intensity, was calculated for each of the voxels showing changes above the significance threshold. By summing up all the negative SIC and separately all the positive SIC, two areasunder-the-curves (AUC's) were calculated; these AUC's were normalized by dividing them by the total number of voxels within the MR defined tumour volume.

The same type of analysis was applied for the EPI images obtained during the intermittent carbogen breathing condition. These analyses also were performed for all tumours.

The results obtained during the air or the carbogen breathing condition were compared using a paired non-parametric statistical test (Wilcoxon's signed rank test); p-values $<0.05$ were considered significant.

\section{IV.2.3. Results}

The comparison of the tumour sizes $(n=12)$, as either obtained from the $T_{2}{ }^{*}$ weighted images or with the calliper, is shown in Figure 1. The MR determined volumes of the 12 rat rhabdomyosarcomas under investigation ranged from 1.62 to $10.37 \mathrm{~cm}^{3}$. Using the calliper method, the volume of the tumours measured just before the fMRI study ranged from 0.9 to $8.9 \mathrm{~cm}^{3}$. An optimal linear fit was obtained between both methods of measuring volume by using the following function: MR volume $=0.8451 \times$ caliper volume $+0.3982(R=0.84)$. The MR defined tumour volumes were used throughout the further analysis of all fMRI images. Figure 2 displays a representative image of the rat tumour signal intensity evaluation, both during air breathing (Figure 2A) and during the carbogen breathing condition (Figure 2B). 


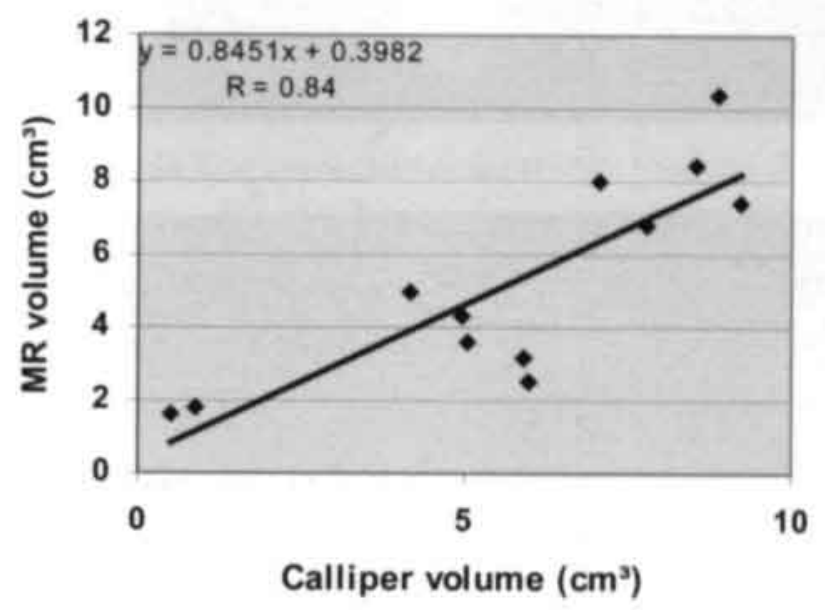

Figure 1. Comparison of the tumour sizes, determined either with the delineation at the $T_{2} *$ weighted images (indicated as MR volume) or with the calliper approach. 


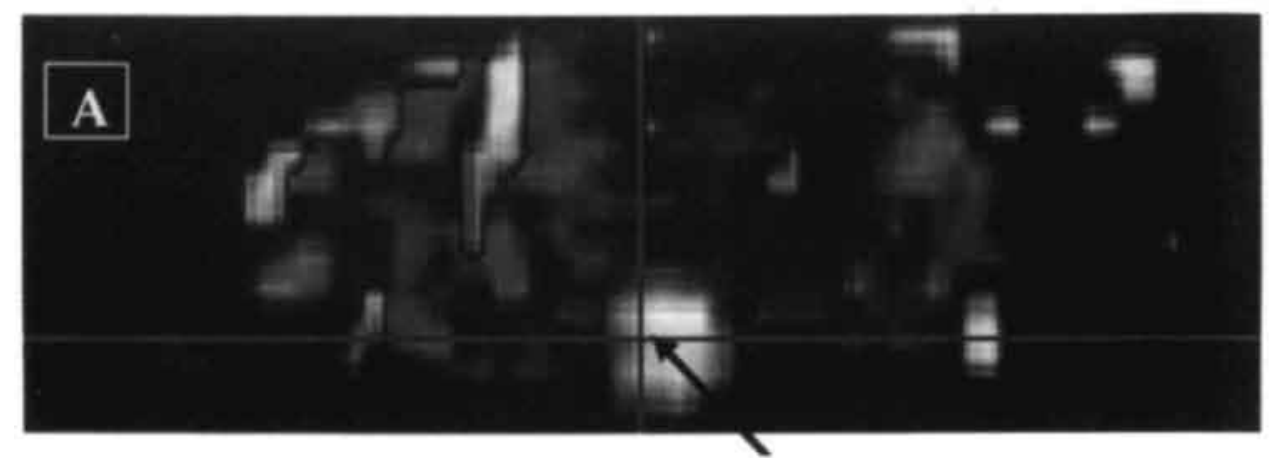

Tumour location s, c.at the lower flank

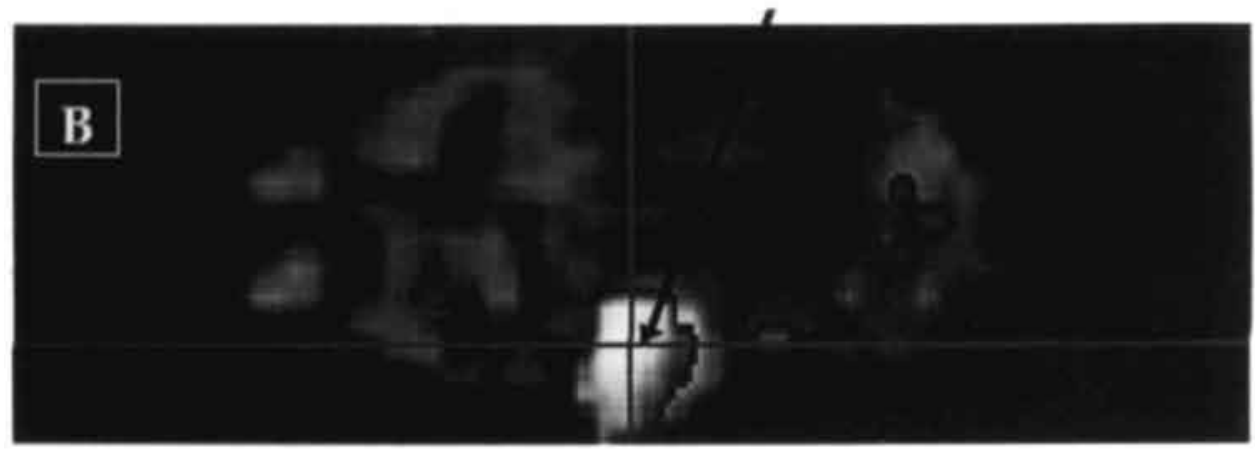

Figure 2. BOLD fMRI with EPI 39: example of carbogen-induced (B) signal intensity enhancement versus air breathing condition $(A)$ within a random selected medium sized rat rhabdomyosarcoma.

Table I gives an overview of the absolute number of voxels that showed positive, negative or zero signal intensity changes (SIC) either during the continuous air breathing condition or during the switch to carbogen. Figure 3, A and B, summarizes the voxel-based measurements (percentages deduced from the absolute values presented in Table 1). During the prolonged air breathing, voxels with negative SIC were present in some tumours (Figure $3 \mathrm{~A}$ ), clearly seen in 6 of the 12 tumours: about or less than $10 \%$ of the total voxel number in 4 tumours, $27 \%$ and $43 \%$ in 2 other tumours (Table 1). The number of voxels that remained without SIC dominated the picture for the various tumours. In comparison with the results during air breathing, a significantly ( $p=0.022$ ) lower percentage of voxels showing zero SIC was found during the carbogen breathing (Figure 3 B). This was parallelled by a non- 
significant $(p=0.907$ ) decrease in voxels with negative SIC, and by a highly significant $(\mathrm{p}=0.002)$ increase in percentage of voxels with a positive SIC. In 4 tumours for which voxels with negative SIC were recorded during air breathing $(<7$ $\%-43 \%$ ), no negative SIC were observed during the carbogen condition (Table I). A negative change of signal intensity of $22 \%$ and $56 \%$ was observed in 2 tumours, and $5-9 \%$ in 2 others, when the rats breathed carbogen (Table 1). For those tumours that were responsive to carbogen, the change in the EPI $\mathrm{T}_{2}{ }^{*}$ signal intensity was very rapid, most often reaching the highest value within 1 minute after the switch from air to carbogen (data not shown).

Table 1. Tumour responses during air or carbogen breathing of the rats; analysis on the basis of voxel numbers $\left(\mathrm{T}_{2}{ }^{*}\right.$ weighted images)

\begin{tabular}{|c|c|c|c|c|c|c|c|}
\hline \multirow[b]{2}{*}{$\begin{array}{c}\text { MR } \\
\text { volume } \\
\left(\mathrm{cm}^{3}\right)\end{array}$} & \multirow[b]{2}{*}{$\begin{array}{c}\text { Total } \\
\text { number of } \\
\text { voxels }\end{array}$} & \multicolumn{3}{|c|}{$\begin{array}{c}\text { AIR condition } \\
\text { (responding voxels) }\end{array}$} & \multicolumn{3}{|c|}{$\begin{array}{l}\text { CARBOGEN condition } \\
\text { (responding voxels) }\end{array}$} \\
\hline & & negative & zero & positive & negative & zero & positive \\
\hline 1.62 & 45 & 0 & 45 & 0 & 1 & 30 & 14 \\
\hline 1.8 & 50 & 0 & 50 & 0 & 11 & 32 & 7 \\
\hline 2.52 & 70 & 0 & 67 & 3 & 1 & 45 & 24 \\
\hline 3.17 & 88 & 9 & 78 & 1 & 2 & 84 & 2 \\
\hline 3.6 & 101 & II & 89 & 1 & 12 & 87 & 2 \\
\hline 4.32 & 120 & 51 & 69 & 0 & 2 & 89 & 29 \\
\hline 4.97 & 138 & 37 & 101 & 0 & 0 & 106 & 32 \\
\hline 6.8 & 189 & 0 & 189 & 0 & 42 & 147 & 0 \\
\hline 7.42 & 206 & 0 & 206 & 0 & 0 & 190 & 16 \\
\hline 7.99 & 222 & 16 & 206 & 0 & 1 & 112 & 109 \\
\hline 8.42 & 234 & 5 & 198 & 31 & 0 & 204 & 30 \\
\hline \multirow[t]{2}{*}{10.37} & 288 & 17 & 271 & 0 & 5 & 212 & 71 \\
\hline & 1751 & 146 & 1569 & 36 & 77 & 1338 & 336 \\
\hline
\end{tabular}




\section{A Air breathing condition}

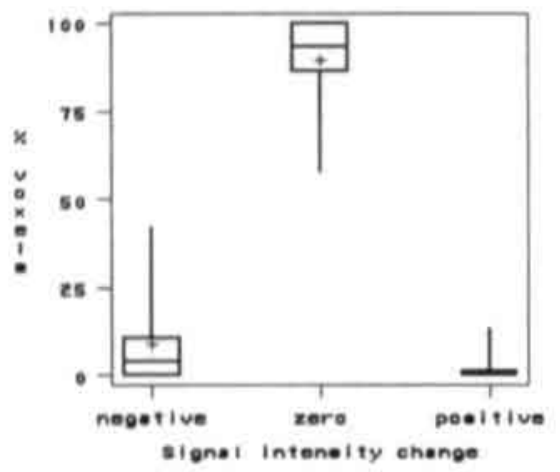

B Carbogen breathing condition

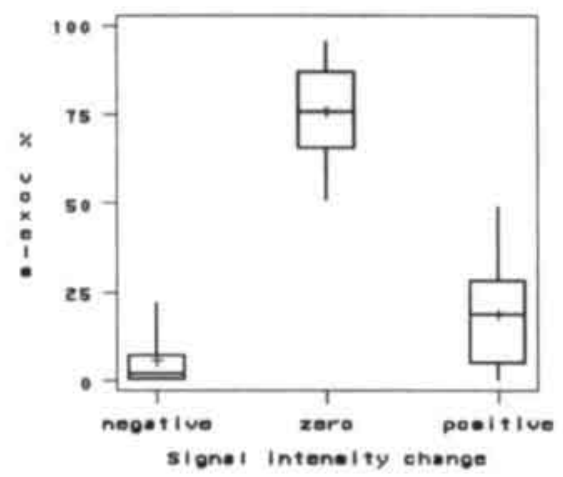

Figure 3. Box-and-whisker plot, for (A) air condition and (B) carbogen condition, representing the percentage of voxels with or without signal intensity changes (SIC), and related to the $M R$ volumes of the tumours investigated. Mean $(+)$ and median (horizontal bar in the box), as well as the $25 / 75$ percentiles (lower and upper edges of the box) are indicated. Comparing the carbogen with the air condition, statistical evaluation revealed a highly significant increase in number of voxels with positive SIC $(p=0.0024)$, a lesser but significant $(p=0.022)$ decrease in number of voxels with zero SIC, and a non-significant yet clear decrease of the number of voxels with negative SIC.

Figure 4 (A and B) shows the variation in AUC for SIC, present for air breathing and, although to a lesser extent, also for carbogen breathing conditions. No correlation was apparent between the AUC for SIC and the various tumour volumes that were analysed.

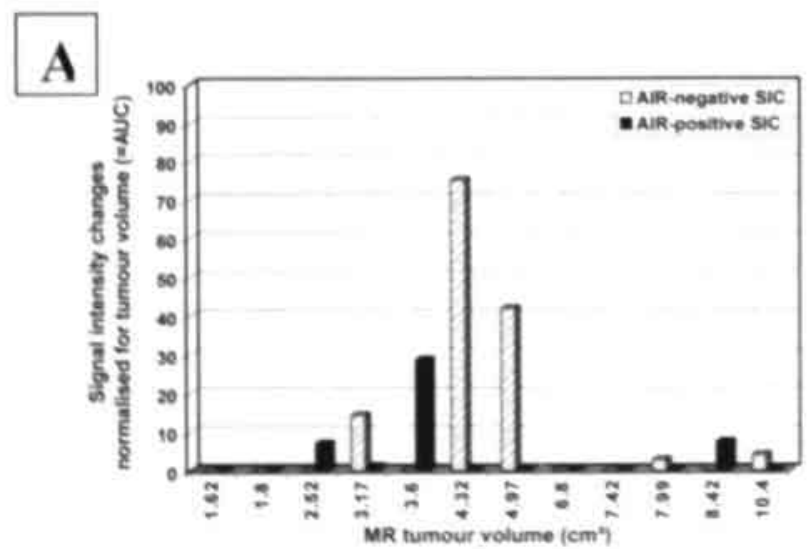




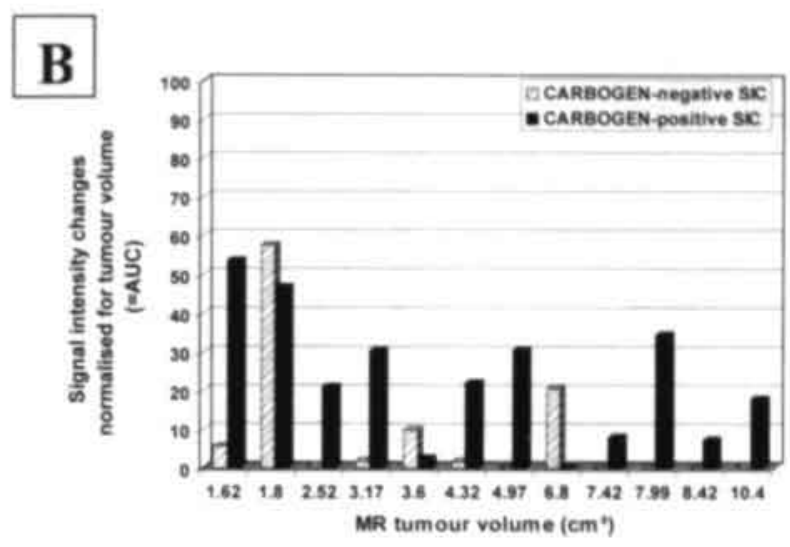

Figure 4. Display of AUC for the normalized SIC in the responding voxels, for either air $(A)$ or carbogen $(B)$ breathing condition, in relation to the individual MR tumour volumes;

graph A: The heterogenous character of the intratumoral SIC during the prolonged air condition, evaluated with respect to the base line signal intensity (average of first imaging minute), is reflected in positive (dark bars) and negative (clear bars) SIC;

graph B: The relative homogenous positive change in signal intensity (dark bars) during carbogen breathing can be deduced for all tumours, exept 3 with also or only negative (clear bars) SIC. This observation obviously relates to the baseline signal intensity, but has increased power when comparison is done with the imaging results for prolonged air condition.

Overall, in comparison with the air breathing condition (Figure $4 \mathrm{~A}$ ), a much larger AUC for the positive signal changes is found during the carbogen breathing (Figure 4 B). As also can be read from Figure 3 B, in 3 tumours a clearcut AUC of negative SIC is present. With these three tumours (sizes at imaging $=1.8 \mathrm{~cm}^{3} ; 3.6 \mathrm{~cm}^{3}$ and $6.8 \mathrm{~cm}^{3}$ respectively), the benefit of using carbogen to improve the oxygenation status is nihil.

Figure 5 displays, only for the carbogen breathing condition, the percentage of voxels showing positive SIC compared with the AUC for degree of positive SIC within the responding voxels for the remaining 9 tumours individually (main aim of our investigation). The product of the reponding voxels and their respective AUC, calculated for each tumour separately, indicates that only 6 of the 12 tumours were very significant $(p<<0.05)$ responsive to the carbogen application (insert Figure 5. relative unit for response). 


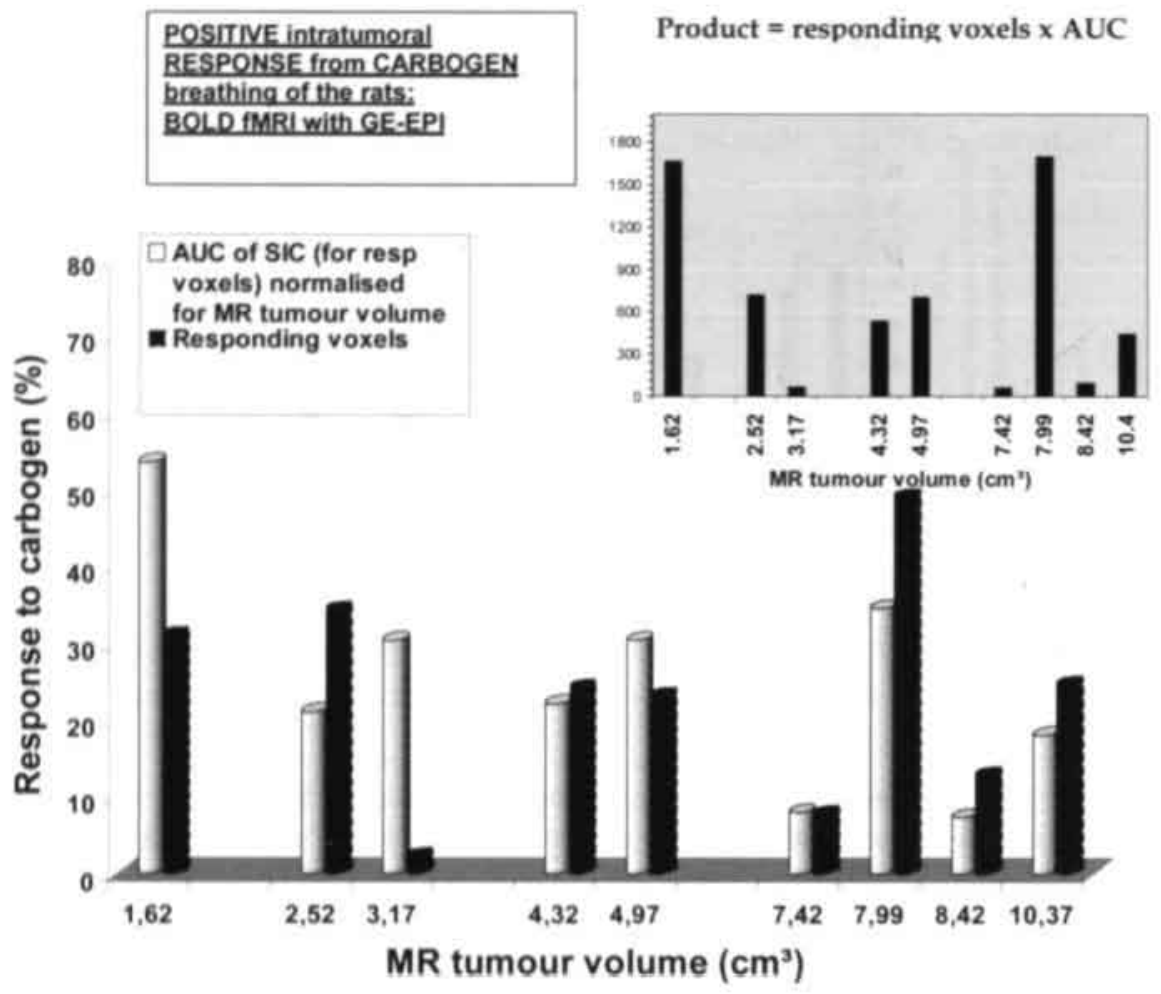

Figure 5. Overview of the data for only positive intratumoral SIC induced with carbogen breathing of the rats, in relation with tumour size (the 3 tumours with which strong negative SIC were observed during carbogen, see Figure 3 B, have been omitted). Both AUC (clear bars) and voxel number (dark bars) are plotted.

The 'insert graph' represents the product of both results of the analysis, and allows to depict the rhabdomyosarcomas that showed a highly significant response (6/12 tumours in the present study condition) to carbogen inhalation of the host.

\section{IV.2.4. Discussion}

In choosing a MR scanning technique for fMRI, spatial resolution, acquisition speed (i.e. temporal resolution) and signal-to-noise ratio (SNR) play an important role. Optimizing one factor will be at the cost of the other two. Echo planar imaging allows rapid acquisition of a single slice. Repeated measurements of the same slice require a time interval of at least 2 s. In the present study, however, this time window 
was used for the measurement of adjacent slices. Disadvantages of the technique are the relatively low spatial resolution and the sensitivity to susceptibility artefacts. The large acquisition band width needed for the rapid sampling results in a poor SNR. Susceptibility artefacts are caused by field inhomogeneity at air/tissue interfaces, gradient non-linearity and chemical shift. Using a body-adapted mould, significant improvement of image quality has been obtained by decreasing the magnetic susceptibilily at the air/body interface boundary of an animal [27]. However, this correction is not perfect, and may explain the non-optimal correlation $(\mathrm{R}=0.84)$ between the tumour volumes determined by the calliper method with those measured on the MRI GE-EPI-images, with the former being the most secure volume approach. The low SNR is compensated by repeated measurements and analysis using statistical methods.

Studies on fMRI of tumours published until now used single slice GRE sequences at high field strength [e.g. 19-21]. The in-plane spatial resolution and SNR during these experiments is better than what can be obtained with the GE -EPI technique that we describe. Applying the GRE technique, however, we could not visualize an effect of carbogen inhalation as attempted in at least 5 tumour bearing rats, wheras GE-EPI images did show a response in all the tumours that were analysed

An obvious limitation of GRE images is that the single section may not be representative for the entire tumour. EPI sequences allow however to examine the entire body/tumour in a multi-slice fashion, and may therefore provide a more comprehensive evaluation of the tumour response to carbogen breathing. The limited spatial resolution of GE-EPI introduces a problem of signal averaging within each voxel, and thus a very detailed mapping of tumour oxygenation is not feasible, which counterbalances somewhat the gain of temporal resolution obtainable with this imaging procedure. However, every technique used to estimate tumour oxygenation suffers to some extent from the problem of signal averaging; furthermore, none of the thus far applied methodologies, including microelectrode measurements, allows evaluation of the entire tumour.

During the application of the body-adapted mould and the subsequent BOLD contrast fMRI , the animals were immobilised with an anaesthetic. Possible subtle effects of the Nembutal ${ }^{*}$ anaethesia on the effectivity of carbogen breathing and 
consequently also on the oxygenation of the s.c. growing rhabdomyosarcomas can not be excluded. However, no straightforward agreement on such a bias can be deduced from the literature involving s.c. tumour models. Some blood flow reducing or hypoxia inducing effect from this anaesthetic has been reported, but it was insignificant or not at all different from the s.c. tumour condition during physical restraint without any sedation [31-33]. Moreover, all of these published data involved tumours much smaller than $1 \mathrm{~cm}^{3}$. With our study, the s.c. rhabdomyosarcomas were much larger at the time of the imaging; and thus inherent to the natural process of hypoxia development during tumour growth, any slight additional hypoxia from the use of the pentobarbital likely will become proportionately of lesser influence anyway. The moulding should not affect the tumour oxygenation condition since it remains flexible, thus allowing the normal breathing of the animals.

The present fMRI data for rat rhabdomyosarcoma show that when carbogen was administered to the rats bearing the rhabdomyosarcoma, a rapid change (less than I minute to reach the maximum) in $\mathrm{T}_{2}{ }^{*}$ weighted signal intensity was observed in most tumours, independent of the tumor size (graphical pixel-by-pixel data-analysis not shown). With BOLD contrast GE-EPI fMRI, increases in $\mathrm{T}_{2}{ }^{*}$ weighted signal intensity are related to decreases in deoxyhemoglobin. and therefore indicative for improved oxygenation in the tissue under investigation. Inversely, decreases in $\mathrm{T}_{2}$ * weighted signal intensity are related to increases in deoxyhemoglobin and thus likely reflective for tissue hypoxia induction. Other research teams investigated oxygenation changes under different gass breathing conditions in a variety of tumor systems [1921]. The carbogen-induced changes of tumour oxygenation published for these other tumor types with different techniques were, when present, also recorded rapid in time and to a significant extent.

The second observation in our study was the large intertumour variability as well as an important intratumour difference in SIC when the rats breathed carbogen. Separate from the major presence of tumour parts with zero changes, in most tumours positive signal intensity changes were observed (indicating improved oxygenation). However, also negative changes in intensity (indicating reduced oxygenation) were seen both in separate as well as in the same tumours. This was true when analyzing both the number of responding voxels, and the changes of the signal intensity within these voxels (AUC). 
The proportion of voxels with zero SIC (see Table 1) should be interpreted as the simultaneous presence of oxygenated tumour parts and areas of necrosis, proportionately depending on the tumour size at measurement. A correlation between the at random distribution/extent of necrosis and the tumour volume in rat rhabdomyosarcomas has been indicated previously by histopathological evaluation of hematoxylin-eosin stained sections of tumours of the present size-range investigated [34]. On the other hand, sufficient hemoglobin saturation with oxygen at the time of imaging could also explain the absence of a carbogen effect in some tumour parts. This information correlates with the heterogeneous response to carbogen breathing seen in our fMRI studies (present work) and the GRE-MRI studies of others [e.g. 2022]. Already in this perspective of heterogeneity, the possibility to analyse the whole tumour in a short time is an attractive and necessary feature to quantitate the variable effects of oxygenation modifying compounds.

The increases in signal intensity observed with MR spectroscopic imaging of s.c. R3230AC rat mammary adenocarcinomas (volumes of about $0.5 \mathrm{~cm}^{3}$ ) have been discussed as the result of improved blood oxygen concentration and oxygen diffusion [35]. Such relationships may likely explain the carbogen-induced positive changes in $\mathrm{T}_{2}{ }^{*}$ weighted $\mathrm{BOLD}$ contrast images as measured in the present investigation with s.c. rat rhabdomyosarcomas. Also other studies illustrate that the amelioration of tumour oxygenation is highly related to the blood $\mathrm{pO}_{2}$ increases. With near infrared spectroscopy, van der Sanden and colleagues demonstrated a clearcut improvement of the oxyhemoglobin concentration in tumour blood, when the mice breathed carbogen at any $\mathrm{CO}_{2}$ content between $1 \%$ and $5 \%$ [36]. These measurements were performed on a xenografted human glioma, when tumour size was on average $0.5 \mathrm{~cm}^{3}$. Obviously, the balance between the rate of oxygen consumption of tumour and stromal cells and the oxygen diffusion during carbogen application will impact on the overall analysis outcome. The latter will therefore and in the first place depend on the tumour type, inplantation site, and its changing general morphology as well as quality of vascularity during growth.

Furthermore, yet not really surprising, carbogen also induced prominent negative signal intensity changes in 3 rhabdomyosarcomas, independent of tumour size. In at least three studies involving GRE-MRI of different tumours, researchers demonstrated a transient decrease in signal intensity or no response during carbogen breathing $[21,23,37]$. Also with MRS, such negative as well as positive SIC from 
carbogen inhalation compared to air breathing (control condition) have been seen[19]. These observations strenghten the biological reality of this phenomenon. This heterogeneity within a single tumour was attributed by $\mathrm{Al} \mathrm{Hallaq}$ and colleagues to an intratumoral 'steal effect' [19]. They suggested that this could be due to redistribution of blood flow within the tumours. In a patient study, the steal effect seemed the most obvious explanation for the reduced GRE-MRI signal during the carbogen breathing as observed in two different tumour types [23]. To our opinion, it could be the result of the intratumoral change in balance between the vasodilating effect from the $\mathrm{CO}_{2}$ partner and the vasoconstriction effect from the $\mathrm{O}_{2}$ partner in the carbogen. It should be noted that the breathing of $100 \%$ oxygen either had no effect on the oxy- to deoxyhemoglobin ratio, or reduced the oxyhemoglobin concentration in the tumour blood circulation as the result of vasoconstriction, as indicated through two different studies $[36,38]$. These 'seemingly conflicting' phenomena may well be the result of a similar physiological response from the intratumoral vasculature, partly controlled to a thusfar unknown extent of the microvessel maturity and configuration.

Finally, also with the prolonged air-only condition heterogeneity was appreciated, with tumours showing some positivity in SIC and others with definite evidence of negative SIC. The presence of voxels with negative signal intensity during 8 minutes of air breathing (identical box car function analysis as with the carbogen response analysis), as seen strongly in 3 rhabdomyosarcoma tumours and slightly in 3 others, could indicate the occurence of areas with acute-type transient tumour hypoxia at the time of the MRI multislice measurements. This type of hypoxia is a relatively well-known physiological behavior that is the result of sequential opening and closure of tumour microregional vessels [39,40]. These intermittent changes of the oxygenation status in tumours may thus relate to a transient reduction in erythrocyte flux, with subseqently alterations in oxygen diffusion and consumption rate [see for discussion e.g. 41,42]. The time course of transient changes in blood flow within a rat mammary adenocarcinoma has been documented using Fourier analysis, and shown to be much stronger present in the tumour as compared with muscle [43].

The overall scenery indicates the appropriateness of imaging the whole tumour for the translation of oxygenation changes. Other methods appreciated until now as 'standard' (such as Eppendorf $\mathrm{pO}_{2}$ microelectrode or biopsy-related hypoxia immunohistochemistry) enable a certain yet limited level of knowledge about the oxygenation condition in tumours, and only however for those that can be reached. 
The fMRI data obtained with GE-EPI and presented here-in, being non-invasive and short in time, should permit the study of tumour oxygenation also during the treatment phase. Several recent small-scaled clinical studies, using either microelectrode $\mathrm{pO}_{2}$ measurements or perfusion MRI, reported the importance to evaluate tumour characteristics before and during the course of radiochemo- or radiation-only therapy [e.g. 44-46].

Our initial results with the rat rhabdomyosarcoma tumour model provide good evidence for the feasibility to image tumour oxygenation using the BOLD fMRI with GE-EPI operating at 1.5 Tesla. Significant inter- and intratumoral heterogeneity in changes in $\mathrm{T}_{2}{ }^{*}$, reflecting changes in intratumoral oxygenation status from the carbogen breathing, were observed. The imaging and analysis methodology enabled the selection of tumours that reacted favourably (or the opposite) to the carbogen breathing of the hosts. The fMRI methodology also allowed to indicate the spontaneous presence of transient hypoxia, as evidenced by the analysis of intratumoral signal intensity fluctuations that occurred during continuous ( 8 minutes) air breathing of the rats. The proposed total body fMRI methodology involving a clinical applicable magnetic field strength and fast whole tumour screening should help to select for differential oxygen-improvement related treatments.

\section{IV.2.5. References}

1. Brizel DM, Dodge RK. Clough RW, Dewhirst MW. Oxygenation of head and neck cancer: changes during radiotherapy and impact on treatment outcome. Radiother Oncol 53: 113-117 (1999).

2. Höckel M, Schlenger K, Mitze M, Schäffer U, Vaupel P. Hypoxia and radiation response in human tumors. Semin Radiat Oncol 6: 3-9 (1996).

3. Nordsmark M, Overgaard J. A confirmatory prognostic study on oxygenation status and loco-regional control in advanced head and neck squamous cell carcinoma treated by radiation therapy. Radiother Oncol 57: $39-43$ (2000).

4. Bussink J, Kaanders JHAM, Rijken PFJW, Peters JP, Hodgkiss RJ, Marres HA, van der Kogel AJ. Vascular architecture and microenvironmental parameters in human squamous cell carcinoma xenografts: effects of carbogen and nicotinamide. Radiother Oncol 50: $173-184$ (1999). 
5. Martin L, Lartigau E, Weeger P, Lambin P, Le Ridant AM, Lusinchi A, Wibault P. Eschwege F, Luboinski B, Guichard M. Changes in the oxygenation of head and neck tumors during carbogen breathing. Radiother Oncol 27: 123-130 (1993).

6. Powell ME, Collingridge DR, Saunders MI, Hoskin PJ, Hill SA, Chaplin DJ. Improvement in human tumour oxygenation with carbogen of varying carbon dioxide concentrations. Radiother Oncol 50: 167-171 (1999).

7. Denekamp J. Fowler JF. ARCON--current status: summary of a workshop on preclinical and clinical studies. Acta Oncol 36: 517-525 (1997).

8. Kaanders JH, Pop LA, Marres HA, Liefers J, van den Hoogen FJ, van Daal WA, van der Kogel AJ. Accelerated radiotherapy with carbogen and nicotinamide (ARCON) for laryngeal cancer. Radiother Oncol 48: 115-122 (1998).

9. Hoskin PJ, Saunders MI, Dische S. Hypoxic radiosensitizers in radical radiotherapy for patients with bladder carcinoma: hyperbaric oxygen, misonidazole, and accelerated radiotherapy, carbogen and nicotinamide. Cancer 86: 1322-1328 (1999).

10. Rojas A, Hirst VK, Calvert AS, Johns H. Carbogen and nicotinamide as radiosensitizers in a murine mammary carcinoma using conventional and accelerated radiotherapy. Int $J$ Radiat Oncol Biol Phys 34: 357-365 (1996).

11. Helmlinger G, Yuan F, Dellian M, Jain RK. Interstitial $\mathrm{pH}$ and $\mathrm{pO}_{2}$ gradients in solid tumors in vivo: high-resolution measurements reveal a lack of correlation. Nature Medicine 3: 177-182 (1997).

12. Höckel M, Knoop C, Schlenger K. Vorndran B, Baussmann E. Mitze M, Knapstein PG, Vaupel P. Intratumoral $\mathrm{pO}_{2}$ predicts survival in advanced cancer of the uterine cervix. Radiother Oncol 26: 45-50 (1993).

13. Koch CJ, Evans SM, Lord EM. Oxygen dependence of cellular uptake of EF5 [2-(2-nitroIH-imidazol-1-yl)-N-(2,2,3,3,3-pentafluoropropyl)a cet amide] : analysis of drug adducts by fluorescent antibodies vs bound radioactivity. Br J Cancer 72: 869-874 (1995).

14. Wijffels KI, Kaanders JH, Rijken PF, Bussink J, van der Hoogen FJ, Marres HA, de Wilde PC, Raleigh JA, van der Kogel AJ. Vascular architecture and hypoxic profiles in human head and neck squamous cell carcinoma. Br J Cancer 83: 674-683 (2000).

15. Hodgkiss RJ, Jones G, Long A. Parrick J, Smith KA. Stratford MRL, Wilson GD. Flow cytometric evaluation of hypoxic cells in solid experimental tumors using fluorescence immunodetection. Br J Cancer 63: 119-125 (1991).

16. Ogawa S, LeeTM, Nayak AS, Glynn P. Oxygenation-sensitive contrast in magnetic resonance image of rodent brain at high magnetic fields. Magn Reson Med 14: 68-78 (1990). 
17. van Zijl PCM, Eleff SM, Ulatowski JA, Oja JME, Ulug AM, Traystman RJ, Kauppinen RA. Quantitative assessment of blood flow, blood volume and blood oxygenation effects in functional magnetic resonance imaging. Nature Medicine 4: 159-167 (1998).

18. Kwong KK, Belliveau JW, Chesler DA, Goldberg IE, Weisskoff RM, Poncelet BP, Kennedy DN, Hoppel BE, Cohen MS, Turner R, Cheng HM, Brady TJ, Rosen BR. Dynamic magnetic resonance imaging of human brain activity during primary sensory stimulation. Proc Natl Acad Sci USA 89: $5675-5679$ (1992).

19. Al-Hallaq HA, River JN, Zamora M, Oikawa H, Karczmar GS. Correlation of magnetic resonance and oxygen microelectrode measurements of carbogen-induced changes in tumor oxygenation. Int J Radiat Oncol Biol Phys 41: 151-159 (1998).

20. Robinson SP, Howe FA, Griffiths JR. Noninvasive monitoring of carbogen-induced changes in tumor blood flow and oxygenation by functional magnetic resonance imaging. Int J Radiat Oncol Biol Phys 33: 855-859 (1995).

21. Robinson SP, Rodrigues LM, Ojugo AS, MeSheehy PM, Howe FA, Griffiths JR. The response to carbogen breathing in experimental tumour models monitored by gradientrecalled echo magnetic resonance imaging. Br J Cancer 75: 1000-1006 (1997).

22. Howe FA, Robinson SP, Griffiths JR. Modification of tumour perfusion and oxygenation monitored by gradient recalled echo MRI and 3IP MRS. NMR Biomed 9: 208-216 (1996).

23. Griffiths JR, Taylor NJ, Howe FA, Saunders MI, Robinson SP, Hoskin PJ, Powell ME, Thoumine M, Caine LA, Baddeley $\mathrm{H}$. The response of human tumors to carbogen breathing, monitored by Gradient-Recalled Echo Magnetic Resonance Imaging. Int J Radiat Oncol Biol Phys 39: 697-701 (1997).

24. Lemieux SK, Dorie MJ, Glover GH, Moseley MM, Brown JM, Spielman DM. Tumor response to changes of breathing gas mapped by the functional magnetic resonance imaging technique. Proceedings ISMRM, 2, 898 (abstract) (1995).

25. Peller M, Weissfloch L, Shehling MK, Weber J, Bruening R, Senekowitsch-Schmidtke R, Molls M, Reiser M. Oxygen-induced MR signal changes in murine tumors. Magn Reson Imaging 16: $799-809$ (1998).

26. Rijpkema M, Kaanders J. Joosten F. van der Sanden B, Van der Kogel A, Heerschap A. Method to investigate heterogeneity in human tumors by mapping of T2* and Gadolinium uptake, ISMRM Workshop, Geiranger, Norway, (abstract p 52) (2000).

27. Bosmans H. Landuyt W, Farina D, Sunaert S, Béatse E, Hermans R, Lambin P, Marchal G. Improvement of (in vivo) gradient echo imaging using a body-adapted mould: a practical approach. Eur Radiol 10(Suppl 1): 425 (2000).

28. Friston KJ, Jezzard P. Turner R. Analysis of functional MRI time-series Hum Brain Map 1: $153-171$ (1994). 
29. Friston KJ, Worsley KJ, Frackowiak RSJ, Mazziotta JC, Evans AC. Assessing the significance of focal activations using their spatial extent. Hum Brain Map 1: 214-220 (1994).

30. Friston KJ, Holmes AP, Poline JB, Grasby PJ, Williams SCR. Analysis of fMRI timeseries revisited. Neuroimage 2: 45-53 (1995).

31. Suit HD, Marshall N, Woerner D. Oxygen, oxygen plus carbon dioxide, and radiation therapy of a mouse mammary carcinoma. Cancer 30: 1154-1158 (1972).

32. Shibamoto $\mathrm{Y}$, Sasai K, Abe M. The radiation response of SCCVII tumor cells in $\mathrm{C} 3 \mathrm{H} / \mathrm{He}$ mice varies with the irradiation conditions. Radiat Res 109: $352-354$ (1987).

33. Milross CG. Peters, L. Hunter NR, Mason KA. Tucker SL, Milas L. Polagorgraphic $\mathrm{pO}_{2}$ measurement in mice: effect of tumor type, site of implantation, and anesthesia. Radiat Oncol Invest 4: 108-114 (1996).

34. Landuyt W, Verdoes O, Darius DO, Drijkoningen M. Nuyts S, Theys J, Stockx L, Wynendaele W, Fowler JF, Maleux G, Van den Bogaert W. Anné J, van Oosterom A. Lambin P. Vascular targeting of solid tumours: a major 'inverse' volume-response relationship following combretastatin A-4 phosphate treatment of rat rhabdomyosarcomas, Eur J Cancer 36: 1833-1843 (2000).

35. Karczmar GS, River JN, Li J, Vijayakumar S. Goldman Z, Lewis MZ. Effects of hyperoxia on $\mathrm{T}_{2}^{*}$ and resonance frquency weighted magnetic resonance images of rodent tumours. NMR Biomed 7: 3-11 (1994).

36. van der Sanden BP. Heerschap A, Hoofd L, Simonetti AW, Nicolay K, van der Toorn A, Colier WN, van der Kogel AJTI. Effect of carbogen breathing on the physiological profile of human glioma xenografts. Magn Reson Med 42: 490-499 (1999).

37. Kuperman VY, River JN, Lewis MZ, Lubich LM, Karczmar GS. Changes in $T_{2}^{* *}$ weighted images during hyperoxia differentiate tumors from normal tissues. MRM 33: 318-325 (1995).

38. Hill SA, Collingridge DR, Vojnovic B, Chaplin D. Tumour radiosensitization by highoxygen-content gases: influence of the carbon dioxide content of the inspired gas on $\mathrm{pO}_{2}$, microcirculatory function and radiosensitivity. Int J Radiat Oncol Biol Phys 40: 943-951 (1998).

39. Reinhold HS, Blackiwiecz B, Blok A. Oxygenation and reoxygenation in "sandwich" tumors. Bibl Anat 15: 270-272 (1977).

40. Chaplin DJ, Olive PL, Durand RF. Intermittent blood flow in a murine tumour: radiobiological effects. Cancer Res 47: 597-601 (1987).

41. Chaplin DJ. Hill SA. Temporal heterogeneity in microregional erythrocyte flux in experimental solid tumours. Br J Cancer 71: 1210-1213 (1995). 
42. Trotter MJ, Chaplin DJ, Olive PL. Possible mechanisms for intermittent blood flow in the murine SCCVII carcinoma. Int J Radiat Biol 60: 139-146 (1991).

43. Braun RD, Lanzen JL, Dewhirst MW. Fourier analysis of fluctuations of oxygen tension and blood flow in R3230Ac tumors and muscle in rats. Am J Physiol 277: H551-H568 (1999).

44. Stadler P, Feldmann HJ, Creighton C, Kau R, Molls M. Changes in tumor oxygenation during combined treatment with split-course radiotherapy and chemotherapy in patients with head and neck cancer. Radiother Oncol 48: 157-164 (1998),

45. Mayr NA, Yuh WT, Magnotta VA, Ehrhardt JC, Wheeler JA, Sorosky JI, Davis CS, Wen BC, Martin DD, Pelsang RE, Buller RE, Oberley LW, Mellenberg DE, Hussey DH. Tumor perfusion studies using fast magnetic resonance imaging technique in advanced cervical cancer: a new noninvasive predictive assay. Int J Radiat Oncol Biol Phys 36: 623-633 (1996).

46. Knopp MV, Lumer MM, Schlemmer HPW, Dietz A, Lucht R, Hawighorst H, Vanselow B, van Kaick G. Functional MRI of head and neck carcinomas to assess microcirculation and changes during therapy. Eur Radiol 10(Suppl 1): 111 (2000). 



\section{Chapter V}

\section{Summary and general discussion}

V.1. Introductory notes

V.2. Tumour blood vessel-based treatment efficacy in relation with tumour volume

V.3. CombreAp vascular targeting combined with different anti-cancer treatments

V.4. Non-invasive imaging of intra-tumoural oxygenation

V.5. Perspectives

V.6. References 


\section{V.1. Introductory notes}

Expanded vascularization is a prerequisite for continued growth of solid tumours. This important biological event seems mainly regulated through the 'parallel' development of hypoxia, in combination with oncogenic transformation and cell survival selection. Both experimental laboratory and clinical evidence have been supplied for the existence of these tumour characteristics, globally referred to as a highly specific micro-environment. Many published data point at the influence of these characteristics on classical therapy and their association with increased malignancy, metastasis and ultimately prognosis. These include the development of bio-reductive compounds, selective drug-delivery systems, both vessel- and hypoxia-specific gene therapy systems, and anti-angiogenesis and vascular targeting. In parallel, becoming aware of this potential for therapy, researchers aimed to identify the intratumoural vessel network and oxygenation status using biopsy- or microprobe-based technologies and non-invasive nuclear medicine or radiology imaging.

The broad background of these important tumour micro-environment aspects is presented in Chapter I.1, and sets the scene of the present thesis research.

The investigations were guided by several working hypotheses and questions in relation to the tumour micro-environment (see Chapter I.2). Briefly, they related to

- (i) Anti-angiogenesis and vascular targeting are two different approaches, for which the efficacy in general and more specifically the impact of tumour volume was investigated;

- (ii) Since these treatments on their own were not expected to eradicate the whole tumour, whatever its size, vascular targeting was combined with radiotherapy or with anti-angiogenesis;

- (iii) The poor intra-tumoural oxygenation condition was previously exploited (by our research group) to establish an anaerobe bacteria-based therapeutic protein transfer system. Tumour volume-related quality and safety of this selective transfer system, and specifically the further improvement of colonization and protein expression from the combination with vascular targeting, were evaluated:

- (iiii) Finally, based on the potential to modulate the intra-tumoural hypoxic condition. a fast and whole body functional MR imaging methodology was investigated for its feasibility to select tumours for a specific oxygenation treatment. 
Assessment of the hypotheses and questions (Chapter II.1 to Chapter IV.2), and eventual inter-comparison of the various tumour micro-environment-related research, was done with the rat rhabdomyosarcoma (R1). This tumour originated in the jaw musculature of inbred WAG/Rij rats that received a total body irradiation, and has been established in vitro and in vivo (subcutaneous implantation) for radiobiological investigations since three decades [1, 2]. Cell kinetic measurements showed a cell cycle duration of about 20 hours, and correspondingly a volume doubling time of 3-5 days [3]. The rhabdomyosarcoma tumour consists of spindle cells, showing atypia and numerous mitoses (see Figure V.1).

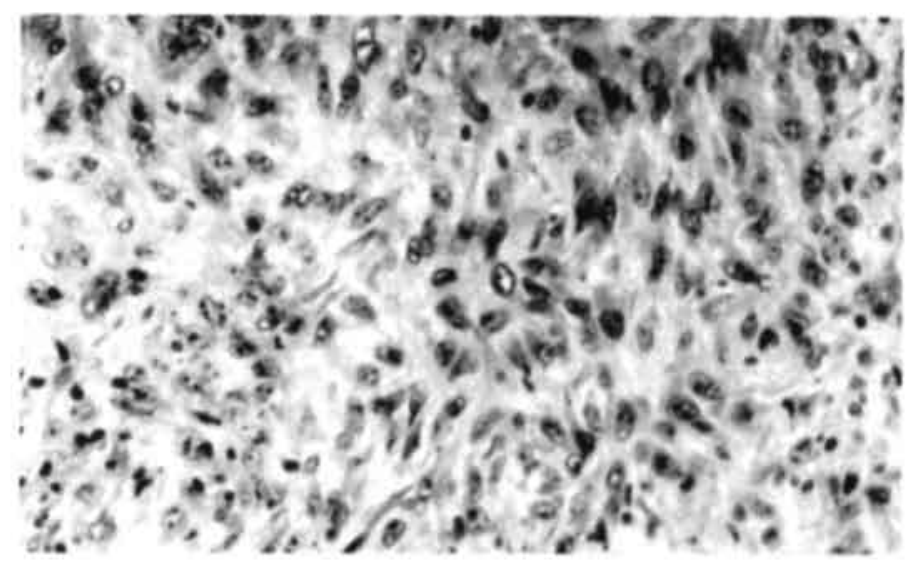

Figure V.1: Representative image $(x 100)$ of paraffin-embedded non-treated rhabdomyosarcoma tissue; haematoxylin/eosin staining.

More detailed description using histology and digital subtraction angiography can be found in the description of research results of Chapter II.1 and II.2.

\section{V.2. Tumour blood vessel-based treatment efficacy in relation with tumour volume}

The first part of the present pre-clinical studies elaborated the activity of antiangiogenesis (using the fumagillin analogue TNP-470) and vascular targeting (using the tubulin-interfering combretastatin A-4 phosphate (combreAp)), specifically investigating effects in a broad range of tumour sizes. 
Although surely not a general rule for all anti-angiogenic compounds, and although growth delay was definitely longer with small tumours, a transient growth inhibition after repeat subcutaneous injections of TNP-470 was present with tumours having a volume even up to 7 $\mathrm{cm}^{3}$ at treatment start (see Chapter II.1). One plausible explanation of this result may be offered by the relation between the relatively rapid tumour growth and accompanying angiogenesis. Most if not all anti-angiogenic compounds show activity against very small tumours (often very much less than $0.5 \mathrm{~cm}^{3}$ ) only, a growth period during which additional blood vessel formation may be more important for these tumour types. This possibility has however been questioned by Beecken and colleagues, demonstrating about equal effectivity in both poorly vascularized and highly vascularized human bladder carcinoma cell lines growing in severe combined immune deficient (SCID) mice [4]. TNP-470 has been shown to be a strong cytostatic agent with both human and rat endothelial cells [5]. Additionally, TNP-470 showed activity in a broad range of tumour types, both primary lesions and metastasis. The compound was therefore one of the first to enter a clinical phase I trial, and was in several

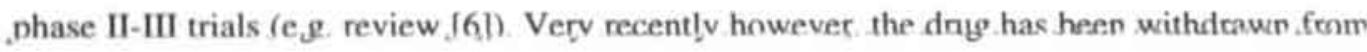
clinical application. This likely is the consequence of side effects, narrowing the therapeutic window. Severe skin reactions at the site of the repeated subcutaneous injections were observed in our rat study, as was a transient drop in the body weight (10-15\%) at the doses used.

Obviously, drug activity in relation to the tumour type and the site of growth, including quality and quantity of angiogenesis as well as the phase of the angiogenic cascade with which the drug interferes, all need attention when comparing various published data-sets. Yet, based on the volume aspect in our study and taking into account the relatively short doubling time of rodent tumours including xenografts as compared with the temporal evolution of human cancer, the lack of important anti-angiogenic activity in clinical studies is not fully surprising, as very large tumours are involved in human phase I-II studies.

Opposed to the results with TNP-470 anti-angiogenesis is the intra-tumoural activity of the vascular targeting compound combreAp. It is our conviction that a distinction should be made between newly sprouting vessels and the already established yet immature microcirculation. Indeed, not only is proliferation and migration of endothelial cells necessary to expand vascularization, but of equal importance is the perfect establishment of the endothelial cell cytoskeleton for adequate function within the blood vessel wall. This characteristic (together with the necessity of support cells such as pericytes) could make the difference in 
response to agents that specifically target endothelium, as during tumour growth more vessels become established and thus dividing endothelial cells are not exclusively the vulnerable element. Using digital subtraction angiography we were able to visualize the acute and dramatic reduction in the intra-tumoural vascular network evolving in a short time after combreAp treatment. The parallel process of necrosis formation in about the total tumour volume confirmed the idea to kill tumour cells indirectly by cutting off the supply of proliferation nutrients (see Chapter II.2). More severe overall intra-tumoural changes from the use of a single intra-peritoneal combreAp injection were anticipated in our studies involving large rat rhabdomyosarcoma tumours as compared to small ones. It does however seem that the effectivity of combreAp differs somewhat among tumour types, with for example the mouse KHT sarcoma [7] and the WAG/Rij rat rhabdomyosarcoma (present thesis research) showing more intra-tumoural damage than the mouse $\mathrm{C} 3 \mathrm{H}$ mammary carcinoma [8] or the rat BT4An glioma [9].

Notwithstanding the presence or absence of a difference in morphological outcome, a very important observation with the WAG/Rij rat rhabdomyosarcoma was a clear-cut 'inverse' effectivity of combreAp as compared with the tumour volume-dependent efficacy obtained in general, as well as with the same tumour model, with radiotherapy (see Figure V.2, A versus B) or chemotherapy.
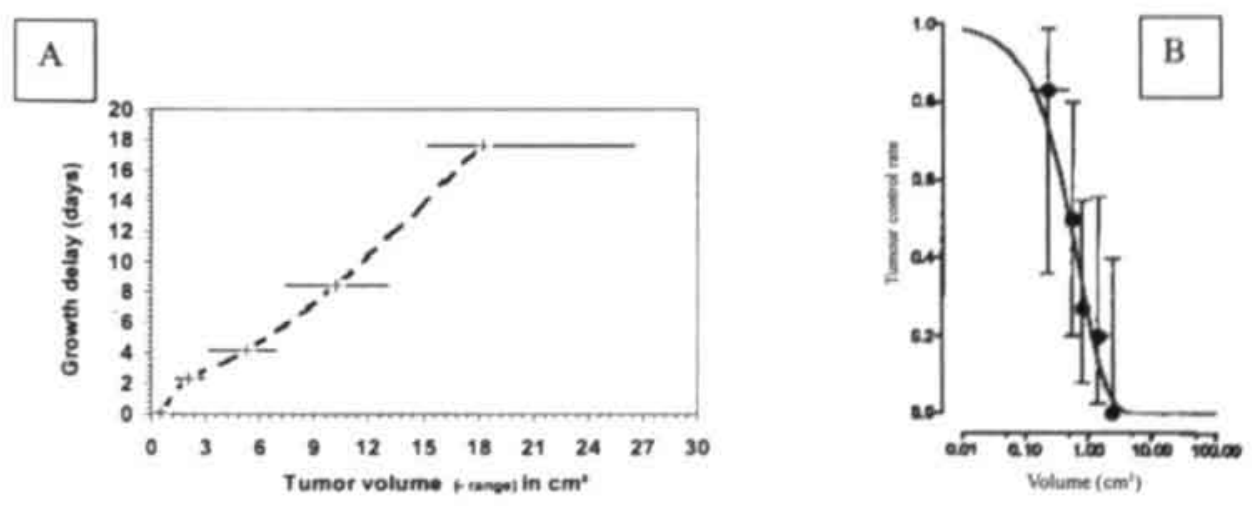

Figure V.2: A. 'INVERSE' volume-response relationship after combreAp treatment, with respect to e.g. radiotherapy (part B; reproduced with permission). 
Indeed with larger tumors $\left(>6 \mathrm{~cm}^{3}\right)$ a much stronger effect in terms of growth delay was measured, including some regression shortly after the combreAp treatment (see Chapter II.2, Figure II.2.1), whereas with the very small tumours no significant growth delay was present. Absence of clear-cut growth delays was also observed with the different rodent tumour studies published until now (always involving volumes less than $1 \mathrm{~cm}^{3}$ ). A similar finding of tumour volume-related increase in combreAp efficacy has been presented by D.W. Siemann (invited lecture, ESTRO workshop on The Biology of Radiation Oncology, June 2001, Fulgsö, Denmark) using the KHT mouse sarcoma model. In this study, 2-3 logs less cell survival was measured with tumours of $1.5-2 \mathrm{~g}$ than with those of only $0.1-0.5 \mathrm{~g}$ following a single intraperitoneal injection with combreAp. Our results, and likely those with the KHT sarcoma, strongly suggests a relationship between combreAp activity and the quantity of illformed blood vessels established in the larger tumours as compared with the smaller ones. The importance of deficient blood vessel maturation during the establishment of a functional intra-tumoural vascularity has been nicely documented by Benjamin and colleagues [10]and Morikawa and colleagues [11]. These data, demonstrating the control of tumour blood vessel sprouting and maturation through the complex involvement of pericytes, vascular endothelial growth factor and angiopoietins, may help to explain the selectivity of vascular targeting with combreAp and analogues. The information certainly invites further research to exploit the difference between normal host vasculature and the aberrant tumour vessels, a difference that may allow improved anti-cancer therapies.

Of equal potential to explain the 'inverse' tumour size-related effect could be the growing imbalance of viable hypoxic tumour cells in regions with ill-formed vasculature, a fraction that becomes proportionately larger with increase in tumour size, compared with welloxygenated cells in regions with mature blood vessels. Adding to this explanation is the fact that the combreAp activity not only is directed at endothelium, but seemingly also exerts a cytostatic activity towards tumour cells $[12,13]$. This has recently been further investigated and clearly demonstrated by us (Angiogenesis Laboratory, Univ. Hosp. Maastricht) with in vitro research involving various human tumour cell lines as well as the Rl rhabdomyosarcoma cells [14]. In fact, using the ${ }^{3} \mathrm{H}$-thymidine incorporation assay, the antiproliferative activity of combreAp was 20-30 times stronger in the human breast (Hs578T) and colon carcinoma (LS174T) cell lines as compared with human umbilical vein endothelial cells. A similar difference of sensitivity was measured in favour of the R1 rhabdomyosarcoma cells as compared with rat heart endothelial cells in these investigations. 
Though indications for an anti-angiogenic activity were present in some published research papers on combreAp vascular targeting, we provided direct evidence that such a component plays a role in the overall anti-tumour activity [14]. Indeed, not only inhibition of endothelial cell migration (HUVEC) but also reduced sprouting (BCE) was measured after combreAp application at drug doses that did not interfere with the cell growth (no inhibition of the proliferative activity). Yet, should this activity be most important, the small-sized rhabdomyosarcoma tumours would show a significant growth delay, as was observed with the larger tumours (differential staining of newly formed vessels versus all blood vessels can help to further clarify this item). This deduction is also based on the TNP-470 results, where important growth delays were measured for small rhabdomyosarcoma tumours; yet, we should bear in mind that a different anti-angiogenic pathway is involved (combreAp interfering with the tubulin polymerisation, while TNP-470 inhibits methionyl aminopeptidase-2 activity), and drug-scheduling for both agents was different as well.

Elevated interstitial fluid pressure (IFP) is a known obstacle for the effective drug delivery in solid tumours. The importance to investigate IFP is further highlighted by a recent publication from Milosevic and colleagues, which illustrates that IFP may serve as a significant independent prognostic factor in cervix cancer patients [15]. Part of the research recently published by Eikesdal and colleagues [16], using the subcutaneous implanted BT4An rat glioma, was to assess whether and how the IFP was affected by combreAp and whether such information could add to the understanding of the differential efficacy of the drug in large versus small tumours. Our underlying hypothesis was the occurrence of a strong IFP reduction by virtue of the fact that combreAp induces intra-tumoural vascular collapse and vessel number decrease. However, independent of tumour size (range 3-19 $\mathrm{cm}^{3}$ ), no effect from a single combreAp treatment on the IFP was measured in this rat glioma tumour model. This could eventually reflect the following: the combreAp-induced vascular damage, including vessel permeability changes, could improve diffusion of drug into tumour tissues. which however is counter-balanced by a 'renewed' increase of the IFP from increased vessel leakage. The lack of IFP changes may be explained on the basis of a lesser efficacy of combreAp in the rat glioma (see [9]): however, in the referred study only very small tumours were analysed. At some point of this complex pattern of changes in IFP, it may be of interest to think of self-trapping of combreAp in larger tumours. An extended presence of low doses of combreAp could be more endothelial as well as tumour cell cytostatic than a brief exposure (evidence for the latter can be found through published in vitro results). More extensive evaluation in different tumour models including eventually rat rhabdomyosarcoma, is for sure 
necessary to enable a conclusion about the impact of IFP changes on the overall tumou response after combreAp treatments. The importance of such studies is accentuated b ongoing studies on combinations with chemotherapeutic drugs.

The discovery of several mechanisms firmly associated with the tumour-selective bloo vessel targeting capacity (in the first place), has evolved into small scale clinical researct Currently a limited number of phase I-IB clinical studies in the United States and the Unite Kingdom examine the impact of combreAp on tumour physiology as well as genero compliance and normal organ function. Reports at scientific meetings have provided som encouraging data about the tumour-selective vascular-mediated effects for various tumou types and locations, specifically involving dynamic magnetic resonance imaging of tumou perfusion (Rustin G. et al, proceedings of the first International Conference on Translationa Research, 2001, Lugano, Switzerland). Very recently, data about these clinical phase I studie have been published, indicating the potent efficacy of repeated cycles of combreAp in th treatment of patients with advanced cancer at doses which did not induce limiting acute sid

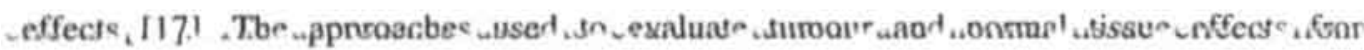
combreAp treatments indicate vascularity-related anti-tumour activity at doses that do not induce systemic toxicity.

Taking into account the substantial efficacy demonstrated in our (and others) pre-clinical research, as well as the small scale clinical study, and with the necessary caution in mind, the use of such a vascular targeting agent may be beneficial in the first place to de-bulk large tumours. Secondly, vascular targeting may help to improve overall outcome when combined with specifically selected treatment strategies, such as a triple combination using irradiation and either chemotherapy or a hypoxia-based therapy.

The fact that combreAp induces a strong anti-tumour effect at doses below the MTD, generated the search for novel agents with stronger anti-tumour activity. One example is the tubulin-binding agent ZD6126, for which recent data show major selective tumour vascular damage with subsequent hemorrhagic necrosis in both primary and metastatic mouse tumour models, using either a single or repeat injections [18, 19]. However, to which extent the application of this compound results in a broader therapeutic window when compared with combreAp or AC-7700 remains to be firmly documented. 


\section{V.3. CombreAp vascular targeting combined with different anti-cancer treatments}

Following the single combreAp injection, after which only a peripheral viable rim of cells remained, tumours either continued to grow (small sized ones) or re-grew after a certain time delay (large rhabdomyosarcomas). This was documented with histological analysis for large tumours as peripheral thickenings or nodular outgrowths. With the small rhabdomyosarcomas however, the continuing growth was translated as a broad expansion of the peripheral viable rim. Treatment with a second combreAp injection of these small or large tumours at a selected stage of (re)-growth, resulted in an additional growth delay, however without eradication (see Chapter II.2). The failure to fully destroy the tumour, even after a double combreAp treatment, requires this vascular targeting treatment to be combined with other anti-cancer therapies such as radiotherapy.

Since the tumour consists not only of hypoxic tumour cells but at least also of oxygenated proliferating cells, it is obvious to combine radiotherapy with combreAp. The hypothesis is that irradiation given first would kill the oxygenated cells, leaving the hypoxic cells to die as the consequence of vascular targeting induced vessel collapse (see Chapter III.1.1). Our data support this elegant idea, as they show an increased growth delay with the rat rhabdomyosarcoma tumour model. Interestingly, these results demonstrate that again the additional anti-tumour effect was more pronounced with large tumours than with the small ones. When combreAp was given before or simultaneous with irradiation, no additional growth delay was observed; this may be explained on the basis of an increase in the hypoxic micro-environment and thus a larger radioresistant cell population. Others have published similar findings (no enhanced efficacy when combreAp was given before irradiation) with for example a subcutaneous mouse mammary carcinoma [20]. Yet, the proposed theory does not seem to fit the overall response of all tumour types. For example with the mouse KHT sarcoma tumour model also an enhanced efficacy (reduced tumour cell surviving fraction) was seen when combreAp was given before or simultaneous with a single irradiation [7, 20]. These opposing data are difficult to explain unless we assume an important interplay from intermittent acute hypoxia.

When combinations of cytotoxic or cytostatic compounds with ionising radiation are tested for their efficacy, it is usual to consider the presence of a broader therapeutic window as compared with either agent given alone. The published data from Murata and colleagues demonstrate the absence of any increase in radiation-induced acute mouse skin damage 
following the combination with combreAp [20]. To further evaluate the important issue of potential increases of radiation-induced normal tissue damage when combreAp is administered in combination with irradiation, we used a mouse gastro-intestinal model. The novel non-invasive methodology that was applied in our experiments specifically assesses the small bowel injury reflected by a reduction of citrulline concentration in plasma, thus offering an estimate of the intensity of induced functional damage (Lutgens $\mathrm{L}$ et al, proceedings ESTRO meeting, September 2000, Istanbul, Turkey; and [21]). Citrulline is a nitrogen endproduct of glutamine metabolism in small bowel mucosa. Combining a single injection of combreAp with total body irradiation at doses from $2 \mathrm{~Gy}$ up to $12 \mathrm{~Gy}$ did not change the plasma citrulline concentration as compared with the measurements for irradiation only (see Figure V.3).

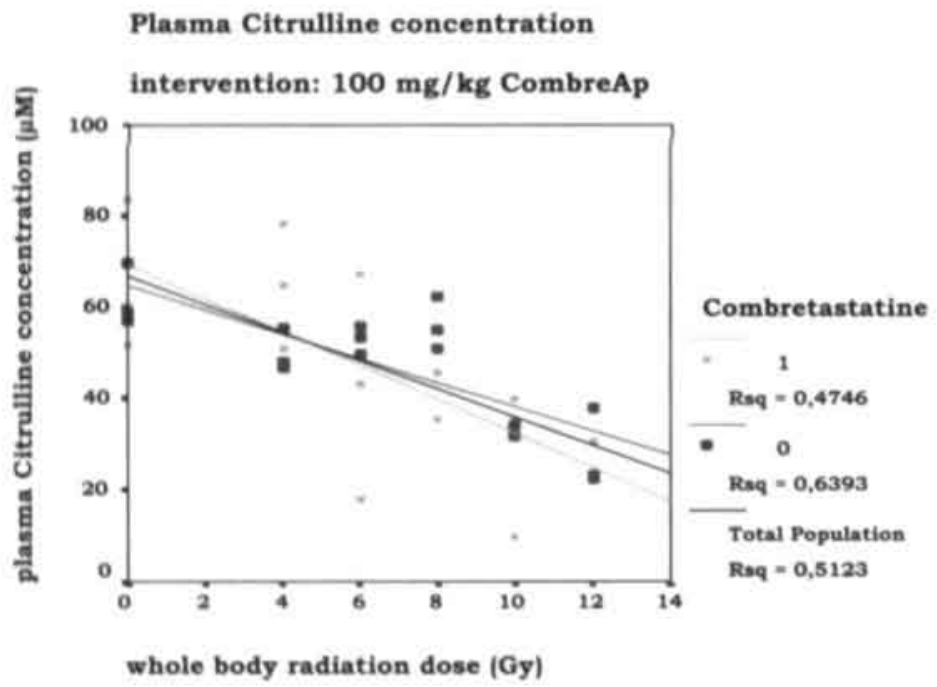

Figure V.3: Data illustrating the lack of a major change in gastro-intestinal damage, measured by the citrulline concentration in plasma, in mice treated with total body irradiation without $(0)$ or with $(1)$ combreAp.

Within the limitations of the selected dosing, sequence and time interval as used in the present investigation, there seems to be a therapeutic gain, specifically when large tumours are considered for such a combination (Landuyt W et al, proceedings ESTRO workshop on Biology of Radiation Oncology, June 2001, Fulgsö, Denmark). However, in view of the recently published data on the endothelial cell-involvement with early occuring irradiation 
effects in normal mouse intestine [22] and accepting that radiation-damaged normal endothelial cells may become vulnerable for combreAp activity, further research certainly is necessary to determine the most favourable treatment criteria in such combinations, including late effect evaluation. Radiation-induced damage to endothelial cells at clinically relevant doses was demonstrated as early as the 1980 's, and the impact of a vascular component in the development of late treatment complications in normal tissues co-determines the therapeutic window.

Our studies combining TNP-470 with combreAp were based on the hypothesis that the further expansion (observed with small tumours) or the re-growth (with larger tumours) after the combreAp treatments should be accompanied by renewed angiogenesis (see Chapter III.1.2). The fact that no significant additional growth delay has been observed when TNP470 was administered during the period of tumour growth could possibly be explained by either an insufficient delivery of the anti-angiogenic drug and/or by a too short duration of TNP-470 application. This contrasts the combination of repeated TNP-470 intraperitoneal injections with hypericin-based photodynamic therapy (PDT), which resulted in a significantly longer growth delay of the murine RIF-I fibrosarcoma tumour when comparing with the result of either agent alone [23]. Ongoing dedicated studies on differential expression of genes in tumour versus normal endothelial cells $[24]$ will certainly aid in defining more efficient combination therapies, for example involving agents interfering with the extracellular matrix modeling process. For sure, also the combination of vascular targeting with agents that interfere with endothelial cell growth simultaneously through several pathways, such as the recently developed anginex [25] deserves further exploration.

Experiments investigating the use of combreAp to further advance the novel anaerobe bacteria-based therapeutic protein transfer to the tumour micro-environment showed a clearcut beneficial outcome (see Chapter III.2). The introduction of the vascular targeting compound was based on the finding of an increase in anoxia and necrosis. This condition should hypothetically favour the Clostridium growth and subsequently the expression of the transferred therapeutical protein in the tumour micro-environment. A first part of our research dealt with the evaluation of improving the tumour colonisation with apathogenic anaerobe clostridia (specifically in tumours less than $3 \mathrm{~cm}^{3}$ ). These small tumours were poorly or not at all colonised with bacteria following spore administration only. CombreAp was injected 4 
hours after the systemic administration of Clostridium spores, then yielding a bacterial colonisation level almost equal to the one observed with large tumours. The difference in bacterial colonisation between combreAp-treated and non-treated tumours was highly significant, even for tumours much smaller than $1 \mathrm{~cm}^{3}(\mathrm{p}<0.0001)$. Of equal importance in those experiments were the results that indicated absence of Clostridium-specific antibodies in serum of the treated tumour-bearing rats. The lack of induced immune response allows repeated administration with similar colonization, even if a clinical reason necessitates an intermittent arrest of the bacterial application.

The second series of investigations was carried out to define, separately from the colonisation, the potential improvement of the intra-tumoural expression of the stable therapeutic cDNA construct from the use of a single combreAp treatment. These experiments involved the $E$. coli-cytosine deaminase (CDase). This enzyme converts the non-toxic prodrug 5Fluorocytosine (5-FC) to the cytotoxic 5-Fluorouracil (5-FU), cloned in-frame with the clostripain promoter into a $E$. coli/C. acetobutylicum shuttle vector. The results clearly indicate stability of the plasmid as well as expression of CDase in aff the combreAp-treated tumours. A significantly improved intra-tumoural conversion efficiency of 5-FC to 5-FU was measured (thin layer chromatography), as compared to tumours not treated with combreAp. As expected, based on previous research of our group [26], no proliferating bacteria nor 5-FU were detectable in normal tissues of the combination-treated tumour-bearing rats. Further indication for the in vivo anti-tumoural efficacy from this novel combination strategy has been offered by Liu and colleagues [27]. In their study using a mouse squamous cell carcinoma, a stronger growth delay was measured with the $C$. sporogenes $\mathrm{CDase}-5$ - FC system as compared with daily systemic 5-FU injection at MTD for 5 days. Combining a vascular targeting compound with the bacterial enzyme-prodrug system may, apart from the advantages presented and discussed in the thesis research (Chapter III.2), improve the anti-tumour efficacy of the 5-FU. Grosios and colleagues [28] indeed demonstrated the enhanced antitumour effect in a mouse colon adenocarcinoma from the combination of combreAp with systemic 5-FU treatment.

Our data and the results of research colleagues from the Stanford University School of Medicine (USA) taken together demonstrate the potential of the novel anti-cancer strategy, likely to gain benefit from combination with radiotherapy. Indeed, (i) the chemotherapeutic compound 5-FU is known to 'sensitize' cells for improved ionising radiation efficacy, as demonstrated in many publications (e.g. review [29]). Furthermore, because 5-FU has a high diffusion capacity and because continuous infusion is shown to be the most effective delivery 
system, the anaerobe bacteria-based CDase-5-FC treatment strategy with 5-FU production selectively in the tumour micro-environment should permit a beneficial therapeutic window; and (ii) the use of a radiation-inducible promotor of the highly conserved SOS-repair system of $E$. coli (e.g. recA gene) further enhances the tumour-selectivity of these anaerobe recombinant bacteria (e.g. [30, 31]). Indeed, this should limit the expression of a therapeutic protein only within the defined, irradiated, tumour volume and in a time-dependent way. This procedure should moreover result in reduced or absent normal tissue reactions which are seen with the classical combination of systemically given 5-FU with radiotherapy.

Other developments in the bacteria-based transfer of therapeutic proteins are offered by the use of e.g. Bifidobacterium longum [32] or attenuated Salmonella Typhimurium, engineered to express CDase in the tumour micro-environment (e.g. [33]). High tumour to normal tissue ratios were observed in their pre-clinical investigations with mice and large animals, as well as in our rat study [34]. Our study moreover indicates that an optimal 'therapeutic bacteria dose' can be defined and that the tumour-colonizing recombinant Salmonella (VNP20047) produced 5-FU selectively in the tumours and not in any normal tissues. These data, together with published results from combining X-ray irradiation (5-15 Gy single dose) with attenuated Salmonella (VNP20009), non-recombinant for CDase, thus indicate the potential gain that may be obtained from the combination of recombinant bacteria and irradiation [35]. Even more so in the attenuated Salmonella setting, the introduction of a radiation-inducible promoter will advance the spatial control and allow the temporal switch for therapeutic protein expression.

\section{V.4. Non-invasive imaging of intra-tumoural oxygenation}

Hypoxia- and blood vessel-related treatments necessitate a firm knowledge of (i) the tumour micro-environment, (ii) the potential modulation of these parameters and (iii) the temporal follow-up of induced changes. The modulation of the intra-tumoural oxygen tension when applying for example either carbogen breathing or recombinant EPO administration, does increase the sensitivity of tumour cells to e.g. radiotherapy, but not equally with all tumours. The end-result of individual tumour screening should therefore enable tailored therapy combinations, and a reduction of the chances of treatment failure, while also avoiding unnecessary addition of treatment. 
It is well known that heterogeneity of oxygenation is present in all tumour types. Evidenci has been provided using for example the Eppendorf polarographic needle electrodes " measure $\mathrm{pO}_{2}$ or antibody-based staining of hypoxic cells in pre-clinical and patient studies These studies also indicated that unfortunately the heterogeneity was also often strongl present within the individual tumours, whatever the type or the site of growth. Thi heterogeneity has also been observed in the subcutaneous implanted rat rhabdomyosarcom using immunohistochemical staining and fibre-optic microprobe $\mathrm{pO}_{2}$ measurements (Oxylite Oxford Optronix,UK). A global and fast picture may allow a more optimal tumoú stratification for such individualized treatment. Functional MRI using the BOLP methodology provides a complete non-invasive screening with both spatial and tempord tumour physiology information.

The application of EPI sequences in $\mathrm{T}_{2}{ }^{*}$-weighted functional MRI allows us to examine th entire tumour and body in a multi-slice way, and thus provides a comprehensive evaluation $d$ responses to external stimuli. However, the optimal balance between spatial and tempord resolution remains a deicate ttem when using the $1_{2}{ }^{*}$-weignted imaging in Eri: spauai resolution is reduced by geometric distortion and susceptibility artefacts related to the airtissue interface. We demonstrated that a practical and rapid mold technique, using a fast setting alginate, objectively reduced these problems (see Chapter IV.1). Indeed, improved $\mathrm{T}_{2}{ }^{*}$-weighted image quality and delineation of anatomical structures under investigation was obvious. Separately from the rat tumour study, the objective improvement of image quality was also seen in the larger-animal study of brain function after external stimuli, a result that indicates its broader applicability in this radiological analysis.

Subsequently, the results of a separate series of experiments using BOLD fMRI with GE-EPI (TE39) operating at 1.5 Tesla (see Chapter IV.2), and incorporating the mold technique, provided good evidence for the feasibility to image tumour oxygenation changes from carbogen breathing of the host. Changes in intensity of the $\mathrm{T}_{2}^{*}$ weighted images were very rapidly seen after the start of the carbogen breathing. The data indicate that the quantity of hypoxia modulation was not dependent on the tumour size; inter-, but also intra-tumoural variability was found. An additional advantage of our method is the possibility to detect paradoxical responses to carbogen breathing instantaneously within an individual tumour. The combined analysis of the tumour volume showing intensity changes (voxel number) together with the change in intensity within the responding voxels allowed the selection of those tumours that significantly reacted favourably. 
Our functional MR measurements involved a clinical apparatus (1.5 T) and therefore the present application can be considered feasible in terms of patient translation. The BOLD MR methodology has very recently been demonstrated to be a valuable tool to study tumour oxygenation status and modulation in a patient group which involved different tumour types and sites of growth [36]. Though this was a single slice evaluation using $\mathrm{T}_{2}{ }^{*}$-weighted gradient-echo imaging on a 1.9 Tesla scanner, the data also indicated inter-tumour variability of carbogen response even for tumours of the same type and similar location. Some tumours showed a high signal intensity change, while for others this was very small. Similar observations were made in pre-clinical rodent tumour models by the same research group as well as other teams using the gradient-echo single slice MR technique.

Not unimportantly, the recent introduction of stronger magnetic fields (well above $2 \mathrm{~T}$ ) in clinical radiology may broaden the applicability of the fast whole body BOLD fMRI. Indeed, their use should improve resolution (smaller voxel and increased signal-to-noise performance) and thus the modelling of physiological oxygenation changes.

Since the methodology is completely non-invasive, changes can be evaluated in time. This is very important, as some recently published small-scale clinical studies using dynamic MRI indicated the necessity to evaluate tumour micro-environment before and during the course of treatment.

Temporal information in addition to established parameters of tumour response may, whilst gaining prediction of the result of the ongoing treatment, ultimately guide treatment.

\section{V.5. Perspectives}

Treatment resistance is, apart from intrinsic cellular characteristics, to an important extent due to the physiologic and biochemical heterogeneity within tumours. Presently, strong interest in morphological and functional parameters that define the difference between tumour and normal tissue vasculature and its relationship with the oxygenation status of tumours evolves into the use of this information for treatment selection and prognosis evaluation.

Throughout the discussion parts of the present thesis research, the potential benefit from using the proposed novel approaches in clinical oncology has been indicated. It is at the same time however realized that several shortcomings still remain to be resolved to optimize such strategies. Also research about the complementary information on tumour oxygenation and its 
relation with the vascularity, which can be gained by using different invasive and noninvasive techniques, needs much more in-depth documentation for various tumour types.

The pre-clinical studies demonstrated the disruption of the intra-tumoural blood supply, either through anti-angiogenesis or vascular targeting methodologies, which significantly resulted in tumour cell loss. It was clearly shown in the present thesis research that the combreAp vascular targeting activity was stronger against larger rat rhabdomyosarcoma tumours as compared with small ones. Although this very interesting aspect (the reverse efficacy as observed with for example radiotherapy) has been reported to some extent with the mouse KHT sarcoma model by D.W. Siemann (invited lecture, ESTRO Radiobiology Workshop, June 2001, Fulgsö, Denmark), more information is necessary to explain and to firmly establish this characteristic with other tumour models. Already, the issue of large tumours being attractive for the combreAp vascular targeting activity can be deduced to some extent from the phase I study, data that have been reported very recently [17]. The knowledge about tumour size involvement in vascular targeting treatment will become even more important when combination therapies are introduced.

Combining the tubulin-interfering compounds such as combreAp, which are active at doses below MTD, with radio- or chemotherapy or anti-angiogenesis seems promising. But this aspect needs more pre-clinical elaboration before such strategies can safely enter clinical trials. Published results and data offered by the present thesis research indicate an increased anti-tumour effect with single dose combinations. Based on these results, the combination of vascular targeting with ionizing radiation, both fractionated and at clinically relevant doses, can provide a broader therapeutic window but only when the appropriate scheduling is used. The latter has to delicately take into account the different changes in oxygenation resulting from both treatments in order to avoid a reduced efficacy of either agent. The fact that such fractionation combinations can be advantageous towards tumour cell death has been indicated very recently by a mouse KHT sarcoma study of Siemann and Rojiani [18]. Injecting the novel vascular targeting compound ZD6126 twice during a 10-fraction radiation treatment, the authors measured a significantly increased growth delay (with very small tumours at treatment start) as compared with ionising radiation only. Again, such an improvement may be tumour type dependent, as it may relate to differences in oxygenation changes during radiotherapy. Indeed, we did not find a change in the radiation-induced growth delay of the small rat rhabdomyosarcoma when fractionated radiation treatment was combined with the vascular targeting combreAp (abstract 354, proceedings ESTRO meeting, Istanbul, September 2000). The increase in local tumour control from the combined combreAp and fractionated 
irradiation had borderline significance in comparison with radiotherapy alone in the $\mathrm{C} 3 \mathrm{H}$ mouse mammary carcinoma study of Murata and colleagues (abstract 353, proceedings ESTRO meeting, Istanbul, September 2000).

Furthermore the combination of blood vessel targeting modalities with the classical therapies necessitates the study of normal tissue responses (cfr. supra: general discussion). The involvement of blood vessel damage induced by ionizing radiation has been well recognized to play a major role in the development of consequential as well as late occurring normal tissue defects. The recently published data on intestinal crypt damage in mice demonstrate the involvement of radiation-induced endothelial lesions also in the evolution of this acute doselimiting side effect [22]. Absence of an increased radiation-induced acute (e.g. gut) and late (e.g. lung) normal tissue effect has been suggested by us (cfr. supra Chapter V) and by Horsman and colleagues (presentation at ESTRO meeting, Prague, September 2002). Yet, these studies involved single dose treatments only, as well as a single time interval between both agents. Therefore, results from experiments including fractionation and prolonged drug use, including different sequencing, are of major importance for safety and eventual establishment of the therapeutic window. Of interest in this context are the results published by Park and colleagues, describing the increased mitogen activated protein kinase-dependent VEGF expression in glioblastoma cells but also in primary astrocytes and this following exposure to a radiation dose of $2 \mathrm{~Gy}$ [37]. The understanding of gene expression changes that occur after irradiation, such as VEGF, will further improve the combined use of radiotherapy with either vascular targeting or anti-angiogenesis or even the triple combination.

An additional hypothesis that deserves stringent research is the combination of vascular targeting with bioreductive compounds. The latter may indeed kill tumour cells in transient hypoxic condition that is induced by the vascular targeting activity. Although normal tissue toxicity could limit the applicability, as reported by Lash and colleagues [38] when however DMXAA was combined with various bioreductive drugs, the type of combination remains attractive and should be examined with the tubulin-interfering systemically less toxic compounds such as combreAp. Such a treatment may circumvent the reduced efficacy of classical therapies that is the result of hypoxia-related resistance and changes to a more malignant phenotype (the latter problems are nicely reviewed by e.g. [39]).

As indicated in the general discussion, several directions to improve the bacteria-based therapeutic gene transfer need experimental evidence. One of these involves the non-invasive assessment of the intra-tumoural expression of the transferred active protein. Regarding the CDase-5-FC strategy, the non-invasive ${ }^{18} \mathrm{~F}$ MRS is the most attractive methodology. The 
potential utility has already been demonstrated in other treatment conditions both in vitro and in vivo; for instance to measure the 5-FU metabolism following the systemic injection of the chemotherapeutic drug, or to evaluate the conversion of 5-FC to 5-FU by the CDase (e.g. [4042]). The parallel evaluation of the 5-FC conversion and the growth changes in tumour bearing rodents is under investigation by us.

Due to the ongoing development of tumour vessel-based therapies and due to the need for non-invasive screening of individual tumours before, during and after any therapy, the refinement of functional and contrast-based dynamic MRI and PET is a pre-requisite in oncology. Specifically the evaluation of the complementary information that may be gained on tumour micro-environmental characteristics and their modulation when using different methods of analysis will enable treatment guidance and reduce the chances of failure. This could be possible by relating for example the oxygenation and metabolic condition with the vascular function and with the proliferation characteristics for an individual tumour and for different tumour types. These aspects have been indicated to some extent in the literature, as well regarding the tumour micro-crowommem (e.g. $[43-45])$ as in refationship with the MRI evaluation of vascular targeting effects $[46,47]$. The bottom line: a close-to-ideal concept for the future planning is to further evaluate the efficacy of novel anti-tumour strategies using stringently documented and complementary non-invasive imaging methodologies.

\section{V.6. References}

1. Hermens AF and Barendsen GW (1967) Cellular proliferation patterns in an experimental rhabdomyosarcoma in the rat. Eur J Cancer 3, 361-369

2. Barendsen GW and Broerse JJ (1969) Experimental radiotherapy of a rat thabdomyosarcoma with $15 \mathrm{MeV}$ neutrons and $300 \mathrm{kV}$ x-rays. I. Effects of single exposures. Eur J Cancer 5, 373-391

3. Curtis SB, Barendsen GW, and Hermens AF (1973) Cell kinetic model of tumour growth and regression for a rhabdomyosarcoma in the rat: undisturbed growth and radiation response to large single doses. Eur J Cancer 9, 81-87

4. Beecken WD, Fernandez A, Joussen AM, Achilles EG, Flynn E, Lo KM. Gillies SD, Javaherian K. Folkman J, and Shing Y (2001) Effect of antiangiogenic therapy on slowly growing, poorly vascularized tumors in mice. J Natl Cancer Inst 93, 382-387

5. Kusaka M, Sudo K. Matsutani E, Kozai Y, Marui S, Fujita T, Ingber D, and Folkman J (1994) Cytostatic inhibition of endothelial cell growth by the angiogenesis inhibitor TNP-470 (AGM1470). Br J Cancer 69, 212-216

6. Gervaz P and Fontolliet C (1998) Therapeutic potential of the anti-angiogenesis drug TNP-470. Int J Exp Pathol 79. 359-362

7. Li L. Rojiani A, and Siemann DW (1998) Targeting the tumor vasculature with combretastatin A-4 disodium phosphate: effects on radiation therapy. Int J Radiat Oncol Biol Phys 42, 899-903 
8. Horsman MR, Ehrnrooth E, Ladekarl M, and Overgaard J (1998) The effect of combretastatin A-4 disodium phosphate in a $\mathrm{C} 3 \mathrm{H}$ mouse mammary carcinoma and a variety of murine spontaneous tumors. Int J Radiat Oncol Biol Phys 42, 895-898

9. Eikesdal HP, Bjerkvig R, Mella O, and Dahl O (2001) Combretastatin A-4 and hyperthermia;a potent combination for the treatment of solid tumors. Radiother Oncol 60, 147-154

10. Benjamin LE, Golijanin D, Itin A, Pode D, and Keshet E (1999) Selective ablation of immature blood vessels in established human tumors follows vascular endothelial growth factor withdrawal. J Clin Invest 103, 159-165

11. Morikawa S, Baluk P, Kaidoh T, Haskell A, Jain RK, and McDonald DM (2002) Abnormalities in pericytes on blood vessels and endothelial sprouts in tumors. Am J Pathol 160, 985-1000

12. el Zayat AA, Degen D. Drabek S, Clark GM, Pettit GR, and Von Hoff DD (1993) In vitro evaluation of the antineoplastic activity of combretastatin A- 4, a natural product from Combretum caffrum (arid shrub). Anticancer Drugs 4, 19-25

13. Nabha SM, Mohammad RM, Wall NR, Dutcher JA, Salkini BM, Pettit GR, and Al Katib AM (2001) Evaluation of combretastatin A-4 prodrug in a non-Hodgkin's lymphoma xenograft model: preclinical efficacy. Anticancer Drugs 12, 57-63

14. Ahmed B, van Eijk LI, van der Schaft DWJ, Bouma-ter Steege JCA, van Esch AM, JoostenAchjanie SR, Lambin Ph, Landuyt W, and Griffioen AW (2002) The vascular targeting effect of combretastatin A-4 phosphate dominates the inherent angiogenesis inhibitory activity. Ref Type: Unpublished Work

15. Milosevic M, Fyles A, Hedley D, Pintilie M, Levin W, Manchul L, and Hill R (2001) Interstitial fluid pressure predicts survival in patients with cervix cancer independent of clinical prognostic factors and tumor oxygen measurements. Cancer Res 61, 6400-6405

16. Eikesdal HP. Landuyt W, and Dahl O (2002) The influence of combretastatin A-4 and vinblastine on interstitial fluid pressure in BT4An rat gliomas. Cancer Lett 178, 209-217

17. Dowlati A, Robertson K, Cooney M, Petros WP, Stratford M, Jesberger J, Rafie N, Overmoyer B. Makkar V, Stambler B, Taylor A, Waas J, Lewin JS, McCrae KR, and Remick SC (2002) A phase I pharmacokinetic and translational study of the novel vascular targeting agent combretastatin a-4 phosphate on a single-dose intravenous schedule in patients with advanced cancer. Cancer Res 62, 3408-3416

18. Siemann DW and Rojiani AM (2002) Enhancement of radiation therapy by the novel vascular targeting agent ZD6126. Int J Radiat Oncol Biol Phys 53, 164-171

19. Goto H, Yano S, Zhang H, Matsumori Y, Ogawa H, Blakey DC, and Sone S (2002) Activity of a new vascular targeting agent, ZD6126, in pulmonary metastases by human lung adenocarcinoma in nude mice. Cancer Res 62, 3711-3715

20. Murata R. Siemann DW. Overgaard J, and Horsman MR (2001) Interaction between combretastatin A-4 disodium phosphate and radiation in murine tumors. Radiother Oncol 60. 155-161

21. Lutgens LCHW, Deutz NEP, Cleutjens JPM, Gueulette J, Berger MPF, Wouters BG, von Meyenfeldt MF, and Lambin P (2002) Citrulline: a physiological marker enabling quantitation and monitoring of epithelial radiation-induced small bowel damage. Ref Type: Unpublished Work

22. Paris F. Fuks Z, Kang A, Capodieci P. Juan G. Ehleiter D. Haimovitz-Friedman A, Cordon-Cardo C, and Kolesnick R (2001) Endothelial apoptosis as the primary lesion initiating intestinal radiation damage in mice. Science 293, 293-297

23. Chen B, Landuyt W. Roskams T. and de Witte P (2002)

TNP-470 enhances the efficacy of hypericin-mediated photodynamic therapy. Ref Type: Unpublished Work

24. St Croix B. Rago C. Velculescu V. Traverso G, Romans KE, Montgomery E, Lal A, Riggins GJ. Lengauer C, Vogelstein B, and Kinzler KW (2000) Genes expressed in human tumor endothelium. Science 289, 1197-1202

25. Griffioen AW, van der Schaft DW, Barendsz-Janson AF, Cox A. Struijker Boudier HA, Hillen HF, and Mayo KH (2001) Anginex, a designed peptide that inhibits angiogenesis. Biochem J 354. 233-242 
26. Lambin P, Theys J, Landuyt W, Rijken P, van der Kogel A, van der Schueren E, Hodgkiss R, Fowler J, Nuyts S, de Bruijn E, Van Mellaert L, and Anne J (1998) Colonisation of Clostridium in the body is restricted to hypoxic and necrotic areas of tumours. 4, 183-188

27. Liu SC, Minton NP, Giaccia AJ, and Brown JM (2002) Anticancer efficacy of systemically delivered anaerobic bacteria as gene therapy vectors targeting tumor hypoxia/necrosis. Gene Ther 9. 291-296

28. Grosios K, Loadman PM, Swaine DJ, Pettit GR, and Bibby MC (2000) Combination chemotherapy with combretastatin A-4 phosphate and 5- fluorouracil in an experimental murine colon adenocarcinoma. Anticancer Res 20, 229-233

29. McGinn CJ and Kinsella TJ (1993) The clinical rationale for S-phase radiosensitization in human tumors. Curr Probl Cancer 17, 273-321

30. Nuyts S, Van Mellaert L, Theys J, Landuyt W, Bosmans E, Anne J, and Lambin P (2001) Radioresponsive recA promoter significantly increases TNFalpha production in recombinant clostridia after 2 Gy irradiation. Gene Ther 8, 1197-1201

31. Nuyts S, Van Mellaert L. Theys J, Landuyt W, Lambin P, and Anne J (2001) The use of radiationinduced bacterial promoters in anaerobic conditions: a means to control gene expression in Clostridium-mediated therapy for cancer. Radiat Res 155, 716-723

32. Yazawa K, Fujimori M. Amano J, Kano Y, and Taniguchi S (2000) Bifidobacterium longum as a delivery system for cancer gene therapy: selective localization and growth in hypoxic tumors. Cancer Gene Ther 7, 269-274

33. Pawelek JM, Low KB, and Bermudes D (1997) Tumor-targeted Salmonella as a novel anticancer vector. Cancer Res 57, 4537-4544

34. Mei S, Theys J, Landuyt W, Anné J, and Lambin P (2002) Optimization of tumor-targeted gene delivery by engineered attenuated Salmonella Typhimurium. Anticancer Res, in press

35. Platt J, Sodi S, Kelley M, Rockwell S, Bermudes D, Low KB, and Pawelek J (2000) Antitumour effects of genetically engineered Salmonella in combination with radiation. Eur J Cancer 36 , 2397-2402

36. Taylor NJ, Baddeley H, Goodchild KA, Powell ME, Thoumine M, Culver LA , Stirling JJ, Saunders MI, Hoskin PJ, Phillips H, Padhani AR, and Griffiths JR (2001) BOLD MRI of human tumor oxygenation during carbogen breathing. J Magn Reson Imaging 14, 156-163

37. Park JS, Qiao L, Su ZZ. Hinman D. Willoughby K, McKinstry R, Yacoub A, Duigou GJ, Young CS, Grant S, Hagan MP. Ellis E, Fisher PB, and Dent P (2001) lonizing radiation modulates vascular endothelial growth factor (VEGF) expression through multiple mitogen activated protein kinase dependent pathways. Oncogene 20, 3266-3280

38. Lash CJ, Li AE, Rutland M, Baguley BC , Zwi LJ, and Wilson WR (1998) Enhancement of the anti-tumour effects of the antivascular agent 5,6- dimethylxanthenone-4-acetic acid (DMXAA) by combination with 5 - hydroxytryptamine and bioreductive drugs. $\mathrm{Br}$ J Cancer 78, 439-445

39. Wouters BG, Weppler SA, Koritzinsky M. Landuyt W, Nuyts S, Theys J, Chiu RK, and Lambin P (2002) Hypoxia as a target for combined modality treatments. Eur J Cancer 38. 240-257

40. Aboagye EO, Artemov D, Senter PD, and Bhujwalla ZM (1998) Intratumoral conversion of 5fluorocytosine to 5 -fluorouracil by monoclonal antibody-cytosine deaminase conjugates: noninvasive detection of prodrug activation by magnetic resonance spectroscopy and spectroscopic imaging. Cancer Res 58, 4075-4078

41. Bell JD and Taylor-Robinson SD (2000) Assessing gene expression in vivo: magnetic resonance imaging and spectroscopy. Gene Ther 7, 1259-1264

42. Kamm YJ, Heerschap A, Rosenbusch G, Rietjens IM, Vervoort J, and Wagener DJ (1996) 5 Fluorouracil metabolite patterns in viable and necrotic tumor areas of murine colon carcinoma determined by 19F NMR spectroscopy. Magn Reson Med 36, 445-450

43. Rijken PF, Bernsen HJ. Peters JP. Hodgkiss RJ. Raleigh JA, and Van Der Kogel AJ (2000) Spatial relationship between hypoxia and the (perfused) vascular network in a human glioma xenograft: a quantitative multi-parameter analysis. Int J Radiat Oncol Biol Phys 48, 571-582

44. Begg AC, Hofland I, Van DP. I, Van Der SB, and Haustermans K (2000) Use of thymidine analogues to indicate vascular perfusion in tumours. Br J Cancer 83, 899-905 
45. van der Sanden BP, Rijken PF, Heerschap A, Bernsen HJ, and Van Der Kogel AJ (1997) In vivo $31 \mathrm{P}$ magnetic resonance spectroscopy and morphometric analysis of the perfused vascular architecture of human glioma xenografts in nude mice . Br J Cancer 75, 1432-1438

46. Beauregard DA, Pedley RB, Hill SA, and Brindle KM (2002) Differential sensitivity of two adenocarcinoma xenografts to the anti- vascular drugs combretastatin A4 phosphate and 5,6dimethylxanthenone-4- acetic acid, assessed using MRI and MRS. NMR Biomed 15, 99-105

47. Maxwell RJ, Wilson J, Prise VE, Vojnovic B, Rustin GJ, Lodge MA, and Tozer GM (2002) Evaluation of the anti-vascular effects of combretastatin in rodent tumours by dynamic contrast enhanced MRI. NMR Biomed 15, 89-98 



\section{Chapter VI}

Samenvatting

Curriculum Vitae

Lijst van publicaties (vanaf 1998) 


\section{Samenvatting}

De intense celdelingsactiviteit inherent aan de groei van tumoren noodzaakt een afdoende en constante beschikbaarheid van voedingsstoffen en zuurstof. Initieel zorgen gecoopteerde en nabijgelegen vaatstructuren voor deze aanvoer, maar al snel ontstaat een onevenwicht met de tumoruitbreiding wat resulteert in hypoxische regio's. Via de productie van hypoxie-gemedieerde angiogene factoren wordt de ontwikkeling van nieuwe bloedvaten uit de bestaande vasculatuur geïnduceerd. Op deze wijze kunnen tumorcellen overleven en kan het proces van celproliferatie voortgaan of hervatten. Juist deze verschillende belangrijke stappen in de vicieuse cirkel van lokale tumorexpansie zijn het aanknopingspunt voor nieuwe methoden in behandeling en diagnose van vaste tumoren.

Ook het onderzoekswerk beschreven in de voorliggende thesis relateerd gebruikt karakteristieken van de tumorale micro-omgeving voor het testen van gerichte therapie en diagnose.

In hoofdstuk I.1 worden specifieke parameters van de tumorale micro-omgeving gedefinieerd.

In de cerste plaats en voornamelijk in relatie met het gepresenteerde onderzoek, zijn een aantal aspecten van tumorale vaat-gerichte behandelingen in het kort geschetst. Steunend op de tot hiertoe gekende actiemechanismen wordt onderscheid gemaakt tussen "antiangiogenese' en 'vascular targeting'. Produkten met anti-angiogene eigenschappen verhinderen de vorming van nieuwe bloedvaten, terwijl vascular targeting stoffen selectief de bestaande, slecht ontwikkelde, intra-tumorale bloedvaten beschadigen en vernietigen.

Naast de enkelvoudige tumorbehandeling met zulk een produkt, wordt de potentiële verruiming van het therapeutisch venster via een combinatie met een klassieke behandelingsmethode (bijvoorbeeld radiotherapie) in het kort besproken.

Verder wordt het belang en het evalueren van hypoxie in vaste tumoren uitgelegd in functie van tumor evolutie en behandeling. Vooral wordt aandacht besteed aan invasieve versus nietinvasieve methoden om hypoxie in kaart te brengen.

Aansluitend worden de belangrijkste behandelingsmogelijkheden gericht op de intra-tumorale hypoxie, zoals het toedienen van bioreductieve produkten, bondig voorgesteld. Specifiek wordt de achtergrond voor het gebruik van anaerobe apathogene clostridia als transfersysteem van een therapeutisch proteïne naar de tumorale micro-omgeving uitgelegd. Tevens wordt de 
mogelijkheid van hypoxie modulatie door gebruik van bijvoorbeeld een zuurstofrijk gas of een vasodilatator belicht.

Tot slot worden in hoofdstuk I.2 de doelstellingen met inhoudelijke hypothesen voor het thesisonderzoek geschetst.

Hoofdstuk II beschrijft de resultaten van in vivo experimenten enerzijds met de angiogenese-inhibitor TNP-470 en anderzijds met de vascular targeting stof combretastatin A4 fosfaat. Ondermeer omwille van het verschil in specifieke actie voor beide bloedvat-gerichte behandelingen is het zeer belangrijk hun effecten in tumoren van verschillende grootte te onderzoeken.Voor dit onderzoek werd de syngene WAG/Rij rat rhabdomyosarcoma tumor (R1 cellijn) gebruikt, waarbij longitudinaal voor de verschillende experimenten een onderhuidse inplanting van $1 \mathrm{~mm}^{3}$ stukje weefsel in de abdominale flank gebeurde. Tumor volumina variërend tussen $0.1 \mathrm{~cm}^{3}$ en meer dan $20 \mathrm{~cm}^{3}$ werden beoogd, en als volgt ingedeeld: $<1 \mathrm{~cm}^{3}$ (zeer klein), 1-3 $\mathrm{cm}^{3}$ (klein), 3-7 (medium), 7-14 $\mathrm{cm}^{3}$ (groot) en $>14 \mathrm{~cm}^{3}$ (zeer groot).

Een significante groeivertraging $(\mathrm{p}<0.01)$ werd gemeten na het onderhuids toedienen (om de twee dagen, 5x) van de maximum tolereerbare dosis TNP-470 bij tumoren kleiner dan $7 \mathrm{~cm}^{3}$ (hoofdstuk II.1). Er was geen verschil in groeivertraging voor de kleine tumoren tegenover de medium groep. $\mathrm{Bij}$ de tumoren groter dan $7 \mathrm{~cm}^{3}$ werd een groeivertraging slechts vastgesteld wanneer de TNP-470 dosering gepaard ging met een ernstige lokale huidlaesie op de plaats van de onderhuidse inspuiting alsmede systemische toxiciteit onder de vorm van een blijvend gewichtsverlies van ruim $15 \%$. Een lagere dosering minder frequent gegeven (minimale en transiente toxiciteit), induceerde groeivertraging enkel bij rhabdomyosarcoma tumoren kleiner dan $7 \mathrm{~cm}^{3}$. Rechtstreeks vergelijk met gepubliceerde resultaten en dus met andere in vivo tumor modellen is niet mogelijk, aangezien deze pre-klinische studies enkel bij tumoren kleiner dan $1 \mathrm{~cm}^{3}$ werden uitgevoerd. TNP-470 bleek evenwel in deze studies zeer aktief te zijn bij zowel primaire tumoren (syngene en humane xenografts) als bij metastasen. Ook klinische studies (fase I tot III) toonden belangrijke anti-tumorale effecten door toedienen van TNP-470. Recent werd het klinisch gebruik van deze angiogenese remmer echter stopgezet, waarschijnlijk omwille van een ongunstige balans tussen intra-tumorale activiteit en ernstige nevenwerkingen ( $c f r$ supra onze studie). 
In hoofdstuk II.2 worden de resultaten beschreven van de in vivo experimenten met het onderhuids groeiend rat rhabdomyosarcoom na behandeling met de vascular targeting stof combretastatin A-4 fosfaat (combreAp), een intracellulair tubuline-interfererend molecule.

Het toepassen van vascular targeting als anti-kanker behandeling is op zich een gekende strategie. Vooral hyperthermie, en ook fotodynamische therapie, zijn niet enkel rechtstreeks tumor celdodend maar zijn tevens gekenmerkt door het aanbrengen van bloedvatschade. Belangrijke berperkingen van deze modaliteiten zijn (i) dat alleen oppervlakkige tumoren (of intra-operatief bereikbare tumoren) kunnen worden behandeld, en (ii) het afwezig zijn van selectieve activiteit in het tumorweefsel. Het gebruik van producten die systemisch worden toegediend en selectief de tumorvaten beschadigen, zoals combreAp, kunnen een bredere toepassing kennen.

$\mathrm{Na}$ een éénmalige intraperitoneale inspuiting van combreAp aan 1/3 MTD is een snelle en sterke vermindering van het aantal bloedvaten zowel histologisch als angiografisch gedocumenteerd. Deze ernstig vaatschade werd gevolgd door een uitgebreide necrosevorming, ongeacht het tumorvolume op het ogenblik van de combreAp inspuiting. De door combreAp aangebrachte intra-tumorale vaatschade en necrose kan best worden vergeleken met de resultaten na gebruik van tumor necrosis factor alfa (TNF $\alpha$ ). Een belangrijk verschil evenwel is de afwezigheid van systemische toxiciteit bij een combreAp dosering met toch een sterk anti-tumoraal effect.

Deze stevige combreAp-geinduceerde schade werd echter niet vertaald in een algemene groeivertraging of regressie van de behandelde tumoren. Bij zeer kleine en kleine tumoren $\left(<3 \mathrm{~cm}^{3}\right)$ werd geen significante verandering in de groeisnelheid gemeten; de grotere tumoren (vooral deze $>7 \mathrm{~cm}^{3}$ ) vertoonden een zeer significante groeivertraging $(\mathrm{p}=0.001)$. Deze tumor volume-afhankelijke resultaten zijn precies het omgekeerde van de resultaten na radio- of chemotherapie. Bij deze laatste behandelingsmodaliteiten zijn grotere tumoren veel slechter of niet behandelbaar vergeleken met de kleine, en dit vooral door de ontwikkeling van inefficiente vasculatuur en daarmee gepaard gaande hypoxie. Het feit dat grotere tumoren vatbaarder zijn voor combreAp op basis van een belangrijker aantal slecht gevormde bloedvaten kan een uitleg zijn voor deze omgekeerde resultaten in vergelijking met radio- en chemotherapie. Mogelijks zijn in grotere tumoren een grotere proportie tumorcellen afhankelijk van elk intra-tumoraal bloedvat, of zijn veranderingen in interstitiële druk mede de oorzaak van deze resultaten. Andere veronderstellingen die de volume-respons relatie mede kunnen verklaren zijn gerelateerd aan een hypoxie-gemedieerde verandering van de 
combreAp activiteit of aan een direct cytostatisch effect van de stof voor de tumorale cellen. Vergelijkingen met literatuurgegevens betreffende tumor groeivertraging of tumorcontrole na combreAp behandeling zijn niet evident, want in zowat alle bekende studies werden alleen zeer kleine tumoren onderzocht.

Het gebruik van een dubbele combreAp toediening (met 1 week interval) resulteerde, zij het minder duidelijk dan bij de éénmalige toediening, eveneens in een tumorvolume-afhankelijke effect. Grotere tumoren waren ook hier vatbaarder voor combreAp dan kleinere. Een bijkomende bevinding was dat kleine tumoren dus ook een groeivertraging vertoonden na een herhalingsbehandeling met een gelijke dosis combreAp.

Hoofdstuk III toont de resultaten van verschillende reeksen experimenten waarbij combreAp werd gecombineerd met een andere vorm van anti-kanker behandeling.

Zoals duidelijk is uit de gegevens beschreven in hoofdstuk II.2, induceert combreAp als monotherapie niet een algemene necrose en is er dus geen tumor eradicatic. Aan de rand van de rhabdomyosarcoma tumoren bleven een aantal tumorcellen overleven, en is hergroei vanuit die regio's dan ook logisch.

De combinatie met ioniserende straling is uiteraard de eerste keuze. Dit houdt verband met de hypothese dat cellen in de buitenste schil van de tumor voldoende van zuurstof en voedingsmiddelen zijn voorzien, en dus stralingsgevoelig zijn. De resultaten wijzen op een duidelijk tumor volume-afhankelijk effect (hoofdstuk III.1): bij grote tumoren $\left(>7 \mathrm{~cm}^{3}\right)$ werd een belangrijke bijkomende groeivertraging gemeten in vergelijking met de vrij effectieve bestraling alleen. Kleinere tumoren $\left(<3 \mathrm{~cm}^{3}\right)$ vertoonden een niet-significante of afwezige verandering van de groeisnelheid. In al deze experimenten werd de énmmalige bestraling eerst gegeven, om intra-tumorale inductie van hypoxie door combreAp (en dus stralingsresistentie) te vermijden. Het gebruik van combreAp vooraf aan de bestraling, of zelfs gelijktijdig gegeven, leidde niet tot een verlengde groeivertraging

Tijdens de hergroei van de rhabdomyosarcoma tumoren was er een duidelijke toename van het aantal bloedvaten (vooral perifeer), zoals in beeld gebracht met de digitale subtractie angiografie techniek (zie hoofdstuk II.2). Het verhinderen van deze revascularizatie zou moeten leiden tot een afremming van de tumorgroei. Op basis van deze hypothese werd I dag na combreAp de angiogenese remmer TNP-470 gedurende 1 week driemaal toegediend. Deze 
reeks experimenten (hoofdstuk III.1) wees op een zeer beperkte bijkomende groeivertraging, ongeacht het tumor volume bij de start van de behandelingen. Mogelijks is de afwezigheid van een duidelijk effect het gevolg van een nog té geringe hergroei van de vasculatuur bij de meeste tumoren gedurende de eerste week na de combreAp toediening.

De combinatie van combreAp met een nieuwe recent ontwikkelde anti-kanker strategie, met name het gebruik van anaerobe apathogene clostridia met selectieve transfer van therapeutische proteïnen naar vaste tumoren, werd eveneens onderzocht (hoofdstuk III.2.A en B). Onder andere binnen onze onderzoeksgroep werd dit bacterieel systeem met Clostridium op punt gesteld voor transfer van het suicide gen cytosine deaminase (CDase) en het cytokine tumor necrosis factor (TNF) $\alpha$. Met deze combinatie werd een verbreding van het bactericel systeem-gerelateerd therapeutisch venster beoogd op basis van intra-tumorale kolonisatie verbetering. De hypothese was dat combreAp necrose induceert, ook in zeer kleine tumoren, waardoor de kolonisatie en potentieel ook de proteïne expressie wordt geoptimaliseerd. Daarnaast werd binnen het kader van therapeutische optimalisatie ook gekeken naar mogelijke in vivo toxische effecten. Het gebruik van combreAp resulteerde in een uitstekende Clostridium kolonisatie van alle tumoren, ook de zeer kleine, equivalent aan de kolonisatie gemeten in grote tumoren niet behandeld met combreAp. In een parallelle reeks experimenten werd de afwezigheid van een duidelijke immuunreactie aangetoond: nietsignificante Clostridium-specifieke antilichaam concentratie in serum van de proefdieren en geen stijging van de rectale temperatuur. Tevens werd aangetoond dat, indien nodig, de clostridia kunnen worden verwijderd met een specifiek antibioticum zoals metronidazole. De verdere evaluatie van een mogelijke winst door het combineren van combreAp met het anaerobe bacterie transfer systeem gebeurde door het meten van de intratumorale expressie van het CDase. Dit enzyme zorgt voor de omzetting van het schimmelwerend 5Fluorocytosine (5-FC) tot het cytotoxisch 5-Fluorouracyl (5-FU). De combinatie van combreAp met de clostridia recombinant voor het CDase resulteerde in een stabiele en sterk verbeterde proteine expressie in alle onderzochte tumoren. De CDase expressie was, zoals geanticipeerd werd, afwezig in al de onderzochte normale weefsels van de met deze combinatie therapie behandelde tumordragende proefdieren.

Het is nuttig de resultaten bekomen met de bloedvat gerichte behandelingen, al dan niet in combinatie met een klassieke anti-kanker therapie, in iedere tumor longitudinaal te kunnen volgen. Het is eveneens noodzakelijk dat een selectie van tumoren kan gebeuren voor 
een optimaal gebruik van bijvoorbeeld het anaerobe bacterie-gemedieerde therapeutisch proteïne transfer systeem. Een snelle en degelijke selectie van tumoren die potentieel in aanmerking kunnen komen voor hypoxie-modulerende stoffen zoals hyperoxische gassen en vasoactieve produkten is eveneens gewenst. In dit kader is het gebruik van een niet-invasieve sreening techniek zoals magnetische resonantie beeldvorming (MRI), welke zowel snel als volledig tumor-omvattend is, zeer belangrijk. In hoofdstuk IV wordt een specifieke toepassing van MRI, gesteund op "blood oxygen level dependent" (BOLD) endogeen contrast, voor het evalueren van tumor hypoxie en de modulatie hiervan met carbogeengas $\left(95 \% \mathrm{O}_{2}+5 \% \mathrm{CO}_{2}\right)$ onderzocht. Dit onderzoek gebeurde met een in de klinische radiologie gebruikt apparaat, een totaal lichaam 1,5 Tesla MRscanner.

Het toepassen van snelle sequenties (hoge temporale resolutie), zoals mogelijk met echo planar imaging (EPI), resulteert echter in een verlies van spatiale resolutie, De bekomen suboptimale kwaliteit van de $\mathrm{T}_{2}{ }^{*}$ gewogen beelden is ook het resultaat van geometrische distortie ten gevolge van susceptibiliteits-artefacten, zoals die kunnen ontstaan op luchtweefsel overgangen. Door gebruik te maken van een soepel blijvend alginaat, dat over het te evalueren lichaamsdeel werd aangebracht, kon een objectieve verbetering van de beeldkwaliteit worden bekomen (hoofdstuk IV.1). Deze gegevens tonen duidelijk de winst voor functionele MRI (fMRI) door gebruik te maken van zulk een alginaat in zowel oncologisch als neurologisch onderzoek bij proefdieren.

In een aparte reeks experimenten werd de haalbaarheid en gevoeligheid van de fMRI techniek getest bij WAG/Rij ratten met het onderhuids rhabdomyosarcoom (hoofdstuk IV.2). Met deze methode werden meerdere sneden gemaakt doorheen het volledige volume van de individuele tumoren, terwijl de proefdieren of met lucht of met carbogeen werden beademd. De evaluatie van de voxelintensiteit, als vertaling van de BOLD veranderingen ten gevolge van carbogeen beademing, was voor alle tumoren mogelijk doorheen het ganse volume. De lage signaal-ruis ratio werd gecompenseerd door het snelle opeenvolgend herhalen van de metingen en door analyse van deze metingen met een aangepast statistisch pakket (SPM96). De $\mathrm{T}_{2}{ }^{*}$ gewogen beelden toonden verschillen in intensiteitsveranderingen ten gevolge van carbogeen, zowel binnen dezelfde tumor als tussen de verschillende tumoren (ook deze met een vergelijkbaar volume). De verandering in intensiteit was zeer akuut na de start van de carbogeen beademing, maar echter niet voor alle tumoren even sterk. Tevens had het gebruik van carbogeen bij enkele tumoren een negatief effect (vermindering in signaalintensiteit), wat 
kan worden toegeschreven aan een 'stelen van zuurstof' binnen de tumor of binnen he omliggende weefsel. Op basis van de gecombineerde metingen van (i) het volume, aanta voxels, van intensiteitsveranderingen en (ii) de grootte van deze intensiteitsveranderin! kunnen individuele tumoren met een globaal positief antwoord op carbogeen beademin; worden uitgezocht. De niet-invasieve fMRI methode blijkt een snelle evaluering van dt modulatie van hypoxie toe te laten, en dit voor het totale tumorvolume. 


\title{
Curriculum Vitae
}

Willy A.X. Landuyt werd op 29 juli 1947 geboren te Tienen (België). In 1965 behaalde hij het diploma Secundair Onderwijs 'Wetenschappelijke A' aan het Koninklijk Atheneum te Landen. Het diploma NUHO, richting paramedisch/scheikunde onderwijs, werd in 1968 behaald aan de Technische Hogeschool te Sint-Truiden. Gedurende het daaropvolgende jaar volgde hij een specialisatiecursus in het gebied van electronenmicroscopie van cellen en weefsels (Dienst Morfologie en EM, KULeuven). Nadien was hij gedurende 15 maanden in opleiding als officier bij het Belgisch leger, Medische Dienst (huidige rang: kapitein-commandant). Vanaf 1970 werkte hij aan de Katholieke Universiteit, Universitair Ziekenhuis Sint-Rafaël, achtereenvolgens aan diverse projecten op de laboratoria Electronenmicroscopie en Anatomie (Dr. Jadin JM; Prof.Dr. Creemers J; Prof.Dr. van der Schueren G) en Celbiologie (Prof.Dr. Cassiman JJ) tot 1980. Vanaf 1981 is hij verbonden aan het laboratorium Gezwelziekten en Experimentele Radiotherapie, UZ Sint-Rafačl, van de KULeuven. Onder de supervisie van Prof.Dr. van der Schueren E (toenmalig Diensthoofd) werd tot 1996 als BSc onderzoek verricht naar de effecten op normale weefsels bij gebruik van ioniserende stralen, al of niet gecombineerd met chemotherapie en groeifactoren (co-supervisie van Prof.Dr. Ang KK. Prof.Dr. Van der Kogel AJ en Prof.Dr. Fowler JF). Hij is, voor deze periode, auteur en mede-auteur van een dertigtal artikels in tijdschriften (met 'referee' systeem) en mede op basis hiervan gecertifieerd 'DEA in fundamenteel radiobiologisch onderzoek', betreffende dit pre-clinisch normaal-weefsel onderzoek.

Vanaf 1997 werd het onderzoek uitgebreid naar tumorbiologie onder supervisie van en samenwerking met Prof.Dr. Lambin P (samen met Prof.Dr van Oosterom A, Directeur-Diensthoofd Oncologie, en Prof.Dr. Van den Bogaert W, Diensthoofd Radiotherapie); als belangrijkste richtingen, het evalueren met behulp van proefdiermodellen van nieuwe anti-kanker behandelingen, alsook van beeldvorming in functie van fysiologische aspecten van tumoren. Dit onderzoek gebeurde in samenwerking met de afdelingen Experimentele Bacteriologie voor onderzoek naar bacteriele gentherapie als anti-kanker strategie (Prof.Dr. Anné J en Dr. Van Mellaert G), Radiologie/Experimentele MR voor onderzoek in verband met tumorfysiologie (Prof.Dr. Hermans R. Prof.Dr. Bosmans H en Prof.Dr. Marchal G) en Pathologie voor klassieke en histochemische evaluatie van vaat-gerichte anti-kanker stoffen (Prof.Dr. Van den Oord J, Prof.Dr. Drijkoningen M en Prof.Dr. Verbeken E). Binnen dit onderzoek verzorgde hij de begeleiding van meerdere pre-doctorale en MSc studenten, en was hij verantwoordelijk voor de dag-dagelijkse laboratoriumactiviteiten. Een viertal jaar geleden werd besloten van een doctoraal proefschrift uit te bouwen (Promotor Prof.Dr. Lambin P, huidig Directeur-Diensthoofd Radiotherapie aan het RTIL Heerlen/Maastricht, en Co-promotor Prof.Dr. van Oosterom A).

Hij is tevens lid van meerdere binnen- en buitenlandse wetenschappelijke verenigingen, waaronder 'European Society for Therapeutic Radiology and Oncology, ESTRO', de 'American Society, ASTRO', de 'American Radiation Research Society', de 'EORTC Translational Research Radiotherapy Group', en de 'Belgische Vereniging voor Radiotherapie en Oncologie, BVRO'

Hij ontving, samen met Prof.Dr. Lambin P, de vijfjaarlijkse prijs 'Dr. Raoul Biltris', Koninklijke Academie voor Geneeskunde van Belgiè, november 2002, voor het experimenteel kankeronderzoek in verband met ' $V$ ascular targeting: a potential additional anti-cancer treatment'.

\section{Lijst van publicaties (vanaf 1998)}

\author{
P. Lambin, J. Theys, W. Landuyt, P. Rijken, A. Van der Kogel, E. Van der Schueren, R. Hodgkiss, J. \\ Fowler, S. Nuyts, E. de Bruijn, L. Van Mellaert, J. Anné. \\ Colonisation of Clostridium in the body is restricted to hypoxic and necrotic areas of tumours. \\ Anaerobe 4: 183-188, 1998.
}

P. Loubeyre. T. De Jaegere, H. Bosmans, Y. Miao, Y. Ni, W. Landuyt, G. Marchal.

Comparison of iron oxide particles (AMI227) with a gadolinium complex (Gd-DOTA) in dynamic susceptibility contrast MR imagings (FLASH and EPI) for both phantom and rat brain at 1.5 tesla. J. Magn. Reson. Imaging (JMRI) 9: 447-453, 1999. 
J. Theys, S. Nuyts, W. Landuyt, L. Van Mellaert, C. Dillen, M. Böhringer, P.Dürre, Ph. Lambin, J. Anné. A stable Escherichia coli-Clostridium acetobutylicum shuttle vector for the secretion of murine tumor necrosis factor $\alpha$ : construction and in vitro evaluation. Appl. Environ. Microb. 65: 4295-4300, 1999.

P. Loubeyre, T. De Jaegere, Y. Miao, W. Landuyt and G. Marchal. Assessment of iron oxide particles (AMI227) and a gadolinium complex (Gd-DOTA) in dynamic susceptibility contrast MR imaging (FLASH and EPI) in a tumor model implanted in rats. Magn. Reson. Imaging 17: 627-631, 1999.

P. Lambin, S. Nuyts, W. Landuyt, J.Theys, E. de Bruijn, J. Anné, L. Van Mellaert and J. Fowler. The potential therapeutic gain of radiation-associated gene therapy with the suicide gene cytosine deaminase. Int. J. Radiat. Biol.76: 285-293, 1999.

W. Landuyt, O. Verdoes, D.O. Darius, M. Drijkoningen, L. Stockx, W. Wijnendaele, J. Fowler, G. Maleux, S. Nuyts, J. Theys, J. Anné and Ph. Lambin. Vascular targeting of solid tumours: a major 'inverse' volume-response relationship with combretastatin A-4 phosphate in rat rhabdomyosarcomas. Eur. J. Cancer 36: 1833-1843, 2000.

W. Landuyt, B. Ahmed, S. Nuyts, J. Theys, M. Op de Beeck, A. Rijnders, J. Anné, A. van Oosterom, W. Van den Bogaert, P. Lambin. In vivo anti-tumor effect of vascular targeting combined with either ionizing radiation or anti-angiogenesis treatment. Int. J. Radiat. Oncol. Biol. Phys. 49: 443-450, 2001 .

W. Landuyt, J. Theys, S. Nuyts, M. Drijkoningen, J. Fowler, A. Rijnders, S. Liekens, J. Neyts, E. de Bruijn, J. Anné, P. Lambin. Effect of TNP-470 (AGM-1470) on the growth of rat rhabdomyosarcoma tumors with different sizes. Cancer Invest. 19: 35-40, 2001.

J. Theys, W. Landuyt, S. Nuyts, L. Van Mellaert, A. Rijnders, W. Van den

Bogaert, A. van Oosterom, J. Anné and P. Lambin. Evaluation and improvement of a bacterial vector gene transfer system with an in vivo.

rat tumour model. FEMS Immunol. Med. Microbiol. 30: 37-41, 2001.

J. Theys, W. Landuyt, S. Nuyts, L. Van Mellaert, J. Anné and P. Lambin. Specific targeting of cytosine deaminase to solid tumors by engineered Clostridium acetobutylicum. Cancer Gene Ther. 8: 294-297, 2001.

W. Landuyt, R. Hermans, H. Bosmans, S. Sunaert, E. Béatse, D. Farina, M. Meijerinck,

H. Zhang, W. Van den Bogaert, P. Lambin and G. Marchal. BOLD contrast functional magnetic resonance imaging of whole tumour during air or carbogen breathing: initial experience in rat rhabdomyosarcoma using echo planar imaging at 1.5 Tesla. Eur. Radiol. 11: 2332-2340, 2001.

J. Theys, W. Landuyt, S. Nuyts, L. Van Mellaert, P. Lambin and J. Anné. Clostridium as a tumorspecific delivery system of therapeutic proteins. Cancer Detect. Prev. 25: 548-557, 2001.

S. Nuyts, J. Theys, W. Landuyt, L. Van Mellaert. J. Anné and P. Lambin. Increasing specificity of anti-tumor therapy: cytotoxic protein delivery by non-pathogenic clostridia under regulation of radioinduced promoters. Anticancer Res. 21: 857-862, 2001.

S. Nuyts, L. Van Mellaert, J. Theys, W. Landuyt, P. Lambin and J. Anné. The use of radio-induced bacterial promoters in anaerobic conditions: a means to control gene expression in Clostridiummediated therapy for cancer. Radiat. Res. 155: 716-723, 2001. 
S. Nuyts, L. Van Mellaert, J. Theys, W. Landuyt, E. Bosmans, J. Anné and P. Lambin. Radioresponsive recA promotor significantly increases TNF $\alpha$ production in recombinant clostridia after 2 Gy irradiation. Gene Ther. 8: 1197-1201, 2001.

S. Nuyts, L. Van Mellaert, S. Barbé, E. Lammertyn, J. Theys, W. Landuyt, E. Bosmans, P. Lambin and J. Anné. Insertion or deletion of the cheo box modifies radiation inducibility of Clostridium promoters. Appl. Environ. Microb. 67: 4464-4470, 2001

B.G. Wouters, S. Weppler, M. Koritzinsky, W. Landuyt, S. Nuyts, J. Theys, R.K. Chiu and P. Lambin. Hypoxia as a target for combined modality treatments. Eur J Cancer 38: 240-257, 2001.

P. Lambin, J. Theys, S. Nuyts, W. Landuyt, L. Van Mellaert, J. Anné. Clostridium-mediated transfer of therapeutic proteins to solid tumors: an alternative to gene therapy approaches. In: Vector targeting for therapeutic gene delivery. Eds. DT Curiel and JT Douglas. John Wiley \& Sons, Inc., New York; 527-546, 2002.

H.-P. Eikesdal, W. Landuyt, O. Dahl. The influence of combretastatin A-4 and vinblastine on interstitial fluid pressure in BT4An rat gliomas. Cancer Lett. 178: 209-217, 2002.

G. Basha, W. Landuyt, J., Fowler, D. Vordermark, K. Haustermans, K. Geboes, W. Van den Bogaert, S.H. Yap, P. Lambin, F. Penninckx. An experimental in vivo-in vitro evaluation of three preoperative radiation regimens for rectal cancer. Ann. Surg. Oncol. 9: 292-7, 2002.

H. Wildiers, G. Guetens, G. de Boeck, W. Landuyt, E. Verbeken, M. Highley, E. de Bruijn, A. van Oosterom. Melphalan availability in hypoxia-inducible factor-1 alphat/+ and factor-1 alpha- $/$ tumors is independent of tumor vessel density and correlates with melphalan erythrocyte transport. Int. J. Cancer 99: 514-519, 2002.

W. Landuyt, S. Sunaert, D. Farina, M. Meijerink, E. Béatse, P. Van Hecke, B. Hermans, G. Marchal, P. Lambin, H. Bosmans. In vivo animal functional MRI: improved image quality with a body-adapted mould. J. Magn. Reson. Imag. 16: 224-227, 2002.

S. Nuyts, L. Van Mellaert, J. Theys, W. Landuyt, P. Lambin, J. Anné. Clostridium spores for tumorspecific drug delivery. Anti-Cancer Drugs 13:115-125 (review), 2002.

A.D. Billiau, S. Fevery, O. Rutgeerts, W. Landuyt, M. Waer. Crucial role of timing of donor lymphocyte infusion in generating dissociated graft-versus-host and graft-versus-leukemia responses in mice receiving allogeneic bone marrow transplants. Blood 100: 1894-1902, 2002.

S. Mei, J. Theys, W. Landuyt, J. Anné, P. Lambin. Optimization of tumor-targeted gene delivery by engineered attenuated Salmonella Typhimurium. Anticancer Res.: in press, 2002. 



\section{Dankwoord / Acknowledgments}

Doorheen de jaren is het plezier van een dankwoord te schrijven niet alleen stukken groter maar tevens delikater geworden. Zeker wanneer je met een heel veel boeiende personen in contact bent gekomen. Het is méér dan vervelend om wie-dan-ook te vergeten. Mag ik vragen dat éénieder, al of niet hierna vermeld, mijn hartelijke dank als persoonlijk wil aanvaarden. De contacten met elk van jullie waren en blijven vanuit hun verschillende invalshoeken een belangrijke invloed en drijfveer in mijn dagdagelijks leven (al of niet op het laboratorium).

Het onderzoek onderliggend aan dit proefschrift beschouw ik alvast als een extra stukje legger-vulling van mijn wetenschappelijke kast. Het is het resultaat van veel proefjes, van een translationele opstelling en zeker ook van een perpetuum mobile van vinden en trachten te begrijpen. Boven alles, echter, is het een resultaat van een coherent samenwerken binnen de eigen laboratoria en met verschillende wetenschappelijke disciplines.

In de eerste plaats wil ik mijn directe team-genoten Jan Theys, Sandra Nuyts, Jozef Anné, Hilde Bosmans, Robert Hermans, Davide Farina, Martijn Meijerink, en mijn promotor Philippe Lambin met hart en ziel in het licht van de schijnwerper plaatsen. Aan stimuli en uitdagingen (inclusief weddenschappen en extreme deadlines) heeft het nooit ontbroken. Filosofische en andere beschouwingen gebeurden niet altijd volgens de regels van de letter, nietwaar Jan en Sandra. Evenwel. in het alfabet staat de v(riendschap) nog steeds voor de w(etenschap), en dat is prima zo. Wie het schoentje past, trekke het aan, en aldus zijn Jan en Sandra mijn paranimfen tijdens de promotic. En dat er licht in de duisternis te vinden is, met of zonder WASP, weet ik intussen via Hilde, Bob en collega's. Met Jef had ik niet alleen een prima leermeester in de bacteriologie, maar tevens een uitdaging voor 'wie sluit zijn deur vandaag het laatst?' (een duel zonder uitkomst, denk ik).

Philippe, jouw vindingrijke maar tevens analytische geest heeft mijn enthousiasme voor verruiming van de projecten meestal in goede banen weten te houden. Het was en is dan ook meer dan prettig met jou samen te werken en van gedachten te wisselen, beste promotor en vriend. Voor alle duidelijkheid: zeer veel dank voor de exponentiële steun en voor de steun bij de uiteindelijke realisatie van een van mijn diepe wensen.

Mijn co-promotor Allan van Oosterom, en evenzeer ook Walter Van den Bogaert, hebben mij de vrijheid gegeven om mijn onderzoek binnen hun diensten Oncologie en Radiotherapie, op het laboratorium 'experimentele Radiobiologie/LEO' efficient uit te voeren. Bedankt voor de kritische noot bij enkele schrijfstukken, de steun en vooral voor het vertrouwen.

In verband met dit laatste denk ik met plezier, en tegelijk ook met droefheid en bezinning. terug aan de sublieme kort-op-de-bal begeleiding van wijlen Emmanuel van der Schueren tijdens de eerste jaren van mijn radiobiologisch laboratoriumwerk. Een bijzondere dank voor het begeleiden van mijn introductie. via werkbezoeken en wetenschappelijke vergaderingen, in deze boeiende, drukke en tegelijk vriend-rijke wereld. Zijn inzichten en opstelling hebben zeer zeker bijgedragen tot de persoonlijke aanpak van mijn huidig onderzoek.

Enthousiasme voor in vivo translationeel onderzoek heb ik zonder twijfel eveneens van Kian Ang en Albert van der Kogel, de mede-begeleiders van het eerste uur, kunnen opsteken. Beste Kian en Bert, met bijzonder genoegen denk ik ook terug aan de vele experimenten op soms 'ondenkbare!" ogenblikken van de dag en de nacht. Samen met onder andere Luc Van Uytsel, Jan-Willem Leer. Johan Menten, Dirk De Ruysscher, Pierre Scalliet, Georg Stüben, Monique Ramaekers, Karin Haustermans, Eric Van Limbergen, Yan Feng.... werden de radiobiologische modellen ten volle benut voor het beantwoorden van klinisch relevante vraagstellingen. Technische ondersteuning was er toen vooral van Herman Govaerts, Eddy Boon, Lut Debecker en Jo Vloeberghs, terwijl de administratie werd verzorgd door Lea Minnen. Edmée Boyen en collega's. Germaine Heeren was ook toen altijd te vinden voor een praatje over de wetenschap heen. Jan Van Dam en Alex Reijnders waren steeds paraat voor de vele dosimetrische aspecten en berekeningen voor onze in vivo opstellingen.

Though not possible to phrase properly. I am more than grateful to Jack Fowler and late Julie Denekamp for guidance in the magic of research, for their generous teaching and encouragement. 
Terug naar de recente periode (gedeeltelijk overlappend met de ontwikkeling van het huidige $\mathrm{PhD}$ werk) met een in versneld tempo opgelopen aantal personen die in min of meerdere mate hebben bijgedragen tot het vergaren van de onderzoeksresultaten en de inherente discussie ervan. Zeer veel dank in de cerste plaats aan alle medewerkers die met mij een publicatie delen, vooral voor hun interesse in de vraagstelling en/of de daarmee gepaard gaande vlotte aanpak en uitvoering (bovenop hun dagelijkse praktijk). Beste Bisan Ahmed, het is fijn met jou in het laboratorium te staan, en tevens een plezier van jouw PhD onderzoek mee te mogen begeleiden. In één adem ook veel dank voor Arjan Griffioen (Angiogenese groep. AZMaastricht) voor de verschillende, soms onstuimige maar steeds vruchtbare, besprekingen van resultaten en literatuurgegevens.

De dienst Radiofysica was en is er altijd voor de adequate hulp bij diverse dosimetrie, aanverwante vragen bij proefopstellingen en bij toestel-problemen tijdens de bestralingsreeksen. Een grote dank beste Dominique Huyskens, Alex Reijnders, An, Achiel, Jan, Ans, Bianca, Jurgen ....

Zowel de stafleden van Radiotherapie, Radiofysica en niet in het minst alle verplegenden, van harte dank voor de prima afspraken bij het gebruik van de bestralingsapparatuur.

Beste Ernst de Bruijn en collega-onderzoekers Hans Wildiers, Laurence Goethals, Wim Wynendaele. Gunter, Gert, Bart, Ulla, Katleen,..., het is tof met jullie samen te werken. Vooral dank voor de stimuli en voor de diverse productieve besprekingen.

De pathologie afdeling: bedankt voor de ondersteuning en de glasheldere uitleg bij een klassieke of een immunohisto kleuring, beste Joost Van den Oord, Ria Drijkoningen, Eric Verbeken en de medewerkers.

De stafleden van de diensten Radiotherapie en Oncologie dank ik voor de interesse in mijn onderzoek en voor de stimulerende gesprekken in de coulissen.

Lieve Van Mellaert, Elke Lammertijn en Jozef Anné waren altijd te vinden voor uitleg en bijschaving van mijn bacteriologie experimenten. Ook de collega's van de intussen uitgebreide ploeg, met name Sofie Barbé, Wesley Van Dessel. Tine Schaerlaekens, Ilya Lebeau, Asferd Mengesha, Nick Geukens, .... van harte dank voor de gezelligheid op het drukke laboratorium en de plezante uitstappen. Beste Sofie, voor de nuttige babbels, het goede humeur: een grote dank. En goede vrienden Wesley Van Dessel en Pierre Fiten, bijzonder veel dank voor de ondersteuning bij hard- en software, en niet in het minst voor de spoed-dienst wanneer een figuur niet wou lukken of de pc uit de bocht ging.

Deze laboratoriumfanaten zijn samen met een nog groter getal Rega-medewerkers (waarvan sommigen reeds andere oorden kozen) onvergetelijk. Een open deur was en is in dit onderzoeksinstituut een feit, een geschikte voedingsbodem voor gesprekken allerlei; van wetenschappelijke uitleg, over advies bij aanvragen voor onderzoeksfinanciering, tot met humor doorspekte gedachtenwisseling. Bedankt Ghislain Opdenakker, Jozef Van Damme, Alfons Billiau, Paul Proost. .... Niet alleen voor een oplossing van ogenschijnlijk kleine dingen/vragen of het lenen van een boek of het soms voorbereiden van materiaal nodig voor bacterieel onderzoek, maar ook voor de volleybal-spirit zijn er een hele hoop Rega-fellows die een warm woord van dank verdienen, zoals Inge Nelissen, Patrick Matthys, Hubertine Heremans, Patrick Chaltin, René Conings, Josée De Greef. Lieve Vandenbulcke, Chris Dillen,....

Met bijzonder genoegen denk ik ook terug aan de kortere samenwerkingen met de verschillende eindwerk-studenten: toffe periodes, waarvoor dank beste Chris, Evemie, Filip, Bart, Sofie, Pieter. En via Evemie Schutyser en Paul De Troch staat, ten minste een stukje, klassieke muziek enkele keren per jaar op mijn agenda.

Van groot belang is de prima verzorging van de proefdieren in de loop van de reeksen experimenten en de ondersteuning bij bijvoorbeeld de kweek of het toedienen van een medicatie. Bedankt beste Kris Meurrens en. de laatste paar jaar, Filip Mulkens voor de deskundige begeleiding bij proefdierproblematiek. Bedankt ook Michel, Julien, Erna, Ronny, Joke, René, Wim, Luc, ... voor de inzet en goede samenwerking. En Michel, met jouw medewerking werden bepaalde resultaten en hun verwerking op een snellere manier bekomen, waarvoor ontzettend veel dank.

Dat de technische diensten een onmisbaar element zijn voor laboratoria, is in dit proefschrift tussen de regels te lezen. Steeds kon er worden gerekend op de efficiente en dikwijls snelle afwerking van proefopstellingen: van harte dank beste René, Omer, Rudy, Herman. Maurice, Gerry, Theo, Ivo, .... 
Ook Jan en Jo, een dikke dank voor de hulp bij onder andere de verhuis en het onderhoud van het $\mathrm{kV}$ toestel.

Waar laboratoria zijn, is de dienst fotografie en reproductie nooit veraf. Bedankt Nathalie, Vital, Rik en Leo voor de dikwijls met een formule-1 snelheid geleverde dia's, posters, kleurrepro's, ....

De secretariaten van Oncologie en Radiotherapie met An, Greet, Lieve, Brigitte, ...., van Radiofysica met Edmée Boyen, en van het Rega onderzoeksinstituut met Inge, Dominique, Chantal, waren en zijn een grote hulp bij het verwerken van een diversiteit van administratieve opdrachten. Eveneens is het secretariaat van de Faculteit Geneeskunde gekenmerkt door een grote open deur; bedankt voor het veelvoud aan inlichtingen, beste Joseph Knapen.

De contacten met een aantal leden van de afdeling Radiotherapie van het RTIL Maastricht/Heerlen zijn steeds vlot en gezellig; veel dank voor de leerrijke en dikwijls leuke gedachtenwisselingen beste Ludy, Dirk, Tom, Francis, Danielle, Janet, ....

Beste Loes Klaasse, van bij mijn eerste stap in dit Unimaas avontuur kon ik op jou rekenen; van harte dank voor je engagement en de steun. Een dikke dank ook aan Rianne en Francine voor de hulp bij de administratieve voorbereidingen van mijn proefschrift en verdediging binnen de Faculteit Geneeskunde en het College van Decanen van de Universiteit Maastricht.

De laboratoriumgroep met Brad, Roland, Marianne, Sherry, Ludy, Dirk, Jan, Ruud, Kim, Chantal. Carla, Servé: wat mij betreft vormen de pilootexperimenten een goede basis om op verder te bouwen. Van bouwen gesproken: beste Ruud, op jou kan dat voor alles en nog wat. Allemaal alvast bedankt voor de soms subtiele steun en de gezamelijke bespreking van laboratoriumresultaten.

Van essentieel belang in wetenschappelijk onderzoek was en is voor mij een vlotte, eerlijke en brede omkadering, ook over de grenzen heen. Many researchers thus contributed, each in their own way, to my training in radiobiology as well as to the ongoing experiments in the early years as well as today. It has been, and still is, a pleasure to be in your company, whatever (although!) the time or place of the meeting. Cheers, dear Howard Thames, Jack Fowler, Mike Robbins, John Hopewell, Jaap Haveman, Wolfgang Dörr, Hans Kummermehr, Jan Wondergem, Adrian Begg. Fiona Stewart. Michael Baumann, Wolfgang Eicheler, Daniel Zips, Simon Robinson. Mike Horsman, Peter Sminia, ....

Beste Aernout Luttun, An Billiau, Sabine Fevery, Hugo Vankelecom, Chantal Mathieu, Heidi Jonckheere, Marc Tjwa, Peter de Witte, Bin Chen, Appolinary Kamuhabwa, Genc Basha, ..., bedankt voor de enthousiaste belangstelling in de loop van mijn onderzoek, de vlotte samenwerking en voor, indien de tijd het toeliet, de gezellige babbels.

Familie en vrienden, dank, niet alleen voor de blijvende interesse in mijn werk, maar niet minder voor jullie aanwezigheid op die tijdstippen wanneer het nodig was en is.

Stille krachten:

Esther, geduld zal zeker niet ontbreken in jouw woordenboek; Miette, je realistische kijk op de dingen en tegelijk je rustige geest waren, en zijn meer dan ooit, een belangrijke steun. 

